Florida International University FIU Digital Commons

9-6-2012

\title{
The Impact of Round II Urban Empowerment Zones on Local Communities
}

\author{
Agatha S. Caraballo \\ Florida International University, acarabal@fiu.edu
}

DOI: $10.25148 /$ etd.FI12110704

Follow this and additional works at: https://digitalcommons.fiu.edu/etd

\section{Recommended Citation}

Caraballo, Agatha S., "The Impact of Round II Urban Empowerment Zones on Local Communities" (2012). FIU Electronic Theses and Dissertations. 719.

https://digitalcommons.fiu.edu/etd/719 


\title{
FLORIDA INTERNATIONAL UNIVERSITY
}

Miami, Florida

\section{THE IMPACT OF ROUND II URBAN EMPOWERMENT ZONES ON LOCAL COMMUNITIES}

\author{
A dissertation submitted in partial fulfillment of the \\ requirements for the degree of \\ DOCTOR OF PHILOSOPHY \\ in \\ PUBLIC AFFAIRS \\ by
}

Agatha Swift Caraballo

2012 
To: Dean Kenneth Furton

College of Arts and Sciences

This dissertation, written by Agatha Swift Caraballo, and entitled The Impact of Round II Urban Empowerment Zones on Local Communities, having been approved in respect to style and intellectual content, is referred to you for judgment.

We have head this dissertation and recommend that it be approved.

$\begin{array}{r}\hline \text { Shaoming Cheng } \\ \hline \text { N. Emel Ganapati } \\ \hline \text { Richard Tardanico } \\ \hline \text { Milena Neshkova } \\ \hline \text { Sukumar Ganapati, Major Professor }\end{array}$

Date of Defense: September 6, 2012

The dissertation of Agatha Swift Caraballo is approved.

$\begin{array}{r}\begin{array}{r}\text { Dean Kenneth Furton } \\ \text { College of Art and Sciences }\end{array} \\ \hline \begin{array}{r}\text { Dean Lakshmi Reddi } \\ \text { University Graduate School }\end{array}\end{array}$

Florida International University, 2012 
(C) Copyright 2012 by Agatha Swift Caraballo

All rights reserved. 


\section{DEDICATION}

I dedicate this dissertation to my loved ones, especially my husband Leo, daughter Kesya, and son Arlen. Their patience, support, understanding, encouragement, and unconditional love, gave me the strength and motivation to achieve this milestone. To my dear friend and colleague Donna - "Thank you." 


\section{ACKNOWLEDGMENTS}

I wish to thank the members of my committee for their support and guidance. I would especially like to thank Dr. Sukumar Ganapati for his guidance, patience and understanding throughout my journey as a doctoral student and candidate. 


\section{ABSTRACT OF THE DISSERTATION \\ THE IMPACT OF ROUND II URBAN EMPOWERMENT ZONES \\ ON LOCAL COMMUNITIES}

by

Agatha Swift Caraballo

Florida International University, 2012

Miami, Florida

\section{Professor Sukumar Ganapati, Major Professor}

In the United States, the federal Empowerment Zone (EZ) program aimed to create and retain business investment in poor communities and to encourage local hiring through the use of special tax credits, relaxed regulations, social service grants, and other incentives. My dissertation explores whether the Round II Urban EZs had a beneficial impact on local communities and what factors influenced the implementation and performance of the EZs, using three modes of inquiry.

First, linear regression models investigate whether the federal revitalization program had a statistically significant impact on the creation of new businesses and jobs in Round II Urban EZ communities. Second, location quotient and shift-share analysis are used to reveal the industry clusters in three EZ communities that experienced positive business and job growth. Third, qualitative analysis is employed to explore factors that influenced the implementation and performance of EZs in general, and in particular, Miami-Dade County, Florida.

The results show an EZ's presence failed to have a significant influence on local business and job growth. In communities that experienced a beneficial impact from EZs, there has been a pattern of decline in manufacturing companies and increase in service-driven firms. The case study suggests that institutional factors, such as governance structure, leadership, administrative 
capacity, and community participation have affected the effectiveness of the program's implementation and performance. 


\section{TABLE OF CONTENTS}

CHAPTER

PAGE

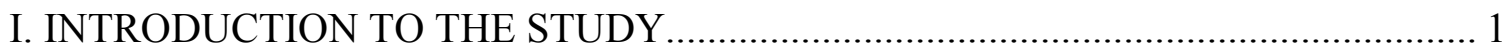

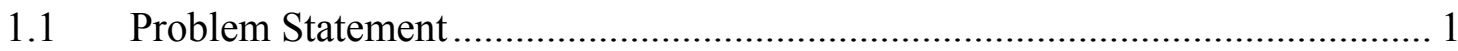

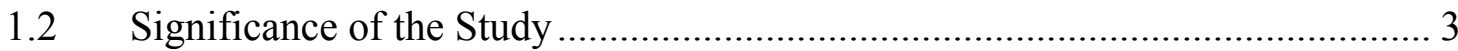

1.3 Theoretical Framework ………………………..................................... 5

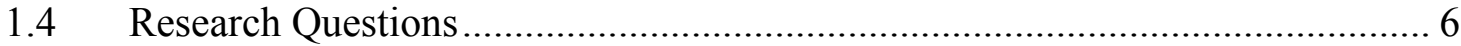

$1.5 \quad$ Organization of the Dissertation .................................................................. 9

II. BACKGROUND AND LITERATURE REVIEW ……........................................... 11

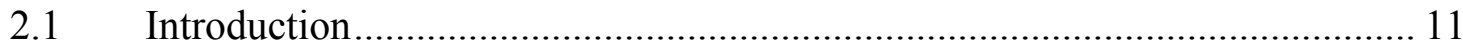

2.2 Special Economic Zones: The Hong Kong Model ......................................... 12

2.3 History of EZs in the United States .......................................................... 16

2.4 The Federal EZ/EC Initiative........................................................................ 17

2.5 EZ Application and Selection Process .............................................................. 19

2.6 EZ Program Characteristics and Benefits ……………………………….... 22

2.7 Do EZs work? Lots of questions, few answers................................................ 25

2.8 Impact of Governance Structure on Performance............................................ 27

2.9 Competitive Advantages/ Disadvantages of Inner Cities ………………........... 29

2.10 Conclusion: Significance of Study .................................................................. 33

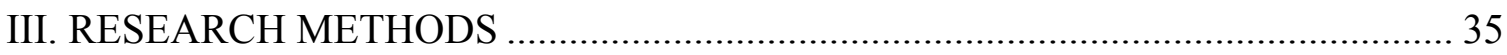

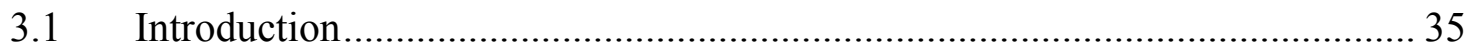

3.2 Research Questions and Hypotheses ............................................................ 35

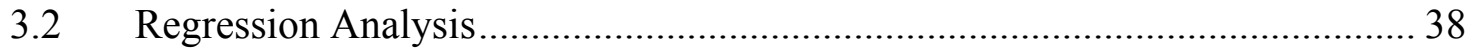

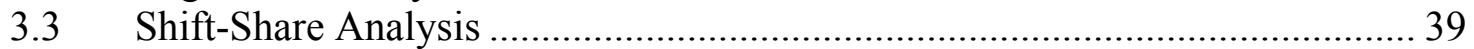

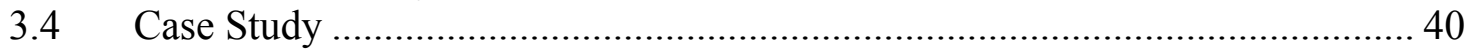

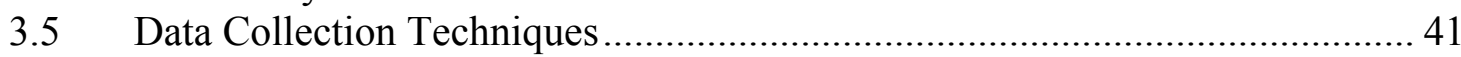

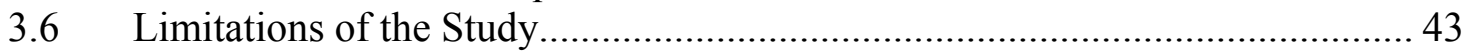

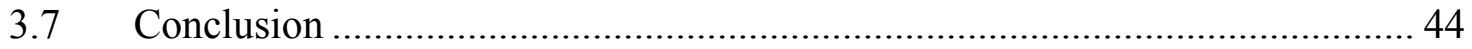

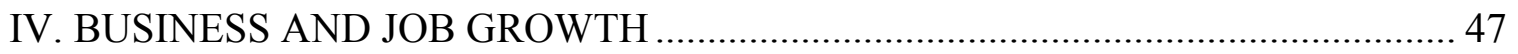

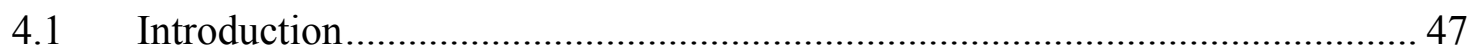

4.2 Multiple Regression Analysis ..................................................................... 49

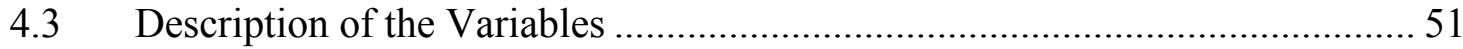

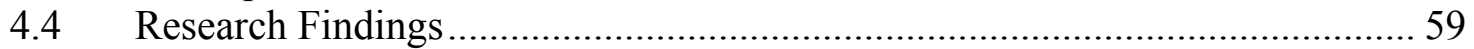

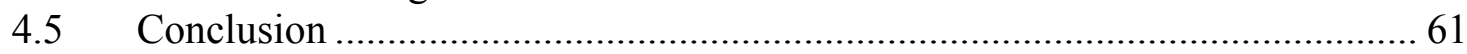

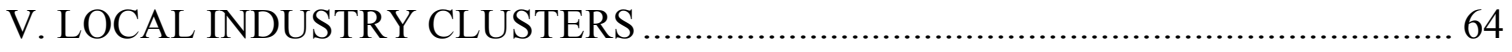

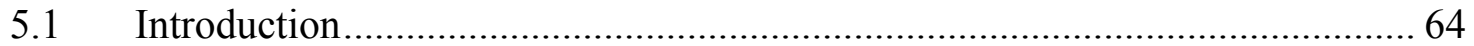

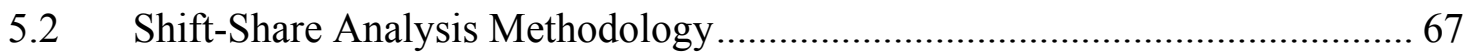

5.3 Data Source: County Business Patterns ......................................................... 70 
5.4 Norfolk/ Portsmouth, Virginia .................................................................. 72

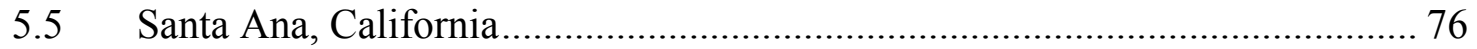

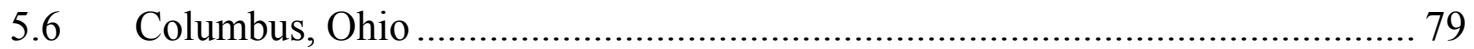

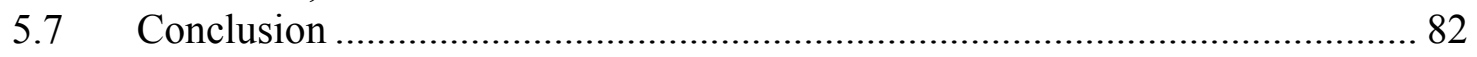

VI. INSTITUTIONAL FACTORS AFFECTING EZS' PERFORMANCE ................... 85

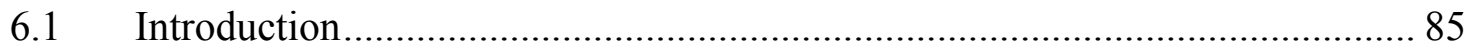

6.2 Factors affecting EZ Implementation and Performance ................................ 86

6.3 EZ Implementation and Performance in the Miami-Dade County EZs .......... 92

C.4 Conclusion ....................................................................................... 103

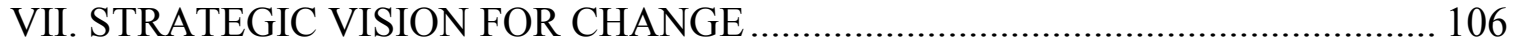

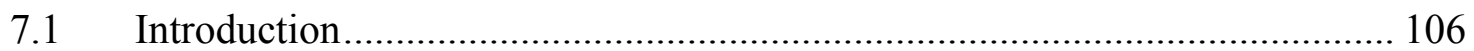

7.2 Best Practices ........................................................................................ 110

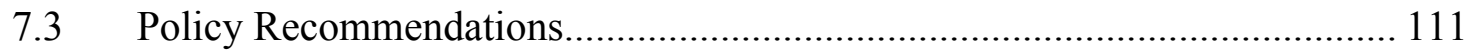

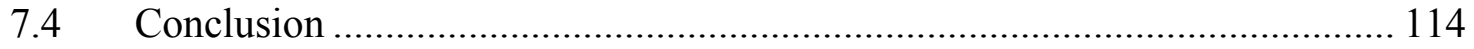

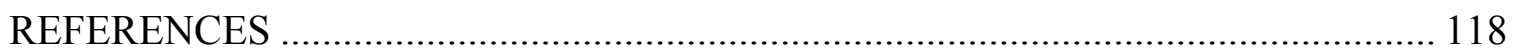

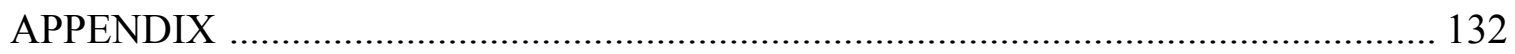

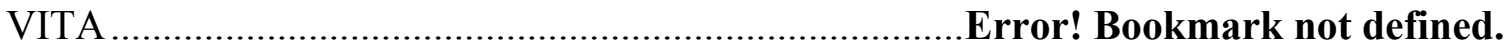




\section{LIST OF TABLES}

TABLE

PAGE

1: $\quad$ Fifteen Round II Urban Empowerment Zones ................................................. 8

2: $\quad$ Summary of Legislation Authorizing the EZ/EC and RC Programs..................... 18

3: $\quad$ Round II Urban EZ Eligibility Requirements............................................... 20

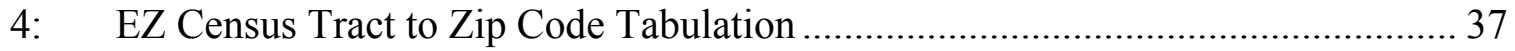

5: $\quad$ EZs and Comparison Group Census Tracts and Zip Codes................................ 49

6: Criteria Used for Identifying Matched Control Counties .................................. 52

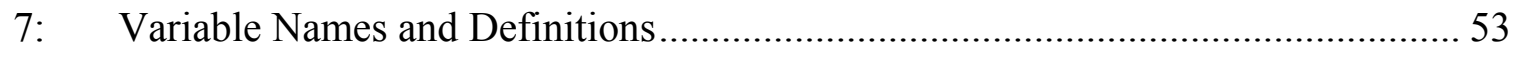

8: Descriptive Statistics of the Models' Control Variables ..................................... 56

9: $\quad$ Population and Retail Density ( $1 \mathrm{~K}$ residents per square mile) ............................... 58

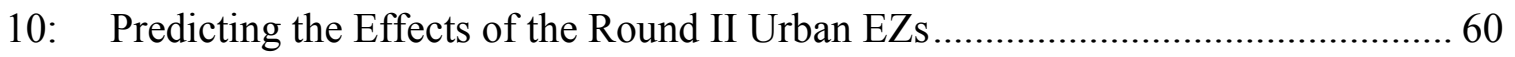

11: Percentage Change in the Number of Businesses and Employees in the EZs from 1998 to 2007

12: Shift-Share for Norfolk/Portsmouth EZs, relative to the Virginia Beach-NorfolkNewport News, Virginia/North Carolina MSA ................................................ 74

13: Shift-Share for Santa Ana EZs, relative to the Los Angeles-Santa Ana, California MSA

14: Shift-Share for Columbus EZs, relative to the Columbus, Ohio MSA.................. 81

15: Coordinating Responsible Authorities (CoRA) of the Round II Urban EZs......... 91

16: Miami-Dade County EZs census tract and corresponding zip codes ................... 94 


\section{LIST OF ACRONYMS AND ABBREVIATIONS}

\begin{tabular}{|c|c|}
\hline APFC & Asia Pacific Foundation of Canada \\
\hline CA & California \\
\hline CBD & Central Business District \\
\hline CDBG & Community Development Block Grant \\
\hline CDFI & Community Development Financial Institution \\
\hline CEPA & Closer Economic Partnership Agreement \\
\hline $\mathrm{CEO}$ & Chief Executive Officer \\
\hline $\mathrm{CFO}$ & Chief Financial Officer \\
\hline CoRA & Coordinating Responsible Authority \\
\hline $\mathrm{CPB}$ & County Business Patterns \\
\hline CT & Connecticut \\
\hline $\mathrm{DC}$ & District of Columbia \\
\hline DV & Dependent Variable \\
\hline EBMC & Empower Baltimore Management Corporation \\
\hline $\mathrm{EC}$ & Enterprise Communities \\
\hline $\mathrm{EZ}$ & Empowerment Zones \\
\hline $\mathrm{EZ} / \mathrm{EC}$ & Empowerment Zones and Enterprise Communities \\
\hline $\mathrm{EZ} / \mathrm{RC}$ & Empowerment Zones and Renewal Communities \\
\hline FIAS & Foreign Investment Advisory Service \\
\hline FL & Florida \\
\hline GAO & United States Government Accounting Office \\
\hline GDP & Gross Domestic Product \\
\hline
\end{tabular}




$\begin{array}{ll}\text { GPRA } & \text { Government Performance and Results Act } \\ \text { HHS } & \text { United States Department of Health \& Human Services } \\ \text { HUD } & \text { United States Department of Housing and Urban Development } \\ \text { ICIC } & \text { Initiative for Competitive Inner Cities } \\ \text { IMF } & \text { International Monetary Fund } \\ \text { IN } & \text { Indiana } \\ \text { IRS } & \text { United States Internal Revenue Service } \\ \text { IV } & \text { Independent Variable } \\ \text { LQ } & \text { Location Quotient } \\ \text { MA } & \text { Massachusetts } \\ \text { M-D EZ } & \text { Miami-Dade County Empowerment Zones } \\ \text { MDET } & \text { Miami-Dade Empowerment Trust } \\ \text { MN } & \text { Minnesota } \\ \text { MSA } & \text { Metropolitan Statistical Area } \\ \text { MO } & \text { Missouri } \\ \text { NAFTA } & \text { North American Free Trade Agreement } \\ \text { NAICS } & \text { North American Industrial Classification System } \\ \text { NGO } & \text { Non-Governmental Organization } \\ \text { NJ } & \text { New Jersey } \\ \text { NPM } & \text { New Public Management } \\ \text { OECD } & \text { Organisation for Economic Cooperation \& Development } \\ \text { OH } & \text { Ohio } \\ \text { Ordinary-Least-Squares regression }\end{array}$




$\begin{array}{ll}\text { RC } & \text { Renewal Communities } \\ \text { RC/EZ/EC } & \begin{array}{l}\text { Renewal Communities, Empowerment Zones, } \\ \text { and Enterprise Communities }\end{array} \\ \text { SEZ } & \text { Special Economic Zones } \\ \text { SF } & \text { Sample File } \\ \text { SIC } & \text { Standard Industrial Codes } \\ \text { SC } & \text { South Carolina } \\ \text { SSA } & \text { Shift-Share Analysis } \\ \text { TN } & \text { Tennessee } \\ \text { TX } & \text { Texas } \\ \text { USDA } & \text { United States Department of Agriculture } \\ \text { US } & \text { United States } \\ \text { VA } & \text { Virginia } \\ \text { WOTC } & \text { Work Opportunity Tax Credit } \\ \text { WtWC } & \text { Welfare to Work Credit } \\ \text { WTO } & \text { World Trade Organization } \\ \text { WV } & \text { West Virginia } \\ \text { YWCA } & \text { Young Women's Christian Association } \\ \text { ZCTA } & \text { Zip Code Tabulation Area } \\ & \end{array}$




\section{INTRODUCTION TO THE STUDY}

\subsection{Problem Statement}

The federal initiative for Empowerment Zones and Renewal Communities $(\mathrm{EZ} / \mathrm{RC})$ aimed to create and retain business investment in poor communities and to encourage local hiring through the use of special tax credits, relaxed regulations, social service grants, and other incentives. Essentially, the EZ/RC Initiative was a place-based people strategy that emerged from the realization that, "in a very meaningful sense, people cannot be separated from place, and that an anti-poverty strategy needs to treat individuals in the context of their community" (Butler, 1981, p. 35). Following the devastating aftermath of the Los Angeles riots in 1992, the Clinton Administration, led by Vice-President Al Gore, adopted the EZ/RC Initiative to help revitalize America's struggling inner cities.

After a nationwide competition, several communities were picked to participate in the federal EZ/RC Initiative (or Community Renewal Initiative as it later came to be known), which was designed to stimulate sustainable local economic development. The United States Department of Agriculture (USDA) selected and managed the zones located in rural areas, while the United States Department of Housing and Urban Development (HUD) designated and administered the urban zones. Under the Omnibus Budget Reconciliation Act of 1993, six urban Empowerment Zones (EZs) were identified in New York City, Chicago, Baltimore, Detroit, Cleveland, and Philadelphia (HUD, 2010). These were the Round I EZ designations, which were undertaken from 1994 to 2011. Extant literature on EZs has mainly focused on this round.

There have been two additional rounds of urban EZ designations: Round II (19982011) and Round III (2001-2011). The tax incentives for all three Rounds of the EZ/RC programs were extended from the original expiration date of December 31, 2009 to 
December 31, 2011 by the Obama administration, under Tax Relief, Unemployment Insurance Reauthorization, and Job Creation Act of 2010. My dissertation focuses on the Round II Urban EZs, since the literature on these EZs is very thin. These EZs were authorized under the Taxpayer Relief Act of 1997. After a nationwide competition, HUD identified fifteen EZ areas based on four key principles: 1) strategic vision for change, 2) economic opportunity, 3) community-based partnerships, and 4) sustainable community development (HUD, 2010). The urban EZ areas generally consisted of inner city census tracts, with high poverty and unemployment rates (25 percent or greater in 1990) and between 50,000 to 200,000 residents in a selected metropolitan area.

By one account, corporations claimed an estimated $\$ 2.6$ billion in EZ tax credits during the program's initial tenure, with no credible evidence that they were used as intended (GAO, 2010). Another report highlighted that more than $\$ 11$ billion in tax credits was given to businesses, despite concerns about the effectiveness, efficiency, and equity of the program (HUD, 2010). The incentives were meant to stimulate the private sector's interest in revitalizing struggling inner cities and rural areas. In many ways, the federal EZs, a twist on traditional special economic zones, were not just business development tools, but also locality and human resource development tools with defined borders and targeted groups of people. The overall purpose of my dissertation is to examine if the EZ program had a beneficial impact on the communities where the Round II EZ/RC program was implemented. I construe beneficial impact to be the creation of new businesses and jobs. As such, there are three main aims of my dissertation: 1) to examine if the EZ program led to the creation of new businesses and employment; 2) to analyze changes in the types of local industries; and 3) to identify institutional factors that may have contributed to economic development and job creation in the EZ areas. To accomplish these aims, I use three methodologies respectively: ordinary-least-squares 
statistical regression models, shift-share analysis, and an in-depth case study of an EZ community.

\subsection{Significance of the Study}

The significance of this dissertation is fourfold. First, my research contributes to the literature on the effectiveness and sustainability of central city economic revitalization efforts. In an October 2009 speech at Harvard University, HUD Secretary Shaun Donovan referred to a growing disconnect between where people live and where jobs are located, which impedes the development of sustainable inner cities. Donovan argued that only the federal government has the capacity to deal with the widespread effects of job loss and foreclosures through the implementation of flexible policy tools “that recognize one-size doesn't fit all” (Donovan, 2009, p. 2). The EZ program was such an attempt that warrants an in-depth investigation.

As the entire country struggles to recover from the recent economic downturn and lingering high unemployment, it is important to look at what works now and what will continue to work in the future, in terms of sustainable local economic development. The national government is increasingly partnering with local governments to create innovative solutions that include improved data, performance-based management, and evidence-based policymaking. According to Donovan (2009), President Obama has ordered a comprehensive review of all place-based federal policies implemented since the Carter Administration. My dissertation is a contribution towards such a review, focusing on the $\mathrm{EZ} / \mathrm{RC}$ initiative.

Second, my research fills a gap in the literature, specifically on the Round II Urban EZs. Most of the existing program evaluations, including reports from the Government Accountability Office (GAO), focus mainly on the original six Round I Urban EZs (e.g. Busso and Kline, 2008; Hyman, 1998; Davila 2004; Oakley and Tsao, 
2006; and Hebert et. al., 2001). As a result of the limited number of studies on the EZ/RC program, researchers often rely heavily on evidence from state enterprise zones and overseas special economic zones (see Papke, 1994; Boarnet and Bogart, 1996; Bondonio and Engberg, 2000).

The subject was so under-researched that the GAO (2006) found only 11 evaluations that systematically collected and analyzed data on the EZ/RC program effectiveness, despite reviewing more than 1,100 articles and report abstracts. The GAO highlighted the imperative for a study that: 1) focused on the EZ/RC Program, 2) systematically collected and analyzed empirical data, 3) evaluated the program's effect on poverty, unemployment, or economic growth as congressionally mandated, or 4) evaluated the EZ/RC program's success at achieving other program goals. My study is aligned with these criteria, and is the first known study to focus exclusively on the Round II Urban Empowerment Zones and their impact on local business and job growth.

Third, the study uses Shift-Share Analysis, a methodology commonly used in local economic development analysis, in a new way to test Harvard economist Michael E. Porter's (1995) emphasis on industrial clusters in his theory on the "Competitive Advantage of Inner Cities." Porter's theory implies that inner-city neighborhoods, like those where the urban EZs are located, should be able to attract and retain businesses when the neighborhoods are integrated with local industry clusters. Shift-Share Analysis is used to identify the predominant local industry clusters for the testing Porter's theory. Fourth, my research would inform policy makers on successful location-based economic development strategies through the identification of common institutional factors found in EZ communities that experienced business and job growth. 


\subsection{Theoretical Framework}

Porter's (1995) theory on the "Competitive Advantages of Inner Cities," suggests that urban areas like the EZs should be able to attract and sustain business growth when they are: strategically located, integrated with regional clusters, designed to tap into unmet local demand, and committed to developing human resources through training and education. These principles, which have been widely acclaimed by community and economic development scholars, helped guide the research questions, hypotheses, and design of my dissertation.

Although inspired by Hong Kong's free port system, the EZ/RC program is incomparable to traditional Special Economic Zones (SEZs) in terms of both concept and approach. The American version has featured a higher level of government intervention and emphasized social wellbeing over industry prosperity. The historical and socioeconomic context of the SEZs in the United States and abroad raises concern that the effort to make cities more competitive really constitutes a race to the bottom.

The recent literature tends to focus on lessons from state enterprise zones (e.g., Papke, 1994; Boarnet and Bogart, 1996; Bondonio and Engberg, 2000) or outcomes from the original six Round I EZs (e.g., Rubin, 1994; Peters and Fisher, 2002; Oakley and Tsao, 2006; Busso and Kline, 2008). In regard to the EZs, researchers frequently ask the question, "Do they work?” (Ladd, 1994). The recurring conclusion is best expressed in the title of the $2006 \mathrm{GAO}$ report on the EZ/RC program - Improvement occurred in the communities, but the effect of the program is unclear. Although the focus of that GAO report was mainly the Round I EZs, the Round II and Round III EZs have thin research coverage.

For the most part, EZ researchers have evaluated the program's effects on poverty, unemployment, and housing values, with mixed results (see Peters and Fisher, 2002; Krupka and Noonan, 2009; Busso and Kline, 2008; Oakley and Tsao, 2006). Many 
of the studies rely on census-derived indicators of community outcomes, use a regression-based approach, and establish a counter factual comparison to estimate what would have occurred in the program's absence (Rich and Stoker, 2010).

My study takes a similar approach in terms of quantitative and qualitative methodologies. Previous case studies of the EZs (such as Chaskin and Peters, 1997; Davila, 2004) utilize site visits, interviews with officials and stakeholders and a review of secondary sources to describe neighborhood demographics, local strategies and community dynamics that may affect performance. However, mine is the first study to use Shift-Share Analysis to examine industry clusters within an EZ and explore the potential for a skills mismatch between zone residents and local jobs. The potential for "spatial mismatch", in which residents are systematically excluded from local jobs, has been documented in inner city communities (Kain, 1968, 1993; Holzer 1991, 1996; Hyman, 1998; Stoll, 2005) and must be considered as a possible deterrent to the program's stated objective of job creation specifically for zone residents.

Stoll (2005) examined skills mismatch by analyzing the geographic search patterns of job seekers in inner cities. He found that since minorities, particularly African-Americans, tend to live in inner cities and have fewer transportation options, they are more likely to seek jobs for which they are not qualified. Furthermore, other studies have shown that minority-owned businesses are more likely to hire inner-city residents than white-owned businesses (Porter, 1995 and Hyman, 1998). Despite the challenges associated with business development and job creation in inner cities, Porter (1995) insists there are distinct competitive advantages under the right circumstances.

\section{$1.4 \quad$ Research Questions}

The overarching question of the dissertation is: Did Round II Urban EZ designations have a beneficial economic impact on local communities? For the purpose 
of the dissertation, beneficial economic impact is defined as: 1) the growth of businesses, and, 2) the growth of jobs between 1998 and 2007 (before the economic crisis hit, to minimize the effects of the economic downturn). The explicit research questions and hypotheses are:

Q1. Did the EZ designation contribute to business and employment growth in communities?

H1. EZ designation contributed to business and employment growth in such communities. That is, I hypothesize that the Round II EZ program achieved its intended goal.

Q2. In EZ communities that experienced business and employment growth, in which industries were gains made?

H2. In EZ communities that experienced business and employment growth, the gains were concentrated in industries with a relative competitive advantage in 1998. The intent of this question is to verify if the EZ communities with beneficial impacts followed Porter's cluster theory.

Q3. What institutional factors influenced the implementation and performance of EZs?

H3. This research question is exploratory. Based on the extant literature, I hypothesize the institutional factors that could influence the program's effectiveness in communities are: community participation, organizational capacity, governance structure, and leadership.

The Round II Urban EZs were implemented in fifteen sites, listed in Table 1. The sites encompassed 261 census tracts. The census tracts were matched with corresponding 88 zip codes for the purpose of this study. The match of census tracts to zip codes was used because the zip code is the lowest geographic denomination for which detailed annual economic indicators data are available from the U.S. Census Bureau. The 
limitation, however, is that the census tracts do not exactly match with the zip code boundaries. Zip code level analysis is yet appropriate since this would capture the spatial spillover effects of the EZs.

\section{Table 1: Fifteen Round II Urban Empowerment Zones}

\begin{tabular}{lll}
\hline$\#$ & City & State \\
\hline 1. & Boston & Massachusetts \\
2. & Cincinnati & Ohio \\
3. & Columbia/ Sumter & South Carolina \\
4. & Columbus & Ohio \\
5. & Cumberland County & New Jersey \\
6. & El Paso & Texas \\
7. & Gary/ Hammond/East Chicago & Indiana \\
8. & Huntington/ Ironton & West Virginia/ Ohio \\
9. & Knoxville & Tennessee \\
10. & Miami-Dade County & Florida \\
11. & Minneapolis & Minnesota \\
12. & New Haven & Connecticut \\
13. & Norfolk/ Portsmouth & Virginia \\
14. & Santa Ana & California \\
15. & St. Louis & Missouri \\
\hline
\end{tabular}

To answer the research questions and test the hypotheses, I apply three modes of inquiry. With respect to the first question, I use an Ordinary-Least-Squares (OLS) regression model to reveal the statistical significance of the EZ designation in all fifteen Round II Urban EZs on the local business growth. For the second question, Shift-Share Analysis (SSA) is employed to identify industry clusters and shifts relative to the regional economy from 1998-2007, in three representative Round II Urban EZs. For the third question, I conducted a detailed case study of the Miami-Dade County EZs to identify possible institutional characteristics that may have influenced the implementation and performance of the zones. The case study is constructed through interviews with EZ 
stakeholders, including federal administrators, local program officials, board members, business owners, community leaders and residents.

\subsection{Organization of the Dissertation}

With a focus on the Round II Urban EZs, my study investigates the history, background, theory and impact of the federal economic development program on local communities.

The second chapter, Background and Literature Review, explores the history and background of special economic zones, starting with the Hong Kong model. The former British colony and free trade zone and critical port, spawned adaptations of special economic zones (SEZs) around the world, including eventually the United States. SEZs had already been adopted at the state and municipal levels when the federal EZ/RC program was introduced in the 1990s. The chapter details the design and implementation of the EZ/RC Initiative, including the application and selection processes, program characteristics and benefits. The chapter also reviews the existing evaluations.

The third chapter, Research Methodologies, describes the purpose and objectives of the study, outlines the research design, specifies the units of analysis and data collection techniques, and reviews the limitations of the study. To answer the research questions, three research methods are applied.

The fourth chapter, entitled Economic Opportunity, includes the statistical regression analyses used to examine the impact of the program on business and job growth. I used Ordinary Least Squares regression models to determine whether the presence of an EZ designated census tract had a statistical impact on the rate of change in the number of businesses and employees in a given zip code.

The fifth chapter, Sustainable Community Development, shows how Shift-Share Analysis and Location Quotient were used to identify the local industries likely to 
contribute to a healthy economy and examine changes in the composition and concentration.

The sixth chapter, Community Based Partnerships, presents the findings of a comprehensive case study on one of the fifteen Round II Urban EZs, Miami-Dade County, as well as overall impressions of the program from national administrators from the United States Department of Housing and Urban Development in Washington, DC. The seventh and final chapter, Strategic Vision for Change, includes the study's conclusion, best practices, and recommendations. Although, the EZ/RC initiative has been concluded there are lessons to be learned that can be applied to other location-based economic revitalization programs and specialized tax incentives, such as the New Market Tax Credits. 


\section{BACKGROUND AND LITERATURE REVIEW}

\section{$2.1 \quad$ Introduction}

The Empowerment Zones and Renewal Communities (EZ/RC) program in the United States was inspired by the free port system in Hong Kong. Free ports are a type of Special Economic Zones (SEZs) that allow a broad range of activities, such as duty-free privileges and access to the domestic market. The underlying economic theory of SEZs is that they spur local business growth by easing zoning restrictions, simplifying permitting processes, and lowering fees and taxes. The SEZs have expanded in both developing and developed nations. Special Economic Zones are of different types determined by their objectives, such as Industrial Zones (to serve domestic and export markets), Free Trade Zones (for trade through ports and airports), Export Processing Zones (for export manufacturing), Free Economic Zones (form an integrated domestic and export markets), and Enterprise Zones (for community renewal in urban and rural areas). In the United States, the SEZs are known as Empowerment Zones, Opportunity Zones, Enterprise Communities, and Renewal Communities.

The economic success of Hong Kong's free port spawned derivative SEZ models throughout the world, including the United States. However, the Hong Kong model and the United States' Empowerment Zones differ markedly. In the United States, the EZ/RC program was focused on increasing the wellbeing of zone residents by improving their surroundings in various ways, including through economic development options for businesses, but also through affordable housing construction, jobs and skills training, and social service programs. The American model also featured a higher level of government intervention and involvement than models in other countries. The present chapter provides an overview of the evolution of Empowerment Zones in the United States, including a critical review of the extant literature on these EZs. 


\subsection{Special Economic Zones: The Hong Kong Model}

The roots of the free port in Hong Kong go back to the First Opium War from 1839 to 1842 between Great Britain and China, which set the foundation for modern Hong Kong (Tsang, 2004). Surpassed only by tea and silk at that time, opium was an important import for Britain from Asia. Even though the drug was prohibited in China, Britain was allowed to import opium from India using Chinese trade routes. Until 1834, the East India Company had monopoly of trade in China. However in the 1830s, Imperial China exercised strict controls on external trade and considered suppressing the opium trade.

The Opium War ensued, as the British were concerned with protecting their economic interests and maximizing overall trade. With the British emerging victorious, China ceded Hong Kong to the British as a Crown Colony under the Nanking Treaty of 1842. Hong Kong was a "barren island with hardly a house upon it" (Tsang, 2004). Yet, the British claimed it mainly to open up China to further trade, partly because of its natural harbors. Charles Elliot, the Chief Superintendent of Trade in 1836, pronounced Hong Kong a "free port," declaring it as the "unintended result of the British Empire pursuing its economic interests in East Asia" (Tsang, 2004. p.20). The United Kingdom later signed a 100 year lease of the surrounding areas (the "New Territories) in 1898 to defend the island.

Hong Kong became a free port with very little tariff and nontariff barriers to trade. Indeed, Hong Kong prospered as one of the world's most dynamic and free economies, with a Gross Domestic Product (GDP) comparable to other developed countries. It relied heavily on foreign trade, with China as its most significant trading partner. When the 99-year lease expired in 1997, Hong Kong became a Special Administrative Region of the People's Republic of China. Indeed, Hong Kong has been identified as a success story by conservative economists such as Milton Friedman. Many 
countries have had a "long history of bestowing special economic incentives to promote the development of a part of parts of their territories" (Sit, 1985. p. 3). Policies of removing tariffs and barriers to promote trade have been applied in Gibraltar in 1704, Singapore in 1819, and Hong Kong in 1848.

Inspired by the economic success of Hong Kong's Free port system, Sir Peter Hall, an English professor of urban planning, proposed "enterprise zones" during the 1970s as a way to lure private investment to abandoned industrial areas in the United Kingdom (Green, 1991). The enterprise zones were expected to encourage business investment through low taxes, minimal land restrictions, and decreased regulation. Hall's enterprise zone concept suggested that reduced governmental regulation in economically depressed urban communities would stimulate economic growth within those areas. Reduced regulation, lower taxes, and other financial incentives for businesses would reduce the cost of operating businesses within those areas (Hyman, 1998).

Indeed, Sir Peter Hall is considered to be the father of the modern industrial enterprise zone concept. In the 1977 annual conference of the Royal Town Planning Institute in Britain, Hall proposed creating "free ports" devoid of government taxes and regulations, as a way to spur local business investments:

Small, selected areas of inner cities would be simply thrown open to all kinds of initiative, with minimum control. In other words, we would aim to recreate the Hong Kong of the 1950s and 1960s inside inner Liverpool or inner Glasgow (Hall, 1982).

In Hall's vision, small innovative technological firms would employ highly skilled individuals, which would then spur new service-sector businesses that would employ low-skilled workers. Jobs would be generated as a result of unfettered business growth. He envisioned these zones as free of most regulations that were otherwise 
imposed on British industries. Hall's concept of enterprise zones was considered radical by social critics for its embracement of laissez faire capitalism. Even he acknowledged:

Since it would represent an extremely drastic last-ditch solution to urban problems, it could be tried only on a very small scale. It is most appropriate to inner city areas that are largely abandoned and denuded of people, or alternatively areas with very grave social and economic problems (Hall, 1982).

The enterprise zone concept was adopted by Sir Geoffrey Howe, a Conservative Party leader in Britain and Dr. Stuart Butler from the Heritage Foundation in Washington D.C. (Hardison, 1981). During the 1980s, Howe was instrumental in gaining support for the British version of enterprise zones. In the United States, Butler introduced a slightly modified version of enterprise zones in 1979, derived from the concepts proposed by Hall and Howe. Unlike Hall and Howe, who viewed enterprise zones as a means of promoting industrial development, Butler saw them as community development tools to benefit the local inhabitants of economically distressed areas.

Worldwide, the Free port system came to be adapted as Special Economic Zones (SEZs), which were a part of wider economic reform strategies or experimental laboratories in capitalism and free markets. According to Ferrara (1982, p. 363), "the basic concepts of EZs indicated that in their pure form they should not involve any government appropriations or expenditures." The SEZs were designed to attract foreign investments by lowering tariffs and easing investment regulations. The SEZs were also used as "pressure valves" to alleviate high unemployment.

The SEZs grew across the world as instruments of local development. According to a 2008 report by the Foreign Investment Advisory Service (FIAS), a multi-donor investment climate advisory service for the World Bank, the SEZs grew exponentially from 79 zones in 25 countries in 1979 to approximately 3,000 zones in 2008, in over 135 
countries. About $62 \%$ of the 2,301 zones in developing and transitional countries were privately developed and operated.

The FIAS study highlighted many obstacles that could impede success of SEZs: poor locations, uncompetitive policies, poor zone development, subsidized rent, cumbersome procedures and controls, inadequate administrative structures, and weak coordination between private developers and governments regarding infrastructure provision. The FIAS emphasized, "the root of many of these obstacles to optimal zone performance is a lack of effective coordination, both in terms of the parties involved and various physical and procedural aspects of the zone itself" (2008. p. 5). Appropriate legal, regulatory, and institutional framework is required to encourage diverse activities and to promote private development.

On the basis of the literature review on SEZs (Hardison, 1981; Ferrara, 1982, Hyman, 1998; FIAS, 2008), five universal best practices could be identified for a zone's success. First, the SEZ should act as a catalyst for reform in the overall investment and economic climate within a host country or regional community. Second, the private sector should develop and operate zones on a cost-recovery basis and should not rely on government subsidies. Third, governments should specify and regulate SEZ activities only and should not directly own, operate or develop them. Fourth, SEZs should be linked to outside enterprises and stimulate growth in surrounding communities instead of existing as isolated enclaves. Fifth, SEZs should focus on building long-term competitiveness in businesses within the area as opposed to relying on incentives.

The literature on SEZs also suggests that location, development, management, and policy and incentive frameworks can be linked to zone success and failure. The emerging concept of modern zones indicates a shift toward creating large integrated economic communities utilizing public-private partnerships to stimulate growth and 
development. There is greater interest in achieving sustainable, social and economic development, particularly in the world's congested urban cores (FIAS, 2008). Critics of SEZs and non-governmental organizations (NGOs) contend that these institutions suffer from problems associated with internal dysfunctions and failure of accountability. The success of East Asian SEZs, like Hong Kong and Shenzhen, has been difficult to replicate in other parts of the world as a consequence of demographical, historical and geographical circumstances. In the United States, SEZs have been implemented at the local, state and federal levels with mixed results (Hyman, 1998, Rubin, 1994, GAO, 1997).

\subsection{History of EZs in the United States}

While inspired by Hong Kong's Free port system, the federal EZ/RC program in the United States is essentially a place-defined people strategy that emphasizes the wellbeing of people over industries in demarcated geographical areas. First introduced in Congress by Congressmen Republican Jack Kemp and Democrat Robert Garcia in 1980, EZs were viewed as a way to jump-start economic growth (Rubin, 1994). State governments took the lead and more than $75 \%$ of the states implemented some type of enterprise zone program (Rubin, 1994). A concerted federal initiative failed to take off the ground under the Ronald Reagan and George H.W. Bush administrations, as there was no congressional support to implement a national program. However, the Los Angeles Riots of 1992 prompted the Clinton Administration to pursue a modified version

of enterprise zones as a federal initiative to spur revitalization and job growth in troubled inner cities.

Consequently, the Omnibus Budget Reconciliation Act of 1993 established the first federal Empowerment Zones and Enterprise Communities, which combined tax incentives for businesses with social service grants to increase the quality of life in 
distressed communities (GAO, 1997). The Clinton administration's model of enterprise zones was a departure from earlier versions, such as Hong Kong's free port system, which focused solely on business and economic growth rather than community and social development. Rather than a reinvention of federal urban policy, the Clinton Administration's EZ/EC initiative was an improvement upon the lessons learned from the state enterprise programs under Reagan and the first Bush administrations, as well as Lyndon B. Johnson's Model Cities Program (Rubin, 1994). President Clinton summarized the goals of the new urban policy thus:

Our challenge is to provide opportunity to all Americans. We believe the best strategy for community empowerment is a community-driven comprehensive approach which coordinates economic, physical, environmental, community and human needs (HUD, 1994, p. 4).

By emphasizing the well-being and inclusion of community inhabitants, the EZ program differs from its global counterparts that simply view the location-centered concept as a means to economic prosperity. In the United States, the program was expected to produce a measurable impact on several indicators, including poverty, unemployment, and economic growth.

\subsection{The Federal EZ/EC Initiative}

The main purpose of the Empowerment Zones and Enterprise Communities (EZ/EC) Initiative was to provide "grants to both private and public entities for social services and community development and tax benefits to local businesses to attract or retain jobs and businesses in distressed communities (GAO, 2006, p.1). To date, Congress has authorized three rounds of Empowerment Zones (EZs), two rounds of Enterprise Communities (ECs), and one round of Renewal Communities (RCs), under four separate acts of legislation (Table 2). 
Table 2: Summary of Legislation Authorizing the EZ/EC and RC Programs

\begin{tabular}{|c|c|c|}
\hline Program & Title & Summary \\
\hline \multirow{5}{*}{$\frac{\text { Round I }}{\mathrm{EZ/EC}}$} & \multirow{5}{*}{$\begin{array}{l}\text { Omnibus Budget } \\
\text { Reconciliation Act of } \\
1993\end{array}$} & Established the EZ/EC program and its \\
\hline & & package of grants and tax benefits \\
\hline & & $\begin{array}{l}\text { Authorized six urban and three rural Round I } \\
\text { EZs }\end{array}$ \\
\hline & & Authorized 65 urban and 30 rural Round I ECs \\
\hline & & $\begin{array}{l}\text { Established the eligibility requirements and } \\
\text { selection criteria for EZ/ECs }\end{array}$ \\
\hline \multirow{5}{*}{$\frac{\text { Round II }}{\underline{\text { EZ/EC }}}$} & \multirow{4}{*}{$\begin{array}{l}\text { Taxpayer Relief Act of } \\
1997\end{array}$} & Authorized 5 rural and 15 urban Round II EZs \\
\hline & & Authorized two additional Round I EZs \\
\hline & & $\begin{array}{l}\text { Changed the eligibility requirements for } \\
\text { EZ/ECs }\end{array}$ \\
\hline & & Created the Washington, D.C. Enterprise Zone \\
\hline & $\begin{array}{l}\text { Omnibus Consolidated \& } \\
\text { Emergency Supplemental } \\
\text { Appropriations Act of } \\
1999\end{array}$ & Authorized up to 20 additional rural ECs \\
\hline Round III & \multirow{7}{*}{$\begin{array}{l}\text { Community Renewal Tax } \\
\text { Relief Act of } 2000\end{array}$} & Authorized two rural and seven urban Round \\
\hline \multirow{6}{*}{ EZ\& RC } & & III EZ designations \\
\hline & & $\begin{array}{l}\text { Established the RC program and its package of } \\
\text { tax benefits }\end{array}$ \\
\hline & & $\begin{array}{l}\text { Authorized designation of } 40 \mathrm{RCs} \text {, with } 12 \\
\text { designations reserved for rural areas. }\end{array}$ \\
\hline & & Designation valid until Dec. 31, 2011 \\
\hline & & $\begin{array}{l}\text { Made some additional tax benefits available to } \\
\text { EZs }\end{array}$ \\
\hline & & $\begin{array}{l}\text { Extended Round I and II EZ designations } \\
\text { through December } 31,2011\end{array}$ \\
\hline
\end{tabular}

Four federal agencies share responsibility for the implementation and oversight of the EZ/EC Program - the United States Department of Housing and Urban Development (HUD), the United States Department of Agriculture (USDA), the United States Department of Health and Human Services (HHS) and the Internal Revenue Service (IRS). The United States Department of Housing and Urban Development oversees urban areas while rural districts generally fall under USDA jurisdiction. In the earlier rounds, 
HHS provided block grants directly to host states, which then distributed the flexible funding to the designated municipalities. The IRS is responsible for administering the tax benefits (GAO, 2006). The economic revitalization initiative adopted a "bottom-up" approach to allow communities the flexibility and discretion to identify local demands and develop appropriate solutions (HUD, 2008).

\subsection{EZ Application and Selection Process}

The Clinton Administration launched the EZ/EC program as a nationwide competition, in which applications were invited from cities, and rural communities that met the required criteria for poverty, population and level of distress. Census tracts with poverty levels of at least $25 \%$ in 1990 qualified, as long as they had between 50,000 to 200,000 residents, or represented $10 \%$ of the surrounding city's population. In short, eligibility depended on pervasive poverty, high unemployment and general distress (HUD, 2010).

Table 3 provides a more detailed breakdown of the program eligibility requirements as it relates specifically to the Round II Urban Empowerment Zones. The legislature authorizing the program mandated that qualified census tracts meet minimum criteria for poverty, unemployment, population, general distress, and maximum size. 


\section{Table 3: Round II Urban EZ Eligibility Requirements}

Minimum required poverty rate

Minimum required unemployment rate.

Required population

Maximum required area

Conditions of general distress

Other Requirements
$25 \%$ in $90 \%$ of tracts, $20 \%$ in all tracts

$6.3 \%$ (1990 national rate)

Maximum: 200,000 or the greater of 50,000 or $10 \%$ of the population of the most populous city within the nominated area. Minimum: None

20 Square miles, with up to 3 developable sites

17 indicators, like average years of school completed, number of persons on welfare, and dropout rate Strategic plan based on the four key principles of the EZ/EC program: 1) Strategic Vision for Change, 2) Community-based Partnerships, 3) Economic Opportunity and 4) Sustainable Community Development

Source: GAO summary of P.L. 103-66, P.L. 105-34, P.L. 106-554, 24 C.F.R. 597, 24 C.F.R. 598, 24 C.F.R. 599, and 7 C.F.R. 25. (2010)

For the urban EZs, HUD scored and ranked cities on the strength of a comprehensive strategic plan that was built on the framework of the EZ Initiative's four key principles: 1) Strategic Vision for Change, 2) Community-based Partnerships, 3) Economic Opportunity and 4) Sustainable Community Development (HUD, n.d.).

The Strategic Vision for Change identified what the community endeavored to become and detailed strategies for revitalization. It included a statement of values in the community that would be used to accomplish its vision. In building this strategic map for revitalization, each EZ developed a plan that:

- States a clear vision and goals for the future;

- Explains how the vision creates economic opportunity, encourages selfsufficiency, and promotes sustainable community development; 
- Builds on the assets and opportunities available and presents a coordinated strategy toward solving them;

- Sets out performance standards for measuring progress, and a framework for evaluation and making future adjustments to the Strategic Plan (HUD, 2009. p. 2).

In terms of Community-centered Partnerships, EZs were expected to involve all segments of a community and stakeholders and promote representative participation. "Partnerships include residents, businesses, local political leaders, local, state and Federal governments, community development corporations, local public health and social service departments, regional planning organizations, unions, environmental groups, schools and universities, faith-based organizations, and other community groups" (HUD, 2009, p. 3). The Department of Housing and Urban Development mandated that residents should take an active role in the implementation and monitoring of the revitalization plan through an established governance structure.

Every EZ was responsible for designing its own governance structure and designating a Coordinating Responsible Authority (CoRA) that was responsible for the coordination and development within the zone. The CoRA could be any entity, organization, person or persons authorized by the state or local government that nominated the EZ for designation. The CoRA served as the central point of contact with HUD and assumed responsibility and authority for implementing the strategic plan and tax incentive utilization plan. According to $\operatorname{HUD}(2009$, p. 3), "Some communities established a non-profit to implement their strategic plans and they used the non-profit's Board of Directors as the governance mechanism for the Zone. Others created standalone advisory boards to guide local officials during implementation."

Economic Opportunity refers to a community's potential to generate new jobs and attract industries. The main priority of the EZ program was to create jobs specifically for 
existing residents, but also included providing technical assistance to entrepreneurs, and helping businesses secure access to capital and credit so that they could expand and create employment opportunities, and providing job training and skills development for residents.

The Sustainable Community Development principle was aimed to create vibrant and livable neighborhoods "through comprehensive approaches that coordinate economic, physical, environmental, community and human development" (HUD, 2009, p. 4). Beyond simply short-term and long-term job creation, it entailed a holistic approach to sustain positive momentum for responsible community development.

\subsection{EZ Program Characteristics and Benefits}

In 1994, the HUD awarded Round I EZ designations to six metropolitan areas that were selected through a competitive application process: 1) Atlanta, Georgia; 2) Baltimore, Maryland; 3) Chicago, Illinois; 4) New York City, New York; 5) Detroit, Michigan; and 6) Philadelphia, Pennsylvania/ Camden, New Jersey (HUD, 2008). Atlanta later lost its EZ status in 2000 when shared census tracts were designated as part of a Renewal Community. Los Angeles and Cleveland were designated as 'Supplemental Empowerment Zones' in the competition, and in 1999 received full EZ status. The selection criteria in the competition included the strength of a comprehensive plan, how EZ funds were proposed to be spent, and an action plan detailing how goals would be achieved (GAO, 2006).

The Taxpayer Relief Act of 1997 authorized the second round of EZ designations, adding fifteen new urban zones (HUD, 2008). The Community Renewal Tax Relief Act of 2000 implemented the third round, which brought eight new urban Empowerment Zones The 2000 Act also extended the deadlines for the first and second rounds beyond 
their original ten years and mandated that the GAO periodically audit and report on the program's effect on poverty, unemployment, and economic growth (GAO, 2006).

Between 1994 and 2000, altogether HUD and USDA designated 41 Empowerment Zones, 115 Enterprise Communities, and 40 Renewal Communities. On December 31, 2009, all three rounds of the EZ program initially expired. However, the Tax Relief, Unemployment Insurance Reauthorization, and Job Creation Act of 2010 (Public Law No: 111-312), signed by President Obama on December 17, 2010, retroactively extended the tax incentives through December 31, 2011, for all three Rounds of the EZ program.

The Department of Health and Human Services initially issued \$100 million in Social Service Block Grants to each of the six original Empowerment Zones. The Economic Development Initiative Grants applied only to Los Angeles and Cleveland and awarded $\$ 125$ million and $\$ 87$ million respectively. The second and third rounds did not receive as much grant funding as the first round and relied more extensively on tax incentives. The incentives included a range of tax credits, bond financing, and regulatory exceptions, as described below.

The Wage Credits, otherwise known as the Employment Credits, which were a significant component of the latter rounds, could be claimed for eligible employees for up to ten years. It allowed employers located in an EZ to claim a salary credit up to $\$ 3,000$ per year for the first $\$ 15,000$ paid to an employee residing in the zone (Busso and Kline, 2008). Employers could use HUD's Address Locator on the Internet (www.hud.gov/crlocator) to verify that the business location and address of employee residences were located in the designated Empowerment Zones.

The Work Opportunity Tax Credit applied to businesses employing certain groups that faced employment disadvantages, such as urban teenagers during the summertime (Kaye and Nightingale, 2000). Businesses could claim a tax credit up to $\$ 2,400$ per 
employee from specially identified groups, including residents between the ages of 1839. The Welfare to Work Credit rewarded companies that employed long-term welfare recipients.

Qualified zone businesses could finance certain property with Enterprise Zone Facility Bonds. State and local governments were able to issue bonds of up to $\$ 230$ million per EZ to make low-cost loans to EZ businesses (HUD, 2003). Increased Section 179 Expensing allowed EZ companies to claim tax deductions of up to $\$ 35,000$ for depreciable, tangible property and equipment purchases, and allowed EZ businesses to write-off all or part of their equipment costs the year that they purchased them rather than deducting the expenses over time (HUD, 2003).

In addition, EZ/RC areas received priority consideration in other federal assistance programs and were encouraged to request regulatory waivers when available. The Department of Housing and Urban Development (HUD) chose the urban EZs based on each municipality's ability to demonstrate a scope for economic opportunity, community-based partnerships, a plan for sustainable community development, and a strategic vision for change (HUD, 2004). The Clinton Administration added social welfare programs to the business-friendly concept of enterprise zones to win support for the Empowerment Zones and Enterprise Community (EZ/EC) Initiative. The program targeted specially designated urban and rural census tracts for economic revitalization.

In summary, the EZ program offered special tax benefits and other incentives to businesses that relocated, created jobs and hired residents within its boundaries. In addition, block grants allowed for infrastructure and general location improvements, as well as human resource development. These incentives were meant to stimulate the private sector's interest in revitalizing struggling inner cities and rural areas. In many ways, EZs were not just business development tools, but also locality and human resource development tools with defined borders and targeted groups of people. 


\subsection{Do EZs work? Many questions, few answers}

The literature on enterprise zones frequently asks the question, "Do they work?" (e.g., Rubin, 1994; Boarnet and Bogart,1996; Peters and Fisher, 2002). The resounding conclusion is best expressed in the title of the 2006 Government Accountability Office (GAO) report on the federal Empowerment Zone and Enterprise Community (EZ/EC) Program - Improvement occurred in the communities, but the effect of the program is unclear.

Several GAO reports found that the federal agencies have been unable to agree on a way to properly account for spending expenditures or verify that tax benefits are being used as intended (1996, 1997, $2004 \& 2006)$. The flexibility that allows communities to determine how funds should be spent has hindered a full accounting of where the money goes. As a result, "data were not collected on program benefits for specific activities, limiting the ability of federal agencies to oversee the program, and the monitoring performed at the state and local levels varied" (GAO, 2006, p. 3).

To date, most of the literature on enterprise zones involves state programs (e.g. Baum, 1999; Boarnet and Bogart, 1996; Bondonio and Engberg, 2000) or the Round I EZ/ECs (e.g. Busso and Kline, 2008; Chaskin and Peters, 1997). In particular, many of these studies measure changes in unemployment and poverty rates. Given that these two measures were part of the criteria that allowed these communities to be designated for assistance, it is logical to measure their outcomes after the program's implementation.

Bondonio and Engberg (2000) found that enterprise zone participation in five states failed to have a direct impact on local employment outcomes. Their study consisted of a comparative evaluation of EZ programs on employment using two econometric methods - the random growth rate approach and propensity score approach. They concluded that the EZ programs did not lead to local employment growth. 
Likewise, Boarnet and Bogart (1996) found that the urban enterprise zone program in New Jersey failed to have a positive effect on employment measures derived from a panel data econometric analysis. Boarnet and Bogart suggested that their findings may not be representative of all enterprise zones and suggested that further research is needed to identify why some tax abatement programs succeed while others fail. Their results suggest that state enterprise zone programs did not have a positive effect on total municipal employment, and therefore, did not meet the goal of improving economic conditions in and around those areas. In contrast, in a study of Indiana state enterprise zones, Papke (1994) found that unemployment claims decreased in cities with Empowerment Zones. However, her results also indicated that EZs increase job opportunities for all city residents, not just zone inhabitants.

In a recent study on the federal EZ/EC program, Busso and Kline (2008) compared Round I EZs with those that were selected in subsequent rounds. They found substantial improvements in local labor and housing market conditions in EZ neighborhoods from 1994 to 2002 . They concluded that some market gains were a result of neighborhood turnover, which is consistent with the feedback that EZ stakeholders shared with the Government Accountability Office (2006). Housing and cost of living increases in Empowerment Zones could result in gentrification. Busso and Kline (2008) argue that additional research is needed to determine whether new jobs are the result of expansion of existing firms, the creation of new firms, or the relocation of outside firms.

Investigating the extent of community participation, Davila's case study in 2004 of the East Harlem Empowerment Zone suggests that Puerto Ricans were systematically excluded from participating in EZ program. Business plan and quality requirements disqualified many Latino cultural initiatives as inadequate to generate profits, employment and tourists. As a result, many Latino residents felt alienated from the 
program and felt that it was not benefiting current residents but rather encouraging the neighborhood's gentrification, since more affluent residents were replacing the poor.

\subsection{Impact of Governance Structure on Performance}

Given the emphasis and federal mandate on community participation, increased citizen representation should improve the responsiveness of third-party governing bodies in Empowerment Zones. In addition, adequate local, state and federal oversight should minimize accountability issues. While poverty, business growth and unemployment within American EZs have been key areas of interests for researchers, less attention has been paid to the governance structure of these community-focused programs.

In a preliminary examination of governance in fifteen Empowerment Zones, Supplemental Empowerment Zones, and Enhanced Enterprise Communities, Chaskin and Peters (1997) found common problems related to: 1) the nature of representation; 2) conflicts of interest; and 3) recruiting and maintaining involvement. They also discovered that citizen input and influence decreased from the planning to the establishment phases of zone programs and activities. Specifically, Chaskin and Peters focused on "the engagement of local actors in a process of planning and governance for the empowerment zones, and their place within the broader governance structure of the program as a whole" (1997, p. 3).

Like other EZ researchers, Chaskin and Peters (1997) faced several limitations. First, they noticed that comparable documentation was unavailable across sites. Second, each site had unique relationships and history that had to be taken into consideration. Third, the small number of respondents in their study prevented them from generalizing their findings. Fourth, their study was conducted very early in the implementation phase. Lastly, they acknowledged that the planning and implementation of the EZ program is highly political (Chaskin and Peters, 1997). 
In a cross-case analysis of their 15 selected zones, Chaskin and Peters established that "regardless of the choice of formal auspices, local government has played a significant role in appointing participants to the governing or advisory committees" (1997, p. 7). They discovered three distinct organizational auspices for the EZ programs: the existing city, county or municipal governmental authority; a newly created corporation or nonprofit; or an existing nonprofit or community-centered organization. They concluded that in establishing the governance structure of an EZ, it is important that planners "ensure that the structure fulfilled the requirements and the spirit of the federal mandate of public participation," as well as "provide the proper fiscal accountability of the program" (Chaskin and Peters, 1997, p. 12). In sites that delegated authority to a new or existing non-profit organization or corporation, a "hollow state" was created, a la Milward, Provan, and Else (1993) that describes the organizational system of third party governance. The hollow state is a metaphor for the increasing use of third parties, like nonprofits, to deliver social services in the name of the state (Milward and Provan, 2000).

Baum's 1999 case study of Baltimore's Empowerment Zone revealed governance and funding challenges in regards to educational initiatives. Baum described education in the Baltimore EZs as a "turbulent organizational field" in which the school system was considered just another bidder, instead of an integral social institution. Instead of collaborating, the Empower Baltimore Management Corporation (EBMC), which managed the city's federal Empowerment Board, regarded education as secondary to economic development. As a result, few EBMC board members had a background or interest in education. Baum argues that improvements to EZ schools require networks and cooperation among various formal and informal organizations.

Rich and Stoker's (2007) report Governance and Urban Revitalization: Lesson from the Urban Empowerment Zones Initiative highlighted the important differences that exist between and within empowerment zones. Their study combined a quantitative 
evaluation of job growth in the six original empowerment zones and qualitative context from the EZ programs in Atlanta and Baltimore. They found that the quality of local governance played a critical role in the program's outcomes. For example, Baltimore succeeded as a result of community participation, effective coordination and good planning; in contrast, community infighting in Atlanta undermined the efforts and impacts of the empowerment zone program. They highlight how effective governance is required for a comprehensive community revitalization strategy to work better:

Governance systems can coordinate programs, increase the number of redevelopment tools available to stimulate business and job growth, enhance services, inform businesses about redevelopment incentives, solve collective action problems, and address market failures, all in a context tailored to the distinctive needs and opportunities that exist within local communities. (Rich and Stoker, 2007, p.36)

\subsection{Competitive Advantages/ Disadvantages of Inner Cities}

While poverty, business growth and unemployment within EZs have been key areas of interests, less attention has been paid to the matching skills of the zones residents with the industries. A cornerstone of the EZ program is the creation of sustainable employment opportunities for current zone residents. Are they, however, qualified for these new positions? One study found that local residents mainly find entry-level jobs in the inner-city neighborhoods (Reingold, 1999). The study used data from the Urban Poverty and Family Life Study's survey of Chicago-area employers to estimate the impact of neighborhood poverty and hiring practices on the employment of local residents. It concluded, "it seems likely that inner-city employers hire local residents not because they prefer workers from these areas but because these employers have trouble 
finding entry-level workers from working- and middle-class communities" (Reingold, 1999, p. 302).

Holzer (1996) suggests that inner-city residents are less likely to be hired for suburban jobs as a consequence of discrimination, limited information, and inadequate transportation. In his study of "local working" (i.e., residents working within or near their neighborhoods) in Chicago, Immergluck (1996) explored the effect of concluded, "Higher local working rates are likely to yield benefits, including decreased commuting, the improvement of neighborhood-centered job networks, and even neighborhood economic growth" (1996, p. 185). However, he acknowledges that "local working" is only likely to increase if there is an occupational match between residents and jobs.

Kasarda (1985) has highlighted the potential for geographic skills mismatch between under-educated minorities and the highly skilled jobs of central business districts. Stoll (2004) examined skills mismatch by analyzing the geographic search patterns of job seekers in inner cities. He found that since minorities, particularly African-Americans, tend to live in inner cities and have fewer transportation options, they are more likely to seek jobs for which they are not qualified. He writes:

To the extent that high-skill job requirements are greater in central cities than in suburbs and that blacks', and perhaps Latinos', geographic search is limited to central city job centers, perhaps because of their greater search costs stemming from racial residential segregation or their inferior access to private modes of travel, the job skill requirements faced by black (Latino) searchers will be higher than those of whites (Stoll, 2004, p. 2). Stoll (2004) relied on the geographic search patterns of undereducated workers in Los Angeles and Atlanta, as well as employer data provide by the 1994 Multi-City Study of Urban Inequality and Multi-City Employer Surveys. He concluded that a geographic skills mismatch between the high-skill jobs of central cities and the location of less- 
educated minorities, particularly African Americans, contributes to that group's high unemployment rates. Based on Stoll's findings, it would appear that minorities face greater disadvantages in seeking employment within their local communities.

Other studies show that minority-owned businesses are more likely to hire innercity residents than white-owned businesses (Porter, 1997; Hyman, 1998; ICIC, 2009). Hyman (1998) analyzed the impact of the EZ/EC program on inner city employment and black-owned businesses. He concluded, "minority-owned businesses should serve as the focus of every urban development program, particularly the EZ/EC program” (1998, p. 145). Hyman differentiates between the "traditional line" black businesses and "emerging line" black businesses. The "traditional line" black businesses are small-scale operations that usually require little capital and have low wages, such as barber shops. The "emerging line" black businesses are associated with more professional fields such as financing but may need to be located outside of an EZ to be sustainable.

The theoretical debate between place-based and people-based strategies for community development has waged for nearly half a century (Winnick, 1966, Crane \& Manville, 2008). Place-based aid, sometimes referred to as demand side, is tied to a particular geographical area and can take the form of improvements to infrastructure or incentives for local operations. Alternatively, people-based programs, sometimes referred to as supply side, typically occur in the form of monetary transfers, education, skills training or job placement initiatives. For the most part, place-based strategies tend to be considered more effective and efficient methods for local economic development (Bolton, 1992; Gyourko, 1998; and Crane \& Manville, 2008). However, without a people-based component to community development, for example, through job training for existing local residents, improvements to a locale will likely result in a mismatch of disproportionate skills and further disenfranchise the base population. 
A study by the Initiative for a Competitive Inner City (ICIC) found that the average inner city business creates three times the number of jobs for inner city residents than the same size business in another part of the region. The Harvard Business School Professor Michael E. Porter founded ICIC to highlight the competitive advantages of inner cities. According to him, (Porter, 1997), inner cities have an intrinsic competitive advantage because of their 1) strategic location, 2) integration with regional clusters, 3) unmet local demand and 4) human resources. Furthermore, he argues that they can be revitalized through private sector investment and high-quality employment training, and preparation. Industry clusters in inner cities that are integrated with the encompassing regions would be strategic in the revitalization process. Regionally integrated industry clusters will have the greatest chance of creating jobs for local residents and contributing to overall business growth.

Critics of Porter's theory claim that his analysis of the deep-rooted issues that plague inner cities is superficial, and relies on the private sector and natural market forces, while diminishing the role of government and the effectiveness of social programs (Bates, 1997; Goozner, 1998; Cummings, 2003; Boston \& Ross, 1995; Harrison \& Glasmeier, 1997; and Sawicki \& Moody, 1999). Goozner, for example, points out that, 'In Porter's view, only the private sector, both big corporations and entrepreneurial startups, can transform the inner city" $(1998$, p. 58). Despite his belief that the private sector needs to be driving force in the revitalization of struggling inner cities, Porter admits that businesses located in urban cores are unlikely to hire local residents. For that reason, he suggests that minority businesses would be the most probable catalyst to stimulate hiring of neighborhood residents.

Notwithstanding the critics, Porter has made a seminal contribution in "1) reigniting debate about the plight of inner-city minority communities and appropriate policies for alleviating their malaise and 2) inducing the business community to 
reconsider their view that investing in the inner city is a waste of resources" (Bates, 1997, p. 3). Porter's critics also concede that he has helped dispel long-held misconceptions about the feasibility of private sector involvement in the economic revitalization of inner city areas. The ICIC has successfully developed programs to support inner city businesses and help them overcome obstacles and maximize their available resources.

\subsection{Conclusion: Significance of Study}

The federal EZ/RC program was inspired by the Hong Kong model of free ports, but is significantly different from the Sir Peter Hall's vision of enterprise zones in the United Kingdom. The American program provided tax credits, but included the wellbeing and participation of community residents. The primary aim of the federal EZ/RC program is to promote economic development in distressed inner-city areas through new businesses (Dabney, 1991) or jobs (O’Keefe, 2004). Previous studies have focused on state enterprise zones (Papke, 1997; Boarnet and Bogart, 1996; Bondonio and Engberg, 2000) or Round I EZ designations (Rubin, 1994; Chaskin and Peters, 1997, Rich and Stoker, 2007; Busso and Kline, 2008). My dissertation focuses on the under-researched Round II Urban Empowerment Zones

There are three imperatives addressed by my dissertation. First, there is a policy imperative since the EZ program is currently under revision. According to HUD Secretary Shaun Donovan (2009), President Obama has ordered a comprehensive review of all place-based federal policies implemented since the Carter Administration. My conversations with key staff at the HUD Office of Community Renewal have confirmed that there is an urgent need for this research from a policy perspective, and they have expressed interest in the expected findings of my dissertation.

Second, the literature on the latter rounds of the EZ program is extremely limited. Beyond the program guides produced by HUD's Office of Community Renewal, there 
are very few qualitative evaluations of the EZ program. Existing government and academic evaluations, including all three of the federally mandated reports from the Government Accountability Office (GAO 2004, 2006, 2010) do not include any Round II EZs in their case studies. The existing literature focuses mainly on the Round I EZs (Chaskin and Peters, 1997; Peters and Fisher, 2002; Busso and Kline, 2008). There is a significant lack of studies particularly on the Round II Empowerment Zones. Round II and Round III EZs relied more heavily on tax incentives to businesses than the first round, yet little is known of the effect of the program on the change in the number of local businesses and jobs. Corporations claimed an estimated \$2.6 billion in EZ tax credits during the program's initial tenure, with no credible evidence that they were used as intended (GAO 2010). Despite concerns about the program, more than $\$ 11$ billion in tax credits was made available to eligible businesses (HUD, 2010).

Third, the study contributes to the literature on the effectiveness and sustainability of location based central city revitalization efforts. Porter's theory highlights the competitive advantage of the inner city areas. Despite the obvious theoretical overlap between Porter's theory and the federal EZ/RC program, there is no empirical examination of the EZ/RC program using the lens of Porter's seminal theory. The connection is important to investigate for why some EZs succeed, and others do not. 


\section{RESEARCH METHODS}

\subsection{Introduction}

Chapter Three describes the research methods used to examine the economic impact of the federal Empowerment Zones (EZ) program on local communities. The United States Department of Housing and Urban Development (HUD) administered three rounds of urban EZ designations: Round I (1994-2011); Round II (1998-2011); and Round III (2001-2011). Enacted during the Clinton administration, the Empowerment Zones and Renewal Communities (EZ/RC) program, which later became known as the Community Renewal Initiative, aimed to revitalize poor neighborhoods by mainly providing tax incentives to businesses that created job opportunities for existing local residents.

My dissertation focuses exclusively on the urban Round II EZ program from 1998 to 2007 (before the current economic recession hit). There are three main aims of my dissertation: 1) to evaluate if the EZ program led to the creation of new businesses and employment; 2) to analyze changes in the types of local industries founded in cities with EZs; and 3) to identify the institutional factors that contributed to economic development and job creation in the EZ areas.

\subsection{Research Questions and Hypotheses}

My specific research questions and hypotheses are:

Q1. Did the EZ designation contribute to business and employment growth in communities?

H1. EZ designation contributed to business and employment growth in such communities. That is, I hypothesize that the Round II EZ program achieved its intended goal. 
Q2. In EZ communities that experienced business and employment growth, in which industries were gains made?

H2. In EZ communities that experienced business and employment growth, the gains were concentrated in industries with a relative competitive advantage in 1998. The intent of this question is to verify if the EZ communities with beneficial impacts followed Porter's cluster theory.

Q3. What institutional factors influenced the implementation and performance of $E Z s ?$

H3. This research question is exploratory. Based on the extant literature, I hypothesize the institutional factors that could influence the program's effectiveness in communities are: community participation, organizational capacity, governance structure, and leadership.

To answer these research questions, I apply three modes of inquiry. First, Ordinary-Least-Squares (OLS) multiple regression models measure the impact, if any, that the EZs had on the change in the number of businesses and jobs within those communities. Second, shift-share analysis is used to identify the local industry clusters and shifts relative to the state and regional economies. Third, the case-study method is used to discover the institutional factors that contributed to business and job growth and gain insights into the perceptions of federal and local zone officials and stakeholders.

My study begins by examining all fifteen Round II Urban EZs for the first part on regression, then focuses on the three top performing communities for the second part on shift-share analyses, and finally examines one EZ community — that of Miami-Dade County - for the case study method. I chose the Miami Dade County EZ because it was a mid-level performer, in terms of business and employment growth, and was not included in the previous research. I obtained data for the regression and shift-share analysis from the United States Census Bureau. I constructed the case study from semi-structured 
interviews with HUD officials in the Office of Community Renewal, as well as local program administrators, residents, business owners and other community stakeholders in Miami-Dade County.

The fifteen Round II Urban EZs consisted of 261 census tracts designated by HUD, defined by specific criteria for population, unemployment, poverty, and general distress. However, since the census tracts are small and do not capture the broader neighborhood effects, for the purposes of my dissertation, the geographical unit of analysis is the zip code. Zip codes are the smallest geographical units for which annual business and employment data are available from the Census Bureau. Hence, the 261 census tracts were re-tabulated into corresponding 88 zip codes using the Census Bureau website's “Geo within Geo” detailed tables for 2000 Decennial Census Data.. Table 4 summarizes the census tracts and corresponding zip codes for each of the fifteen Round II Urban EZ communities.

Table 4: EZ Census Tract to Zip Code Tabulation

\begin{tabular}{lll}
\hline Round II EZs & $\begin{array}{l}\text { EZ Census } \\
\text { Tracts }\end{array}$ & $\begin{array}{l}\text { Corresponding } \\
\text { Zip Codes }\end{array}$ \\
\hline Boston, MA & 28 & 8 \\
Cincinnati, OH & 21 & 6 \\
Columbia, SC/ Sumter, SC & 18 & 5 \\
Columbus, OH & 21 & 6 \\
Cumberland County, NJ & 5 & 2 \\
El Paso, TX & 12 & 5 \\
Gary, IN/ Hammond, IN, East Chicago, IN & 25 & 6 \\
Huntington, WV/Ironton, OH & 12 & 6 \\
Knoxville, TN & 19 & 6 \\
Miami-Dade County, FL & 14 & 7 \\
Minneapolis, MN & 22 & 8 \\
New Haven, CT & 10 & 4 \\
Norfolk, VA/ Portsmouth, VA & 21 & 7 \\
Santa Ana, CA & 7 & 3 \\
St. Louis, MO & 26 & 9 \\
\hline TOTAL & $\mathbf{2 6 1}$ & $\mathbf{8 8}$ \\
\hline
\end{tabular}




\subsection{Regression Analysis}

My first research question examines whether the EZ designation contributed to business and employment growth in communities. The hypothesis is that the EZ designation achieved its intended goal of contributing to a positive economic impact in such communities. To test this hypothesis, I use OLS multiple regression model to examine the statistical impact of the EZ program on the change in the number of business establishments and employees from 1998 to 2007.

As mentioned before, there are $88 \mathrm{EZ}$ zip codes in the Round II EZ/RC program. These EZ zip codes were matched with 88 non-EZ zip codes that were located in either the same or neighboring communities. The communities and specific zip codes that make up the counterfactual comparison group were selected for inclusion based on comparable geographic locations and similar eligibility criteria used to qualify the Round II Urban EZs. Basically, the alternative cities have parallel conditions of high poverty rates, persistent unemployment, and overall distress.

The resulting 176 zip codes were pooled together for determining if the EZ zip codes gained businesses and jobs relative compared to the non-EZ zip codes. The regression model is as follows:

$\mathrm{Y}=\beta_{0}+\beta_{1} \mathrm{D}_{1}+\sum \beta_{\mathrm{i}} \mathrm{X}_{\mathrm{i}}+\mu \mathrm{i}$

Where

$\mathrm{Y}_{1}$ is the dependent variable (change in the Number of Businesses or Employees from 1998 to 2007) 
$\beta_{0}=$ Intercept

$\beta_{\mathrm{X}}=$ Slope Parameter

$\mathrm{D}_{1}=\quad$ Dummy for Empowerment Zone Designation $(\mathrm{EZ}=1$, Non-EZ $=0)$

$\mathrm{X}_{\mathrm{i}}=\quad$ Set of selected control variables

$\mu_{\mathrm{i}}=\quad$ Residual or Error Term

The model describes the relationship between the EZ designation, the independent variable, and the change in the number of businesses or employees, the dependent variable as a straight line. The control variables include demographic and socio-economic parameters (e.g., race, poverty, housing tenure, travel characteristics, etc.), which were identified from a literature review and tested for multicollinearity (see Appendix).

\subsection{Shift-Share Analysis}

My second research question concerns the types of industries that grew in the EZ areas. On the basis of the related literature, my second hypothesis is that industries that grew were the clusters that had competitive advantage in the region. This hypothesis is consistent with Michael Porter's economic development theory of The Competitive Advantage of the Inner City, which emphasizes the importance of integration with regional cluster for sustainable economic growth. According to this theory (Porter, 1995, 56), "Economic activity in and around inner cities will take root if it enjoys a competitive advantage and occupies a niche that is hard to replicate elsewhere."

The shift-share analysis (SSA) is used to test the hypothesis. Shift-share analysis indicates which industries in a local area have a relative competitive advantage and experienced growth over a given time period. Shift-share analysis can be used to analyze the health of individual industries or the overall regional economy. On the basis of the traditional shift-share approach, economic growth or decline in a local area combines 
three related factors: 1) economic growth, 2) industrial shift, and 3) differential shift (Blakely and Bradshaw 2002).

Although SSA is not new, it has not previously been adapted in examining the industry clusters in the EZ areas. My study informs policy makers on successful locationbased economic development strategies through the identification of common characteristics found in EZ communities that experienced business and job growth. The three communities selected for the SSA are: Columbus, Ohio; Norfolk, Virginia; and Santa Ana, California. These communities were selected because they had the largest percentage increase in the number of businesses from 1998 to 2007, out of the fifteen Round II Urban EZs.

\subsection{Case Study}

For the third research question, an in-depth case study of the Miami-Dade County Empowerment Zones was conducted to reveal institutional factors that may have contributed to a positive economic impact. Miami-Dade County was selected as the focus

of the case study because of its unique status as the only community to change its governance structure from the coordinating authority of a non-profit trust, specifically established for the purpose of the EZ program, to the oversight of the local government department. The change was made as a result of a media scandal that raised serious allegations of misconduct and financial mismanagement.

The case study consists of a qualitative analysis of primary and secondary sources. The primary sources include a total of eleven interviews with EZ national and local officials and stakeholders in Miami-Dade County, including the local program director, executive board members, advisory board members, local businesses, and community residents. The director and deputy director of the United States Department of Housing and Urban Development's Office of Community Renewal, which 
administered the entire Empowerment Zone program, as well as the Assistant Secretary for Economic Development, were also interviewed as part of the case study. The interview questions solicited insights into the EZ area's community participation, organizational capacity, strategic planning, governance structure, and leadership. The case study also relies on extensive secondary sources, including program legislation, internal memos and referendums, annual reports, program guides, and media coverage.

In August 2011, I traveled to the HUD headquarters in Washington DC to meet with key staff from the Office of Community Renewal to gain insight into the program's design and performance from the perceptions of the program officials responsible for administering and overseeing the national initiative. The semi-structured interviews lasted approximately two hours and consisted of open-ended questions designed to gather retrospective perceptions of the programs and suggestions for possible improvement. Follow up interviews were conducted with local EZ officials, residents, business owners, and other stakeholders in Miami-Dade County, Florida (a full list of all of the interviewees is provided in the Appendix).

\subsection{Data Collection Techniques}

The first phase of my empirical data collection process involved downloading the data spreadsheet which identified the 261 designated census tracts in the fifteen Round II Urban EZs from the Office of Community Renewal page on the HUD website. As a consequence of the limited availability of census tract level data, I consolidated the census tracts into zip codes to capture the neighborhood effects and facilitate the use of the Census County Business Patterns data. I used the 'Geo within Geo' option within the American Fact Finder Tool on the Census Bureau website to tabulate the zip codes and also compared street boundaries and other landmarks on local census tract and zip code maps. 
Previous studies on state enterprise zones have also used aggregate data on zip codes (e.g., Bondonio and Greebaum, 2007; Dowall, 1996). However, these imprecise approximations may result in a bias towards finding no significant effect (Neumark and Solko, 2010). The use of zip codes, instead of census tracts may also introduce measurement error with the inclusion of non-EZ businesses and jobs, but at the same time, is helpful to capture the neighborhood spillover effects. Even though the program in some cases focused on relatively small geographic regions, these neighborhoods do not exist as islands and must also be considered within the context of the surrounding community.

The quantitative data used in this study were collected from the Census Bureau website (www.census.gov), using the American Fact Finder tool, between September 2008 and December 2011. For the regression models and shift-share analysis, all of the quantitative data come from the United States Census Bureau, specifically the Census 2000 Summary File (SF 3) - Sample Data and Census County Business Patterns respectively. According to the Census website, the "Summary File 3 presents detailed population and housing data ... collected from a 1-in-6 sample and weighted to represent the total population" and was collected on a sample basis from the 2000 long form questionnaire (2011). The shift-share analysis was performed using the number of businesses and employees in 1998 and 2007 from the Census County Business Patterns for a particular zip code containing at least one EZ-designated census tract.

For the qualitative component of my research, I conducted an in-depth review of the available secondary sources (including annual reports, audits, media coverage and internal memos) and conducted semi-structured interviews with key program officials at the United States Department of Housing and Urban Development's Office of Community Renewal with administers the EZ program in urban areas, and with stakeholders and board members of the Miami-Dade County EZs. 


\subsection{Limitations of the Study}

For the OLS regression models and Shift-Share Analysis, zip code level data were used in place of census tract data for two reasons. First, census tract data is decennial with 2000 being the most recent year available at the time of the data collection for this dissertation. Second, zip codes are the smallest unit of measurement provided by the Census County Business Patterns, which were collected for the zip codes to reveal the number and type of business establishments based on North American Industrial Classification System (NAICS) codes. The temporary nature of the EZ/RC initiative and its use of census tracts limit the ability to immediately measure the program's impact on unemployment, poverty, and other zone demographics. In the meantime, when it comes to census tracts, neighborhoods and other micro-communities, researchers often cite independent data source Claritas, which was prohibitively expensive for my dissertation.

The Round II Urban EZs encompassed 261 census tracts, which were tabulated into 88 zip codes for the purpose of my study. One limitation of the study is that the census tracts did not exactly match with the zip code boundaries. Zip Code Tabulation Areas (ZCTA) often contain overlapping and partial census tracts. Even so, zip codes are appropriate for this study to capture the neighborhood effects and facilitate the use of Census County Business Patterns to measure local business growth. Lastly, the number of businesses and employees within a zip Code does not reveal how many employees are qualified EZ residents. On the basis of the findings of this report, the effectiveness of the EZ program remains largely inconclusive. If the EZ program is to be reinstated in the future, proper procedures must be put in place to ensure a higher level of accountability and oversight.

The main limitation of the study is that adequate census tract data were not readily available and zip codes are the smallest geographical units for business and employment data provided by the Census County Business Records. Previous studies on enterprise 
zones have also used aggregate data on zip codes (e.g., Bondonio and Greebaum, 2007; Dowal, 1996); however, the imprecise approximations may result in a bias toward finding no significant effect (Neumark and Kolko 2010). The use of zip codes, instead of census tracts may introduce measurement error with the inclusion of non-EZ businesses, but at the same time, it captures the spillover effects.

Another limitation of the study is the singular focus on Miami-Dade County for the in-depth case study in the sixth chapter. Although all of the Round II Urban EZs are generally examined in terms of performance and implementation, the majority of the interviews with local stakeholders were from Miami-Dade County. There is a great deal of diversity in the nine neighborhood assemblies that were located in the three different municipalities where the Empowerment Zone program was implemented in the MiamiDade County.

\subsection{Conclusion}

To examine the impact of the Round II urban EZs within their local communities, I investigated changes in the number and types of businesses and employees, as well as potential institutional factors that may or may not have had contributed to economic growth and community revitalization. My dissertation research employs three methodologies. First, Ordinary-Least-Squares regression analysis is used to reveal the statistical impact of the EZ program on local business and employment growth, as well as possibly identify other variables that may be significant. Second, a Shift-Share Analysis is used to provide detailed information on the industry make-up and examine shifts within three EZ areas. Third, an in-depth focused case study was used to identify institutional factors that may lead to sustainable economic development. The findings of my dissertation help inform the best practices and policy recommendations for placebased strategies for economic revitalization. 
The recommendations provided are likely to be accepted within the broader community of related scholars and practitioners for three reasons. First, my dissertation builds on extant literature on the Round I Empowerment Zones, relying on similar methodology and control variables (Chaskin and Peters, 1997; Busso and Kline, 2008; Rich and Stoker, 2010). Chaskin and Peter's qualitative study of the first Round EZ/ECs helped frame my case study and raised concerns about the impact and importance of local governance and leadership. The control variables used in my regression model, resemble those used in empirical models constructed by Busso and Kline (2008) and Rich and Stoker (2010).

Second, my study has a national and local scope, using all fifteen Round II Urban EZs in the regression models, incorporating regional and state level date in the shift-share analysis to analyze three top performers, and then providing an in-depth case study of an outlier community. Hence, some of the recommendations could be generalized for informing national, state, and local level policies. Despite the limited nature of the federal $\mathrm{EZ} / \mathrm{RC}$ program, location-based zones remain popular at the state and local levels, and particularly overseas.

Third, I apply Porter's (1995) popular theory of The Competitive Advantage of the Inner City in the context of the federal EZ program to determine whether or not certain inner cities have an innate edge over other inner cities. Porter's theory, which serves as the theoretical framework of my study, suggests that urban areas similar to those found in the EZs should be able to attract and sustain business growth when: 1) strategically located; 2) integrated with regional clusters; 3) designed to tap into unmet local demand; and 4) committed to developing human resources through training and education.

These principles, which have been widely acclaimed by community and economic development scholars, have guided the research questions, hypotheses, and design of my dissertation. The first principle, strategic location, was examined through a site evaluation 
and assessment of the conditions encompassing and surrounding the designated EZ communities. For the most part, these EZs were centrally located or adjacent to the community's downtown business district. Geographically and economically speaking, overall the Round II Urban EZs were advantageously located and significant to their regional and state economies. The second principle, integration with regional clusters, is explored through the use of the Shift-Share methodology. Shift-Share Analysis is a helpful analytical tool to identify the industries that dominate in a given area or exist in large concentrations, also referred to as 'clusters.' The third principle of Porter's Competitive Advantage theory is that the economic growth should ideally be designed to tap into unmet local demand. Along with the fourth and final principle, commitment to developing human resources through education and training, these two principles are explored through an in-depth case study. Secondary sources such as media coverage, audits, reports and memos helped identify the originally stated objectives of the local leadership, while interviews with various EZ stakeholders reveal the perceptions and practices of those involved. 


\section{BUSINESS AND JOB GROWTH}

\subsection{Introduction}

The Round II Urban Empowerment Zones (EZs) are part of the United States Department of Housing and Urban Development (HUD)'s Community Renewal Initiative in which EZs were designed to encourage business and job development in economically struggling areas. There were three rounds of urban EZ designations: Round I (19942011); Round II (1998-2011); and Round III (2001-2011).

My study focuses exclusively on the Round II Urban EZs, as they have been largely excluded from other major studies. More importantly, the employment tax incentives played a significant role in the second round. Thus, this study concentrates on the program impact as it relates to the creation and retention of local businesses and job opportunities. This chapter focuses on my first research question:

Did EZ designations contribute to business and employment growth in communities?

To examine whether or not there was a statistically significant impact of the EZs on local business and job growth, an Ordinary-Least-Squares (OLS) multiple regression analysis is employed. Multiple regression analysis is a method to determine the relationship between a dependent variable and several independent variables by fitting a straight line through a number of points or case observations. Ordinary-Least-Squares multiple regression is a quantitative method used to estimate the unknown coefficients in a regression model. The estimation is achieved by fitting a hypothetical line, which minimizes the sum of distances, squared deviations in the OLS context, from this line to each data point.

In a linear relationship, the association between the observations of two intervalratio variable can be approximated with a straight line. When there is a deterministic or 
perfectly linear relationship then all of the observations fall along the straight line (Frankfort-Nachmias and Leon-Guerrero, 2011). The line provides a predicted value of Y (the dependent variable or vertical axis) for any value of $\mathrm{X}$ (the independent variable or horizontal axis).

Regression analysis is used to explore whether the presence of an EZ census tract in a zip code has a statistically significant effect on the rate of business and employment growth. My models consist of the 88 identified zip codes that contain EZ census tracts, along with an additional 88 adjacent zip codes that do not contain any EZ census tracts $(0=$ zip code does not contain an EZ census tract, 1=zip code contains at least one EZ census tract). The benchmark 88 non-EZ zip codes are located in either the same or neighboring communities. The communities and specific zip codes that make up the counterfactual comparison group were selected for inclusion based on comparable geographic locations and similar eligibility criteria used to qualify the Round II Urban EZs. Basically, the alternative cities have parallel conditions of high poverty rates, persistent unemployment, and overall distress.

As noted in the previous chapter, one of the key challenges to investigating the Empowerment Zones (EZ) program is HUD's use of census tracts, for which reliable and cost-effective data are limited. To overcome this challenge, the Census Bureau's "Geo within Geo" interactive tables were used to identify the overlapping zip code for a particular census tract. Table 5 gives a breakdown of the tabulation process and shows the counterfactual comparison group used in the regression models. 
Table 5: EZs and Comparison Group Census Tracts and Zip Codes

\begin{tabular}{|c|c|c|c|c|c|}
\hline $\begin{array}{l}\text { Round II } \\
\text { Urban EZ } \\
\text { Communities } \\
\end{array}$ & $\begin{array}{l}\# \text { of EZ } \\
\text { Census } \\
\text { Tract }\end{array}$ & $\begin{array}{l}\text { \# of } \\
\text { Zip } \\
\text { Code }\end{array}$ & $\begin{array}{l}\text { Same } \\
\text { City: } \\
\text { Non- } \\
\text { EZ }\end{array}$ & $\begin{array}{l}\text { Other } \\
\text { City: } \\
\text { Non- } \\
\text { EZ }\end{array}$ & $\begin{array}{l}\text { (Other City: Same } \\
\text { region/ state) }\end{array}$ \\
\hline Boston, MA & 28 & 8 & 4 & 2 & Brookline, MA \\
\hline Cincinnati, OH & 21 & 6 & 3 & 2 & Toledo, $\mathrm{OH}$ \\
\hline Columbia, SC & 18 & 5 & 4 & 3 & Greenville, SC \\
\hline Columbus, $\mathrm{OH}$ & 21 & 6 & 5 & 3 & Akron, $\mathrm{OH}$ \\
\hline Cumberland, NJ & 5 & 2 & 1 & 3 & Toms River, NJ \\
\hline El Paso, TX & 12 & 5 & 6 & 2 & Laredo, TX \\
\hline Gary, IN & 25 & 6 & 1 & 3 & South Bend, IN \\
\hline Huntington, WV & 12 & 6 & 0 & 2 & Charleston, WV \\
\hline Knoxville, TN & 19 & 6 & 2 & 3 & Chattanooga, TN \\
\hline Miami-Dade, FL & 14 & 7 & 7 & 3 & Ft. Lauderdale, FL \\
\hline Minneapolis, MN & 22 & 8 & 7 & 3 & Duluth, MN \\
\hline New Haven, CT & 10 & 4 & 3 & 3 & Bridgeport, CT \\
\hline Norfolk, VA & 21 & 7 & 2 & 3 & Virginia Beach, VA \\
\hline Santa Ana, CA & 7 & 3 & 1 & 3 & Irvine, $\mathrm{CA}$ \\
\hline St. Louis, MO & 26 & 9 & 2 & 2 & Kansas City, MO \\
\hline TOTAL & 261 & 88 & 48 & 40 & \\
\hline
\end{tabular}

Again, as explained in the previous chapter, the census tract tabulation was conducted using geographic interactive tables "Geo within Geo," available on the United States Census Bureau website and the selection of the counterfactual community was based upon similar demographic characteristics and regional proximity.

\subsection{Multiple Regression Analysis}

My OLS regression models look specifically at the EZ program's effect on business and job growth to determine if there is a statistically significant relationship. The equation for the model(s) is as follows:

$$
\begin{aligned}
Y_{1}=\beta_{0} & +\beta_{1} D_{1}+\beta_{2} X_{1}+\beta_{3} X_{2}+\beta_{4} X_{3}+\beta_{5} X_{4}+\beta_{6} X_{5}+\beta_{7} X_{6}+\beta_{8} X_{7} \\
& +\beta_{9} X_{8}+\beta_{10} X_{9}+\beta_{11} X_{10}+\beta_{12} X_{11}+\beta_{13} X_{12}+\mu \mathrm{i}
\end{aligned}
$$


Where

$Y_{1}=$ Dependent Variable: Change in the Number of Businesses 1998 to 2007

Dependent Variable: Change in the Number of Employees 1998 to 2007

$\beta_{0}=$ Intercept

$\beta_{\mathrm{X}}=$ Slope Parameter

$\mathrm{D}_{1}=\quad$ Empowerment Zone Designation $(\mathrm{EZ}=1, \mathrm{Non}-\mathrm{EZ}=0)$

$\mathrm{X}_{1}=$ Unemployment Rate

$\mathrm{X}_{2}=\quad$ Average Household Income

$\mathrm{X}_{3}=$ Average Travel Time to Work

$\mathrm{X}_{4}=\quad$ Population Density (residents per square mile)

$\mathrm{X}_{5}=$ Retail Density (Consumer Goods Stores per square mile)

$\mathrm{X}_{6}=$ Housing Tenure (Resided in the same house in 1995)

$\mathrm{X}_{7}=\quad$ Rental Rate (Percentage of Renter Occupied Housing)

$\mathrm{X}_{8}=\quad$ Vacancy Rate (Percentage of Unoccupied Housing)

$\mathrm{X}_{9}=$ Education (Percentage with a Bachelor degree)

$\mathrm{X}_{10}=$ Race (Percentage of White residents)

$\mathrm{X}_{11}=$ Poverty (Percentage of Families Living in Poverty)

$\mathrm{X}_{12}=$ Poverty (Percentage of Individuals Living in Poverty);

$\mu_{\mathrm{i}}=\quad$ Residual or Error Term

The control variables $\left(\mathrm{X}_{\mathrm{n}}\right)$ were identified from the literature review and the data were obtained from the Census 2000 Summary File (SF 3) - Sample Data).

The algebraic equation stated above describes the relationship between the EZ designation (the independent variable) and the change in the number of businesses or employees (the dependent variables) as a straight line. Regression analysis is useful to determine if there is a relationship between the EZ program's implementation and the rate of local business and job growth.

Since this relationship is not deterministic, or perfectly linear, it is necessary to identify the best-fitting line with the least amount of residual, which is the difference 
between the point and the regression line. The OLS regression method is a technique that produces a line where the residual sum of squares is minimal. The following section provides a detailed description of the variables used in my models.

\subsection{Description of the Variables}

To explain the regression equation provided in the previous section, requires the identification of the dependent variables, the key independent variable, and a description of the control variables. In addition, two similar regression models with the same independent and control variables, but with slightly different dependent variables were created to investigate the program's impact on both businesses and jobs.

In regression Model $\mathrm{A}$, the dependent variable is the percentage change in the number of business establishments within a zip code from 1998 to 2007 determined by the Census Bureau County Business Pattern Records, and is labeled CHGBIZ. In regression Model B, the dependent variable is the percentage change in the number of employees, CHGEMP, and uses the same years and data source. The base year for the regression is 1998 since it is a year before the program was enacted and 2007 is the cutoff date to minimize the negative and neutralizing effects of the current economic recession.

The key independent variable is the presence of an EZ designated census tract. EMPZONE is a dichotomous variable, meaning that it only has two possible values ( $0=$ zip code does not contain an EZ census tract, $1=$ zip code contains at least one EZ census tract). The unit of analysis for the regression models is zip codes (88 EZ Zip Codes +88 Non-EZ Zip Codes $=176$ Total Observations). Such a construct captures the key impact of the Empowerment Zone. A zip code covers a broader area than a census tract; hence, a zip code level analysis arguably includes the neighborhood level spillover effects of the Empowerment Zones. 
The control variables included in the model are taken from the relevant literature as well as HUD's program design. The zip codes included in the counterfactual group were included on the basis of the principles of the EZ program and the literature review (Busso \& Kline, 2008; Rich \& Stoker, 2007, 2010). Most of the quantitative data were gathered from the Census 2000 Summary File (SF 3) - Sample Data. Given the EZ program's emphasis on improvements to local unemployment and poverty rates, the initial control variables are socioeconomic measures. Table 6 shows the criteria used for identifying matched control counties, while Table 7 breakdowns the variable names, descriptions, hypothesized effects and data sources.

\section{Table 6: Criteria Used for Identifying Matched Control Counties}

\begin{tabular}{ll}
\hline Poverty & $\begin{array}{l}\text { Employment } \\
\text { Families living in poverty, 2000 }\end{array}$ \\
Individuals living in poverty, 2000 & $\begin{array}{l}\text { Civilian unemployment rate, 2000 } \\
\% \text { of the labor force employed, 2000 }\end{array}$ \\
$\begin{array}{l}\text { Population Characteristics } \\
\text { Median and earnings }\end{array}$ & $\begin{array}{l}\text { \% of residents who have earned at least a } \\
\text { bachelor's degree }\end{array}$ \\
\hline
\end{tabular}




\section{Table 7: Variable Names and Definitions}

\begin{tabular}{llll} 
I. Dependent Variables & & & Data sources \\
\hline Variable names & Definitions & Census Bureau County Business Patterns & Census Bureau County Business Patterns
\end{tabular}

\begin{tabular}{|c|c|c|c|}
\hline Variable names & Definitions & $\begin{array}{c}\text { Hypothesized } \\
\text { effect }\end{array}$ & Data sources \\
\hline \multicolumn{4}{|c|}{ Key Independent Variable } \\
\hline EMPZONE & $\begin{array}{l}\text { Presence of an EZ designated census tract }(0=\text { zip code does not contain an } \\
\text { EZ census tract, } 1=\text { zip code contains at least one EZ census tract })\end{array}$ & + & $\begin{array}{l}\text { U.S. Department of Housing and Urban } \\
\text { Development }\end{array}$ \\
\hline \multicolumn{4}{|c|}{ Population characteristics } \\
\hline $\begin{array}{l}\text { PERWHITE } \\
\text { OTHLANG } \\
\text { HIGHGRAD } \\
\text { PERBACH } \\
\text { AVGAGE } \\
\end{array}$ & $\begin{array}{l}\% \text { of White non-Hispanic population } \\
\% \text { of population that primarily speak a language other than English at home } \\
\% \text { of population who have earned at least a high school diploma } \\
\% \text { of population who have earned at least a bachelor's degree } \\
\text { Median age of residents }\end{array}$ & $\begin{array}{l}- \\
- \\
+ \\
+ \\
+\end{array}$ & $\begin{array}{l}\text { Census } 2000 \text { Summary File } \\
\text { (SF 3) - Sample Data }\end{array}$ \\
\hline \multicolumn{4}{|c|}{ Employment and income characteristics } \\
\hline $\begin{array}{l}\text { UNEMPL } \\
\text { PEREMP } \\
\text { AVGINC } \\
\text { FAMPOV } \\
\text { INDPOV } \\
\end{array}$ & $\begin{array}{l}\text { Civilian unemployment rate } \\
\% \text { of the labor force employed } \\
\text { Median household income } \\
\text { Poverty rate for families } \\
\text { Poverty rate for individuals }\end{array}$ & $\begin{array}{l}- \\
+ \\
+ \\
- \\
-\end{array}$ & $\begin{array}{l}\text { Census } 2000 \text { Summary File } \\
\text { (SF 3) - Sample Data }\end{array}$ \\
\hline \multicolumn{4}{|c|}{ Housing characteristics } \\
\hline $\begin{array}{l}\text { TENURE } \\
\text { PERRENT } \\
\text { PERVCNT } \\
\end{array}$ & $\begin{array}{l}\% \text { of residents that resided in the same house in } 1995 \\
\% \text { of renter-occupied housing } \\
\% \text { of vacant homes }\end{array}$ & $\begin{array}{l}- \\
- \\
-\end{array}$ & $\begin{array}{l}\text { Census } 2000 \text { Summary File } \\
\text { Sample Data }\end{array}$ \\
\hline \multicolumn{4}{|c|}{ Urban characteristics } \\
\hline $\begin{array}{l}\text { TRVLTIME } \\
\text { POPDENS } \\
\text { RETDENS } \\
\end{array}$ & $\begin{array}{l}\text { Average number of minutes spent traveling to or from work } \\
\text { Ratio of one thousand residents living within a square mile } \\
\text { Ratio of stores per one thousand residents }\end{array}$ & $\begin{array}{l}- \\
+ \\
+\end{array}$ & $\begin{array}{l}\text { Census } 2000 \text { Summary File } \quad \text { (SF 3) }- \\
\text { Sample Data }\end{array}$ \\
\hline
\end{tabular}


In terms of spending power, the variable for median household income, $A V G I N C$, provides some indication of the ability of residents to generate sustainable economic demand. Similarly, the local poverty rates for both families and individuals, FAMPOV and INDPOV, respectively help create a picture of the socioeconomic conditions in a particular community. The variable FAMPOV is the percentage of families living in poverty and $I N D P O V$ is the percentage of individuals living in poverty (derived from the 2000 Census data and national poverty guidelines).

The variable $U N E M P L$ refers to the percentage of the labor force that is unemployed, while PEREMP alternatively measures the percentage of the local labor force that is currently employed. Since many of the zone residents are part of a minority ethnic group, the percentage of non-minorities residents, or White non-Hispanic persons, PERWHITE, was used as the control variable for race and/or ethnicity. The variable OTHLANG measures the percentage of the local population that indicated that they primarily speak a language other than English at home.

In terms of educational attainment, I used two interrelated measures - the percentage of residents who have earned at least a high school diploma, HIGHGRAD, and the percentage of residents who have earned at least a bachelor's degree, PERBACH. Unfortunately, the American Community Surveys from the Census Bureau does not provide detailed records on skilled trades and professional certifications, such as carpentry or plumbing.

The next set of variables pertains to the housing circumstances of zone residents within these specific locations and reinforces the link between people and place. As Butler proclaimed, "in a very meaningful sense, people cannot be separated from place, and that an anti-poverty strategy needs to treat individuals in the context of their community" (1981, p. 35). 
The Community Renewal Initiative was designed to create job opportunities for existing zone residents as a way to catalyze economic revitalization. However in some areas, it appears that neighborhood improvements instead resulted in gentrification as a result of rising real estate values (GAO, 2004, 2006, 2010). The variable TENURE represents the percentage of residents in 2000 that resided in the same house in 1995 and gives an idea of the neighborhood's stability and rate of turnover. Related to TENURE are two other variables dealing with housing arrangements.

The variable PERRENT measures the percentage of renter-occupied housing within a given zip code. Several studies have suggested that homeownership is beneficial for communities since renters are less likely to engage in community activities and contribute to public goods (Dorn, 2010; DiPasquale and Glaeser, 1999; Hoff and Senn, 2005; Charles and Hurst, 2002). On the basis of that assumption, higher levels of renteroccupied housing would coincide with lower levels of business and employment growth due to decreased civic engagement from residents and diminished economic investment from businesses. Alternatively, a lower level of renter-occupied housing suggests that are more homeowners in a particular community and a more stable resident population. Table 8 shows the key descriptive statistics for the model's control variables, including the arithmetic mean, standard deviation, minimum and maximum values. 
Table 8: Descriptive Statistics of the Models' Control Variables

\begin{tabular}{lllll|llll}
\hline & \multicolumn{3}{c}{ Empowerment Zone zip codes } & \multicolumn{3}{c}{ Counterfactual zip codes } \\
\hline Variables & Mean & StdDev & Min & Max & Mean & StdDev & Min & Max \\
\hline UNEMP & 12.5 & 6.4 & 3.2 & 49.5 & 9.3 & 7.2 & 0 & 37.9 \\
PEREMP & 59.9 & 9.9 & 33.0 & 84.0 & 61.9 & 10.8 & 27.8 & 85.0 \\
FAMPOV & 24.2 & 11.4 & 0 & 59.5 & 15.5 & 12.9 & 0 & 58.2 \\
INDPOV & 29.2 & 11.1 & 8.6 & 61.7 & 20.4 & 14.2 & 3.4 & 68.0 \\
AVGINC & 26.5 & 8.9 & 9.7 & 49.1 & 35.8 & 15.2 & 8.7 & 76.9 \\
PERWHITE & 35.3 & 29.9 & 1.0 & 96.5 & 53.8 & 28.1 & 2.7 & 95.1 \\
OTHLANG & 23.7 & 26.5 & 1.7 & 92.3 & 25.6 & 27.8 & 3.3 & 93.8 \\
HIGHGRAD & 67.9 & 14.2 & 26.8 & 96.5 & 77.31 & 14.7 & 41.0 & 100.0 \\
PERBACH & 23.7 & 17.6 & 2.2 & 66.4 & 29.3 & 19.3 & 3.4 & 90.6 \\
PERVCNT & 10.7 & 5.9 & 1.6 & 32.5 & 8.3 & 5.4 & 1.9 & 37.9 \\
PERRENT & 60.9 & 19.1 & 22.1 & 98.5 & 55.2 & 23.2 & 5.8 & 100 \\
\hline
\end{tabular}

The variable, PERVCNT, indicates the percentage of vacant housing in a particular zip code. A high concentration of abandoned or possibly foreclosed structures can attract squatters and lead to elevated crime rates, which deters significant industry investments. The last control variable to be included in the regression models is the mean travel time to work, TRVLTIME, measured as the average number of minutes that residents spend traveling to or from work. Larger travel times imply that residents must travel outside of their immediate communities to find work.

The next set of variables is derived from Michael Porter's economic development theory on the Competitive Advantages of Inner Cities (1995, 1996, and 1997). Porter's theory suggests that strategically located urban areas should be able to foster business and job growth when they are strategically located when there is sufficient economic demand, untapped human resources; and a commitment to developing human resources. 
With regard to the first assumption, most of the EZs are strategically located in close proximity to the central business districts of the surrounding metropolitan areas. Porter's remaining three conditions that contribute to economic competitiveness are open to greater interpretation. Examining population density and retail density helps to approximate the level of local economic demand.

First, population density, or POPDENS, refers to the concentration of people living in a zip code and is appropriate in this model given the population and geographic qualifications of the EZ/EC program. In order to be eligible for zone designation, the program guidelines specified that nominated census tracts should either have less than 200,000 residents or represent $25 \%$ of the surround metropolitan population (HUD, 2000). Population density is measured by the Census Bureau as the ratio of one thousand residents $(1 \mathrm{~K})$ living within a square mile. The data for the control variable, POPDENS, is from the data set, Census 2000 Summary File 1 (SF 1) 100-Percent Data - Table GCTPH1: Population, Housing Units, Area and Density.

Retail Density, RETDENS, is the number of stores per one thousand (1K) residents and is a proxy for unmet economic demand in my study. Areas with a higher retail density rate are presumed to have greater economic activity, while areas with a lower rate are relatively underserved in terms of the number of retail facilities for every thousand residents. However, it is important to note that retail density does not provide information on the nature of products that are being sold in those stores and could include food markets, liquor stores, sporting goods or clothing retailers among others.

As a consequence of their increased population density, inner cities, in particular, face unique challenges in creating sufficient employment opportunities for a high number of potential candidates. The tax incentives associated with the EZ program were intended to entice businesses to hire specifically workers who already lived in the targeted area. 
Table 9 presents the mean population and retail density across the zip codes for the fifteen Round II Urban EZ communities.

Table 9: Population and Retail Density (1K residents per square mile)

\begin{tabular}{lll}
\hline Round II Urban EZs & POPDENS $^{\mathbf{1}}$ & RETDENS $^{\mathbf{2}}$ \\
\hline Cumberland County, NJ & 0.615 & 5.25 \\
Huntington, WV/ Ironton, OH & 1.097 & 0.81 \\
Knoxville, TN & 2.045 & 8.82 \\
Columbia/ Sumter, SC & 2.05 & 6.68 \\
Gary, IN/ East Chicago, IL & 2.86 & 2.03 \\
St. Louis, MO & 3.017 & 6.19 \\
Norfolk/ Portsmouth, VA & 4.403 & 9.63 \\
El Paso, TX & 4.961 & 5.95 \\
Columbus, OH & 5.339 & 8.29 \\
Cincinnati, OH & 7.644 & 3.71 \\
New Haven, CT & 7.785 & 2.55 \\
Miami-Dade County, FL & 8.051 & 9.63 \\
Minneapolis, MN & 8.413 & 4.76 \\
Santa Ana, CA & 16.543 & 2.10 \\
Boston, MA & 16.571 & 6.43 \\
\hline Overall Average & $\mathbf{6 . 0 9}$ & $\mathbf{5 . 5 2}$ \\
\hline
\end{tabular}

On average, there are approximately 6,000 residents per square mile in the Round II Urban EZs. Boston, Massachusetts and Santa Ana, California are the most densely populated areas in the study, with more than 16,500 residents per square mile.

Cumberland County was by far the most sparsely populated area, and could be considered an outlier in this context.

\footnotetext{
${ }^{1}$ Population Density

${ }^{2}$ Retail Density
} 


\subsection{Research Findings}

The first hypothesis in my study predicts that the Round II Urban EZs had an impact on the percentage change of business establishments or employees in a given zip code. However, the results of the linear regression models indicate that the zone presence did not have a statistically significant effect on local business and job growth. The predicted effects of the EZ program presented in Table 10 include the coefficients and standard errors from Model A and Model B, as well as the number of observations, F-test, $\mathrm{R}^{2}$, and Adjusted $\mathrm{R}^{2}$ values. In Model $\mathrm{A}$, in which the change in the number of businesses is the dependent variable, the statistically significant independent variables are the percentages of people residing in the same home since 1995 and families in poverty, and median household income.

Of the two models, Model A (change in number of business establishments) performed better than Model B (change in number of employees). Model A produced a higher F-test value than that obtained by Model B, higher $\mathrm{R}^{2}$, and more statistically significant independent variables than the competing model. As shown in Table 10, the adjusted $\mathrm{R}^{2}$ is 0.2722 for Model $\mathrm{A}$, meaning that approximately $27 \%$ of the variance in the dependent variable can be explained by this model. Both of the models were tested for multicollinearity, heteroskedasticity, skewness, and kurtosis and were within the acceptable ranges to maintain the validity of the regression models (see Appendix for detailed results. 
Table 10: Predicting the Effects of the Round II Urban EZs

\begin{tabular}{|c|c|c|c|c|c|c|}
\hline \multirow[b]{2}{*}{ Variable } & \multirow{2}{*}{$\begin{array}{l}\text { Model } \\
\text { A }\end{array}$} & \multirow{2}{*}{\multicolumn{2}{|c|}{ CHGBIZ ${ }^{3}$}} & \multirow{2}{*}{$\begin{array}{l}\text { Model } \\
\text { B } \\
\end{array}$} & \multirow[b]{2}{*}{ CHGEMP ${ }^{4}$} & \\
\hline & & & & & & \\
\hline Empowerment Zone & 0.044 & $(2.689)$ & & 1.164 & $(5.064)$ & \\
\hline Percent Non-Minority Residents & -0.068 & $(0.074)$ & & -0.753 & $(0.138)$ & \\
\hline Median Age & 0.591 & $(0.292)$ & & -0.029 & $(0.549)$ & \\
\hline Percent Rental Housing & -0.102 & $(0.129)$ & & 0.086 & $(0.243)$ & \\
\hline Percent Vacant Housing & -0.428 & $(0.256)$ & & -0.947 & $(0.482)$ & \\
\hline Retail per 1K Residents & 0.24 & $(0.207)$ & & 0.167 & $(0.389)$ & \\
\hline $\begin{array}{l}\text { Percent Living Same House, } \\
1995\end{array}$ & -0.532 & $(0.189)$ & $* *$ & -0.161 & $(0.357)$ & \\
\hline Percent High School Graduate & 0.000 & $(0.209)$ & & -0.013 & $(0.393)$ & \\
\hline Percent Bachelor Degree & -0.179 & $(0.153)$ & & -0.094 & $(0.287)$ & \\
\hline Language Other than English & 0.060 & $(0.733)$ & & -0.211 & $(0.138)$ & \\
\hline Percent of Labor Unemployed & 0.059 & $(0.275)$ & & 0.342 & $(0.517)$ & \\
\hline Percent of Labor Employed & 0.149 & $(0.193)$ & & -0.688 & $(0.363)$ & \\
\hline Median Travel Time to Work & 0.313 & $(0.356)$ & & 0.185 & $(0.669)$ & \\
\hline Median Household Income & 0.623 & $(0.184)$ & $* *$ & 0.694 & $(0.346)$ & $*$ \\
\hline Families in Poverty & 0.571 & $(0.245)$ & $*$ & 0.226 & $(0.461)$ & \\
\hline Individuals in Poverty & -0.486 & $(0.264)$ & & -0.499 & $(0.497)$ & \\
\hline$N$ & & 176 & & & 176 & \\
\hline F-Statistic & & 4.85 & & & 1.49 & \\
\hline$R^{2}$ & & 0.3429 & & & 0.1054 & \\
\hline Adjusted $R^{2}$ & & 0.2722 & & & 0.138 & \\
\hline$* \mathrm{p}<0.05, * * \mathrm{p}<0.01$ & 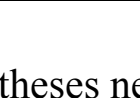 & & & & & \\
\hline
\end{tabular}

In regards to the F-test, Model A is statistically significant at the 0.001 probability level with a F-statistic of 4.85. Therefore, at least one independent variable in this model has a linear relationship with the dependent variable. A Ramsey RESET test found that the models have no omitted variables. In regards to heteroskedasticity, the null hypothesis that the distribution is normal, failed to be rejected on the basis of the result of the Breusch-

\footnotetext{
${ }^{3}$ The dependent variable in Model A is the change in the number of businesses per Zip Code from 1998 to 2007.

${ }^{4}$ The dependent variable in Model B is the change in the number of employees per Zip Code from 1998 to 2007.
} 
Pagan/ Cook-Weisberg test. Therefore, there is heteroskedasticity in Model A.

Multicollinearity does not appear to be an issue with a relatively low Variance Inflation

Factor of 4.42. Further testing suggests that there are no omitted variables. The joint

Skewness/Kurtosis test for normality produced a small probability level in which case, the null hypothesis that there is no skewness can be rejected.

The independent variables found to be statistically significant at $\alpha=0.05$ in Model A are Tenure, Median Household Income, and Families in Poverty. The variable TENURE was significant at alpha level $\alpha=0.01$, as was the Median Household Income. The variable TENURE had a surprising negative influence on the rate of business growth. For every unit increase in TENURE, the percentage change in the number of businesses or $C H G B I Z$, decreased by -0.532 , holding all other variables constant.

For instance, if the number of residents residing in the same house five years ago increases by one percentage point, than the change in the number of businesses in that zip code from 1998 to 2007 is expected to decrease by a little more than half a percentage point. Communities with higher levels of housing tenure or relatively stable resident population would therefore experience lower rates of business growth. The variable TENURE has a negative impact on $C H G B I Z$, thus it strengthens the argument made by government auditors and scholars (e.g. GAO, 2006 and Busso and Kline, 2008) that employment gains may actually be attributed to gentrification and neighborhood turnover.

\subsection{Conclusion}

This chapter evaluated the statistical impact of the Empowerment Zones on local business growth, as measured by the percentage change in the number of business establishments and employees from 1998 to 2007. The presence of an EZ designated census tract within a given zip code was not found to be statistically significant in either model, at the 5\% significance level. The variables found to be significant in Model A 
(CHGBIZ) are the percentage living in the same house in 1995 (TENURE), the average household annual income $(A V G I N C)$, and the percentage of families living in poverty (FAMPOV). Only the variable $A V G I N C$ was found to be significant in Model B $(C H G E M P)$. On the basis of these findings, it appears that a one-unit increase in the average household income will have a slight positive impact on the percentage change in the number of businesses and employees, holding all other variables constant.

Despite media reports, academic papers, and government audits that raised serious issues of accountability and responsiveness regarding the initiative, the United States' Renewal Communities, Empowerment Zones, and Enterprise Communities Initiative (RC/EZ/EC) program continued to expand. A timeline on HUD's website highlighted a $\$ 19$ billion package of EZ/EC and Gulf Opportunity Zones tax incentives in 2006 and another $\$ 11$ billion in tax credits and deductions that were made available to businesses. In December 2010, President Obama retroactively extended the EZ tax incentives until December 31, 2011, two years beyond their original deadline.

In the current economic and political climate, it remains unclear whether or not the program will be reestablished at some point. However, until the agencies responsible for its implementation, like HUD and IRS, are able to successfully collaborate and develop a system for tracking and verifying the use of tax incentives by corporations, the true value and effectiveness of the Community Renewal Initiative will remain elusive. Even if the regression analyses had shown that the EZ presence had a statistically significant impact on the change in the number of business establishments or employees, it would not be possible to discern what aspect of the program had the greatest influence using empirical methods. However, regression is useful for testing the significance of the expected relationship between the dependent and independent variables.

The only independent variable that had a statistically significant impact on the change in the number of businesses and employees (Model A and Model B, respectively) 
was the average household income. As the average household income increases in a given community, the number of businesses and employees is also expected to rise. Based on these findings, it appears that the best way to promote business and employment growth in these communities is to reduce the level of poverty, however it is difficult to ascertain whether the increase in household income is a result of business and employment growth and not vice versa. 


\section{LOCAL INDUSTRY CLUSTERS}

\subsection{Introduction}

In the previous chapter, I employed statistical Ordinary-Least-Squares regression models to investigate whether the federal urban Empowerment Zone (EZ) program contributed to local business and employment growth. The results showed that the EZ designation for certain census tracts did not have a statistically significant effect on the change in the number of businesses or employees in an encompassing zip code. Chapter Four employs Location Quotient (LQ) and Shift-Share Analysis (SSA) as methods to further evaluate the industry composition in the Enterprise Zones and identify shifts in the types of business in the EZs, relative to the encompassing metropolitan region. Specifically, the LQ and SSA methodologies are used to addresses my second research question:

In EZ communities that experienced business and employment growth, in what industries were gains made?

The relative change in each of the fifteen Round II Urban EZs is first examined compared to the encompassing metropolitan region, and then drilled down to the industry makeup of three relatively high-performing EZ communities, based on the percentage change in the number of businesses and employees. The full SSA and LQ tables for the selected Round II Urban EZs are available in the Appendix. These tables reveal the industry composition of the local communities, as well as any competitive advantages that may exist in the form of industry clusters.

Serving as a foundation for this chapter is Michael E. Porter's well-respected theory on the Competitive Advantage of Inner-Cities (1995, 1996, and 1997). Porter's theory suggests that urban areas should be capable of sustainable economic development. The strategic location assumption is made based on the relatively close proximity of the 
EZs to their respective cities' central business districts and the urban cores' significance to the surrounding metropolitan area. The second condition of Porter's theory is integration with regional clusters, which refers to whether or not the businesses located in the inner city areas are connected to the predominant industry employers within the greater geographical region. Porter's assumption is explicitly tested in this chapter using LQ and SSA.

The third and fourth factors in Porter's Competitive Advantage model, "unmet local demand" and "underutilized human resources" were addressed in the previous chapter through the examination of the retail density and unemployment rates in the Empowerment Zones. The SSA within this chapter explores only one specific aspect of Porter's model, namely the integration of business growth in the EZs with the major regional clusters and identification of any relative competitive industrial advantages.

For the purpose of my study, business growth and employment growth are defined as the percentage change in the number of establishments and employees from 1998 to 2007 in the EZ associated Zip Codes, using data from the Census Bureau's County Business Patterns. Although the program ended in 2011, an earlier cut-off date of 2007 is used to minimize the effects of the onslaught of the nationwide economic recession in 2008. To help put the local business and employment growth in perspective, the business and employee rate of change for the encompassing region is also shown in Table 11. The full data used to calculate these figures are presented in the Appendix. The highlighted communities, which had among the highest rates of business growth, are evaluated in further detail in this chapter using LQ and SSA methods. 
Table 11: Percentage Change in the Number of Businesses and Employees in the EZs from 1998 to 2007

\begin{tabular}{lrrrrrr}
\hline Round II & $\begin{array}{c}\mathbf{1 9 9 8} \\
\text { Business }\end{array}$ & $\begin{array}{r}\mathbf{2 0 0 7} \\
\text { Business }\end{array}$ & $\begin{array}{c}\text { Business } \\
\text { Change }\end{array}$ & $\begin{array}{c}\text { 1998 } \\
\text { Employee }\end{array}$ & $\begin{array}{c}\text { 2007 } \\
\text { Employee }\end{array}$ & $\begin{array}{c}\text { Employee } \\
\text { Change }\end{array}$ \\
\hline Boston & 3632 & 3843 & 5.81 & 82673 & 85041 & 9.15 \\
Cincinnati & 2028 & 1518 & -25.15 & 52022 & 57971 & 11.44 \\
Columbia & 5333 & 5312 & -0.39 & 103347 & 104590 & 1.20 \\
Columbus & 4738 & 4930 & $\mathbf{4 . 0 5}$ & 139346 & 131434 & -5.68 \\
Cumberland & 2100 & 2157 & 2.71 & 30410 & 34332 & 12.9 \\
El Paso & 4058 & 3940 & -2.91 & 59109 & 57448 & -2.81 \\
Gary & 1398 & 1201 & -14.09 & 45681 & 34000 & -25.57 \\
Huntington & 2517 & 2368 & -5.92 & 41045 & 41291 & 0.60 \\
Knoxville & 4700 & 4513 & -3.98 & 86526 & 86567 & 0.05 \\
Miami & 5330 & 5213 & -2.2 & 82704 & 85212 & 3.03 \\
Minneapolis & 4770 & 4971 & 4.21 & 82673 & 85041 & 2.86 \\
New Haven & 2156 & 2071 & -3.94 & 48828 & 52520 & 7.56 \\
Norfolk & 2733 & 2947 & $\mathbf{7 . 8 3}$ & 57090 & 64595 & 13.15 \\
Santa Ana & 2600 & 2750 & $\mathbf{5 . 7 7}$ & 23285 & 21729 & -6.68 \\
St. Louis & 3002 & 2805 & -6.56 & 92380 & 84074 & -8.99 \\
\hline
\end{tabular}

On the basis of the data presented in Table 9, it is apparent that some EZ communities performed better than others: including Boston, Cumberland County, Minneapolis and Norfolk/Portsmouth. All of those communities experienced an increase in both the number of businesses and employees in the EZ associated Zip Codes between 1998 and 2007. However, since the Census Business Patterns' employment data for metropolitan areas in 1998 is incomplete, it prevents a more detailed analysis of changes in the number of employees at the local level compared to the respective metropolitan region. As a result, the industry cluster analyses performed in this chapter focus exclusively on the change in the number of businesses establishments.

The EZ communities that I examine using SSA and LQ methodologies in this chapter are 1) Norfolk/Portsmouth, Virginia, 2) Columbus, Ohio and 3) Santa Ana, California. These three communities were selected because of their relatively high rate of business growth in the EZs and their geographic dispersion across the United States. Norfolk/ Portsmouth, Virginia are located on the East Coast, while Columbus, Ohio is in 
the Midwest region of the country, and Santa Ana, California is situated on the West Coast. The first community investigated, Norfolk/Portsmouth, was the best performer in terms of business growth with an increase of $7.83 \%$ during the examined time period. The second community, Santa Ana, increased its number of businesses by $5.77 \%$. The third and final community, Columbus, Ohio experienced a $4.05 \%$ growth in the number of businesses operating in its EZs communities.

It is also important to note that the boundaries of some of the metropolitan regions changed significantly from 1998 to 2007 , and therefore it is impractical to compare the rate of change for some EZs to their respective regions. For example, in 1998 Miami and Fort Lauderdale were considered independent metropolitan regions and were later combined and now also include the neighboring community of Pompano Beach. However, data on the number of businesses and employees in all of the metropolitan regions that contained EZ designated communities were nonetheless compiled, although some of the business and employment growth rates may be misleading. Data on the percentage change of businesses and employees for the fifteen encompassing metropolitan regions and states from 1998 to 2007 are available in the Appendix.

\subsection{Shift-Share Analysis Methodology}

Shift-Share Analysis (SSA) is an analytical tool used to identify clusters and compare changes in the industrial concentrations within the EZ associated zip codes from 1998 and 2007, relative to the respective Metropolitan Statistical Area (MSA) ${ }^{5}$. Use of the SSA approach in my dissertation measures if business expansion or decline in a local area results as a combination of three related factors: 1) economic growth, 2) industrial shift,

\footnotetext{
${ }^{5}$ As defined by the U.S. Census Bureau, a Metropolitan Statistical Area (MSA) is a geographic population cluster of more than 50,000 residents in a single city or consists of an urban area with more than 100,000 residents and includes each affected county.
} 
and 3) differential shift (Blakely and Bradshaw, 2002). Specifically, the SSA formula used in this chapter is given in Figure One.

Figure 1: Shift-Share Analysis Formula

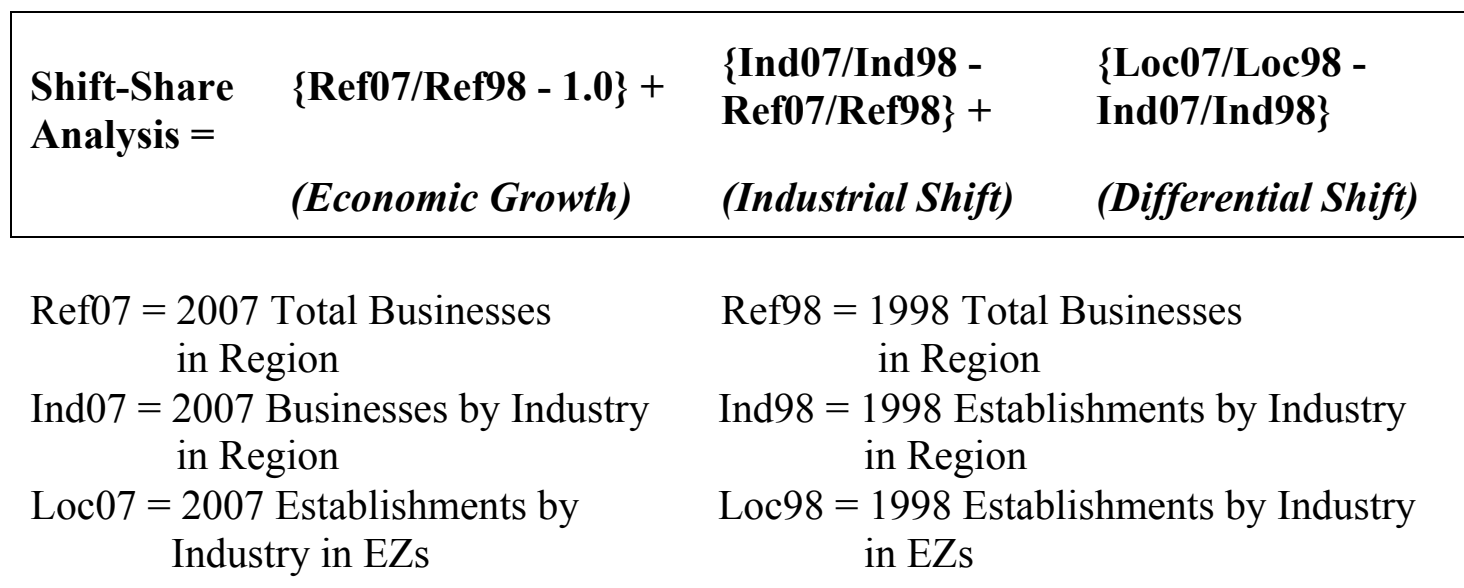

The first factor, Economic Growth, refers to the general effect of fluctuations in the greater national, state, or in this case, the regional economy on local community benefits. Greater economic changes through expansion and recession tend to have an impact on all industries to some extent. Blakely and Bradshaw describe the notion that the "rising or falling tide raises or lowers all boats" (2002, p.128).

The second factor, Industrial Shift, measures the change of a particular industry relative to the total of all industries. Industrial shift, otherwise known as the proportional shift, helps identify industries that contribute to an area's economic growth or decline (Blakely and Bradshaw, 2002).

The third and final factor, Differential Shift, which is sometimes called the competitive advantage, "is the difference in the rate of growth or decline in a local industry relative to the rate of growth or decline in that same industry nationally" or in this case at the regional or state level (2002, p.128). 
Shift-share analysis is one form of economic base analysis that is often used to build a foundation for economic development planning. A related analytical tool, the Location Quotient (LQ), is also used to identify and compare the industry concentrations of a local economy relative to a larger reference economy, such as a metropolitan area or state. However, since the LQ is a static measure examining only one point in time, it does not reveal whether growth or decline is occurring. As Blakely and Bradshaw explain:

The location quotient is shown as a ratio between the percentage of employment in an industry locally to the percentage of the employment in the same industry found in the state or nation being used as a reference. If the ratio of the local economy is greater than one, it means that the industry is concentrated (overrepresented) in the local area compared to the reference economy. If the ratio is less than one, however, the industry is underrepresented. A location quotient of 1.0 means that the local area and the reference economy are perfectly on par with employment generation in the same sector (2002, p. 122).

\section{Figure 2: Location Quotient Formula}

\begin{tabular}{|l|l|}
\hline $\begin{array}{l}\text { Location } \\
\text { Quotient }(\text { LQ) }=\end{array}$ & Local Industry / Local Total Businesses (Li/Lt) \\
\hline
\end{tabular}

The LQ equation, as expressed in Figure 2, calculates the industry concentrations in a local community, in reference to a larger geographical region, such as a region. Because the location quotient only provides a snap-shot of industry composition at a specific period in time, a more comprehensive shift-share analysis was performed to identify the direction of industry changes between 1998 and 2007 in the zip codes that 
encompass the Round II Urban EZs, relative to their respective metropolitan region. The shift-share methodology helps indicates which types of businesses in a local area have a competitive advantage and experience faster growth. The full LQ results for the communities highlighted in this chapter are available in the Appendix.

The economies of the selected three Round II Urban EZs are evaluated using an economic base study to determine the structure and composition of the local market relative to the encompassing region. The LQ technique was used to determine which industries make the most significant contribution to the local economy, however "the shift-share technique presents a supplemental aggregate data analysis method to strengthen the conclusions of the economic base study" (Quintero, 2007, p.28). For that reason this chapter focuses on the results of the SSA utilized to compare local business growth in zip codes that contained EZ designated Census Tracts to the rest of the region.

\subsection{Data Source: County Business Patterns}

The economic base analysis using LQ and SSA both utilize the County Business Patterns (CBP) released annually from the United States' Census Bureau. County Business Patterns organize local, regional and national employment statistics taken from the North American Industrial Classification System (NAICS). Unfortunately, there are certain limitations associated with the use of County Business Patterns. First, the data are usually subject to a two or three year time lag so the statistics do not consider the present situation. Second, certain categories of employees are not typically taken into consideration in the final calculations, including entrepreneurs, agricultural laborers, domestic service workers and government employees (Quintero, 2007).

As methods for economic base analyses, the LQ and SSA are both widely renowned for their use of ease of use with publicly available data like County Business Patterns. Starting in 1997, economic statistics previously categorized under the Standard 
Industrial Classification (SIC) were reclassified under the NAICS as a consequence of the increasing complexity of the international economy as a result of the North American Free Trade Agreement (NAFTA) and the need for more precise methods of measurement. While the four-digit SIC index had only nine industrial categories, the expanded six-digit industrial code used by NAICS has 20 international sector classifications. The Census Bureau defines the six-digit NAICS as follows ${ }^{6}$ :

- The $1^{\text {st }}$ and $2^{\text {nd }}$ digits represent a sector of the economy; this is the broadest level of categorization

- The $3^{\text {rd }}$ digit signifies a sub-sector

- The $4^{\text {th }}$ digit represents an industry group

- The $5^{\text {th }}$ digit designates a particular industry. This digit is the most precise of the national industrial classification codes.

- The $6^{\text {th }}$ and final digit is used to classify industries according to national origin (e.g. United States, Mexico and Canada).

In the each of the following sections, the Location Quotient is first applied to examine the concentration of specific industries in the EZ Zip Codes in 2007, relative to the Metropolitan Statistical Area (MSA). The industry composition of the MSA was then compared to the state to further identify industry clusters at the regional level. Next, a Shift-Share Analysis was conducted to reveal the competitive share of particular industries and comparative shifts. Shift-share analysis (SSA) and location quotient (LQ) are two related analytical tools used to determine an area's industrial strengths and weaknesses.

Location quotient is a static analysis that shows which industries are growing or declining at a particular point in time (in this case, the year 2007 is used as the base). Conversely, SSA is a dynamic analysis that employs data collected at two or more points

\footnotetext{
${ }^{6}$ For additional information, visit the United States Census Bureau - North American Industrial Classification System (NAICS) webpage at http://www.census.gov/naics/2007/index.html.
} 
in time. As Blakely and Bradshaw explain, there are several rationales for conducting a dynamic analysis. First, it allows a communities' planners and analysts to "invest public resources wisely and to allocate public infrastructure for appropriate industrial needs" (2002, p.127). Second, being aware of which industries are most likely to expand helps economic developers make appropriate provisions for employment and skills training.

The rate of growth or decline for each industry was calculated by dividing the 2007 number of establishments by the 1998 number of establishments, minus one (1). Proportional shift is calculated by subtracting the total rate of business growth for the region from the industry-by-industry growth or decline for the local Empowerment Zones, and shows which local industries exceeded or lagged what would be expected if everything grew at the same rate as the region. Differential shift is calculated by subtracting the rate of growth of each industry at the regional level from the rate of growth of the same industry at the local level. Full data tables are available in the Appendix.

\subsection{Norfolk/Portsmouth, Virginia}

The first Round II Urban EZ community to be examined in this chapter includes Norfolk and Portsmouth, Virginia. These two communities are part of a metropolitan region that crosses state lines to also include communities in North Carolina. Of the fifteen Round II Urban EZs, the Norfolk/Portsmouth communities had the highest rate of growth with an almost eight percent increase in the number of establishments between 1998 and 2007. Overall, the encompassing metropolitan region saw the number of businesses increase by about seventeen percent.

The Norfolk/Portsmouth EZs had three industry clusters with LQs of 2.0 or greater, relative to the metro region in 2007: Information (2.50); Manufacturing (2.0); and Arts, Entertainment \& Recreation (2.0). Although, the sectors with the greatest number of 
establishments in the targeted communities in 2007 were Retail Trade with 446 firms, and Professional, Scientific \& Technical with 351 businesses.

The analysis reveals that the other industries in the Norfolk/Portsmouth EZs with a LQ greater than one (1.0), relative to the encompassing MSA, are: 1) Transportation, 2) Finance and Insurance, 3) Professional, Scientific and Technical, Management of Companies, 4) Educational Services, 5) Healthcare and Social Assistance, 6) Accommodations and Food Services, and 7) Other Services. In other words, these are the most highly concentrated industries in the EZs, and are on par or exceed the composition in the rest of the region. Of those predominant industries, Transportation, Finance, and Accommodations are also highly concentrated in the MSA compared to the entire state of Virginia.

Information (2.50) had the highest LQ of all of the industries in the Norfolk/Portsmouth EZs, meaning that it was the most significant concentration, relative to the MSA. Retail Trade, however was the single largest industry in the Norfolk/Portsmouth EZs, with a total of 446 establishments in 2007. The LQ for Retail Trade was slightly less than one (0.94), suggesting that this particular sector is not densely concentrated enough in the area of focus to be considered an industry cluster within the context of the greater geographical region.

Once the predominant industries within the Norfolk/Portsmouth EZs have been identified through the use of LQ, the next step was to apply SSA to learn where the economy is heading and where growth is occurring. Table 12 provides the results of the SSA for the Norfolk/ Portsmouth, relative to the Virginia Beach-Norfolk-Newport News, VA-NC metropolitan region. In both 1998 and 2007, the highlighted industries had a LQ greater than one. 
Table 12: Shift-Share for Norfolk/Portsmouth EZs, relative to the Virginia Beach-Norfolk-Newport News, Virginia/North Carolina MSA

\begin{tabular}{|c|c|c|c|c|c|c|c|c|c|c|}
\hline \multirow[b]{2}{*}{ Industry Description } & \multicolumn{3}{|c|}{ Norfolk EZs } & \multicolumn{3}{|c|}{ MSA/ Region } & \multicolumn{4}{|c|}{ Shift Share } \\
\hline & $\begin{array}{c}1998 \\
\text { Firms }\end{array}$ & $\begin{array}{c}2007 \\
\text { Firms }\end{array}$ & $\begin{array}{l}\text { Rate of } \\
\text { Growth/ } \\
\text { Decline }\end{array}$ & $\begin{array}{c}1998 \\
\text { Firms }\end{array}$ & $\begin{array}{c}2007 \\
\text { Firms }\end{array}$ & $\begin{array}{l}\text { Rate of } \\
\text { Growth/ } \\
\text { Decline }\end{array}$ & $\begin{array}{l}\text { Econ. } \\
\text { Growth }\end{array}$ & $\begin{array}{c}\text { Indust. } \\
\text { Shift }\end{array}$ & $\begin{array}{c}\text { Differ. } \\
\text { Shift }\end{array}$ & Overall \\
\hline Agriculture & 0 & 0 & - & 47 & 54 & 0.15 & 0.16 & -0.02 & - & - \\
\hline Mining & 0 & 0 & - & 14 & 16 & 0.14 & 0.16 & -0.02 & - & - \\
\hline Utilities & 0 & 0 & - & 30 & 33 & 0.10 & 0.16 & -0.06 & - & - \\
\hline Construction & 156 & 176 & 0.13 & 4,120 & 5,245 & 0.27 & 0.16 & 0.11 & -0.14 & 0.13 \\
\hline Manufacturing & 133 & 105 & -0.21 & 1,050 & 988 & -0.06 & 0.16 & -0.22 & -0.15 & -0.21 \\
\hline Wholesale trade & 128 & 96 & -0.25 & 1,612 & 1,576 & -0.02 & 0.16 & -0.19 & -0.23 & -0.25 \\
\hline Retail trade & 379 & 446 & 0.18 & 5,999 & 6,204 & 0.03 & 0.16 & -0.13 & 0.14 & 0.18 \\
\hline Transportation & 107 & 111 & 0.04 & 928 & 1,114 & 0.20 & 0.16 & 0.04 & -0.16 & 0.04 \\
\hline Information & 59 & 146 & 1.48 & 444 & 705 & 0.59 & 0.16 & 0.42 & 0.89 & 1.47 \\
\hline Finance $\&$ insurance & 171 & 187 & 0.09 & 2,053 & 2,489 & 0.21 & 0.16 & 0.05 & -0.12 & 0.09 \\
\hline Real estate & 132 & 150 & 0.14 & 1,596 & 2,222 & 0.39 & 0.16 & 0.23 & -0.26 & 0.14 \\
\hline Professional, scientific \& technical & 303 & 351 & 0.16 & 2,845 & 4,045 & 0.42 & 0.16 & 0.26 & -0.26 & 0.16 \\
\hline Management of companies & 19 & 25 & 0.32 & 170 & 205 & 0.21 & 0.16 & 0.04 & 0.11 & 0.32 \\
\hline Administrative support & 120 & 108 & -0.10 & 1,944 & 2,226 & 0.15 & 0.16 & -0.02 & -0.25 & -0.10 \\
\hline Educational services & 23 & 25 & 0.09 & 341 & 465 & 0.36 & 0.16 & 0.20 & -0.28 & 0.09 \\
\hline Health care and social assistance & 347 & 343 & -0.01 & 2,987 & 3,380 & 0.13 & 0.16 & -0.03 & -0.14 & -0.01 \\
\hline Arts, recreation, entertainment & 33 & 51 & 0.55 & 466 & 561 & 0.20 & 0.16 & 0.04 & 0.34 & 0.55 \\
\hline Accommodation \& food services & 223 & 270 & 0.21 & 2,918 & 3,623 & 0.24 & 0.16 & 0.08 & -0.03 & 0.21 \\
\hline Other services & 373 & 353 & -0.05 & 4,045 & 4,385 & 0.08 & 0.16 & -0.08 & -0.14 & -0.05 \\
\hline Unclassified establishments & 0 & 0 & - & 362 & 31 & -0.91 & 0.16 & -1.08 & - & - \\
\hline TOTAL & 2,733 & 2,947 & 0.08 & 33,971 & 39,567 & 0.16 & & & & \\
\hline
\end{tabular}


According to the information provided by the SSA in Table 12, the Information industry sector in the Norfolk/Portsmouth EZs experienced by far the most significant increase relative to the MSA and had the largest LQ in 2007 (2.50). Locally, the Information industry had a tremendous rate of growth, increasing 148\% from 59 firms in 1997 to 146 firms in 2007 . The growth of the information industry at the regional level is significant also, but the exponential increase of the Information sector in the EZ zip codes indicates that those areas were particularly successful at attracting new establishments and retaining existing ones.

The second highest rate of growth in a particular industry in the Norfolk/Portsmouth EZs was in the Arts, Recreation \& Entertainment sector. At the local level, the number of firms in that sector increased by more than fifty percent, from 33 firms in 1998 to 51 firms in 2007, and was twice the rate of growth seen throughout the region. The other two industries besides the Information sector with significant LQs in the Norfolk/Portsmouth EZs, relative to the MSA, as of 2007 were Healthcare (1.33) and Manufacturing (2.0). The Healthcare industry, in particular, also has a high LQ in the metropolitan region, relative to the state.

Building upon Porter's work on the competitive advantage of inner cities (1995, 1996, 1997), conducting an industry analysis of the EZ communities is useful to identify business sectors that have a strong foothold in the context of the greater region and have a better chance of being sustainable and contributing to the local economic development. Since a key component of the EZ program were tax incentives for businesses to help create and retain jobs in these communities, it is beneficial for local authorities to be aware of the industry composition of local businesses and cognizant of shifts in that makeup, in order to strategically focus marketing and promotional efforts to those sectors that are most likely to feasible for both short-term and long-term success. 


\subsection{Santa Ana, California}

The next community that I examined using SSA is the city of Santa Ana located in Orange County, California. Santa Ana was one of the top performers from the fifteen Round II Urban EZs, in terms of the overall increase in the number of businesses $(+6.88 \%)$ and jobs $(+6.37 \%)$. The industries with a LQ greater than one (1.0) are considered highly concentrated and can be regarded as business clusters. Namely, in Santa Ana those industries are: 1) Manufacturing; 2) Retail Trade; 3) Transportation; 4) Finance \& Insurance; 5) Professional, Scientific \& Technical; 6) Management of Companies; 7) Administrative Support; and 8) Accommodations and Food Services.

These industry strongholds are considered to have a competitive advantage in terms of economic expansion, particularly when compared to other local industries. Although the Santa Ana EZs represent only a small portion of all of the business establishments in the Los Angeles-Long Beach-Santa Ana MSA, it nonetheless has several industries that are densely concentrated and register a high LQ (see Appendix for full tables). The single largest industry in the Santa Ana EZs in 2007 was Professional, Scientific \& Technical, with 388 firms out of a total of 2,750 firms from all industries. However, with a LQ of 1.05, that industry is not the most significant cluster in that community.

The industries with the highest LQs in the Santa Ana EZs are Management of Companies (1.35), Transportation (1.27), Manufacturing (1.26) and Finance \& Insurance (1.26). The second largest industry in the Santa Ana EZs, as of 2007, was Retail Trade, with LQ of 1.16 and 374 business establishments. It is important to note the while industries with a high LQ aren't necessarily the most prevalent industries in a local area; they do however have a significant competitive advantage within the context of the greater geographical area as a consequence of their relative contribution to the regional economy. 
Blakely and Bradshaw (2002) explain why areas like the Santa Ana EZs might have a several industries with a high LQ, stating "From a practical point of view, a high location quotient means that compared with a standard economy, the local area works harder in the industries having higher location quotients" (p.123).

Although highly concentrated industries often times serve as the foundation of a local economy, they are also susceptible to fluctuating market conditions that can potentially threaten their standing and can become a liability if the local economy is too dependent upon it. The decline of the automobile manufacturing industry in both Flint and Detroit, Michigan are examples of the repercussions of relying too heavily on a single industry within a community.

Diversifying the local industry market helps protect communities from fluctuations in a particular area that might otherwise weaken the entire economy. Following the calculation of the LQ, the next step in the local economic analysis is to conduct a shift-share analysis. Table 13 shows the results of the SSA of the Santa Ana EZs, relative to the Los Angeles-Long Beach-Santa Ana MSA. For the year 2007, the highlighted industries had the largest location quotients. 
Table 13: Shift-Share for Santa Ana EZs, relative to the Los Angeles-Santa Ana, California MSA

\begin{tabular}{|c|c|c|c|c|c|c|c|c|c|c|}
\hline \multirow[b]{2}{*}{ Industry Description } & \multicolumn{3}{|c|}{ Santa Ana EZs } & \multicolumn{3}{|c|}{ MSA/ Region } & \multicolumn{4}{|c|}{ Shift Share } \\
\hline & $\begin{array}{c}1998 \\
\text { Firms } \\
\end{array}$ & $\begin{array}{c}2007 \\
\text { Firms } \\
\end{array}$ & $\begin{array}{l}\text { Rate of } \\
\text { Change }\end{array}$ & $\begin{array}{c}1998 \\
\text { Firms } \\
\end{array}$ & $\begin{array}{c}2007 \\
\text { Firms } \\
\end{array}$ & $\begin{array}{l}\text { Rate of } \\
\text { Change }\end{array}$ & $\begin{array}{c}\text { Econ. } \\
\text { Growth }\end{array}$ & $\begin{array}{c}\text { Indust. } \\
\text { Shift }\end{array}$ & $\begin{array}{c}\text { Differ. } \\
\text { Shift }\end{array}$ & Overall \\
\hline Agriculture & 0 & 0 & - & 142 & 161 & 0.13 & 0.56 & -0.43 & - & - \\
\hline Mining & 0 & 0 & - & 153 & 173 & 0.13 & 0.56 & -0.43 & - & - \\
\hline Utilities & 0 & 1 & 1 & 172 & 322 & 0.87 & 0.56 & 0.31 & - & - \\
\hline Construction & 138 & 144 & 0.04 & 12,057 & 21,808 & 0.81 & 0.56 & 0.24 & -0.77 & 0.04 \\
\hline Manufacturing & 247 & 208 & -0.16 & 18,091 & 20,583 & 0.14 & 0.56 & -0.43 & -0.30 & -0.16 \\
\hline Wholesale trade & 168 & 151 & -0.1 & 21,676 & 31,230 & 0.44 & 0.56 & -0.12 & -0.54 & -0.10 \\
\hline Retail trade & 405 & 374 & -0.08 & 27,547 & 40,184 & 0.46 & 0.56 & -0.11 & -0.54 & -0.08 \\
\hline Transportation & 58 & 79 & 0.36 & 4,870 & 7,783 & 0.6 & 0.56 & 0.03 & -0.24 & 0.36 \\
\hline Information & 28 & 35 & 0.25 & 7,787 & 11,151 & 0.43 & 0.56 & -0.13 & -0.18 & 0.25 \\
\hline Finance \& insurance & 141 & 210 & 0.49 & 10,554 & 20,775 & 0.97 & 0.56 & 0.40 & -0.48 & 0.49 \\
\hline Real estate & 98 & 141 & 0.44 & 10,962 & 19,335 & 0.76 & 0.56 & 0.20 & -0.33 & 0.44 \\
\hline Professional, scientific \& technical & 360 & 388 & 0.08 & 23,850 & 46,014 & 0.93 & 0.56 & 0.37 & -0.85 & 0.08 \\
\hline Management of companies & 25 & 21 & -0.16 & 1,254 & 1,952 & 0.56 & 0.56 & -0.01 & -0.72 & -0.16 \\
\hline Administrative support & 122 & 149 & 0.22 & 10,732 & 15,333 & 0.43 & 0.56 & -0.14 & -0.21 & 0.22 \\
\hline Educational services & 24 & 25 & 0.04 & 2,426 & 4,360 & 0.8 & 0.56 & 0.23 & -0.76 & 0.04 \\
\hline Health care and social assistance & 249 & 292 & 0.17 & 22,550 & 37,657 & 0.67 & 0.56 & 0.11 & -0.50 & 0.17 \\
\hline Arts, recreation, entertainment & 18 & 15 & -0.17 & 7,468 & 12,150 & 0.63 & 0.56 & 0.06 & -0.79 & -0.17 \\
\hline Accommodation \& food services & 217 & 250 & 0.15 & 15,831 & 26,147 & 0.65 & 0.56 & 0.09 & -0.50 & 0.15 \\
\hline Other services & 279 & 263 & -0.06 & 19,049 & 26,263 & 0.38 & 0.56 & -0.19 & -0.44 & -0.06 \\
\hline Unclassified establishments & 3 & 4 & 0.33 & 2,762 & 573 & -0.79 & 0.56 & -1.36 & 1.13 & 0.33 \\
\hline TOTAL & 2,600 & 2,750 & 0.06 & 219,933 & 343,954 & 0.56 & & & & \\
\hline
\end{tabular}


According to the SSA results for the Santa Ana EZs presented in Table 13, industry growth in the zip codes associated with the zones faired comparatively well, within the context of the surrounding metropolitan region. Local businesses grew by approximately six percent, which is the highest rate of growth out of the other fifteen Round II Urban EZs nationwide, but still well below the 56 percent growth experienced throughout the Los Angeles-Long Beach-Santa Ana metropolitan region. However, it is important to note that the dramatic increase in the number of businesses operating in that MSA can more likely be attributed to redrawn boundaries rather than actual business growth. The highlighted industries had the highest LQs and are the sectors that should be focused on due to their contribution to the overall local economy.

The industry with the greatest LQ in Santa Ana in 2007, Management of Companies (1.35) declined by 16 percent from 1998 to 2007 and had one of the highest overall shift-share figures (1.11). The second most highly concentrated industry, Transportation (1.27), grew 36 percent, but registered a less significant overall shift-share (0.66). Manufacturing (1.26) also decreased by 16 percent, however it registered the same overall shift-share (1.11) as the other large industry clusters, namely Management of Companies. In other words, even though these industries declined at the local level, they remained significant contributors to the regional economy. Unfortunately, the incomplete availability of employment data from the Census Bureau Business Patterns for the metropolitan areas prevented a more detailed analysis on job creation for this dissertation. Future research could examine fluctuations in the number of employees for each of those industries and evaluate the possible impact on local employment.

\subsection{Columbus, Ohio}

Like the Santa Ana EZs, the Columbus EZs were one of the top performers from the fifteen Round II Urban EZs, in terms of the increased number of establishments. The 
number of firms in the Columbus EZs increased by four percent, while the overall business growth rate for the entire Columbus, Ohio metropolitan region increased by approximately twelve percent. However, unlike the Norfolk/Portsmouth EZs and the Santa Ana EZs, all of the industries identified as clusters, based on their high LQs, experienced positive growth.

The local industries with a LQ of approximately 1.0 or greater were on par or exceeded the industry composition at the regional level. Of those industries, the biggest gains were made in Educational Services, which increased by 44 percent, from 36 establishments in 1998 to 52 educational related businesses almost ten years later. Management of Companies grew by about 30 percent while Accommodations and Food Services increased by roughly 21 percent.

The shift-share analysis of the Columbus EZs shown in Table 14 reveals the number of establishments for each sector in 1998 and 2007 locally and for the entire region. The rate of growth or decline for both geographic areas shows shifts for each the industry sectors and is followed by the components of the shift-share analysis. Namely, the shift-share analysis consists of the overall economic growth rate for the entire region, the industrial shift, and lastly the differential shift. 
Table 14: Shift-Share for Columbus EZs, relative to the Columbus, Ohio MSA

\begin{tabular}{|c|c|c|c|c|c|c|c|c|c|c|}
\hline \multirow[b]{2}{*}{ Industry Description } & \multicolumn{3}{|c|}{ Columbus EZs } & \multicolumn{3}{|c|}{ MSA/ Region } & \multicolumn{4}{|c|}{ Shift Share } \\
\hline & $\begin{array}{c}1998 \\
\text { Firms } \\
\end{array}$ & $\begin{array}{c}2007 \\
\text { Firms } \\
\end{array}$ & $\begin{array}{l}\text { Rate of } \\
\text { Change }\end{array}$ & $\begin{array}{c}1998 \\
\text { Firms } \\
\end{array}$ & $\begin{array}{c}2007 \\
\text { Firms } \\
\end{array}$ & $\begin{array}{l}\text { Rate of } \\
\text { Change }\end{array}$ & $\begin{array}{c}\text { Econ. } \\
\text { Growth }\end{array}$ & $\begin{array}{c}\text { Indust. } \\
\text { Shift }\end{array}$ & $\begin{array}{c}\text { Differ. } \\
\text { Shift }\end{array}$ & Overall \\
\hline Agriculture & 0 & 0 & - & 36 & 29 & -0.19 & 0.12 & -0.09 & - & - \\
\hline Mining & 0 & 0 & - & 77 & 59 & -0.23 & 0.12 & -0.13 & - & - \\
\hline Utilities & 0 & 0 & - & 106 & 112 & 0.06 & 0.12 & 0.16 & - & - \\
\hline Construction & 245 & 230 & -0.06 & 3,456 & 3,427 & -0.01 & 0.12 & 0.10 & -0.05 & 0.16 \\
\hline Manufacturing & 188 & 145 & -0.23 & 1,581 & 1,520 & -0.04 & 0.12 & 0.07 & -0.19 & 0.00 \\
\hline Wholesale trade & 234 & 207 & -0.12 & 2,345 & 2,195 & -0.06 & 0.12 & 0.04 & -0.05 & 0.11 \\
\hline Retail trade & 609 & 630 & 0.03 & 5,265 & 5,688 & 0.08 & 0.12 & 0.18 & -0.05 & 0.26 \\
\hline Transportation & 110 & 101 & -0.08 & 909 & 1,125 & 0.24 & 0.12 & 0.34 & -0.32 & 0.14 \\
\hline Information & 96 & 110 & 0.15 & 559 & 758 & 0.36 & 0.12 & 0.46 & -0.21 & 0.37 \\
\hline Finance $\&$ insurance & 282 & 354 & 0.23 & 1,608 & 3,360 & 1.09 & 0.12 & 1.19 & -0.83 & 0.48 \\
\hline Real estate & 257 & 270 & 0.05 & 1,606 & 2,044 & 0.27 & 0.12 & 0.38 & -0.22 & 0.27 \\
\hline Professional, scientific \& technical & 841 & 897 & 0.07 & 3,962 & 4,813 & 0.22 & 0.12 & 0.32 & -0.15 & 0.29 \\
\hline Management of companies & 43 & 56 & 0.30 & 309 & 406 & 0.31 & 0.12 & 0.42 & -0.01 & 0.53 \\
\hline Administrative support & 225 & 227 & 0.01 & 2,088 & 2,246 & 0.08 & 0.12 & 0.18 & -0.07 & 0.23 \\
\hline Educational services & 36 & 52 & 0.44 & 351 & 461 & 0.31 & 0.12 & 0.42 & 0.13 & 0.67 \\
\hline Health care and social assistance & 463 & 446 & -0.04 & 3,375 & 4,149 & 0.23 & 0.12 & 0.33 & -0.27 & 0.19 \\
\hline Arts, recreation, entertainment & 55 & 60 & 0.09 & 489 & 610 & 0.25 & 0.12 & 0.35 & -0.16 & 0.32 \\
\hline Accommodation $\&$ food services & 411 & 497 & 0.21 & 3,121 & 3,799 & 0.22 & 0.12 & 0.32 & -0.01 & 0.43 \\
\hline Other services & 581 & 619 & 0.07 & 3,819 & 4,242 & 0.11 & 0.12 & 0.22 & -0.05 & 0.29 \\
\hline Unclassified establishments & 0 & 0 & - & 373 & 34 & -0.91 & 0.12 & -0.80 & - & - \\
\hline TOTAL & 4,930 & 4,738 & 0.04 & 41,077 & 36,795 & 0.12 & & & & \\
\hline
\end{tabular}


The predominant industries in the Columbus EZs have been identified as: 1) Information; 2) Real Estate; 3) Professional, Scientific \& Technical; 4) Management of Companies; 5) Administrative Support; 6) Educational Services; 7) Arts, Recreation \& Entertainment; 8) Accommodations and Food Services; and 9) Other Services. The most significant industry cluster, based on the highest LQ, was Professional, Scientific and Technical firms, with a LQ of 1.50. This sector had 897 establishments in 2007, representing more than 18 percent of the total 4930 firms in the Columbus EZ zip codes. Other relevant clusters include the Finance sector (1.36), Accommodations and Food Services (1.11), and Management of Companies (1.08).

It should also be noted that those three industries are also concentrated in the MSA, relative to the state. As a result, the contribution of these industries in the EZs is important to both the regional and state economies. Unlike the other EZ communities featured in this chapter, Columbus, Ohio, was the only urban area that experienced positive gains in all of the industries that have a regional competitive advantage. However, like those other communities, Columbus continued to lose Manufacturing establishments. From 1998 to 2007, the number of Manufacturing firms declined by 23 percents - the largest losses experienced in any particular industry subsector in the Columbus EZs, even though throughout the region, Manufacturing overall declined by only 4 percent. The inner-city neighborhoods associated with the EZ program, lost a disproportionately high number of manufacturing companies, which have lower educational and skills requirements than the other industries that flourished during the same time period.

\subsection{Conclusion}

In this chapter, an industry cluster analysis was performed on three of the fifteen Round II Urban Empowerment Zones to determine the composition of companies by 
sector operating in the zip codes that contained EZ census tracts, and determine any shifts in that makeup during the program's tenure, using 1998 as the base year and 2007 as the cut-off year. Basically, "shift-share is useful to identify the industries in which a local area has a competitive advantage and that are growing faster than would be expected if they were just average" (Blakely and Bradshaw, 2002).

Returning to Porter's theory on the "Competitive Advantage of Inner Cities" it's apparent that there are several important components that contribute to sustainable economic development (1995, 1996, 1997). In 1994, Professor Michael E. Porter founded the Initiative for a Competitive Inner City (ICIC) as a nonprofit research and strategy organization. The ICIC has become a leading authority on inner city economics in the United States with a stated mission to "drive economic prosperity in America's inner cities through private sector investment to create jobs, income and wealth for local residents" (2011, p.1).

Part of the ICIC's strategy to strengthen urban economies is by providing stakeholders and decision makers with comprehensive and actionable information about inner-city market opportunities. One of their methods is to determine industry clusters with the greatest chance of sustainable inner-city business growth and job creation. Fundamentally, Porter feels that "Inner city residents need jobs near their homes that offer good pay and the prospect of long-term employment. These can be created only businesses" (ICIC, 2011). Indeed, an August 2005 study by the ICIC found a causal relationship between inner cities and regional economic health.

Similarly, Chan (2006) concluded that strengthening inner city economies leads to respectively stronger regional economies. Shift-share analysis, as a widely used technique for the analysis of regional economies, is essentially comprised of an informationtheoretic model, traditional accounting-based models, and Analysis of Variance (ANOVA). Basically, it "allows the researcher to quantitatively test hypotheses about 
changes in employment or value added by region or sector" and is a "quick, inexpensive analysis tool that is neither mathematically complex nor data intensive" (Knudsen, 2000, p. 179).

In-depth interviews with the program directors of the Office of Community Renewal at HUD confirmed that this study's findings on the apparent mismatch between new industry growth and the education levels or residents are consistent with the circumstances found in other zones. In March 2012, John Haines, the former Deputy Director of the Office of Community Renewal at HUD, who retired at the beginning of the year after more than 35 years of federal service suggested the generalization of this methodology can be applied to determine industry clusters in other areas throughout the county in need of economic transformation. The information obtained through LQ and SSA can be helpful to drive business recruitment and public investment decisions and structure economic development policy. 


\section{INSTITUTIONAL FACTORS AFFECTING EZS’ PERFORMANCE}

\subsection{Introduction}

In the previous two chapters, I examined the impact of the Round II Urban Empowerment Zones (EZs) on local business and employment growth using regression analysis, and then identified the local industries with a competitive advantage, relative to the greater metropolitan region, through shift-share analysis. The main purpose of this chapter is to identify the factors that affect the implementation and performance of EZs. The chapter begins by broadly examining how these factors affected the $15 \mathrm{EZs}$ generally, and then narrow down to a specific case study of the Miami-Dade County EZs to investigate deeper interactions in the implementation and performance.

First, I conducted semi-structured interviews with key staff for the Community Renewal Initiative at the Department of Housing and Urban Development (HUD) to gain insight into the perceptions of the program's top officials. Second, I conducted an indepth case study focusing on the Miami-Dade County Empowerment Zones (EZ) taken from reports, media coverage, program materials, and semi-structured interviews with members of the local board of directors, business owners, residents, and other stakeholders.

Miami-Dade County was selected as the focus of the case study because of its exclusion from the extant research and its status as a unique case because of its change in governance structure during the program's tenure. The Miami-Dade County EZs were originally managed by the non-profit Miami-Dade Empowerment Trust (MDET) and later came under the jurisdiction of the Miami-Dade County Office of Community and Economic Development because of MDET's mismanagement. The federal Community Renewal Initiative allowed each of the designated communities the flexibility and autonomy to determine what type of entity it would put in place as the Coordinating 
Responsible Authority. The interviews with the HUD officials revealed how this grassroots approach resulted in a wide range of outcomes, influenced in part by the distinctive circumstances of each community's history, political climate, cultural influences, and economic environment. As a result, it is impractical to make broad generalizations on how all of the zones expected or actual performance, however, it is feasible to zero in on a particular community and identify institutional factors that have contributed to business and employment growth in that specific area. The following section summarizes the information gleaned from the interviews with the HUD key staff responsible for implementing and administering the Community Renewal Initiative.

\subsection{Factors affecting EZ Implementation and Performance}

To understand the factors affecting the EZs' implementation and performance, I interviewed Pamela Glekas-Spring and John Haines, the Director and Deputy Director respectively, of HUD's Office of Community Renewal, which administered the EZ program. The joint interview took place at the HUD Headquarters in Washington, D.C., consisted of open-ended questions (see Appendix), and lasted approximately two hours. They also referred me to Nancy Gilbert, a former program administrator and Presidential Fellow in the Office of Community Renewal, who helped conduct numerous interviews with local program officials and has since transferred to the U.S. Small Business Administration. During that visit to DC, I was able to meet with Valerie Piper, the Deputy Assistant Secretary for Economic Development in the Office of Community Planning and Development at HUD to discuss the general direction of federal economic development initiatives under the Obama Administration. The factors for EZs'

implementation and performance are derived from the conversations with these established field experts. 
When asked about possible factors that may affect the program's performance, Director Glekas-Spring and Deputy Director Haines both referred to the importance of marketing, organizational capacity, and local leadership. HUD officials specifically advised local EZ staff and program officials of the challenges of marketing the tax incentives and recommended several strategies to overcome them. The first challenge identified was providing opportunities to businesses outside of the zone boundaries.

Although, most of the incentives were aimed at businesses located within the zone, at least two types of tax credits, the Work Opportunity Tax Credit (WOTC) and Welfare to Work Credit (WtWC), were available to businesses located outside of an EZ that nonetheless hired zone residents. "Generally, RC/EZ wage credits, WOTC and WtWC are available to businesses within the RC/EZ for employees who live within the $\mathrm{RC} / \mathrm{EZ}$, even if the business itself does not qualify as an RC/EZ business" (HUD 2003, p.15).

To maximize the use of the WOTC and WtWC, HUD recommended that local EZ offices target workplaces that traditionally have a strong demand for entry-level positions, such as restaurants, hotels, and retail establishments. Another recommended strategy was to establish a pre-certification program for the tax credits that reinforced how hiring zone residents could help a business' bottom line. In some cases, the HUD officials found that the local EZ staff did not do enough to promote the program incentives and coordinate with local business and residents to help determine their eligibility. Previous experience in working with federal grants, as in Boston, helped the local authorities understand the complicated process and procedures and allowed them to more fully utilize them. However, other sites were victims to circumstances beyond their control. St. Louis operated well but lost a significant proportion of its population due to outmigration following the September $11^{\text {th }}$ terrorist attack when several airlines 
consolidated and it was no longer a hub airport (J. Haines, personal communication, August 9, 2011).

Leadership and the individual site dynamics played a role in how well the communities made use of the different initiatives. For example, some sites did a better job of marketing the tax incentives and getting buy-in from the private sector, but that was due in large part to the strength of their existing and newly developed public-private partnerships, the local leadership overseeing the program, and the unity of the community. Santa Ana had strong leadership and was able to successfully leverage funds and promote incentives, as well as coordinate with other programs (J. Haines, personal communication, August 9, 2011).

For the most part the tax incentives were not as fully utilized as possible. In some sites, the local leadership was preoccupied with getting as much grant funding as the first round to the extent that they did not bother promoting the tax incentives as much as they should have. Again, the leadership dynamics and team capacity seemed to have an impact on performance. It is harder to establish unity and alliance when the program was spread out among different communities that sometimes felt like they were competing against each other instead of collaborating. Columbia and Sumter in South Carolina, which shared an EZ designation, opted to operate separately and split resources. As a result Columbia struggled, while Sumter seemingly performed better. There was also tension between Norfolk and Portsmouth, which hindered collaboration (P. Glekas-Spring and J. Haines, personal communication, August 9, 2011).

Regarding the major factors that could have contributed to the program's effectiveness, several themes seemed to recur: leadership, administrative capacity, citizen participation, and strategic planning. Communities that were united and had wellrespected leadership were more likely to perform well. Leadership dynamics and administrative capacity appeared to be more important than whether or not the program 
was run by a local government office or non-profit organization. Some communities did a better job at fostering meaningful participation and organizing purposeful workforce development. In Cumberland County, they formed a partnership with Rutgers University, while El Paso tried to partner with a local university for a medical imaging facility. Meanwhile, Minneapolis developed a strong strategy for purposeful workforce development in the medical services field (J. Haines, personal communication, August 9, 2011).

In terms of evaluating the effectiveness of the tax incentives, HUD acknowledged that tracking their use was a significant challenge. The IRS data on the use of the tax incentives did not sufficiently identify a particular EZ and reveal the extent to which businesses were taking advantage of the incentives. In terms of organizational capacity, many local zone officials lacked a basic understanding of how to monitor and track the employment opportunities that were being created via the EZ tax credits.

Even though HUD offered training seminars, program guides and other forms of technical assistance, confusion about the benefits persisted in several communities. HUD Director Glekas-Spring (personal communication, August 9, 2011) observed that areas that had personnel who were familiar with the federal grant process and had experience with employment tax credits did a better job of advertising and utilizing the incentives. Director Glekas-Spring and former HUD program administrator Nancy Gilbert (personal communication, August 9, 2011) shared their perceptions from earlier interviews with local program officials, which suggest that organizational and administrative capacity, leadership, and governance structure have also factored into performance. Throughout the program's tenure, they conducted ongoing site visits to multiple EZ locations from all three Rounds, as well as the Enterprise and Renewal Communities and interviewed local program administrators and government officials, as well as community members serving on the neighborhood assemblies. 
By design, the Community Renewal program decentralized authority to individual communities and allowed them to designate their own coordinating responsible authority. Many local governments entrusted the management of the EZs to new or existing nonprofit and community-based organizations; creating a "hollow-state" model of third-party governance. The federal EZ program adopted a "bottom-up" approach to allow communities' flexibility and discretion to identify local demands and develop appropriate solutions.

Chaskin and Peters (1997) conducted a preliminary examination of governance in fifteen Empowerment Zones, Supplemental Empowerment Zones, and Enhanced Enterprise Communities and discovered that three distinct organizational auspices for the community renewal program emerged: 1) the existing city, county or municipal governmental authority; 2) a newly created corporation or nonprofit; or 3) an existing nonprofit or community-centered organization.

As is the case with most of the research conducted on the EZ program, Chaskin and Peters (1997) faced several limitations associated with the lack of comparable documentation across sites. Each site had unique relationships, history, and cultural characteristics that had to be taken into consideration, and as a result hinders the formation of broad generalizations. The small number of respondents to Chaskin and Peters' study also prevented them from being able to generalize their findings.

Furthermore, they acknowledge that the planning and implementation of the EZ program was highly political and argue that, "regardless of the choice of formal auspices, local government has played a significant role in appointing participants to the governing or advisory committees" (1997, p. 7).

Among the fifteen Round II Urban EZs, seven of the zones initially established new non-profit organizations or corporations to run the program, while the other eight delegated the authority of managing the program to a local governmental entity, such as 
the city manager's office, a Community Development Agency, or other planning and economic development office or department. Generally, in the case of dual communities that shared EZ designation status, like Norfolk and Portsmouth in Virginia or Huntington, West Virginia and Youngstown, Ohio, one community took the lead in managing the program. Table 15 shows the governance structure associated with the local Coordinating Responsible Authority (CoRA) of each the Round II Urban EZs, based on information provided on the HUD Office of Community Renewal website.

Table 15: Coordinating Responsible Authorities (CoRA) of the Round II Urban EZs

\begin{tabular}{|c|c|c|}
\hline Community & CoRA & Organization Type \\
\hline Boston, MA & Boston Connects, Inc. & $\begin{array}{l}\text { New Corporation/ } \\
\text { Non-Profit Organization }\end{array}$ \\
\hline Cincinnati, OH & Cincinnati Empowerment Corporation & $\begin{array}{l}\text { New Corporation/ } \\
\text { Non-Profit Organization }\end{array}$ \\
\hline Columbia, SC/ Sumter, SC & $\begin{array}{l}\text { Office of Business Opportunities, City of } \\
\text { Columbia }\end{array}$ & $\begin{array}{l}\text { Existing City } \\
\text { Governmental Authority }\end{array}$ \\
\hline Columbus, $\mathrm{OH}$ & Columbus Compact Corporation & $\begin{array}{l}\text { New Corporation/ } \\
\text { Non-Profit Organization }\end{array}$ \\
\hline Cumberland County, NJ & $\begin{array}{l}\text { Cumberland Empowerment } \\
\text { Zone Corporation }\end{array}$ & $\begin{array}{l}\text { New Corporation/ } \\
\text { Non-Profit Organization }\end{array}$ \\
\hline El Paso, TX & $\begin{array}{l}\text { Community and Human Development, } \\
\text { City of El Paso }\end{array}$ & $\begin{array}{l}\text { Existing City } \\
\text { Governmental Authority }\end{array}$ \\
\hline Gary, IN & $\begin{array}{l}\text { Planning and Zoning Department, City of } \\
\text { Gary }\end{array}$ & $\begin{array}{l}\text { Existing City } \\
\text { Governmental Authority }\end{array}$ \\
\hline Huntington, WV/ & Community Development Agency, City & Existing City \\
\hline Youngstown, $\mathrm{OH}$ & of Youngstown & Governmental Authority \\
\hline Knoxville, TN & $\begin{array}{l}\text { Community Development Department, } \\
\text { City of Knoxville }\end{array}$ & $\begin{array}{l}\text { Existing City } \\
\text { Governmental Authority }\end{array}$ \\
\hline Miami-Dade County, FL $^{7}$ & Miami-Dade Empowerment Trust & $\begin{array}{l}\text { New Corporation/ } \\
\text { Non-Profit Organization }\end{array}$ \\
\hline Minneapolis, MN & $\begin{array}{l}\text { Community Planning \& Economic } \\
\text { Development, City of Minneapolis }\end{array}$ & $\begin{array}{l}\text { Existing City } \\
\text { Governmental Authority }\end{array}$ \\
\hline New Haven, CT & Empower New Haven, Inc. & $\begin{array}{l}\text { New Corporation/ } \\
\text { Non-Profit Organization }\end{array}$ \\
\hline $\begin{array}{l}\text { Norfolk, VA/ Portsmouth, } \\
\text { VA }\end{array}$ & City Manager, City of Norfolk & $\begin{array}{l}\text { Existing City } \\
\text { Governmental Authority }\end{array}$ \\
\hline Santa Ana, CA & $\begin{array}{l}\text { Community Development Agency, City } \\
\text { of Santa Ana }\end{array}$ & $\begin{array}{l}\text { Existing City } \\
\text { Governmental Authority }\end{array}$ \\
\hline St. Louis, MO & $\begin{array}{l}\text { Greater St. Louis Regional EZ } \\
\text { Management Corporation }\end{array}$ & $\begin{array}{l}\text { New Corporation/ } \\
\text { Non-Profit Organization }\end{array}$ \\
\hline
\end{tabular}

\footnotetext{
${ }^{7}$ In 2007, the Miami-Dade Empowerment Trust was dismantled by the Miami-Dade County Commission and responsibility for the EZ program was transferred to the Miami-Dade County Office of Community and Economic Development, an existing county governmental authority.
} 


\subsection{EZ Implementation and Performance in the Miami-Dade County EZs}

The Miami-Dade County EZ program is unique in that it is the only community to change its CoRA from a non-profit organization to a governmental entity (see footnote \#7). Miami-Dade County, was a mid-level performer in terms of business and job growth, and is unique case based on its exclusion from the extant EZ literature and its change in governance structure during the program's operation following a media scandal. The Miami-Dade Empowerment Zones (M-D EZs) have been largely excluded from most academic evaluations and the congressionally mandated audit reports prepared by the United State Government Accountability Office (1996, 1997 \& 2006).

An investigative series by the Miami Herald entitled Poverty Peddlers (Grotto, 2007; Hiassen and Grotto, 2007) raised serious concerns related to accountability and responsiveness in the Miami-Dade County Empowerment Zones. The series detailed how the Miami-Dade Empowerment Trust (MDET or Trust) squandered millions of dollars meant to benefit the poor for celebrities on insider developments deals, block parties, and private jet flights. Many of the success stories in the M-D EZs turned out to be gross exaggerations and in some cases, suspected to be outright fraud (Grotto, 2007). The MDET was first delegated authority to govern, direct, and implement the M-D EZ strategic plan under a Memorandum of Understanding (MOU) approved by the Board of County Commissioners in 1999 and which would later be terminated on July 10, 2007, shortly after the investigative series' publication.

The Miami Herald articles (Grotto, 2007; Hiassen and Grotto, 2007) alleged that in reports submitted to HUD, the MDET falsely reported the number of new jobs fostered in the Empowerment Zones. In some cases, companies that were closed for years were supposedly thriving and creating new jobs. In a review of fifteen annual reports, the Herald reporters could only confirm eight out of 310 claimed newly created jobs. 
Therefore, the credibility and validity of some of the data that MDET reported in annual reports to HUD could be inaccurate or questionable.

A major component of the M-D EZs job creation strategy was the planned construction of the now defunct, Poinciana Park, a multipurpose commercial and residential complex. The Poinciana Park's master plan included a biopharmaceutical facility, outpatient and research clinics but never materialized despite receiving bond financing facilitated by the MDET. The project's developer, Dennis Stackhouse, was accused of improperly collecting millions of dollars from the MDET without ever having constructed a single building (Hiassen and Grotto, 2007).

In the aftermath of the Miami Herald's investigative series, the Trust's President and CEO Aundra Wallace and the CFO Rodney Carey were fired, the MDET was dismantled, and the authority of the EZs moved to the Miami-Dade County Office of Community and Economic Development (OCED). According to the most recent news report related to the failed biotech site, Poinciana Park, the project's disgraced developer Dennis Stackhouse is still awaiting trial on charges of organized fraud and grand theft (Rabin, 2011).

In an interview with Irby McKnight, a MDET Board Member and president of the Overtown Neighborhood Assembly, he insinuated that the failure of the Poinciana Park was also brought about in part to make way for the University of Miami's new Life Sciences and Biotechnology Park that was completed in 2011 on the outskirts of the Overtown community in downtown Miami (personal communication, December 1, 2011). Mr. McKnight pointed out that bond financing that was stripped from the Poinciana Park project and denied for an affordable housing project, was later used to help construct the University of Miami's state-of-the-art biotechnology park. The building's construction and financing was criticized by community activists and worker's groups, such as Miami's PowerU, who complained that the university was reaping 
benefits, designed to help the poor but was not creating enough job opportunities for residents who live in the surrounding areas.

Given the program's emphasis on increasing the wellbeing of EZ residents, the job opportunities created in the zones should have been compatible with the educational levels of zone residents. A limitation of this study is the lack of data on specialized training attainment rates outside of traditional education records. The Census Bureau does not track apprenticeships or training in skilled trades such as plumbing or carpentry. Educational attainment rates provide a base measure for the skill level of zone residents for the purpose of this study.

Since census tract data has been largely restricted to being released every ten years, zip codes were substituted as the unit of analysis. The "Geo within Geo" geographical tabulation tables on the Census Bureau's American FactFinder website were used to identify the zip codes that contain the EZ program designated census tracts. Table 16 below shows M-D EZ designated census tracts and their affiliated zip codes.

Table 16: Miami-Dade County EZs census tract and corresponding zip codes

\begin{tabular}{lll}
\hline County & Census Tracts & Zip Codes \\
\hline Miami-Dade, FL & 17.03 & 33142 \\
Miami-Dade, FL & 19.01 & 33150 \\
Miami-Dade, FL & 24.02 & 33142 \\
Miami-Dade, FL & 27.02 & 33132 \\
Miami-Dade, FL & 28 & 33127 \\
Miami-Dade, FL & 29 & 33127 \\
Miami-Dade, FL & 30.01 & 33136 \\
Miami-Dade, FL & 31 & 33136 \\
Miami-Dade, FL & 34 & 33132 \\
Miami-Dade, FL & 36.02 & 33130 \\
Miami-Dade, FL & 37.01 & 33132 \\
Miami-Dade, FL & 37.02 & 33132 \\
Miami-Dade, FL & 48 & 33136 \\
Miami-Dade, FL & 113 & 33030 \\
\hline
\end{tabular}


The Miami-Dade Empowerment Trust actively worked on projects in nine designated communities: 1) Allapattah/Civic Center; 2) Florida City; 3) Homestead; 4) Liberty City/ Model City; 5) East Little Havana; 6) Melrose; 7) Overtown; 8) Wynwood; and 9) Central Business District and the Port of Miami. According to the City of Miami website, approximately $75 \%$ of the Miami-Dade EZs are concentrated in the neighborhoods of Allapattah, Wynwood, Overtown, East Little Havana and Model City/Liberty City. The M-D EZs also included parts of the Miami International Airport. "Each community has its own unique characteristics, architecture, and history that contributes or detracts from its development" (City of Miami, 2010). Each of the nine designated communities held monthly public neighborhood assembly meetings designed to meet the federal mandate of ongoing citizen public participation and engagement.

The neighborhood of Allapattah is located just northwest of downtown Miami and east of Miami International Airport. The population of Allapattah is approximately 44,486 residents (or $12.3 \%$ of the city of Miami) and is primarily of Hispanic origin (City of Miami, 2010). Allapattah is home to the largest industrial area in Miami and several nationally recognized medical facilities, such as the Bascom Palmer Eye Institute, Jackson-Memorial Hospital, the University of Miami Medical Center, and the Veterans Administration Hospital. Various trades, particularly clothing manufacturing, wholesale trade, and auto repair, are strongly represented in the community.

Just west of Allapattah is the Melrose community, an area encompassing the Miami Jai-Alai facility and casino, and sits on the western edge of the City of Miami, in unincorporated Miami-Dade County. To the east of Allapattah is the community of Wynwood, which has experienced a surge of economic revitalization in the past ten years. Now known as the Wynwood Arts District, the neighborhood has been positioned "at the intersection of contemporary culture and urban revitalization" due to the emergence of galleries, private fine art collections, restaurants and studios (City of 
Miami, 2011). An influx of local artists, have helped transition the neighborhood from a predominately Puerto Rican enclave to a diverse and thriving cultural destination that attracts thousands of visitors to the world renowned Art Basel festivities and monthly Art Walk. As one of the most successful examples of economic redevelopment in the M-D EZs, Wynwood is also home to the mixed-use complex, Midtown Miami, a large-scale infill development that was constructed on an abandoned railroad yard.

The historical neighborhood of Overtown in Miami is located minutes from the central business district and the regional medical center. For decades, Overtown has been the epicenter for African-American culture as a formerly segregated community. Freeway construction during the 1960s intersected the neighborhood and contributed to its steep economic decline. The area still holds significant potential for revitalization as a consequence of its close proximity to the Port of Miami and central business district. Despite a steady influx of federal, state and local funding geared towards its economic revitalization; the neighborhood remains one of the most impoverished areas in MiamiDade County.

Another community that borders downtown Miami is East Little Havana. Unlike Overtown, which has a majority of African-American residents, Little Havana is heavily Hispanic, hence the name for its predominance of Cuban residents. East Little Havana lies east of downtown Miami, alongside the Miami River. The new Marlins baseball stadium was recently completed, however the stadium, which was surrounded by controversy since its construction was largely funded at the expense of taxpayers, and the surrounding retail and dining options have not contributed as greatly as promised to the economic revival of the community following the demolition of the landmark, Orange Bowl.

Model City, also known as Liberty City, contained parts of the M-D EZs and is located in the northwest region of the city. The area consists of a mixture of residential, 
commercial, educational, and commercial districts. The majority of residents are AfricanAmerican and the Edison Business District is considered a focal point of minority entrepreneurship in Miami-Dade County. In terms of affordable housing in the EZs, Palmetto Homes received loans from both the Miami Department of Community Development and the MDET to finance the construction of six infill homes on vacant lots in the M-D EZs, most of them located in the Model City /Liberty City community.

The neighboring communities of Florida City and Homestead are located in the southern region of Miami-Dade County. After the city of Miami, Homestead is the second oldest city in the county and is a major agricultural area. The vicinity is bordered to the east by the Biscayne National Park and the Everglades National Park to the west. The community was particularly hard hit by Hurricane Andrew in 1992 and suffered mass devastation. Between 2002 and 2007, a building and housing boom occurred in the area that converted a large portion of the agricultural land into commercial and residential districts. The Homestead area notably includes the Turkey Point Nuclear Power Plant, the Homestead-Miami Speedway and the Homestead Air Reserve Base.

The diverse characteristics, history and political climate of the nine distinct communities that comprised the M-D EZs create an interesting juxtaposition for the examination of institutional factors that may have contributed to a beneficial economic impact. The opinions expressed in the interviews conducted with the M-D EZ board members suggest that organizational capacity and leadership may have impacted the program's operation and outcomes. The following section explores these themes along with community participation, public-private partnerships and the political climate during the program's tenure.

In addition to the secondary sources reviewed as part of my case study of MiamiDade County, I also conducted semi-structured interviews with several individuals associated with the MDET (the recruiting documents, consent forms, and interview 
questions are available in the Appendix). The interview subjects were asked to describe their involvement with the EZ program and identify factors that may have contributed to the program's effectiveness. They were also asked to evaluate which initiatives they felt were the most and least effective at creating new businesses and jobs. EZ Program Coordinator, Lori Weldon, who declined to be interviewed for this study, was instrumental in facilitating interviews with the study's participants whose identities and roles are available via public records. The interviewees included local program administrators, board members, neighborhood assembly chairpersons, business owners, community-organization leaders, and residents.

One of the first case study subjects to be interviewed played a pivotal role in the M-D EZ program initial implementation. Bryan Finnie was the former President and CEO of the MDET, who incidentally simultaneously served as the Director of the MiamiDade County Office of Community and Economic Development (OCED) during his tenure. The OCED would later take over responsibility of the EZ program from the MDET while maintaining most of the existing staff. Mr. Finnie was recruited for the MDET position in 2000, following a nationwide search, and served until his resignation in 2007. Mr. Finnie now serves as the interim city manager and Chief Administrative Officer for the City of Opa-locka, located in the northwest Miami-Dade County.

Another study participant, Dr. W. Dean Goldsby, Sr. was the Vice-Chair of the MDET Board and is the current President and CEO of Work America, a workforce development non-profit organization, located in and serving the residents of Overtown. Also representing the Overtown community is longtime resident and activist Irby McKnight, who served as the Chairperson for the Overtown Neighborhood Assembly. Paul Velez, the Chief Administrative Officer of the Borinquen Medical Centers of Miami-Dade represented one of the community-centered organizations that was in partnership with the Miami-Dade Empowerment Trust. 
The Borinquen Medical Centers, located in the Wynwood neighborhood in Miami, began as a grass-roots effort in the Puerto Rican community to establish a health clinic in 1972 and has since expanded to provide comprehensive primary health care, dental and behavioral health services. From the EZ communities located in the southern regions of Miami-Dade County, I interviewed Gary Ferguson, the owner of Ferguson Jewelers, Inc. and a resident of the City of Homestead, who served as the Chairperson of the Homestead Neighborhood Assembly. Ario Lundy from Palmetto Homes was another business owner that I interviewed who benefited from the EZ program. Palmetto Homes received various grants and loan from the MDET to construct affordable housing in the Model City/ Liberty City community.

The general consensus of the interviewees was that the MDET had competent and committed individuals working on the program's administrative staff and serving on the board and neighborhood assemblies. However, some communities, such as East Little Havana and Allapattah, had a more difficult time retaining community participation (B. Finnie, personal communication, December 7, 2011). Nonetheless, the neighborhood assemblies were useful means of filtering information to residents about local initiatives and to gather feedback and recommendations on program expenditures (D. Goldsby, personal communication, December 16, 2011).

It was suggested that the dismal retention rate of some neighborhood assemblies might have been the result of apathy, distrust and disappointment on behalf of local residents who might not have fully understood the program or witnessed tangible immediate benefits (I. McKnight, personal communication, December 1, 2011). For the most part, the interview subjects felt the MDET had well-qualified administrators and that the nature of the Miami Herald's allegations were untrue or misleading. As Mr. Finnie stated, "I think the program was so sophisticated that a lot of people didn't really understand the impact of the program. What we weren't able to capture was the amount 
of private sector investment in the zones that was largely triggered by the tax incentives that businesses could utilize" (personal communication, December 7, 2011).

As a result of the complex nature of the zone's tax credits, a definitive accounting of their use and their local economic impact was not possible. Echoing sentiments expressed by the HUD officials in DC, several Miami-Dade County EZ board members pointed out that it was typically larger corporations with in-house lawyers and accountant who were able to fully take advantage of the tax incentives offered, whereas many small businesses lacked the resources and knowledge to properly utilize them despite training workshops offered by the IRS early in the program's implementation. Despite the challenges associated with the tax credits and allegations of financial mismanagement, there were some tangible benefits to the program.

In 2004, HUD produced a publication titled, "Spotlight on Results" which highlighted the success stories that the department identified in all three rounds of the EZ/RC program. The initiatives and projects mentioned in the guide illustrate the diversity of the community-led initiatives launched in the participating cities across the country. That same year, "six affordable infill homes on vacant lots and underutilized property in the EZ," constructed by Palmetto Homes of Miami was made possible due to a $\$ 250,000$ bridge loan from the Miami Dade Empowerment Trust (MDET) and a $\$ 270,000$ forgivable loan from the city of Miami’s Department of Community Development (HUD 2004, p.140).

Palmetto Homes of Miami owner, Ario Lundy, expressed gratitude that the MDET took a risk by funding his company since he didn't have a proven track record, which would have been necessary to receive traditional financing. Furthermore, he felt that the EZ program gave an important opportunity to build his professional reputation and establish valuable business connections that might not have otherwise been possible, remarking "People looked at the product I did for the EZ Trust and gave me the 
opportunity to take it to the next level. It's difficult when you're coming from where I'm coming from and nobody knows you. No one wants to give you an opportunity because 'I don't know who he is, I don't know what he does. He doesn't have financial statements, no books, and no type of records to show what he can do.' And that's where the EZ Trust took a risk (A. Lundy, personal communication, December 6, 2011). His company hired teenaged ex-gang members during a summer program and provided on-the-job training in environmentally sustainable single-family construction, as well as certification in asbestos removal through a partnership with the South Florida Workforce agency.

For the most part, the federal EZs favored community development projects such as affordable housing, education, and infrastructure over economic programs to benefit businesses (GAO, 2006). The Villas of St. Agnes completed in 2006 was "one of the largest single-family home developments built in Overtown in decades" and consists of 80 homes constructed on the site of a demolished public housing project through a partnerships with the MDET, the St. Agnes Rainbow Community Development Corporation, and Bank of America (Arthur, 2006).

Another substantial outlay from the MDET was a \$1.6 million equity investment in LEASA Industries, the largest producers of tofu in Florida and one of the largest growers of bean and alfalfa sprouts. The President and CEO of LEASA, George Yap, stated: "The Empowerment Trust is making it possible for us to continue leading our industry while making a positive impact in the local community" (HUD, 2004, p.74). It was expected that LEASA would create 65 new jobs and expand its operations in the Poinciana Industrial Park, which never materialized so it is unclear of the actual benefit that resulted from the MDET's investment in LEASA Industries. One of the enduring examples of the MDET's investments in business development is the Chili's Bar and Grill restaurant that is still located in the Bayside Marketplace in the heart of the central business district. Chili's received a $\$ 500,000$ investment from the MDET's Venture 
Capital Fund and was expected to create 100 jobs for local EZ residents. A Chili's spokesperson remarked, "This is a really great opportunity for Chili's to complement the attractions offered at Bayside for tourists and local residents. At the same time we are hiring residents from economically distressed areas such as Overtown and Wynwood" (HUD, 2004, p. 75).

In an effort to support small businesses, Community Development Block Grant (CDBG) funding was used to institute a One-Stop Capital Shop in Miami-Dade County to connect entrepreneurs with small business administration resources, bank representatives and local development agencies (Cuomo and Glickman, 1999). Another Miami-Dade County program, the YWCA's YouthBuild, recruited young EZ residents to learn construction skills building low-income apartments in their community. Meanwhile, in the city of Homestead, the United States Department of Justice's Weed and Seed program is credited for providing safer neighborhoods for EZ residents through enhanced law enforcement, community policing, prevention, intervention, and treatment and neighborhood restoration (Cuomo \& Glickman, 1999).

According to the MDET board members that were interviewed, the greatest needs of the communities included affordable housing, job creation, small business development, and private sector investment. In addition, Dr. Goldsby emphasized the importance of having dedicated representatives that are committed to addressing community needs and ensuring that residents' voices are heard (personal communication, December 16, 2011). Trying to create a single vision and direction for the program's implementation was tricky due to the divergent interests communicated by the nine diverse neighborhood assemblies that comprised the M-D EZs. The challenges found at the local level are representative of why a bottoms-up approach was adopted at the federal level. Each area faced different problems and demanded customized solutions. However, former MDET President and CEO, Bryan Finnie felt that, "the greatest need 
was having skilled and trained management implement the appropriate community revitalization program. Money was never an issue. It was having a trained staff that could manage and implement programs" (personal communication, December 7, 2011).

\subsection{Conclusion}

Various interacting and at times opposing factors seemingly contributed or detracted from the program's effectiveness. The political climate at the federal and local levels may have played a role, while it also appears that administrative and organizational capacity, leadership, and governance structure were significant factors in some circumstances. The EZ program was launched during the first term of the Clinton administration and received its full support. However, when the Round II EZs were launched during the second Clinton term, the administration was no longer willing to give those cities the full amount of funding that was allotted to the first round EZs. When George W. Bush was first elected in 2000, the EZ program was extended and a third round was selected, however the program received less political support during his second term in office (P. Glekas-Spring, personal communication, August 9, 2011).

During the program's tenure and after its conclusion, HUD continued to embrace other place-based program such as Choice Neighborhoods, the Gulf Opportunity Zones, and New Markets Tax Credits. A full year after the program expired, President Obama retroactively extended the tax credits until December 31, 2011. According to the EZ program's Deputy Director John Haines, there may be "some additional tax benefits for the EZs, based on reinterpretations of current law. There also is pending legislation to extend or reopen the designation as an employment stimulus" (personal communication, September 10, 2012).

In hindsight, there are several aspects of the EZ program that those involved feel that they would have done differently, if possible. According to the key staff in the Office 
of Community Renewal, it would have been helpful if HUD had been able to meet with lawmakers before the program's legislation was passed so that Congress would have known upfront about problematic concerns regarding to implementation and performance measurement and monitoring (P. Glekas-Spring and J. Haines, personal communication, August 9, 2011). It would have been better to work with legislators, like the Ways and Means Committee, and provide input into the program's design rather than try to make changes retroactively. It also would have been prudent to have a protocol to strip eligibility from nonperformers, as well as the ability to make modifications to the program, for example to reprogram grants for underperformers, or designate replacement zones.

In the Miami-Dade County EZs, the interviewees also shared their suggestions on how the program could have been improved. Former MDET President and CEO, Bryan Finnie acknowledged that in hindsight he would not have taken on the dual responsibility of heading the Miami-Dade County OCED at the same time (personal communication, December 7, 2011). Even though the arrangement allowed for an intertwined relationship between the county economic development agency and the non-profit trust responsible for coordinating the M-D EZs, it became difficult to differentiate their individual tasks and goals, although it did allow for an easier transition upon dissolution of the MiamiDade Empowerment Trust.

Bryan Finnie also remarked that as the former MDET president and CEO, he would have focused more on attracting outside investment and developing public/private partnerships. He suggested that a more entrepreneurial approach was warranted to allow for greater flexibility and adaptability, and that he would have allotted more funding for education and job skills training (personal communication, December 7, 2011).

Overtown Neighborhood Assembly Chairperson Irby McKnight felt that the local government should have been more proactive in notifying businesses of their eligibility 
during standard permitting and licensing processes and could have streamlined procedures to encourage new business development and existing business continuation in the targeted areas. Irby McKnight also lamented the lack of involvement and support of the EZ program from the Beacon Council, a public and private non-profit agency working to support the local business climate in the City of Miami and Miami-Dade County, as well as the Greater Miami Chamber of Commerce (personal communication, December 1, 2011). Overall, the feedback from the interviewees on the program's performance was positive although most felt that more could have been done to promote private sector investment and more resources could have been devoted to job training.

The case study performed in this chapter relied on a review of secondary sources such as media articles, program guides, annual reports, and memorandums, as well as primary sources in the form of interviews with federal HUD program officials in Washington DC and local board members and stakeholders from the Miami-Dade County EZs. The Community Renewal Initiative adopted a "bottom-up" grassroots approach that allowed the individual EZ communities to develop their own strategic plan to address local demands and implement solutions that were appropriate. Similarly, many local communities like Miami-Dade County, relied on those closest to the ground, in the form of neighborhood assemblies to convey the concerns and needs of the residents who would be impacted by the program and were intended to benefit from its implementation. 


\section{STRATEGIC VISION FOR CHANGE}

\subsection{Introduction}

The Empowerment Zones and Renewal Communities (EZ/EC) program introduced in December 1994 aimed to revitalize economically distressed areas around the country through enhanced social service and grant programs, as well as by offering tax credits and other incentives to businesses that created jobs for residents who live within the zone boundaries. The Community Renewal Initiative program was enacted in three rounds: Round I (1994-2011), Round II (1998-2011), and Round III (2001-2011). All three rounds of the EZ/RC program effectively expired on December 31, 2011, but can still be extended retroactively.

My dissertation focused exclusively on the fifteen urban communities designated during the second round, which was not as well researched as the first round. The focus of the case study, the Miami-Dade County Empowerment Zones, were conspicuously omitted from most of the existing academic research as well as the federally mandated program audits performed by the United States Government Accountability Office (GAO, 2004, 2006, 2010). My research utilized a mixed-methods approach to accomplish three research objectives: to examine if the EZ program led to the creation of new businesses and employment; 2) to analyze changes in the types of local industries; and 3) to identify institutional factors that may have contributed to economic development and job creation in the EZ areas.

First, Ordinary-Least-Squares regression models were used to determine that the presence of an EZ designated census tract did not have a statistically significant effect on the rate of business and employment growth in a given zip code. However the empirical analyses revealed that other independent variables, such as the average household income of residents, did have a statistically significant impact on the number of businesses or 
employees within a community. Specifically, a one-unit increase in the average household income of residents will have a slight positive impact on the percentage change in the number of businesses and employees in a zip code, holding all other variables constant.

Second, I conducted both Location Quotient and Shift-Share Analyses to identify the predominant industry clusters operating in the zip codes that contained EZ communities, relative to their respective Metropolitan Statistical Area or Region and State. The cluster analyses showed which industries have a competitive advantage within the selected community and demonstrated how fluctuations at the macro-level can have an effect on business growth or decline at the micro-level. Not surprisingly given the change in the global economy, traditionally low-skill industries such as Manufacturing continued to decrease, while service-driven and high-skill industries such as Professional and Technical firms increased. Some studies have suggested that without proper job training, existing zone residents will be excluded from newly created jobs and be forced from their communities via gentrification (GAO, 2006; Hyman, 1998; and Porter, 1996).

Third, a case study was conducted after on a review of secondary sources and interviews with national program officials and local stakeholders in the Miami-Dade County Empowerment Zones. Several reoccurring themes emerged that suggest certain institutional factors, such as governance structure, and organizational, administrative and leadership capacity, may have contributed to zone performance in terms of business development and job creation. A key component of the EZ program was attracting private sector investment into distressed communities. Inspired by the Hong Kong Freeport model and the success of other Special Economic Zones internationally and domestically, the federal government's spatially targeted economic development program, in the form of the Community Renewal Initiative, was an attempt to create a business-friendly 
atmosphere that would help jumpstart an economic revitalization in poor urban and rural areas.

In the late 1980s, the United States government increasingly began to adopt business-like preferences, in the form of New Public Management (NPM). The major premises of NPM were 1) Productivity, 2) Decentralization, 3) Marketization, 4) Policy, and 5) Accountability. Around the same time that NPM became more popular in the realm of public administration, states started implementing special economic zones or enterprise zones to attract business investments and partnerships.

Kettl's 2000 book, “Global Public Management Revolution” detailed the worldwide reform towards greater privatization and the adoption of business-like practices, particularly in the Westminster Reforms that took place in the United Kingdom and New Zealand. David Osborne and Ted Gaebler's “Reinventing Government” (1992) advised governments to adopt market-friendly approaches to lead to greater efficiency and productivity. Osborne and Gaebler argued that governments should essentially, "Steer, not row," in which they move away from the direct provision of public services to a role of simply ensuring its provision.

In 1993, the Clinton Administration, led by then Vice-President Al Gore, adopted many of Osborne and Gaebler's recommendations as part of a sweeping federal reform effort, referred to as the National Performance Review. The Government Reporting and Performance Act of 1993 required government agencies to develop annual strategic plans that detailed the organizations' goals, objectives, as well as set and meet established performance measurements.

The supporters of NPM echoed the sentiment of the earlier Scientific Management movement, in which there was believed to be a universal approach to administration and that businesses practices could successfully be implemented in public organizations. Although, Scientific Management highly valued efficiency and 
productivity, NPM was more like Liberation Management because it allowed managers to devise creative solutions to problems, instead of insisting on "one best way" to accomplish tasks.

The opposition of New Public Management is best expressed by Robert Denhardt and Janet Denhardt in their 2007 book, "New Public Service: Serve, Not Steer." The Denhardts criticize Osborne and Gaeblers' concept of NPM on the basis that it values productivity over people and places entrepreneurship above citizenship. They argue that organizations should continue to think strategically, but remember to act democratically.

In line with the growing popularity of NPM and the Clinton Administration's embrace of its tenets in the form of the National Performance Review, the federal government implemented the Empowerment Zones and Renewal Communities (EZ/RC) program in an attempt to use business-friendly initiatives to revitalize distressed urban and rural communities. Central components to the EZ/RC program, later known as the Community Renewal Initiative, were tax credits and other incentives that were expected to motivate the private sector to invest in areas that they might not have otherwise considered. The EZ/RC program in the United States was modeled after the success of Special Economic Zones overseas, starting with the historical example of the Freeport trade system in Hong Kong. The reduction or elimination of taxes and regulatory restrictions are among the cited best practices that attributed to successful Special Economic Zones. The Community Renewal Initiative was unique in that it combined tenets of both place-based and people-based community development by focusing on a defined geographical region, but also providing programs specific to the current inhabitants of that particular area. Unlike, Special Economic Zones in other countries and those implemented in many states throughout America, the federal EZ/RC program enacted programs to improve the livelihood of local residents, in addition to the incentives being offered to businesses to attract and retain business investment. 


\subsection{Best Practices}

The literature review on Special Economic Zones (SEZs) suggests that five best practices should be followed in order to maximize zone success (Foreign Investment Advisory Service (FIAS), 2008; Chan and Lee, 2007; Trade and Industry Department, 2008; Cling and Letilly, 2007). First, zones should serve as a catalyst to reform the overall investment and economic climate within a host community. The beneficial economic impact of the zones should not be limited to narrowly-defined geographic areas and targeted funding projects but should instead generate a more widespread economic impact for sustainable community revitalization.

Second, the private sector should develop and operate zones on a cost-recovery basis and should not rely on government subsidies. The American version of SEZs differed greatly from foreign zones in that they did not abide by this key recommendation and instead relied extensively on tax credits and other subsidies to encourage private sector investment. An estimated $\$ 11$ billion in tax credits were made available to businesses, of which corporations claimed approximately $\$ 2.6$ billion during the program's initial tenure (GAO, 2010 and HUD, 2010).

Third, it was recommended that governments should only specify and regulate zone activities and should not directly own, operate or develop zones. The Community Renewal Initiative adopted a bottom-up approach to allow individual communities to develop their own unique solutions to local needs based on a submitted strategic plan. Each designated community was allowed to designate its own local Coordinating Responsibly Authority, which then submitted annual reports to HUD or the United States Department of Agriculture.

Fourth, SEZs should be linked to outside enterprises and stimulate growth in surrounding communities instead of existing as isolated enclaves. Since the EZ program relied on census tracts to create geographically delimited areas they inadvertently 
excluded neighboring businesses and communities. Conversely, using a larger geography such as zip codes, cities or metropolitan areas and ensuring integration with regional clusters allows for a broader economic impact.

Fifth, zones should focus on building long-term competitiveness in businesses within the area as opposed to relying on incentives. The EZ/EC program was designed to be a short-term experiment that would result in long-term economic revitalization in the targeted areas. The tax credits and other incentives were intended to initially attract business investment into struggling communities but were time delimited to avoid creating a culture of dependence on those subsidies in which businesses would not be able to function beyond their expiration.

There are many obstacles that can impede zone success: poor locations, uncompetitive policies, poor zone development, subsidized rent, cumbersome procedures and controls, inadequate administrative structures, and weak coordination between private developers and governments regarding infrastructure provision (FIAS, 2008). The FIAS found "the root of many of these obstacles to optimal zone performance is a lack of effective coordination, both in terms of the parties involved and various physical and procedural aspects of the zone itself" (2008. p. 5). Therefore, it is important that an appropriate legal, regulatory, and institutional framework is established within the context of spatially targeted programs that encourages diverse activities and promotes private development and long-term sustainability.

\subsection{Policy Recommendations}

The EZ/EC program offered special tax benefits and other incentives to businesses that relocated and hired residents for jobs within its boundaries. In addition, block grants allowed for infrastructure and general location improvements, as well as human resource development. These incentives were meant to stimulate the private 
sector's interest in revitalizing struggling inner cities and rural areas and foster a more business-friendly environment conducive to economic growth. In many ways, the federal EZs, a twist on traditional enterprise zones, were not just business development tools, but also locality and human resource development tools with defined borders and targeted groups of people.

Similar to the findings presented in this dissertation, the Initiative for a Competitive Inner City (ICIC) suggests several strategies and best practices for growing inner city economies and creating jobs. These suggestions could be developed into policy recommendations aimed at the United States Department of Housing and Urban Development, as well as the Coordinating Responsible Authority (CoRA) in the local or municipal governments, if the EZ programs were to be reinstated or if other locationbased economic development programs are to be adopted. Based on a longitudinal study of 100 U.S. metropolitan areas and 20 inner cities since 1994, the ICIC recommends the following approaches to job creation and economic development:

- 'Utilize a cluster-led approach to identify market opportunities and focus business attraction and retention efforts;

- Promote and leverage anchor institutions as key economic and community drivers;

- Accelerate inner city business development by improving access to capital, providing business and management education for business owners and connecting businesses to procurement and supply chain networks (ICIC, 2011).

In addition, it is critically important that inner city businesses, both small and large, have adequate access to capital to expand operations and increase their workforce. Even beyond the expiration of the Community Renewal Initiative, there are other ongoing programs and incentives that can be utilized to encourage growth in inner city 
economies, such as the Small Business Administration (SBA) loan programs, Community Development Financial Institution (CDFI) lending activity and the still active New Markets Tax Credits. Existing resources should be identified and more effectively promoted before programs that duplicate efforts are enacted.

Fairlie and Robb determined that "there exist more than 500 non-profit programs providing loans, training or technical assistance to disadvantaged entrepreneurs" (2008, p. 182). More effective communication and coordination would ensure that inner city companies, particularly small businesses and minority-owned firms are made aware of the resources that are available to them. Furthermore, incentives introduced by local, state, and federal governments should focus on strengthening existing regional firms and provide adequate training and development in the use of available programs and resources, before these tools are offered to large multinational corporations.

Another recommendation on how location-based programs like the Community Renewal Initiative could be improved relates to the limitations associated with data collection and availability. A significant limitation of the EZ program was of the use of census tracts to designate eligible communities, which significantly restricted access to Census demographic data to every ten years and created narrowly defined boundaries that did not account for residual effects. Economic development programs, like the Community Renewal Initiative, should be designed to ensure that reliable and readily accessible data is available for administrators and researchers to track performance and monitor changes in key characteristics.

For this reason, my study relied on Zip Code Tabulation Areas (ZCTA), which often contained overlapping and partial census tracts, to capture the neighborhood effects and facilitate the use of Census County Business Patterns to measure local business growth. Nonetheless, the method of data collection via the Internal Revenue Service did not provide information that would allow claimed tax credits to be tied back to a specific 
geographical location. As a result, the effectiveness of the EZ program remains largely inconclusive or speculative. If the EZ program is to be reinstated in the future, proper procedures must be put in place to ensure a higher level of accountability and oversight. Federal and local protocols should be instituted to ensure effective and efficient tracking and disclosure of claimed tax benefits.

\subsection{Conclusion}

Development administrators should be able to assess a region's history and culture to put into practice programs that produce long-term advantages instead of shortterm remedies. Numerous countries have reinvented the modern enterprise zone concept proposed by Hall and inspired by historical trading hubs like Hong Kong, to meet their country's unique characteristics and needs. Like the traditional concept of development pursued by Western nations following World War II, SEZs initially focused almost exclusively on economic growth and industrialization. However, the emerging multidimensional concept of development integrates economic and social development with human, institutional, and sustainable development. This combined approach enriches the definition of development, even though there is some inconsistency among the dimensions.

Development can mean creating and implementing unique solutions to societal issues so that people can maximize their life's potential. The literature and global perspective on development have broadened over the last decade, so that economic factors are no longer considered the only relevant indicators of a country's development. Being a rich nation and a developed nation are not necessarily synonymous. The richest nations all have pockets of deep poverty. Regardless of whether or not a country has a high per capita income, development issues will exist if distressed areas and impoverished residents are ignored. A wealthy nation can have abundant resources but 
fail to provide for the basic needs of all of its residents - namely, nutritious food, clean water, shelter, and access to health care, employment and education. However, what works in one region may be unsuccessful in another due to widely varying circumstances. This research examined the impact of the Round II Urban Empowerment Zones (EZs) on local communities, namely in terms of business and employment growth, using mixed methodology. The Ordinary-Least-Squares regression models gathered data from all fifteen Round II Urban EZs and a counterfactual group, while the Location Quotient and Shift-Share Analysis focused on three communities that experienced positive business growth from 1998 to 2007. Lastly, the in-depth case study summarized findings from interviews with federal program officials and local stakeholders in Miami-Dade County, an outlier community, and also provided a comprehensive review of secondary resources.

My dissertation research is significant for four reasons. First, my study is the first independent research to examine the economic impact of the urban Round II EZ program. Existing government and academic evaluations, including all three of the federally mandated reports from the Government Accountability Office (GAO, 2004, 2006, 2010) focused primarily on the first round urban EZs. Since tax incentives for job creation were more heavily, emphasized during the latter rounds, my research investigates the impact of local business and employment growth. Second, my study contributes to the relatively small literature on the effectiveness and sustainability of location based central city revitalization efforts, like the HUD's EZ program. Third, unlike the previous program evaluations and studies, my dissertation uses a different methodology, Shift-Share Analysis, to identify local industry clusters in the EZs. Although the Shift-Share Analysis is not new, it has not yet been adapted in examining the industry clusters promoted in the EZ areas. Fourth, the study informs policy makers on successful location-based economic development strategies through the identification of institutional factors that may influence business and job growth and characteristics of successful SEZs worldwide. 
My dissertation contributes significantly to the small body of literature on the EZ program by filling several key gaps. There is a dearth of research specifically on the communities designated as Round II Urban EZs. When the Community Renewal Initiative was first launched in the mid-1990s, the program and particularly the six Round I Urban EZs generated a lot of media attention and academic interest. As the program progressed however, the effectiveness of the program was increasingly called into question by both government and independent evaluators. The inconclusive nature of the program's outcomes discouraged many researchers from further investigations. My dissertation picks up where others have left off by looking at the Round II Urban EZs using multiple regression models and case studies, and then adds a new methodology in the form of the Shift-Share Analysis.

Future research on the EZ program could utilize newly released data from the United Census Bureau to provide a more comprehensive examination of the long-term and short-term effects of the program. An examination of the demographic data from before and after the program could reveal any significant changes and reveal intended and unintended consequences of possible gentrification. My dissertation contributes to the body of knowledge in public administration by adding to the literature on placedbased and people-based programs, in the context of the Empowerment Zones, and the effectiveness and efficiency of community development programs.

The Community Renewal Initiatives was originally intended as a ten-year effort, but was extended twice before officially expiring on December 31, 2011. Unfortunately, the complex nature of the program and the difficulty in accounting for the use of the tax credits precludes a definitive evaluation of the program's performance and impact. However, there were visible indicators of positive change in some communities, as seen in the form of business start-ups and expansions, new employment opportunities, real estate developments and enhanced services for community residents. Based on my 
research, it would appear that there were successful attributes to the program, however the were not generalizable to all of the participating communities. Location-based economic development programs, particularly in urban areas, should work to maximize the intrinsic competitive advantage found in inner city communities, due to their strategic location near central business districts and at the heart of many metropolitan regions. In addition, these spatially targeted programs should institute policies that promote integration with regional clusters to strengthen access to networks, supply chains and procurement. Lastly, economic revitalization and job creation strategies like the federal Empowerment Zones should aim to tap into unmet local demand and human resources to maintain the integrity and unique character of these communities while adding value. 


\section{REFERENCES}

Annie E. Casey Foundation. (2002). Voices from the Empowerment Zones: Insights about launching large-scale community revitalization initiatives. Baltimore, Maryland.

Arthur, L. (2006. September 5). Overtown residents celebrate first homes. The Miami Herald. Retrieved March 13, 2012 from http://www.housingissues.org/floridacdc/articles/060925-1.html

Asia Pacific Foundation of Canada. (2005). Can India revitalize its special economic zones to rival those in China? Retrieved March 19, 2009, from http://www.asiapacific.ca/en/apbn/pdfs/bulletin244.pdf

Bates, T. (1997). Response: Michael Porter's conservative urban agenda will not revitalize America's inner cities: What will? Economic Development Quarterly, 11(1), 39-44.

Baum, H. S. (Summer 1999). Education and the empowerment zone: Ad hoc development of an interorganizational domain. Journal of Urban Affairs, 21(3), 289-308.

Billings, S. (2009). Do enterprise zones work? An analysis at the borders. Public Finance Review, 37(1), 68-93.

Blakely, E.J. \& Bradshaw, T.K. (2002). Planning local economic development: Theory and practice. Sage: Thousand Oaks, California.

Boarnet, M.G. \& Boagart, W. T. (September 1996). Enterprise zones and employment: Evidence from New Jersey. Journal of Urban Economics, 40(2), 198-215.

Bondonio, D. \& Greenbaum, R. (2007). Do local tax incentives affect economic growth? What mean impacts miss in the analysis of enterprise zone policies. Regional Science and Urban Economics, 37. 121-136.

Bondonio, D., \& Engberg, J. (2000). Enterprise zones and local employment: Evidence from the states' programs. Regional Science and Urban Economics, 30(5), 519549.

Bolton, R. (1992). Place prosperity versus people prosperity revisited: An old issue with a new angle. Urban Studies, 29, 185-203.

Boston, T.D. \& Ross, C.L. (1996, Winter). Responses to Michael Porter's Model of Inner of City Redevelopment. Review of Black Political Economy.

Boston, T.D. \& Ross, C.L. (1997). The inner city, urban poverty, and economic development in the next century. Transaction Publishers: New Jersey. 
Boyer, B., Gadow, B., Mills, N., \& Roberts, C. (May 2008). The North Dakota Wind Energy Cluster: An Economic Analysis. The State of North Dakota Department of Commerce. Retrieved on January 11, 2012 from http://www.hhh.umn.edu/centers/slp/economic_development/documents/NorthDa kota_Final.pdf

Busso, M. \& Kline, P. (February 1, 2008). Do local economic development programs work? Evidence from the federal empowerment zone program. (Discussion Paper No. 1638). New Haven, CT: Cowles Foundation, Yale University.

Butler, S. (1981). Enterprise zones: Greening the inner cities. New York: Universe Books.

Cain, A. (1999, July 08). Clinton pushes for investment in poor areas. The Washington Times, pp. A4.

Chan, E., \& Lee, G. K. L. (2007). Critical factors for improving social sustainability of urban renewal projects. Hong Kong: Hong Kong Polytechnic University.

Chan, N. H. L. (2006, April 15). Does strengthening inner city economies lead to respectively stronger regional economies? (Unpublished thesis for a Master of Public Policy). Georgetown University Press, Washington, DC.

Chaskin, R. J., \& Peters, C. M. (1997). Governance in empowerment zone communities: A preliminary examination of governance in fifteen empowerment zone communities. Chicago, IL: Chapin Hall Center for Children at the University of Chicago.

Cling, J. P., \& Letilly, G. (2001). Export processing zones: A threatened instrument for global economy insertion? No. DT/2001/17).DIAL/Unite de Recherche CIPRE Document de Travail.

Cobb, K. (2001, March 04). El Paso disappointed by empowerment - zone project. The Houston Chronicle, Performance of the empowerment Zone/Enterprise community program. Subcommittee on Oversight, House of Representatives, 105th Congress, First (1997).

Cramer, R.B. (1998). Local economic development planning in low-income urban America: The case of the Empowerment Zone and Enterprise Community Initiative. United States Department of Housing and Urban Development: Washington, DC.

Crane, R. \& Manville, M. (2008). People or Place? Revisiting the who versus the where of urban development. Land Lines: Lincoln Institute of Land Policy, 2-7.

Cummings, S. L. (2003, Fall). Between markets and politics: A response to Porter's competitive advantage thesis. Oregon Law Review, 82 (901). 38-63. 
Cuomo, A. \& Glickman, D. (1999). What works in empowerment zones and enterprise communities. No. Vol. IV). Washington, DC: U.S. Government Printing Office.

Dabney, D. (1991, November). Do enterprise zone incentives affect business location decisions? Economic Development Quarterly, 5 (4), 325-334.

Dávila, A. (2004). Empowered culture? New York city's empowerment zone and the selling of el barrio. The ANNALS of the American Academy of Political and Social Science, 594(1), 49-64.

DiPasqualie, D. \& Glaeser, E. (1999, March). Incentives and social capital: Are homeowners better citizens? Journal of Urban Economics, 45(2), 354-384.

Donovan, S. (2009, October 26). Toward a more sustainable future: Housing, place and the new federalism. Retrieved July 19, 2010, from http://portal.hud.gov/portal/page/portal/HUD/press/speeches_remarks_statements/ 2009/speech_10262009

Dorn, J. (2010, July/August). The rise of government and the decline of morality. The Freeman, 60(6), 2-18.

Dowall, D. (1996). An evaluation of California's Enterprise Zone Programs. Economic Development Quarterly, 10 (4), 352-368.

Engberg, J.B. (1996, January). Employment policy and urban economic development. Housing Policy Debate. 7(4), 695-714.

Ferguson, G. (2011, December 15). Personal interview.

Ferrara, P.J. (1982). The rationale for enterprise zones. The Cato Journal, 2(2).

Finnie, B. (2011, December 7). Personal interview.

Forbes, J. (2006, Winter). Using economic development programs as tools for urban revitalization: A comparison of empowerment zones and new markets tax credits. University of Illinois Law Review, 1, 177-203.

Foreign Investment Advisory Service. (2008, April). Special economic zones: Performance, lessons learned, and implications for zone development. Washington, D.C.: The World Bank Group.

Frankfort-Nachmias, C. \& Leon-Guerrero, A. (2011). Social statistics for a diverse society. ( $6^{\text {th }}$ ed.). Thousand Oaks, CA: Pine Forge Press.

Fredericksen, P., \& London, P. (2000). Disconnect in the hollow state: The pivotal role of organizational capacity in community-based development organizations. Public Administration Review, 60(3), 230-239. 
Frederickson, D. G., \& Frederickson, H. G. (2007). Measuring the performance of the hollow state. Washington, DC: Georgetown University Press.

Gelder, A., \& Democrat-Gazette, A. (2002, February 07). Bush plan saps empowerment zones budget proposal cuts funds, but won't affect LR, NLR programs. Arkansas Democrat-Gazette.

Gilbert, N. (2011, August 9). Personal interview.

Gilbert, V. B. (2003, December 2). In the zone. St. Louis Post-Dispatch, C1.

Gilbert, V. B. (2003, December 2). Program aids redevelopment in depressed neighborhoods. St. Louis Post-Dispatch,

Gittell, M., Newman, K. \& Pierre-Louis, F. (2001). Empowerment zones: An opportunity missed. A six-city comparative study. New York, NY: The Howard Samuels State Management and Policy Center, The Graduate School and The University Center of the City University of New York.

Glekas-Spring, P. (2011, August 9). Personal interview.

Goldsby, D. (2011, December 16). Personal interview.

Goonan, P. (2009, October 11). Need still greatest in poor cities. The Republican, C01.

Goozner, M. (1998, May-June). The Porter prescription. The American Prospect. 38, 5664.

Green, R. E. (1991). Enterprise zones: New direction in economic development. Newbury Park, CA: Sage Publication.

Greenbaum, R. T., \& Landers, J. (2009). Why are state policy makers still proponents of enterprise zones? What explains their action in the face of a preponderance of the research? International Regional Science Review, 32(4), 466-479.

Grotto, J. (2007, June 24). Developer reaped millions for biotech park never built. The Miami Herald. Retrieved on October 14, 2008 from http://www.miamiherald.com/multimedia/news/povped/part1/index.html

Grotto, J. (2007, June 25). Stalled Liberty City project go insiders' help. The Miami Herald. Retrieved on October 14, 2008 from http://www.miamiherald.com/multimedia/news/povped/part2/index.html

Grotto, J. (2007, June 26). Biotech bid stung Opa-locka. The Miami Herald. Retrieved on October 14, 2008 from http://www.miamiherald.com/multimedia/news/povped/part3/index.html 
Grotto, J. \& Hiassen, S. (2007, October 3). Millions for deals, not for merchants. The Miami Herald. Retrieved on October 14, 2008 from http://www.miamiherald.com/multimedia/news/povped/part7/index.html

Gyourko, J. (1998). Place-baseed aid versus people-based aid and the role of an urban audit in a New Urban Strategy. Cityscape: A Journal of Policy Development and Research, 3(3), 205-229.

Haines, J. (2011, August 9). Personal interview.

Haines, J. (2012, September 10). Personal interview.

Hall, P. (1982). Enterprise zones: A justification. International Journal of Urban and Regional Research. 6, 418-439.

Handler, A. M. (1993). Empowerment zones and other business incentives may provide only limited benefits. The Journal of Taxation, 79(5), 274-277.

Hardison, D. (1981). From ideology to incrementalism: The concept of urban enterprise zones in Great Britain and the United States. Princeton, NJ: Princeton Urban and Regional Research Center, Woodrow Wilson School of Public and International Affairs, Princeton University.

Harrison, B., \& Glasmeier, A. K. (1997, February). Why business alone won't redevelop the inner-city: A friendly critique of Michael Porter's approach to urban revitilization. Economic Development Quarterly, 11(1), 28-38.

Hebert, S., James, F., Vidal, A., Gruenstein, D. \& Mills, G. (2001, November). Interim assessment of the Empowerment Zones and Enterprise (EZ/EC) Program: A progress report appendices. United States Department of Housing and Urban Development: Washington, D.C.

Hiassen, S. \& Grotto, J. (2007, September 30). Projects produce few jobs. The Miami Herald. Retrieved on October 14, 2008 from http://www.miamiherald.com/multimedia/news/povped/part4/index.html

Hiassen, S. \& Grotto, J. (2007, October 1). Agency hypes phantom jobs. The Miami Herald. Retrieved on October 14, 2008 from http://www.miamiherald.com/multimedia/news/povped/part5/index.html

Hiassen, S. \& Grotto, J. (2007, October 2). Political insiders got poverty funds. The Miami Herald. Retrieved on October 14, 2008 from http://www.miamiherald.com/multimedia/news/povped/part6/index.html

Hilton, T. \& Immergluck, D. (1996, November). Breaking down barriers: Prospects and policies for linking jobs and residents in the Chicago Empowerment Zone. Woodstock Institute: Chicago, IL. 
Holzer, H.J. (1991). The spatial mismatch hypothesis: what has the evidence shown? Urban Studies, 28, 105-122.

Holzer, H.J. (1996). What employers want: Job prospects for the disadvantaged. In Freeman R.B. \& Gottschalk, P. (Eds.) Generating jobs: How to increase demand for less-skilled workers. New York: Russell Sage Foundation.

Holzer, H.J. (2000). Mismatch in the low-wage labor market: Job hiring perspective. In K. Kaye, \& D. S. Nightingale (Eds.), The low-wage labor market: Challenges and opportunities for economic self-sufficiency (pp. 127-144). Washington, DC: U.S. Department of Health and Human Services.

Holzer, H.J. (2004). Advancement for low-wage workers: A different approach. Welfare Reform and Beyond Policy Brief. Washington, DC: Brookings Institution.

Holzer, H.J. Raphael, S. \& Stoll, M. (2004). How willing are employers to hire exoffenders? Focus, 23 (2). 40-43.

Hyman, W. (1998, Winter). Empowerment zones, enterprise communities, black business and unemployment. Washington University Journal of Urban and Contemporary Law, 53, 143-169.

Immergluck, D. (1996). Breaking down the barriers: Prospects and policies for linking jobs and residents in the Chicago empowerment zone. Chicago, IL: Woodstock Institute.

Initiative for a Competitive Inner City. (2009, October 5). The federal role in supporting inner city business development. Metropolitan Policy Program. Boston, MA: Brookings Institution.

Initiative for a Competitive Inner City. (2011). Strategies and best practices for growing inner city economies and creating jobs. Retrieved on May 1, 2012 from http://www.icic.org/urban-economic-development/insights-and-strategies

Initiative for a Competitive Inner City. (2011, January). The promise of local clusters. Inner City Insights, 1 (1). 1-6.

International Monetary Fund, Organisation for Economic Co-operation and Development, United Nations, \& World Bank Group. (2000). A better world for all: Progress towards the international development goals. Washington, DC: Communications Development.

Johnson Jr., J. H., Farrell Jr., W. C., \& Henderson, G. R. (1996, Fall/Winter). Mr. Porter's "competitive advantage for inner-city revitalization: Exploitation or empowerment? The Review of Black Political Economy, 
Kain, J.F. (1968). Housing segregation, Negro employment, and metropolitan decentralization. The Quarterly Journal of Economics. 82 (2). 175-197.

Kain, J.F. (1993). The spatial mismatch hypothesis: three decades later. Housing Policy Debate. 3(2). 371-392.

Kasarda, J. (1985). Urban change and minority opportunity. In P. E. Patterson (Ed.), The new urban reality (pp. 33-68). Washington, DC: Brookings Institution.

Kaufman, M., \& Writer, I. S. (1995, JULY 27). Clinton has bold words for mayors empowerment zones are the way of the future, he said, with success crucial. The Philadelphia Inquirer, pp. B01.

Kaye, K., \& Nightingale, D. S. (Eds.). (2000). The low-wage labor market: Challenges and opportunities for economic self-sufficiency. (2nd ed.). Washington, DC: U.S. Department of Health and Human Services.

Keating, W.D. (1999). Rebuilding urban neighborhoods: Achievements, opportunities, and limits. Sage Publications: Thousand Oaks, CA.

Kettl, D.F. (2000). The global public management revolution (2nd ed.). Washington, DC: Brookings Institution Press.

Knudsen, D. C. (2000). Shift-share analysis: Further examination of models for the description of economic change. Socio-Economic Planning Sciences, 34(3), 177.

Kolko, J., \& Neumark, D. (2010). Do some enterprise zones create jobs? Journal of Policy Analysis and Management, 29(1), 5-38. doi:10.1002/pam.20477

Krupka, D. J., \& Noonan, D. S. (2007). Neighborhood dynamics and superfund: Direct and indirect effects on property values. Meeting of the International Atlantic Economic Society, Savannah, GA.

Krupka, D. J., \& Noonan, D. S. (2009). Empowerment zones, neighborhood change and owner-occupied housing. Regional Science and Urban Economics, 39(4), 386396.

Ladd, H. F. (1994). "Spatially Targeted Economic Development Strategies: Do They Work?" Cityscape 1(1): 193-218.

Larson, T. (2003, June.). Why there will be no chain supermarkets in poor inner-city neighborhoods. California Politics and Policy, 7(1), 22-45.

Lavin, M. \& Whysall, P. (2004). From enterprise to empowerment: The evolution of an anglo-american approach to strategic urban economic regeneration. Strategic Change, 13(4), 219-229. doi:10.1002/jsc.681 
Lemann, N. (1994, January). The myth of community development. Housing Policy Debate. 6(3), 27-31, 50, 54, 60.

Liebschutz, S. F. (1995, Summer). Empowerment zones and enterprise communities: Reinventing federalism for distressed communities. Publius, 25(3), 117-160.

Light, P.C. (1999). The true size of government. Washington, DC: Brookings Institution Press.

Loukaitou-Sideris, A. (2000, May). Revisiting inner-city strips: Framework for community and economic development. Economic Development Quarterly, 14(2), 165-181.

Lundy, A. (2011, December 6). Personal interview.

Lynch, T. \& Rho, L. (2011, April). Capital availability in inner cities: What role for federal policy? ICIC Research. Retrieved on May 1, 2012 from http://www.icic.org/ee_uploads/publications/IC_Capital_Access_Brief_For_ICIC -Website1.pdf

Madani, D. (1999). A review of the role and impact of export processing zones. No. Policy Research Working Paper 2238). Washington, DC: World Bank Development Research Group.

Madden, M., \& Staff, I. S. (1999, January 14). Its new empowerment excites Cumberland with $\$ 100$ million in federal funds, a small county expects a big boost. The Philadelphia Inquirer, B01.

Mannies, J. (1994, May 5). St. Louis, KC in hot pursuit of $\$ 100$ million. St. Louis PostDispatch, 5B.

Martinez, E. (2012, February 1). Telephone interview.

McFarlane, A.G. (1995, January). Empowerment Zones: Urban revitalization through collaborative enterprise. Journal of Affordable Housing. 5(1), 35-53.

McKnight, I. (2011, December 1). Personal interview.

Milner, H. V. (2005, December). Globalization, development, and international institutions: Normative and positive perspectives. Perspectives on Politics, 3(4), 833-854.

Milward, H. B., \& Provan, K. G. \& Else, B. (1993). What does the hollow state look like? In B. Bozeman (Ed.), Public management: The state of the art. (). San Francisco, CA: Jossey-Bass. 
Milward, H. B., \& Provan, K. G. (2000). Governing the hollow state. Journal of Public Adminstration Research and Theory, 2, 359-379.

Mossberger, K. (2000). The politics of ideas and the spread of enterprise zones. Washington, DC: Georgetown University Press.

Mossberger, K. (2009). State-federal diffusion and policy learning: From enterprise zones to empowerment zones. Publius, 3(31), 50.

Mulock, B. K. (2002, October 22). Empowerment Zone/Enterprise communities program: Overview of rounds I, II, and III. (CRS Report for Congress No. RS20381). CRS Web.

Neumark, D. \& Kolko, J. (2010, July). Do enterprise zones create jobs? Evidence from California's enterprise zone program. Journal of Urban Economics, 68 (1). 1-19.

Newman, K., \& Ashton, P. (2004). Neoliberal urban policy and new paths of neighborhood change in the American inner city. Environment and Planning, 1151-1172.

Nicklaus, D. (1999, October 6). Benefits from St. Louis -area empowerment zone appear lost. St. Louis Post-Dispatch,

Nicklaus, D., \& Post-Dispatch, O. T. (1999, October 6). Anticipated economic boost appears lost. St. Louis Post-Dispatch,

O'Keefe, S. (2004, January). Job creation in California's enterprise zones: A comparison using propensity score matching model. Journal of Urban Economics, 55 (1). 131-150.

Oakley, D. and Tsao H.S. (2006). A new way of revitalizing distressed urban communities? Assessing the impact of the federal empowerment zone program. Journal of Urban Affairs, 28(5), 443-471.

O'Gara, J. F. X. (1997, July 1). Leveraging big government bucks. The Washington Times, A17.

O'Neal, G. G. S. (2003). Community development in the USA: An empowerment zone example. Community Development Journal, 38(2), 120-129.

Papke, L. E. (1994). Tax policy and urban development: Evidence from the Indiana enterprise zones program. Journal of Public Economics, 54, 34-49.

Parish, N. (1999, January 13). Region may get up to $\$ 100$ million in economic aid. St. Louis Post-Dispatch, B04. 
Peters, A. H., \& Fisher, P. S. (2002). State enterprise zones programs: Have they worked? Kalamazoo, MI: W.E. Upjohn Institute.

Pitcoff, W. (2009, December 19). EZ'er said than done. National Housing Institute Shelterforce Online, 112.

Porter, M. E. (1995, May-June). The competitive advantage of the inner city. Harvard Business Review, 73 (3), 55-71.

Porter, M. E. (1996). An economic strategy for America's inner cities: Addressing the controversy. The Review of Black Political Economy, 24, 2-3, 303-336.

Porter, M. E. (1997). New strategies for inner-city economic development. Economic Development Quarterly, 11(1), 11-27. doi:10.1177/089124249701100102

Porter, M. E. (2000, February). Location, competition, and economic development: Local clusters in a global economy. Economic Development Quarterly, 14(1), 15-34.

Porter, M. E. (2004). An economic strategy for America's inner cities: Addressing the controversy. The Review of Black Political Economy, 2(303), 336.

Pressman, J. \& Wildavsky, A. (1984). Implementation: How great expectations in Washington are dashed in Oakland; or why it's amazing that federal programs work at all, this being a saga of the Economic Development Administration as told by two sympathetic observers who seek to build morals on a foundation of ruined hopes. Berkeley, California: University of California Press.

Quintero, J.P., (2007). Regional Economic Development: An Economic Base Study and Shift-Share Analysis of Hays County, Texas. Applied Research Projects, Texas State University-San Marcos. Paper 259. http://ecommons.txstate.edu/arp/259

Rabin, C. (2011, November 15). Miami-Dade Commission ponders fire union contract, new plan for failed bio-tech park site. The Miami Herald. Retrieved on March 21, 2012 from http://www.miamiherald.com/2011/11/15/2502459/miami-dadecommission-ponders.html.

Rabin, C. (2011, November 16). Neglected Liberty City property to have a new public health clinic soon. The Miami Herald. Retrieved on March 21, 2012 from http://www.miamiherald.com/2011/11/16/2505640/neglected-liberty-cityproperty.html

Reingold, D. A. (1999). Inner-city firms and the employment problem of the urban poor: Are poor people really excluded from jobs located in their own neighborhoods? Economic Development Quarterly, 13(4), 291-306. 
Rich, M. J., \& Stoker, R. P. (2007). Governance and urban revitalization: Lessons from the urban EZ initiative. Conference on A Global Look at Urban and Regional Governance. Atlanta, GA.

Rich, M. J., \& Stoker, R. P. (2010). Rethinking empowerment: Evidence from local empowerment zone programs. Urban Affairs Review, 45(6), 775-796. doi:10.1177/1078087410366530

Riposa, G. (1996, March-April). From enterprise zones to empowerment zones: The community context of urban economic development. American Behavioral Scientist, 39(5), 536-552.

Robinson, M. W. (1995, Spring). Empowerment zones and enterprise communities under the omnibus budget and reconciliation act of 1993: A promising concept with some modifications. The Journal of Law and Politics, 11(2), 345-379.

Rubin, M. M. (1994, March-April). Can reorchestration of historical themes reinvent government? A case study of the empowerment zones and enterprise communities act of 1993. Public Administration Review, 54(2), 161-169.

Samuel, T., \& Bureau, P. W. (1998, May 17). Local leaders will try new tactic to win federal funds: Cooperation; St. Louis and E. St. Louis want a joint proposal for an empowerment zone'; but their efforts are disorganized. St. Louis Post-Dispatch,

Sawicki, D.S. \& Moody, M. (1999). Deja-Vu All Over Again: Porter's Model of InnerCity Redevelopment. In The Inner City: Urban Poverty and Economic Development in the Next Century, ed. Thomas D. Boston and Catherine L. Ross. New Brunswick, NJ: Transaction Publishers.

Sit, V. (1985). The special economic zones of China: A new type of export processing zone? Development Economics. 23(1), 69-86.

Stelzer, C. D. (1999, November 10). The big fix; A desperate St. Louis pays top dollar to gamble on a risky convention-center hotel. Riverfront Times,

Stoker, R. (2004, September 2). Urban regimes and community empowerment: Lessons from the empowerment zones in Atlanta and Baltimore. Paper presented at the Annual Meeting of the American Political Science Association. Chicago, IL.

Stoll, M. (2004). Workforce development in the information technology age. In Melendez, E. (Ed.), Communities and Workforce Development. Kalamazoo, MI: W.E. Upjohn Institute for Employment Research.

Stoll, M. (2005). Geographic skills mismatch, job search and race. Urban Studies. 42(4), 695-717. 
Stonehouse, G. \& Snowdon, B. (2007, September). Competitive advantage revisited: Michael Porter on Strategy and Competitiveness. Journal of Management Inquiry. 16(3), 256-273.

Teitz, M. B., \& Chapple, K. (1998). The causes of inner-city poverty: Eight hypotheses in search of reality. Cityscape, 3(3).

Trade and Industry Department, The government of the Hong Kong Special Administrative Region. (2008, December). Trade and industry department fact sheet.

Tsang, S. (2004). A modern history of Hong Kong. London: I.B. Tauris.

Turner, G. (2009, November 19). Boston connects to end after 10 years. The Boston Herald, pp. 027.

Tweh, B. (2011, April 24). Empowerment Zone shows underwhelming results. The Times. Retrieved on November 15, 2011 from http://www.nwitimes.com/news/local/lake/gary/article_68d40620-876d-586daa86-d0db46e546bc.html

United Nations Development Programme (1996). Human Development Report. New York: Oxford University Press.

United States Census Bureau. (2007, July). Summary File 3: 2000 Census of Population and Housing. Retrieved on April 4, 2009 from http://www.census.gov/prod/cen2000/doc/sf3.pdf\#page=933

United States Congress. House Committee on Small Business. (2001). The future of round II empowerment zones. Washington: U.S. G.P.O.: Congressional Sales Office, Supt. of Docs., U.S. G.P.O., distributor.

United States Department of Housing and Urban Development (2004). Spotlight on Results: Capturing Successes in Renewal Communities and Empowerment Zones. Washington, DC: U.S. Government Printing Office.

United States Department of Housing and Urban Development. (1994). Building communities together. Washington, DC: U.S. Government Printing Office.

United States Department of Housing and Urban Development. (2008, January 30). $R C / E Z$ Initiative Timeline. Retrieved on November 10, 2008 from www.hud.gov/offices/cpd/economicdevelopment/programs/rc/about/timeline.cfm

United States Department of Housing and Urban Development. (2009, August 3). Welcome to the Community Renewal Initiative: Key principles. Retrieved on October 21, 2009 from 
http://www.hud.gov/offices/cpd/economicdevelopment/programs/rc/about/keypri ncipals.cfm

United States Department of Housing and Urban Development. (2010, January 26).

Welcome to the Community Renewal Initiative: Update. Retrieved on February 16,2010 from

http://www.hud.gov/offices/cpd/economicdevelopment/programs/rc/

United States Department of Housing and Urban Development. (2011). RC/EZ Initiative Timeline. Retrieved on September 15, 2011 from

www.hud.gov/offices/cpd/economicdevelopment/programs/rc/about/timeline.cfm

United States Department of Housing and Urban Development. (n.d.). Introduction to the $R C / E Z$ Initiative. Retrieved on November 5, 2008 from

www.hud.gov/offices/cpd/economicdevelopment/programs/rc/about/ezecinit.cfm.

United States General Accounting Office \& United States Congress House Committee on Government Reform and Oversight Subcommittee on Human Resources and Intergovernmental Relations. (1996). Community development microform: Status of urban empowerment zones: Report to the chairman, subcommittee on human resources and intergovernmental relations, committee on government reform and oversight, House of Representatives. Washington, DC: U.S. Government Printing Office.

United States General Accounting Office. (1997, October). Community development: The federal empowerment zone and enterprise community program. No. T-RCED-9827). Washington, DC: United States Government Printing Office.

United States General Accounting Office. (1998, November). Community development: Progress on economic development activities varies among the empowerment zones. No. RCED-99-29). Washington, DC: United States Government Printing Office.

United States General Accounting Office. (1999, September). Community development: Businesses' use of empowerment zone tax incentives. No. GAO/RCED-99-253). Washington, DC: United States Government Printing Office.

United States Government Accountability Office. (1996, December). Community development: Status of urban Empowerment Zones (RCED-97-21). Washington D.C.: U.S. Government Printing Office.

United States Government Accountability Office. (2004, March). Community development: Federal revitalization programs are being implemented, but data on the use of tax benefits are limited. No. GAO-04-306). Washington, DC: United States Government Printing Office. 
United States Government Accountability Office. (2006, September). Empowerment zone and enterprise community program: Improvements occurred in communities, but the effect of the program is unclear. No. GAO-06-727). Washington, DC: United States Government Printing Office.

United States Government Accountability Office. (2010, March). Revitalization programs: Empowerment zones, enterprise communities, and renewal communities. No. GAO-10-464R). Washington, DC: United States Government Printing Office.

United States Internal Revenue Service. (1993). Tax incentives for empowerment zones \& enterprise communities. Washington, D.C.: Dept. of the Treasury, Internal Revenue Service.

Velez, P. (2011, December 12). Personal interview.

Waits, M.J., Rex, T., \& Melnick, R. (1997, April). Cluster analysis: A new tool for understanding the role of the inner city in a regional economy. Phoenix, Arizona: Arizona State University.

Wallace, M. (2003). An analysis of presidential preferences in the distribution of empowerment zones and enterprise communities. Public Administration Review, 63(5), 562-572. doi:10.1111/1540-6210.00320

Wallace, M. A. (2004, Winter). Congressional considerations and urban characteristics in the selection of empowerment zones and enterprise communities. Journal of Urban Affairs, 26(5), 593-610.

Weiler, S., Silverstein, J., Chalmers, K., Lacey, E., Rogers, W., \& Widner, B. (2003, December). Understanding the retail business potential of inner cities. Journal of Economic Issues, 37(4), 1075.

Winnick, L. (1966). Place prosperity versus people prosperity: Welfare consideration in the geographic redistribution of economic activity. Real Estate Research Program, UCLA, Essays in Urban Economics in Honor of the Sixty-Fifth Birthday of Leo Grebler, 273-283.

World Bank Group. (2000). Beyond economic growth: Meeting the challenges of global development. Retrieved February 19, 2009, from http://www.worldbank.org/depweb/beyond/global/chapter1.html

World Commission on Environment and Development. (1987). Brundtland Report. Retrieved on November 4, 2009 from http://www.are.admin.ch/themen/nachhaltig/00266/00540/00542/index.html

Wright, D.J. (2004). Empowerment Zones/Enterprise communities: Implementing a new program. Washington, DC: Brookings Institute. 


\section{APPENDIX TABLE OF CONTENTS}

APPENDIX $\quad$ PAGE

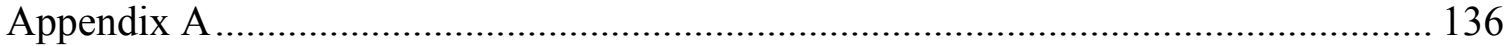

I. Empowerment Zone (EZ) Census Tract to Zip Code Tabulation........................ 136

II. Detailed information for each of the fifteen (15) Round II Urban EZs .............. 136

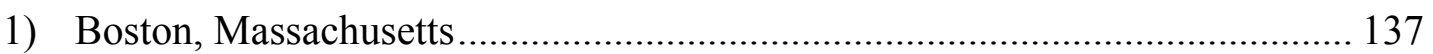

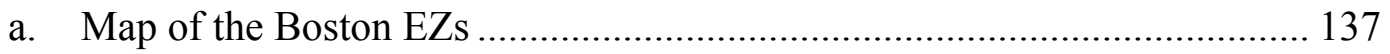

b. Boston Census Tracts and corresponding Zip Codes ................................. 137

c. Boston EZ Business Growth Rate........................................................... 138

d. Boston EZ Employment Growth rate ...................................................... 138

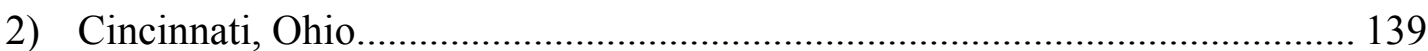

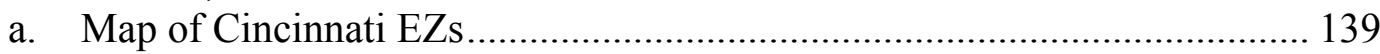

b. Cincinnati Census Tracts and corresponding Zip Codes ............................. 139

c. Cincinnati Business Growth Rate .............................................................. 140

d. Cincinnati Employment Growth Rate...................................................... 140

3) Columbia, South Carolina/ Sumter, South Carolina........................................ 140

a. Map of Columbia and Sumter EZs .......................................................... 140

b. Columbia/Sumter Census Tracts and corresponding Zip Codes .................. 141

c. Columbia/Sumter Business Growth Rate ................................................... 141

d. Columbia/Sumter Employment Growth rate .............................................. 141

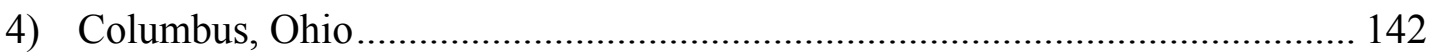

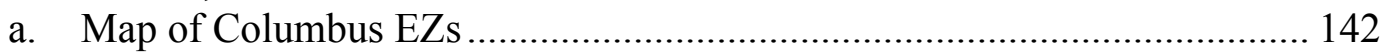

b. Columbus Census Tracts and corresponding Zip Codes ............................. 142

c. Columbus EZ Business Growth Rate ......................................................... 143

d. Columbus EZ Employment Growth rate ……………............................... 143

e. Columbus Location Quotient (LQ), compared to the Columbus, OH Metro

Statistical Area (MSA) in 1998....................................................................... 143

f. Columbus Location Quotient, compared to the Columbus, OH Metro

Statistical Area (MSA) in 2007............................................................... 144

g. Columbus, OH Metro Statistical Area (MSA) Location Quotient, compared to

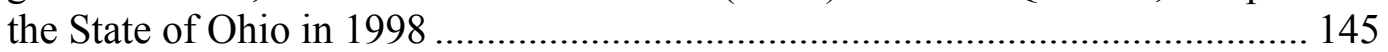

h. Columbus, OH Metro Statistical Area (MSA) Location Quotient, compared to

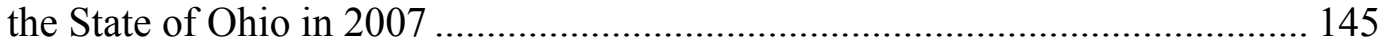

5) Cumberland County, New Jersey ................................................................. 146

a. Map of the Cumberland County EZs …………………................................ 146

b. Cumberland Census Tracts and corresponding Zip Codes ........................... 146

c. Cumberland EZ Business Growth Rate ……………................................... 147

d. Cumberland EZ Employment Growth rate ................................................. 147 


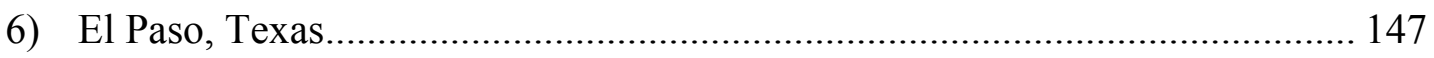

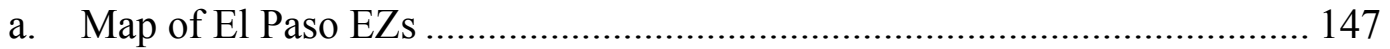

b. El Paso Census Tracts and corresponding Zip Codes................................. 147

c. El Paso EZ Business Growth Rate.......................................................... 148

d. El Paso EZ Employment Growth rate.......................................................... 148

7) Gary, Indiana/ East Chicago, Indiana/ East Hammond, Indiana ...................... 149

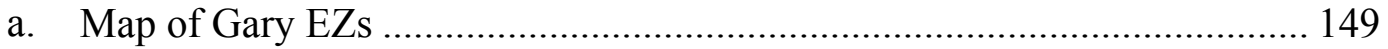

b. Gary Census Tracts and corresponding Zip Codes...................................... 149

c. Gary EZ Business Growth Rate ………………........................................ 150

d. Gary EZ Employment Growth rate.......................................................... 150

8) Huntington, Ohio/ Ironton, West Virginia..................................................... 150

a. Map of Huntington EZs ......................................................................... 150

b. Huntington Census Tracts and corresponding Zip Codes.............................. 151

c. Huntington EZ Business Growth Rate......................................................... 151

d. Huntington EZ Employment Growth rate..................................................... 151

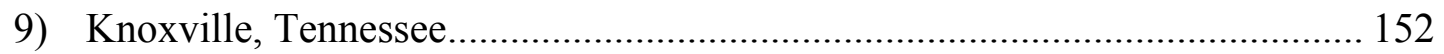

a. Map of the Knoxville EZs..................................................................... 152

b. Knoxville Census Tracts and corresponding Zip Codes................................. 152

c. Knoxville EZ Business Growth Rate ………………................................... 153

d. Knoxville EZ Employment Growth rate........................................................ 153

10) Miami-Dade County, Florida ........................................................................ 153

a. Miami-Dade County Map of EZ Census Tracts designated by HUD ......... 153

b. Miami-Dade County Census Tracts and corresponding Zip Codes.............. 154

c. Miami-Dade County Business Growth Rate................................................ 154

d. Miami-Dade County Employment Growth rate ......................................... 154

e. Miami-Dade County Location Quotient (LQ), compared to the Miami, Ft. Lauderdale-Pompano Beach, FL Metro Statistical Area (MSA) in 1998........... 155

f. Miami-Dade County Location Quotient (LQ), compared to the Miami, Ft. Lauderdale-Pompano Beach, FL Metro Statistical Area (MSA) in 2007........... 155

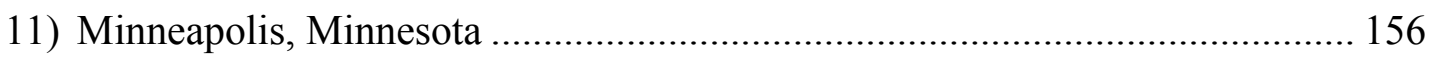

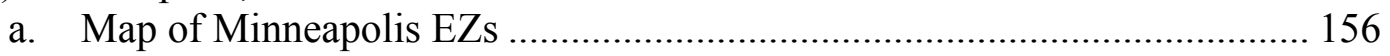

b. Minneapolis Census Tracts and corresponding Zip Codes........................... 156

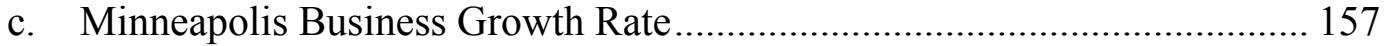

d. Minneapolis Employment Growth rate....................................................... 157

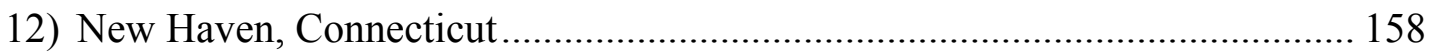

a. Map of New Haven EZs .......................................................................... 158

b. New Haven Census Tracts and corresponding Zip Codes............................ 158

c. New Haven Business Growth Rate........................................................ 158

d. New Haven Employment Growth rate.......................................................... 159 
13) Norfolk, Virginia/ Portsmouth, Virginia ………………………………......... 159

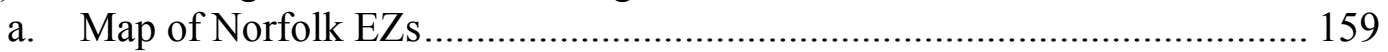

b. Norfolk Census Tracts and corresponding Zip Codes .................................. 159

c. Norfolk Business Growth Rate ................................................................. 160

d. Norfolk Employment Growth rate .................................................................. 160

e. Norfolk Location Quotient, compared to the Virginia Beach-NorfolkNewport News, VA-NC Metropolitan Statistical Area (MSA) in 1998.............. 161

f. Norfolk Location Quotient, compared to the Virginia Beach-NorfolkNewport News, VA-NC Metropolitan Statistical Area (MSA) in 1998 .............. 161

g. Virginia Beach-Norfolk-Newport News, VA-NC Metro Statistical Area (MSA) Location Quotient, compared to the State of Virginia in 1998 .............. 162 h. Virginia Beach-Norfolk-Newport News, VA-NC Metro Statistical Area (MSA) Location Quotient, compared to the State of Virginia in 2007 .............. 163

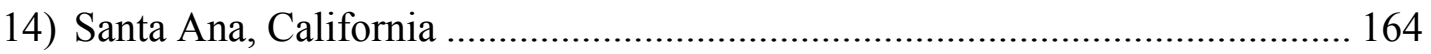

a. Santa Ana Map of EZ Census Tracts designated by HUD ........................... 164

b. Santa Ana Census Tracts and corresponding Zip Codes .............................. 164

c. Santa Ana Business Growth Rate ............................................................. 164

d. Santa Ana Employment Growth rate ............................................................. 164

e. Santa Ana Location Quotient (LQ), compared to the Los Angeles-Long

Beach-Santa Ana, CA Metropolitan Statistical Area (MSA) in 1998 ................ 165

f. Santa Ana Location Quotient (LQ), compared to the Los Angeles-Long

Beach-Santa Ana, CA Metropolitan Statistical Area (MSA) in 2007 ................ 165

g. Los Angeles-Long Beach-Santa Ana, CA Metro Statistical Area (MSA)

Location Quotient, compared to the State of California in 1998 ......................... 166

h. Los Angeles-Long Beach-Santa Ana, CA Metro Statistical Area (MSA)

Location Quotient, compared to the State of California in 2007 ......................... 167

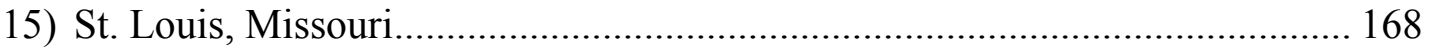

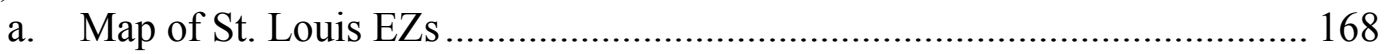

b. St. Louis Census Tracts and corresponding Zip Codes .............................. 168

c. St. Louis Business Growth Rate ............................................................... 169

d. St. Louis Employment Growth rate ......................................................... 169

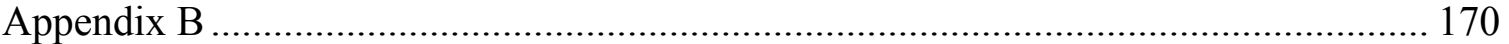

I. Statistical Models Tables and Charts............................................................... 170

1) Model A: Change in Business .................................................................... 170

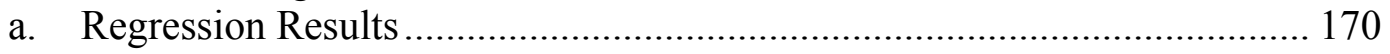

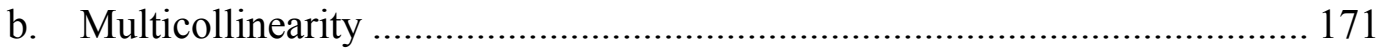

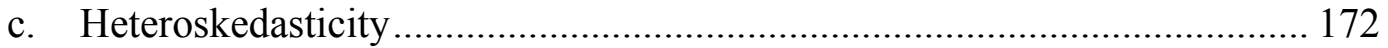

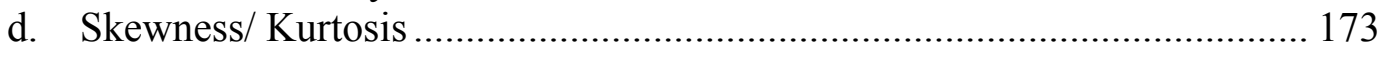

2) Model B: Change in Employees................................................................. 173

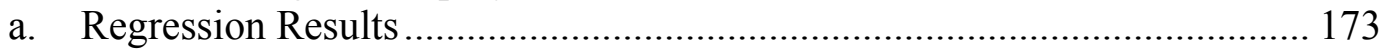

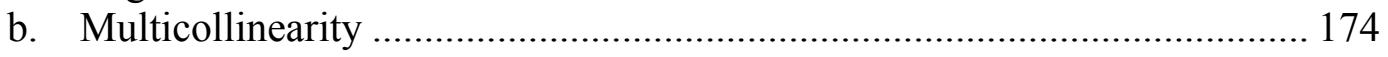

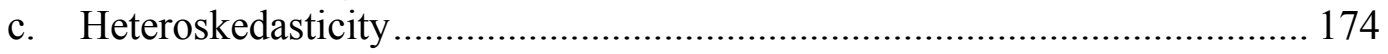


d. Skewness/ Kurtosis .......................................................................... 175

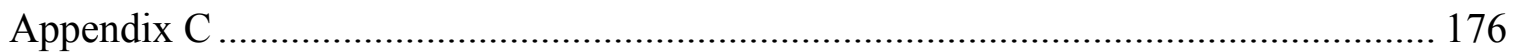

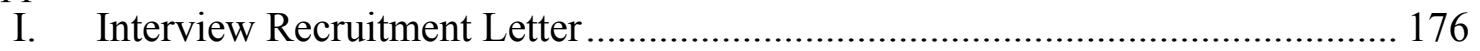

II. Interview Consent Form ............................................................................ 178

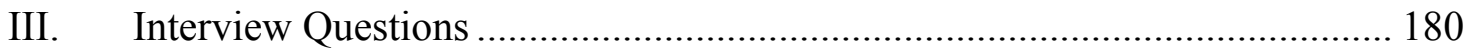

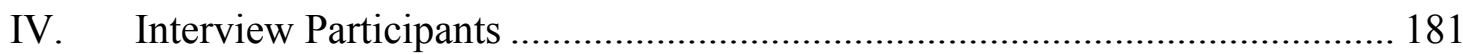




\section{Appendix $A$}

I. Empowerment Zone (EZ) Census Tract to Zip Code Tabulation ${ }^{8}$

\begin{tabular}{lcc}
\hline Round II EZs & $\begin{array}{c}\text { EZ Census } \\
\text { Tracts }\end{array}$ & $\begin{array}{c}\text { Corresponding } \\
\text { Zip Codes }\end{array}$ \\
\hline Boston, MA & 28 & 8 \\
Cincinnati, OH & 21 & 6 \\
Columbia, SC/ Sumter, SC & 18 & 5 \\
Columbus, OH & 21 & 6 \\
Cumberland County, NJ & 5 & 2 \\
El Paso, TX & 12 & 5 \\
Gary, IN/ Hammond, IN/ East Chicago, IN & 25 & 6 \\
Huntington, WV/ Ironton, OH & 12 & 6 \\
Knoxville, TN & 19 & 6 \\
Miami-Dade County, FL & 14 & 7 \\
Minneapolis, MN & 22 & 8 \\
New Haven, CT & 10 & 4 \\
Norfolk, VA/ Portsmouth, VA & 21 & 7 \\
Santa Ana, CA & 7 & 3 \\
St. Louis, MO & 26 & 9 \\
\hline TOTAL & $\mathbf{2 6 1}$ & $\mathbf{8 8}$ \\
\hline
\end{tabular}

II. Detailed information for each of the fifteen (15) Round II Urban EZs, i. Maps of the designated communities ${ }^{9}$

ii. EZ census tracts and corresponding zip codes ${ }^{11}$

iii. Local business and employment growth rates from 1998 to $2007^{10}$

iv. Location Quotients tables for 1998 and $2007^{11}$

v. Shift-Share Analysis tables from 1998 to 2007

${ }^{8}$ Based on the Census Bureau website's "Geo within Geo" detailed tables for 2000 Decennial Census Data

${ }^{9}$ Maps and data downloaded from the HUD Office of Community Renewal website, available at http://www.hud.gov/offices/cpd/economicdevelopment/programs/rc/index.cfm

${ }^{10}$ Local Business and Employment Growth Rates (percentage change) were determined with public data on the number of establishments and employees using Zip Code Business Patterns (NAICS), available from the United States Census website at http://censtats.census.gov/cbpnaic/cbpnaic.shtml

${ }^{11}$ Industries with an asterisk (*) have a Location Quotient equal or greater than 1.0, which means they are highly concentrated in the local area compared to the overall Metropolitan Statistical Area and can be considered local industry clusters 


\section{1) Boston, Massachusetts}

a. Map of the Boston EZs

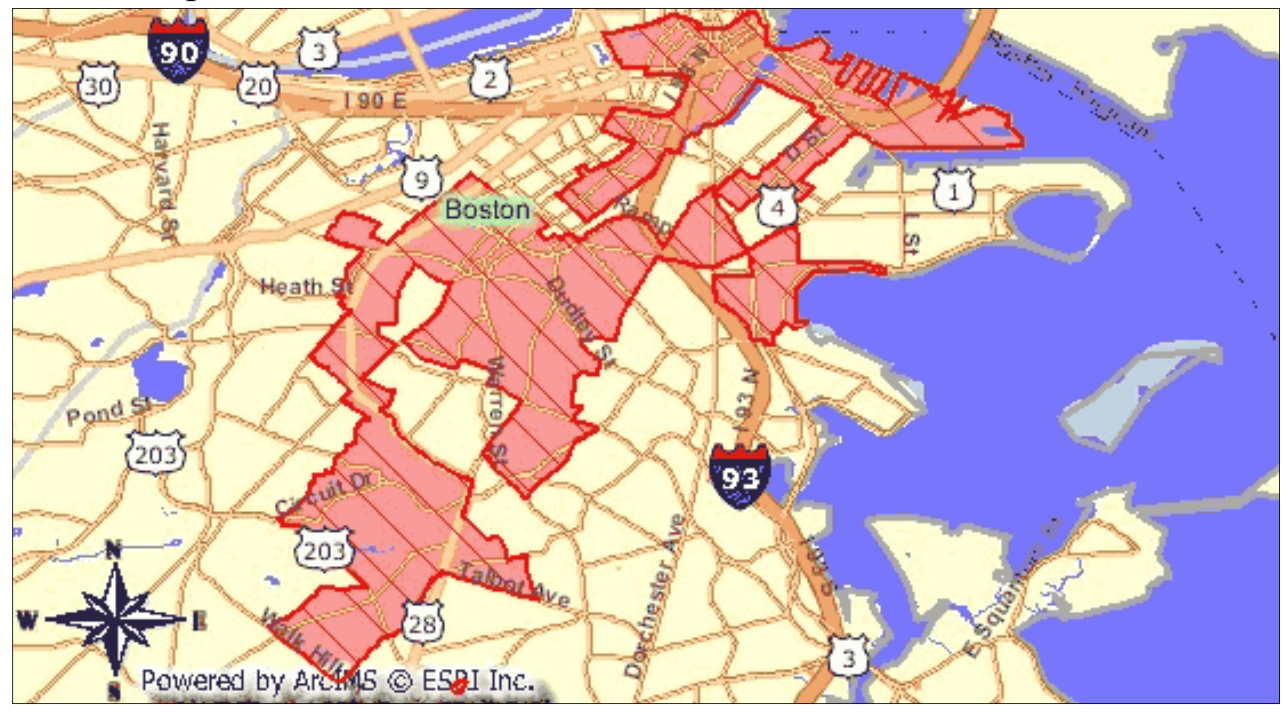

b. Boston Census Tracts and corresponding Zip Codes

\begin{tabular}{lcc}
\hline County & Census Tracts & Zip Codes \\
\hline Suffolk, MA & 606 & 02127 \\
Suffolk, MA & 607 & 02127 \\
Suffolk, MA & 610 & 02127 \\
Suffolk, MA & 611 & 02125 \\
Suffolk, MA & 613 & 02127 \\
Suffolk, MA & 701 & 02111 \\
Suffolk, MA & 704 & 02118 \\
Suffolk, MA & 711 & 02118 \\
Suffolk, MA & 712 & 02118 \\
Suffolk, MA & 801 & 02118 \\
Suffolk, MA & 802 & 02119 \\
Suffolk, MA & 803 & 02119 \\
Suffolk, MA & 804 & 02119 \\
Suffolk, MA & 805 & 02120 \\
Suffolk, MA & 02120 \\
Suffolk, MA & 806 & 02120 \\
Suffolk, MA & 807 & 02120 \\
Suffolk, MA & 808 & 02119 \\
Suffolk, MA & 813 & 02119 \\
Suffolk, MA & 814 & 02119 \\
Suffolk, MA & 817 & 02119 \\
Suffolk, MA & 818 & 02121 \\
Suffolk, MA & 902 & 02121
\end{tabular}


Suffolk, MA

Suffolk, MA

Suffolk, MA

Suffolk, MA

Suffolk, MA

\begin{tabular}{cc}
904 & 02125 \\
905 & 02119 \\
906 & 02119 \\
924 & 02121 \\
1101.1 & 02124 \\
\hline
\end{tabular}

c. Boston EZ Business Growth Rate

\begin{tabular}{lccc}
\hline EZ Zip Codes & Businesses in 1998 & Businesses in 2007 & Percentage Change \\
\hline 02111 & 917 & 875 & -4.58 \\
02118 & 648 & 715 & 10.34 \\
02119 & 355 & 404 & 13.80 \\
02120 & 135 & 168 & 24.44 \\
02121 & 139 & 172 & 23.74 \\
02124 & 464 & 503 & 8.41 \\
02125 & 366 & 392 & 7.10 \\
02127 & 608 & 614 & 0.99 \\
\hline TOTAL & $\mathbf{3 6 3 2}$ & $\mathbf{3 8 4 3}$ & $\mathbf{5 . 8 1}$ \\
\hline
\end{tabular}

d. Boston EZ Employment Growth rate

\begin{tabular}{lccc}
\hline EZ Zip Codes & Employees in 1998 & Employees in 2007 & Percentage Change \\
\hline 02111 & 27470 & 25743 & -6.29 \\
02118 & 15982 & 17766 & 11.16 \\
02119 & 6730 & 6376 & -5.26 \\
02120 & 2404 & 3400 & 41.43 \\
02121 & 1411 & 2107 & 49.33 \\
02124 & 6609 & 6041 & -8.59 \\
02125 & 7984 & 12796 & 60.27 \\
02127 & 10062 & 11622 & 15.50 \\
\hline TOTAL & $\mathbf{7 8 6 5 2}$ & $\mathbf{8 5 8 5 1}$ & $\mathbf{9 . 1 5}$ \\
\hline
\end{tabular}




\section{2) Cincinnati, Ohio}

a. Map of Cincinnati EZs

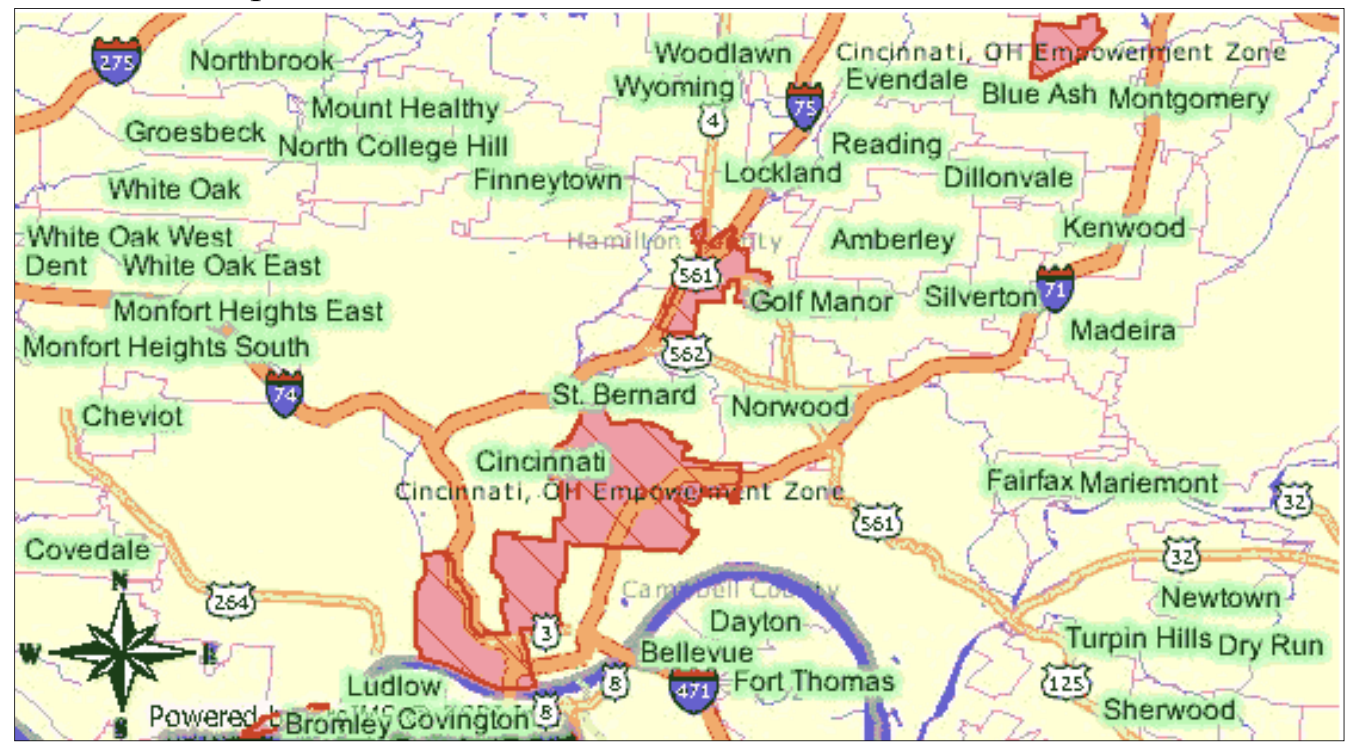

b. Cincinnati Census Tracts and corresponding Zip Codes

\begin{tabular}{lcc}
\hline County & Census Tracts & Zip Codes \\
\hline Hamilton, $\mathrm{OH}$ & 1 & 45203 \\
Hamilton, OH & 4 & 45203 \\
Hamilton, OH & 8 & 45203 \\
Hamilton, OH & 9 & 45210 \\
Hamilton, OH & 10 & 45210 \\
Hamilton, OH & 16 & 45210 \\
Hamilton, OH & 17 & 45210 \\
Hamilton, OH & 23 & 45219 \\
Hamilton, $\mathrm{OH}$ & 25 & 45219 \\
Hamilton, $\mathrm{OH}$ & 26 & 45219 \\
Hamilton, OH & 32 & 45219 \\
Hamilton, OH & 33 & 45219 \\
Hamilton, OH & 34 & 45219 \\
Hamilton, $\mathrm{OH}$ & 35 & 45206 \\
Hamilton, $\mathrm{OH}$ & 36 & 45206 \\
Hamilton, $\mathrm{OH}$ & 37 & 45206 \\
Hamilton, OH & 38 & 45207 \\
Hamilton, $\mathrm{OH}$ & 66 & 45229 \\
Hamilton, $\mathrm{OH}$ & 67 & 45229 \\
Hamilton, $\mathrm{OH}$ & 68 & 45229 \\
Hamilton, $\mathrm{OH}$ & 69 & 45229
\end{tabular}


c. Cincinnati Business Growth Rate

\begin{tabular}{lccc}
\hline EZ Zip Codes & Businesses in 1998 & Businesses in 2007 & Percentage Change \\
\hline 45203 & 277 & 266 & -3.97 \\
45206 & 552 & 423 & -23.27 \\
45207 & 70 & 80 & 14.29 \\
45210 & 339 & 78 & -76.99 \\
45219 & 512 & 432 & -15.63 \\
45229 & 278 & 239 & -14.03 \\
\hline TOTAL & $\mathbf{2 0 2 8}$ & $\mathbf{1 5 1 8}$ & $\mathbf{- 2 5 . 1 5}$ \\
\hline
\end{tabular}

d. Cincinnati Employment Growth Rate

\begin{tabular}{lccc}
\hline EZ Zip Codes & Employees in 1998 & Employees in 2007 & Percentage Change \\
\hline 45203 & 7984 & 12796 & 60.27 \\
45206 & 11368 & 10449 & -8.08 \\
45207 & 3630 & 3750 & 3.31 \\
45210 & 4869 & 1435 & -70.53 \\
45219 & 15037 & 14157 & -5.85 \\
45229 & 9134 & 15384 & 68.43 \\
\hline TOTAL & $\mathbf{5 2 0 2 2}$ & $\mathbf{5 7 9 7 1}$ & $\mathbf{1 1 . 4 4}$ \\
\hline
\end{tabular}

3) Columbia, South Carolina/ Sumter, South Carolina

a. Map of Columbia and Sumter EZs

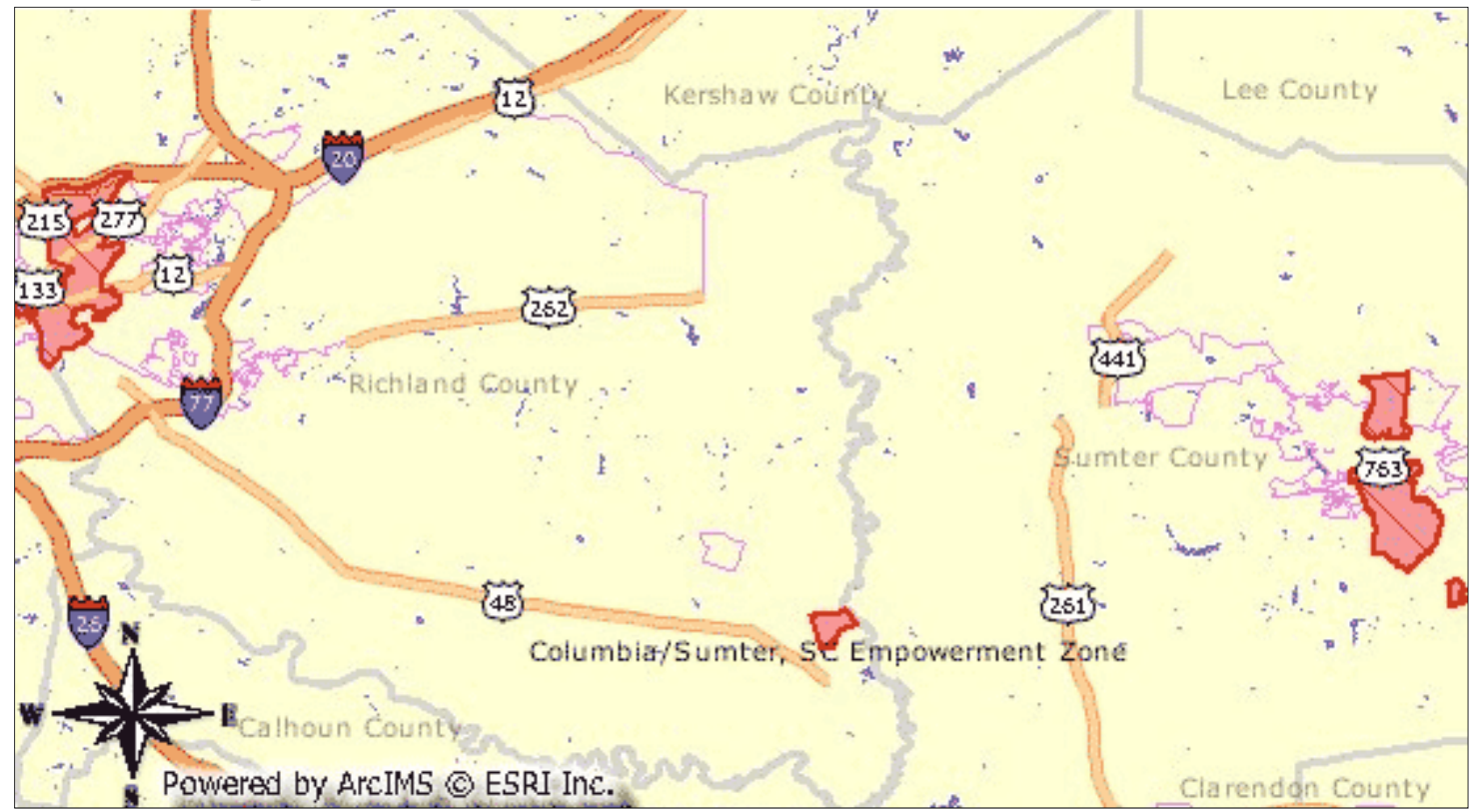


b. Columbia/Sumter Census Tracts and corresponding Zip Codes

\begin{tabular}{lcc}
\hline County & Census Tracts & Zip Codes \\
\hline Richland County & 2 & 29203 \\
Richland County & 5 & 29203 \\
Richland County & 8 & 29202 \\
Sumter County & 8.98 & 29150 \\
Richland County & 9 & 29204 \\
Richland County & 10 & 29204 \\
Richland County & 13 & 29204 \\
Sumter County & 13 & 29150 \\
Richland County & 14 & 29204 \\
Richland County & 15 & 29201 \\
Sumter County & 15 & 29150 \\
Richland County & 16 & 29201 \\
Sumter County & 16 & 29150 \\
Richland County & 18 & 29201 \\
Richland County & 20.02 & 29205 \\
Richland County & 28 & 29205 \\
Richland County & 106 & 29203 \\
Richland County & 109 & 29203 \\
\hline
\end{tabular}

c. Columbia/Sumter Business Growth Rate

\begin{tabular}{lccc}
\hline EZ Zip Codes & Businesses in 1998 & Businesses in 2007 & Percentage Change \\
\hline 29150 & 1192 & 1283 & 7.63 \\
29201 & 1831 & 1851 & 1.09 \\
29202 & 227 & 130 & -42.73 \\
29203 & 605 & 665 & 9.92 \\
29204 & 752 & 672 & -10.64 \\
29205 & 726 & 711 & -2.07 \\
\hline TOTAL & $\mathbf{5 3 3 3}$ & $\mathbf{5 3 1 2}$ & $\mathbf{- 0 . 3 9}$ \\
\hline
\end{tabular}

d. Columbia/Sumter Employment Growth rate

\begin{tabular}{lccc}
\hline EZ Zip Codes & Employees in 1998 & Employees in 2007 & Percentage Change \\
\hline 29150 & 22756 & 22574 & -0.80 \\
29201 & 34528 & 32360 & -6.28 \\
29202 & 6805 & 5269 & -22.57 \\
29203 & 17149 & 24611 & 43.51 \\
29204 & 13709 & 12422 & -9.39
\end{tabular}




\section{4) Columbus, Ohio}

a. Map of Columbus EZs

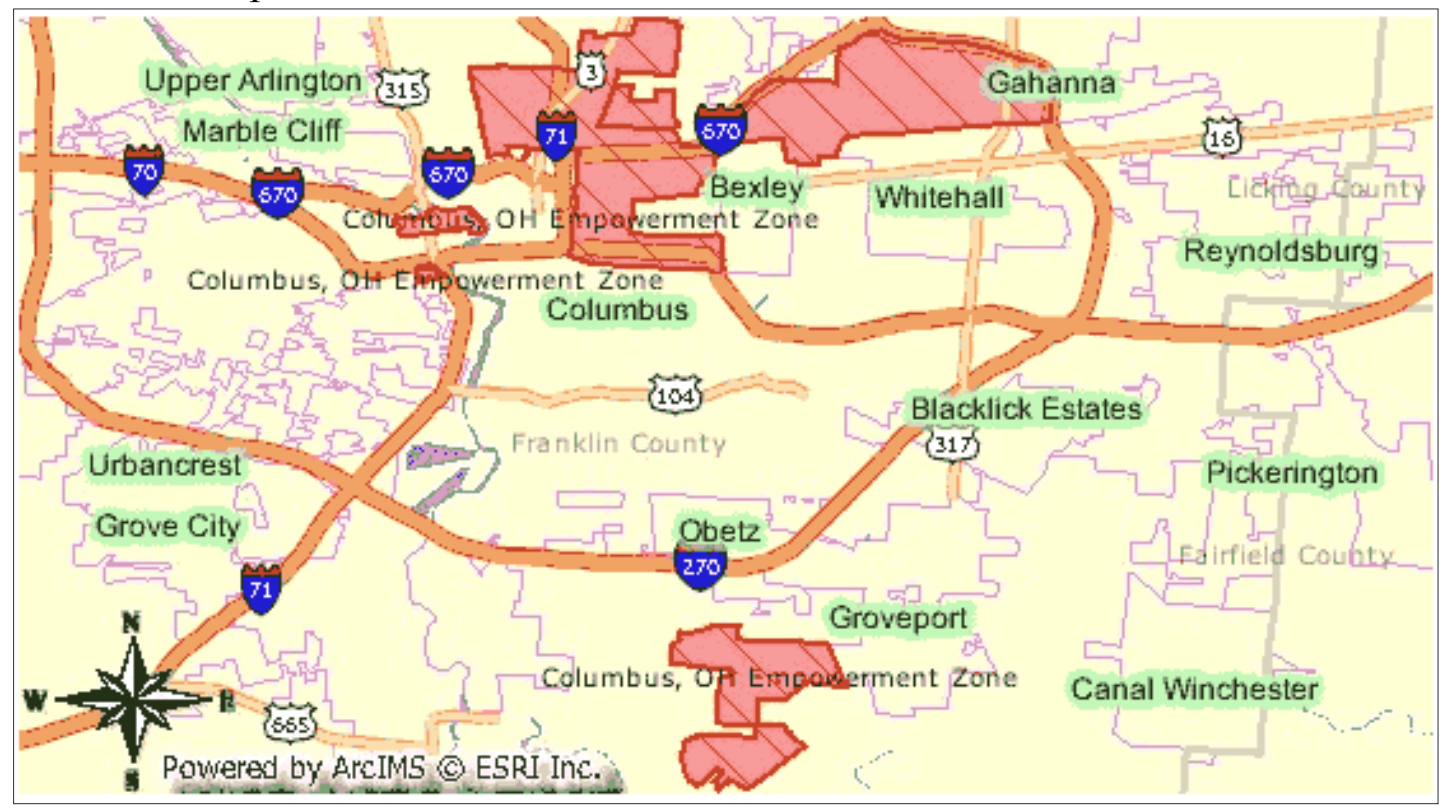

b. Columbus Census Tracts and corresponding Zip Codes

\begin{tabular}{lcc}
\hline County & Census Tracts & Zip Codes \\
\hline Franklin, OH & 7.3 & 43211 \\
Franklin, OH & 13 & 43201 \\
Franklin, OH & 14 & 43201 \\
Franklin, OH & 15 & 43201 \\
Franklin, OH & 16 & 43201 \\
Franklin, OH & 17 & 43201 \\
Franklin, OH & 22 & 43201 \\
Franklin, OH & 23 & 43201 \\
Franklin, OH & 25.2 & 43203 \\
Franklin, OH & 43219 \\
Franklin, OH & 26 & 43219 \\
Franklin, OH & 27.1 & 43203 \\
Franklin, OH & 28 & 43203 \\
Franklin, OH & 29 & 43205 \\
Franklin, OH & 36 & 43205 \\
Franklin, OH & 38 & 43215 \\
Franklin, OH & 42 & 43205
\end{tabular}


Franklin, $\mathrm{OH}$

Franklin, $\mathrm{OH}$

Franklin, $\mathrm{OH}$

Franklin, $\mathrm{OH}$
54.1

54.2

74.1

75.11
43205

43205

43219

43219

c. Columbus EZ Business Growth Rate

\begin{tabular}{lccc}
\hline EZ Zip Codes & Businesses in 1998 & Businesses in 2007 & Percentage Change \\
\hline 43201 & 622 & 585 & -5.95 \\
43203 & 117 & 119 & 1.71 \\
43205 & 353 & 305 & -13.60 \\
43211 & 228 & 228 & 0.00 \\
43215 & 2760 & 2604 & -5.65 \\
43219 & 658 & 1089 & 65.50 \\
\hline TOTAL & $\mathbf{4 7 3 8}$ & $\mathbf{4 9 3 0}$ & $\mathbf{4 . 0 5}$ \\
\hline
\end{tabular}

d. Columbus EZ Employment Growth rate

\begin{tabular}{lccc}
\hline EZ Zip Codes & Employees in 1998 & Employees in 2007 & Percentage Change \\
\hline 43201 & 11659 & 9642 & -17.30 \\
43203 & 1427 & 1072 & -24.88 \\
43205 & 8783 & 12523 & 42.58 \\
43211 & 3272 & 2895 & -11.52 \\
43215 & 90832 & 62483 & -31.21 \\
43219 & 23373 & 42819 & 83.20 \\
\hline TOTAL & $\mathbf{1 3 9 3 4 6}$ & $\mathbf{1 3 1 4 3 4}$ & $\mathbf{- 5 . 6 8}$ \\
\hline
\end{tabular}

e. Columbus Location Quotient (LQ), compared to the Columbus, OH Metro Statistical Area (MSA) in 1998

\begin{tabular}{|c|c|c|c|c|c|}
\hline \multirow[b]{2}{*}{ Industry Firm Description } & \multicolumn{3}{|c|}{ MSA } & \multirow[b]{2}{*}{$(\mathbf{R i} / \mathbf{R t})$} & \multirow[b]{2}{*}{$\mathbf{L Q}$} \\
\hline & EZ 1998 & 1998 & $(\mathbf{L i} / \mathbf{L t})$ & & \\
\hline Agriculture & 0 & 36 & 0.00 & 0.00 & 0.00 \\
\hline Mining & 0 & 77 & 0.00 & 0.00 & 0.00 \\
\hline Utilities & 0 & 106 & 0.00 & 0.00 & 0.00 \\
\hline Construction & 245 & 3,456 & 0.05 & 0.09 & 0.55 \\
\hline Manufacturing & 188 & 1,581 & 0.04 & 0.04 & 0.92 \\
\hline Wholesale trade & 234 & 2,345 & 0.05 & 0.06 & 0.77 \\
\hline Retail trade & 609 & 5,265 & 0.13 & 0.14 & 0.90 \\
\hline Transportation & 110 & 909 & 0.02 & 0.02 & 0.94 \\
\hline Information & 96 & 559 & 0.02 & 0.02 & 1.33 \\
\hline
\end{tabular}




\begin{tabular}{lrrrrr} 
Finance \& insurance & 282 & 1,608 & 0.06 & 0.04 & 1.36 \\
Real estate & 257 & 1,606 & 0.05 & 0.04 & 1.24 \\
Professional, scientific \& technical & 841 & 3,962 & 0.18 & 0.11 & 1.65 \\
Management of companies & 43 & 309 & 0.01 & 0.01 & 1.08 \\
Administrative support & 225 & 2,088 & 0.05 & 0.06 & 0.84 \\
Educational services & 36 & 351 & 0.01 & 0.01 & 0.80 \\
Health care and social assistance & 463 & 3,375 & 0.10 & 0.09 & 1.07 \\
Arts, recreation, entertainment & 55 & 489 & 0.01 & 0.01 & 0.87 \\
Accommodation \& food services & 411 & 3,121 & 0.09 & 0.08 & 1.02 \\
Other services & 581 & 3,819 & 0.12 & 0.10 & 1.18 \\
Unclassified establishments & 0 & 373 & 0.00 & 0.01 & 0.00 \\
\hline TOTAL & $\mathbf{4 , 7 3 8}$ & $\mathbf{3 6 , 7 9 5}$ & & & \\
\hline
\end{tabular}

f. Columbus Location Quotient, compared to the Columbus, $\mathrm{OH}$ Metro Statistical Area (MSA) in 2007

\begin{tabular}{|c|c|c|c|c|c|}
\hline Industry Firm Description & $\begin{array}{c}\mathbf{E Z} \\
2007\end{array}$ & $\begin{array}{l}\text { MSA } \\
2007 \\
\end{array}$ & $(\mathbf{L i} / \mathbf{L t})$ & $(\mathbf{R i} / \mathbf{R t})$ & $\mathbf{L Q}$ \\
\hline Agriculture & 0 & 161 & 0.00 & 0.00 & 0.00 \\
\hline Mining & 0 & 173 & 0.00 & 0.00 & 0.00 \\
\hline Utilities & 1 & 322 & 0.00 & 0.00 & 0.39 \\
\hline Construction & 144 & 21,808 & 0.05 & 0.06 & 0.83 \\
\hline Manufacturing & 208 & 20583 & 0.08 & 0.06 & 1.26 \\
\hline Wholesale trade & 151 & 31230 & 0.05 & 0.09 & 0.60 \\
\hline Retail trade & 374 & 40184 & 0.14 & 0.12 & 1.16 \\
\hline Transportation & 79 & 7783 & 0.03 & 0.02 & 1.27 \\
\hline Information & 35 & 11151 & 0.01 & 0.03 & 0.39 \\
\hline Finance \& insurance & 210 & 20775 & 0.08 & 0.06 & 1.26 \\
\hline Real estate & 141 & 19335 & 0.05 & 0.06 & 0.91 \\
\hline Professional, scientific \& technical & 388 & 46014 & 0.14 & 0.13 & 1.05 \\
\hline Management of companies & 21 & 1952 & 0.01 & 0.01 & 1.35 \\
\hline Administrative support & 149 & 15333 & 0.05 & 0.04 & 1.22 \\
\hline Educational services & 25 & 4360 & 0.01 & 0.01 & 0.72 \\
\hline Health care and social assistance & 292 & 37657 & 0.11 & 0.11 & 0.97 \\
\hline Arts, recreation, entertainment & 15 & 12150 & 0.01 & 0.04 & 0.15 \\
\hline Accommodation \& food services & 250 & 26147 & 0.09 & 0.08 & 1.20 \\
\hline Other services & 263 & 26263 & 0.10 & 0.08 & 1.25 \\
\hline Unclassified establishments & 4 & 573 & 0.00 & 0.00 & 0.87 \\
\hline TOTAL & 2750 & 343954 & & & \\
\hline
\end{tabular}


g. Columbus, OH Metro Statistical Area (MSA) Location Quotient, compared to the State of Ohio in 1998

\begin{tabular}{lrrrrr}
\hline Industry Firm Description & \multicolumn{1}{c}{ MSA } & \multicolumn{1}{c}{ State } & & & \\
\hline Agriculture & $\mathbf{1 9 9 8}$ & $\mathbf{1 9 9 8}$ & $(\mathbf{L i} / \mathbf{L t})$ & $(\mathbf{R i} / \mathbf{R t})$ & LQ \\
Mining & 76 & 385 & 0.00 & 0.00 & 0.69 \\
Utilities & 106 & 512 & 0.00 & 0.00 & 0.70 \\
Construction & 3,456 & 27493 & 0.09 & 0.10 & 0.92 \\
Manufacturing & 1,581 & 18052 & 0.04 & 0.07 & 0.64 \\
Wholesale trade & 2,345 & 17024 & 0.06 & 0.06 & 1.01 \\
Retail trade & 5,265 & 43650 & 0.14 & 0.16 & 0.89 \\
Transportation & 909 & 6945 & 0.02 & 0.03 & 0.96 \\
Information & 559 & 3541 & 0.02 & 0.01 & 1.16 \\
Finance \& insurance & 1,608 & 16450 & 0.04 & 0.06 & 0.72 \\
Real estate & 1,606 & 9614 & 0.04 & 0.04 & 1.23 \\
Professional, scientific \& technical & 3,962 & 23254 & 0.11 & 0.09 & 1.25 \\
Management of companies & 309 & 1771 & 0.01 & 0.01 & 1.28 \\
Administrative support & 2,088 & 13733 & 0.06 & 0.05 & 1.12 \\
Educational services & 351 & 2404 & 0.01 & 0.01 & 1.07 \\
\hline Health care and social assistance & 3,375 & 25120 & 0.09 & 0.09 & 0.99 \\
Arts, recreation, entertainment & 489 & 3837 & 0.01 & 0.01 & 0.94 \\
\hline Accommodation \& food services & 3,121 & 22546 & 0.08 & 0.08 & 1.02 \\
\hline Other services & 3,819 & 31644 & 0.10 & 0.12 & 0.89 \\
\hline Unclassified establishments & 373 & 1476 & 0.01 & 0.01 & 1.86 \\
\hline TOTAL & $\mathbf{3 6 , 7 9 5}$ & $\mathbf{2 7 0 3 4 3}$ & & & \\
\hline
\end{tabular}

h. Columbus, OH Metro Statistical Area (MSA) Location Quotient, compared to the State of Ohio in 2007

\begin{tabular}{lrrrrrr}
\hline Industry Firm Description & \multicolumn{1}{c}{ MSA } & State & & & \\
\cline { 1 - 3 } Agriculture & $\mathbf{2 0 0 7}$ & $\mathbf{2 0 0 7}$ & $(\mathbf{L i} / \mathbf{L t})$ & $(\mathbf{R i} / \mathbf{R t})$ & LQ \\
Mining & 29 & 274 & 0.00 & 0.00 & 0.70 \\
Utilities & 59 & 782 & 0.00 & 0.00 & 0.50 \\
Construction & 112 & 615 & 0.00 & 0.00 & 1.20 \\
Manufacturing & 3,427 & 24793 & 0.08 & 0.09 & 0.91 \\
Wholesale trade & 1520 & 16174 & 0.04 & 0.06 & 0.62 \\
Retail trade & 2195 & 15396 & 0.05 & 0.06 & 0.94 \\
Transportation & 5688 & 39832 & 0.14 & 0.15 & 0.94 \\
& 1125 & 7654 & 0.03 & 0.03 & 0.97
\end{tabular}




\begin{tabular}{lrrrrr} 
Information & 758 & 4249 & 0.02 & 0.02 & 1.17 \\
Finance \& insurance & 3360 & 19278 & 0.08 & 0.07 & 1.15 \\
Real estate & 2044 & 10845 & 0.05 & 0.04 & 1.24 \\
Professional, scientific \& technical & 4813 & 25585 & 0.12 & 0.09 & 1.24 \\
Management of companies & 406 & 2212 & 0.01 & 0.01 & 1.21 \\
Administrative support & 2246 & 13759 & 0.05 & 0.05 & 1.07 \\
Educational services & 461 & 2910 & 0.01 & 0.01 & 1.04 \\
Health care and social assistance & 4149 & 27943 & 0.10 & 0.10 & 0.98 \\
Arts, recreation, entertainment & 610 & 4059 & 0.01 & 0.02 & 0.99 \\
Accommodation \& food services & 3799 & 23951 & 0.09 & 0.09 & 1.04 \\
Other services & 4242 & 29796 & 0.10 & 0.11 & 0.94 \\
Unclassified establishments & 34 & 192 & 0.00 & 0.00 & 1.17 \\
\hline TOTAL & $\mathbf{4 1 0 7 7}$ & $\mathbf{2 7 0 2 9 9}$ & & & \\
\hline
\end{tabular}

5) Cumberland County, New Jersey

a. Map of the Cumberland County EZs

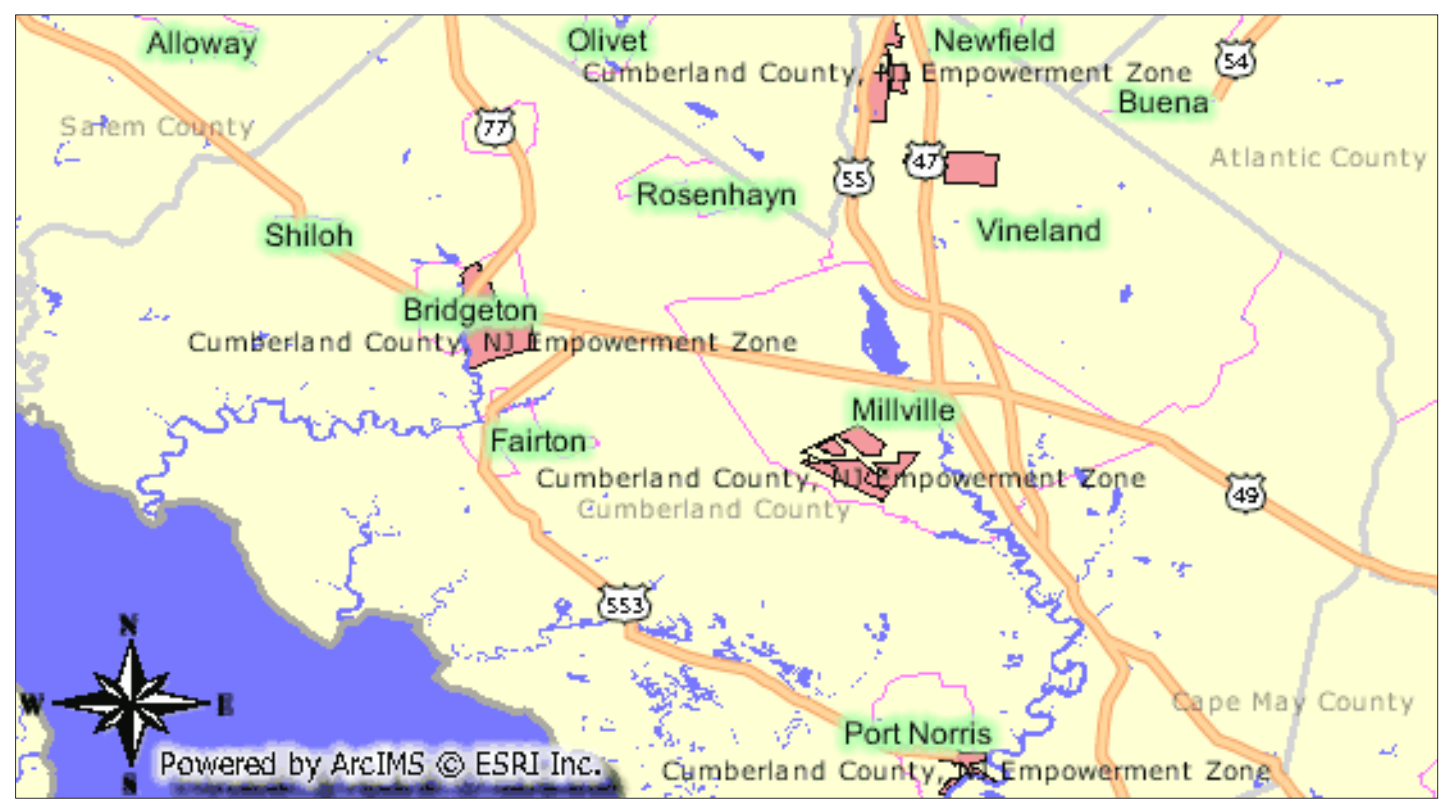

b. Cumberland Census Tracts and corresponding Zip Codes

\begin{tabular}{lcc}
\hline County & Census Tracts & Zip Codes \\
\hline Cumberland, NJ & 201 & 08302 \\
Cumberland, NJ & 203 & 08302 \\
Cumberland, NJ & 205 & 08302 \\
Cumberland, NJ & 401 & 08360
\end{tabular}


c. Cumberland EZ Business Growth Rate

\begin{tabular}{lccc}
\hline EZ Zip Codes & Businesses in 1998 & Businesses in 2007 & Percentage Change \\
\hline 08302 & 686 & 716 & 4.37 \\
08360 & 1414 & 1441 & 1.91 \\
\hline TOTAL & $\mathbf{2 1 0 0}$ & $\mathbf{2 1 5 7}$ & $\mathbf{2 . 7 1}$ \\
\hline
\end{tabular}

d. Cumberland EZ Employment Growth rate

\begin{tabular}{lccc}
\hline EZ Zip Codes & Employees in 1998 & Employees in 2007 & Percentage Change \\
\hline 08302 & 7922 & 9183 & 15.92 \\
08360 & 22488 & 25149 & 11.83 \\
\hline TOTAL & $\mathbf{3 0 4 1 0}$ & $\mathbf{3 4 3 3 2}$ & $\mathbf{1 2 . 9 0}$ \\
\hline
\end{tabular}

\section{6) El Paso, Texas}

a. Map of El Paso EZs

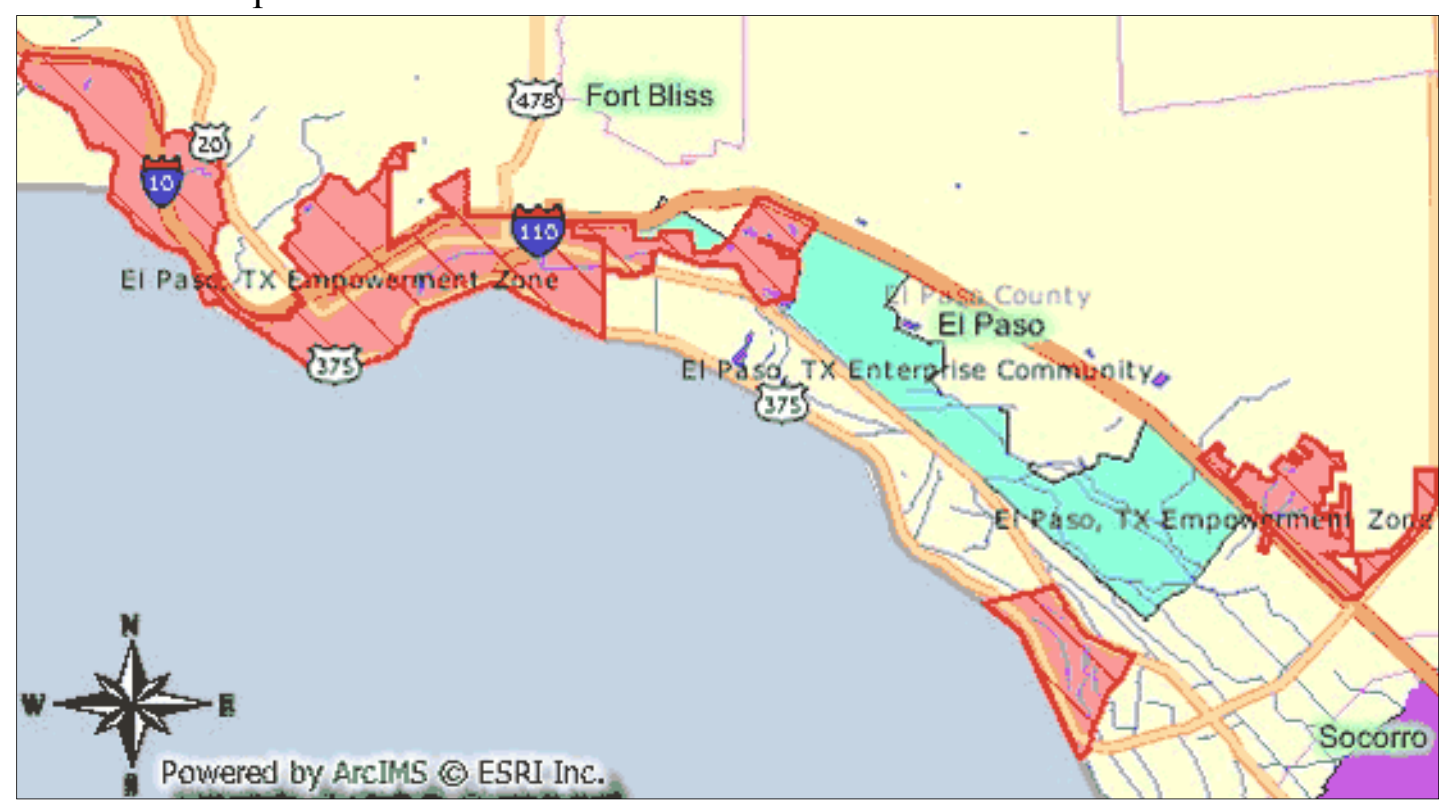

b. El Paso Census Tracts and corresponding Zip Codes

\begin{tabular}{lcc}
\hline County & Census Tracts & Zip Codes \\
\hline El Paso County & 14 & 79902 \\
E1 Paso County & 17 & 79902
\end{tabular}




\begin{tabular}{lcc} 
El Paso County & 18 & 79901 \\
El Paso County & 19 & 79901 \\
El Paso County & 20 & 79901 \\
El Paso County & 21 & 79901 \\
El Paso County & 22 & 79902 \\
El Paso County & 27 & 79903 \\
El Paso County & 28 & 79905 \\
El Paso County & 29 & 79905 \\
El Paso County & 30 & 79905 \\
El Paso County & 39.03 & 79907 \\
\hline
\end{tabular}

c. El Paso EZ Business Growth Rate

\begin{tabular}{lccc}
\hline EZ Zip Codes & Businesses in 1998 & Businesses in 2007 & Percentage Change \\
\hline 79901 & 1104 & 1019 & -7.70 \\
79902 & 1203 & 1124 & -6.57 \\
79903 & 528 & 544 & 3.03 \\
79905 & 641 & 596 & -7.02 \\
79907 & 582 & 657 & 12.89 \\
\hline TOTAL & $\mathbf{4 0 5 8}$ & $\mathbf{3 9 4 0}$ & $\mathbf{- 2 . 9 1}$ \\
\hline
\end{tabular}

d. El Paso EZ Employment Growth rate

\begin{tabular}{lccc}
\hline EZ Zip Codes & Employees in 1998 & Employees in 2007 & Percentage Change \\
\hline 79901 & 13670 & 11878 & -13.11 \\
79902 & 16982 & 19814 & 16.68 \\
79903 & 6127 & 5766 & -5.89 \\
79905 & 12666 & 9523 & -24.81 \\
79907 & 9664 & 10467 & 8.31 \\
\hline TOTAL & $\mathbf{5 9 1 0 9}$ & $\mathbf{5 7 4 4 8}$ & $\mathbf{- 2 . 8 1}$ \\
\hline
\end{tabular}


7) Gary, Indiana/ East Chicago, Indiana/ East Hammond, Indiana a. Map of Gary EZs

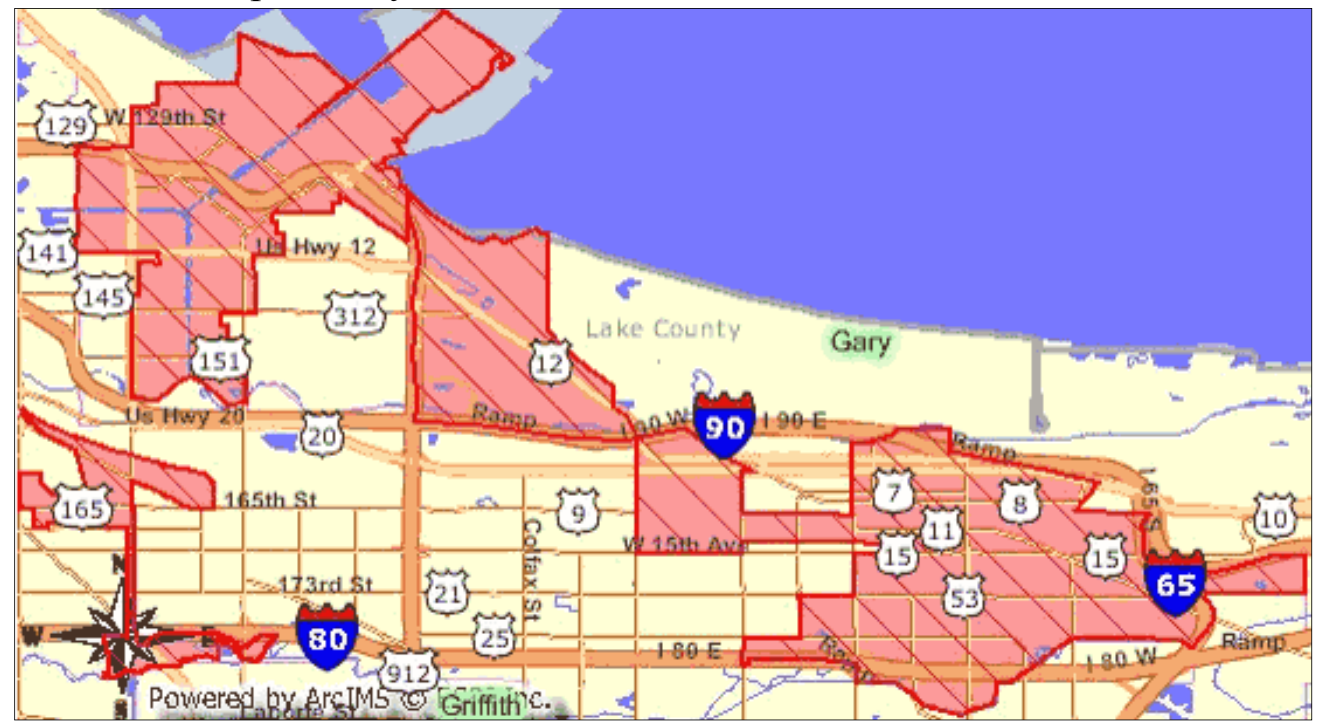

b. Gary Census Tracts and corresponding Zip Codes

\begin{tabular}{lcc}
\hline County & Census Tracts & Zip Codes \\
\hline Lake, IN & 104 & 46404 \\
Lake, IN & 107 & 46402 \\
Lake, IN & 108 & 46402 \\
Lake, IN & 109 & 46404 \\
Lake, IN & 110 & 46404 \\
Lake, IN & 111 & 46404 \\
Lake, IN & 112 & 46404 \\
Lake, IN & 113 & 46407 \\
Lake, IN & 114 & 46407 \\
Lake, IN & 117 & 46407 \\
Lake, IN & 118 & 46407 \\
Lake, IN & 119 & 46407 \\
Lake, IN & 120 & 46407 \\
Lake, IN & 122 & 46407 \\
Lake, IN & 123 & 46407 \\
Lake, IN & 124 & 46407 \\
Lake, IN & 125 & 46408 \\
Lake, IN & 126 & 46409 \\
Lake, IN & 127 & 46409 \\
Lake, IN & 128 & 46407 \\
Lake, IN & 129 & 46407 \\
Lake, IN & 301 & 46312 \\
Lake, IN & 302 & 46312 \\
& &
\end{tabular}


c. Gary EZ Business Growth Rate

\begin{tabular}{lccc}
\hline EZ Zip Codes & Businesses in 1998 & Businesses in 2007 & Percentage Change \\
\hline 46402 & 191 & 180 & -5.76 \\
46404 & 147 & 124 & -15.65 \\
46407 & 146 & 108 & -26.03 \\
46408 & 321 & 283 & -11.84 \\
46409 & 121 & 97 & -19.83 \\
46312 & 472 & 409 & -13.35 \\
\hline TOTAL & $\mathbf{1 3 9 8}$ & $\mathbf{1 2 0 1}$ & $\mathbf{- 1 4 . 0 9}$ \\
\hline
\end{tabular}

d. Gary EZ Employment Growth rate

\begin{tabular}{lccc}
\hline EZ Zip Codes & Employees in 1998 & Employees in 2007 & Percentage Change \\
\hline 46402 & 13573 & 10539 & -22.35 \\
46404 & 2533 & 1834 & -27.60 \\
46407 & 1435 & 790 & -44.95 \\
46408 & 4143 & 3248 & -21.60 \\
46409 & 1189 & 773 & -34.99 \\
46312 & 22808 & 16816 & -26.27 \\
\hline TOTAL & $\mathbf{4 5 6 8 1}$ & $\mathbf{3 4 0 0 0}$ & $\mathbf{- 2 5 . 5 7}$ \\
\hline
\end{tabular}

8) Huntington, Ohio/ Ironton, West Virginia

a. Map of Huntington EZs

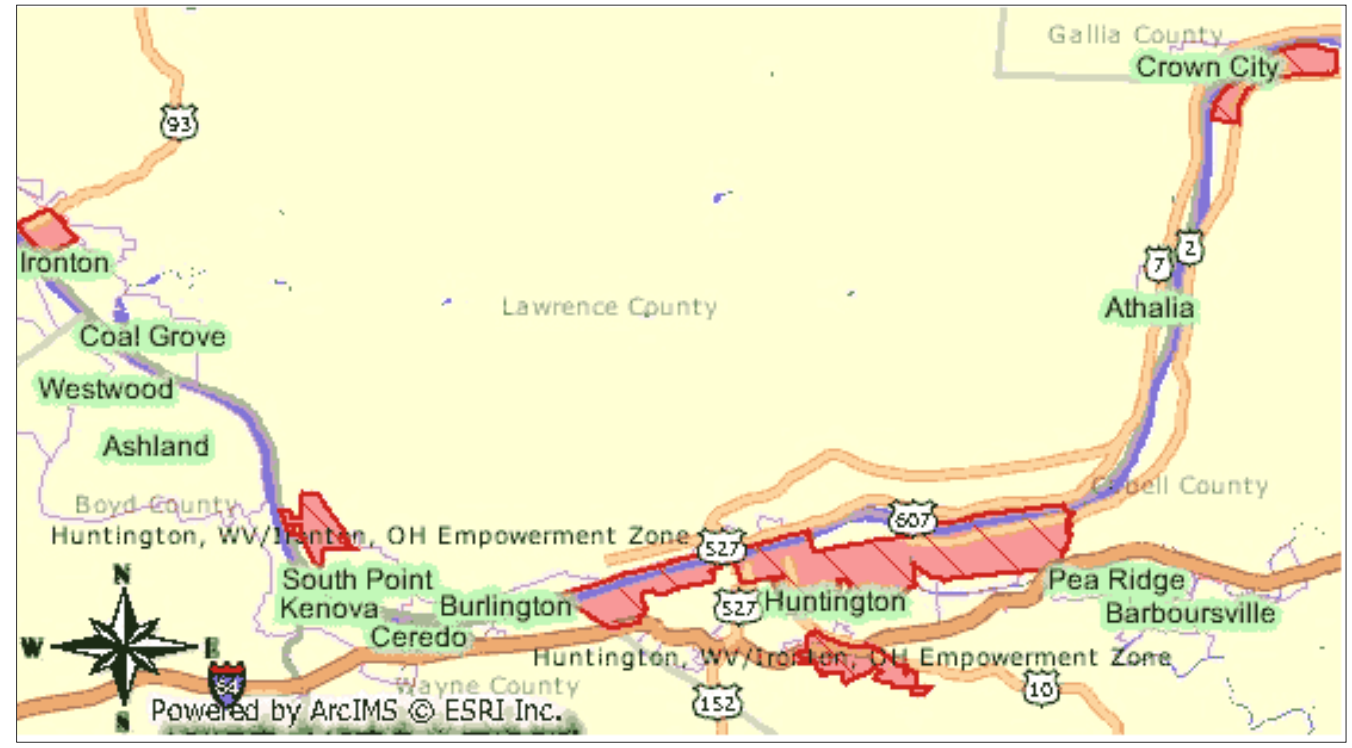


b. Huntington Census Tracts and corresponding Zip Codes

\begin{tabular}{lcc}
\hline County & Census Tracts & Zip Codes \\
\hline Cabell County & 2 & 25702 \\
Cabell County & 4 & 25702 \\
Cabell County & 5 & 25701 \\
Cabell County & 6 & 25702 \\
Cabell County & 7 & 25701 \\
Cabell County & 9 & 25701 \\
Cabell County & 10 & 25701 \\
Cabell County & 14 & 25703 \\
Cabell County & 15 & 25703 \\
Cabell County & 16 & 25703 \\
Cabell County & 18 & 25703 \\
Lawrence County & 503 & 45638 \\
\hline
\end{tabular}

c. Huntington EZ Business Growth Rate

\begin{tabular}{lccc}
\hline EZ Zip Codes & Businesses in 1998 & Businesses in 2007 & Percentage Change \\
\hline 25703 & 189 & 159 & -15.87 \\
25701 & 1072 & 996 & -7.09 \\
25702 & 195 & 193 & -1.03 \\
25704 & 305 & 280 & -8.20 \\
25705 & 325 & 329 & 1.23 \\
45638 & 431 & 411 & -4.64 \\
\hline TOTAL & $\mathbf{2 5 1 7}$ & $\mathbf{2 3 6 8}$ & $\mathbf{- 5 . 9 2}$ \\
\hline
\end{tabular}

d. Huntington EZ Employment Growth rate

\begin{tabular}{lccc}
\hline EZ Zip Codes & Employees in 1998 & Employees in 2007 & Percentage Change \\
\hline 25703 & 3149 & 2177 & -30.87 \\
25701 & 16983 & 16444 & -3.17 \\
25702 & 4751 & 5836 & 22.84 \\
25704 & 5034 & 5614 & 11.52 \\
25705 & 5648 & 6599 & 16.84 \\
45638 & 5480 & 4621 & -15.68 \\
\hline TOTAL & $\mathbf{4 1 0 4 5}$ & $\mathbf{4 1 2 9 1}$ & $\mathbf{0 . 6 0}$ \\
\hline
\end{tabular}


9) Knoxville, Tennessee

a. Map of the Knoxville EZs

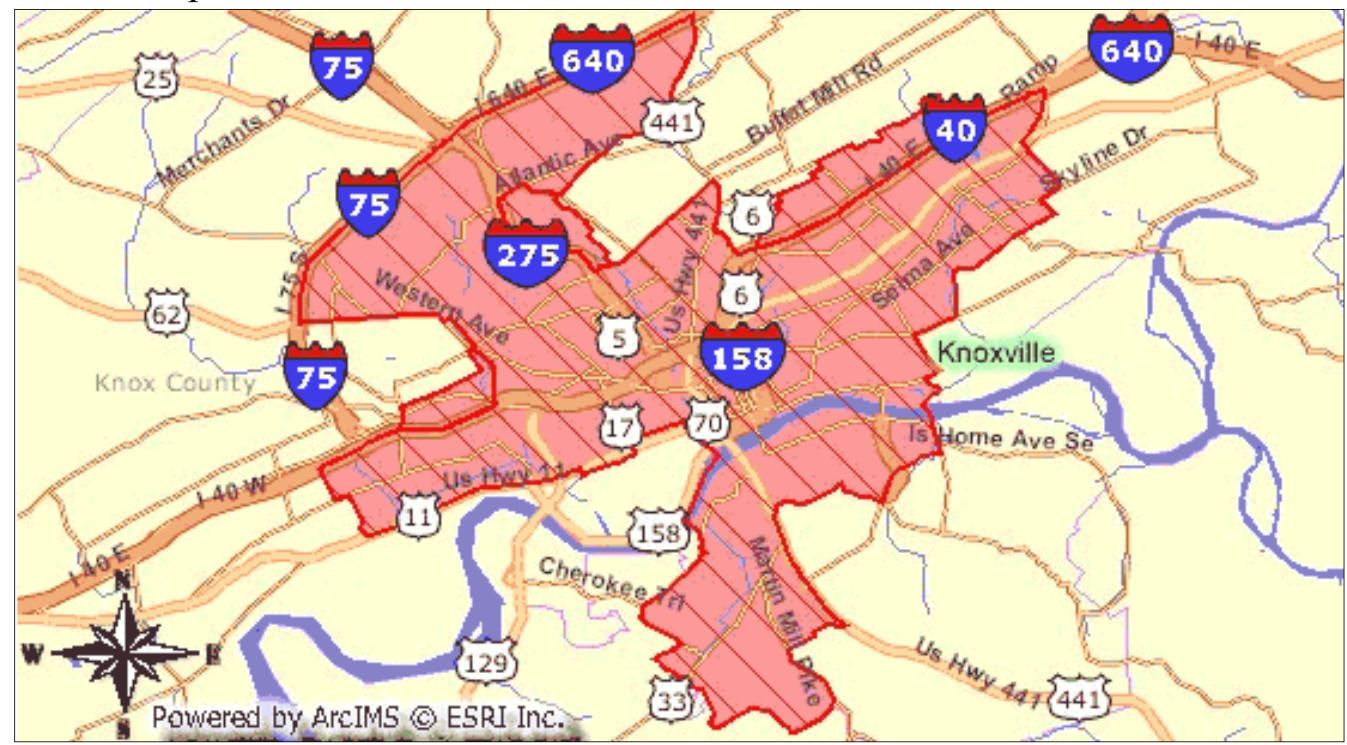

b. Knoxville Census Tracts and corresponding Zip Codes

\begin{tabular}{lcc}
\hline County & Census Tracts & Zip Codes \\
\hline Hancock County & 1 & 37902 \\
Hancock County & 2 & 37917 \\
Hancock County & 3 & 37917 \\
Hancock County & 4 & 37917 \\
Hancock County & 5 & 37917 \\
Hancock County & 6 & 37915 \\
Hancock County & 7 & 37915 \\
Hancock County & 8 & 37920 \\
Hancock County & 10 & 37921 \\
Hancock County & 11 & 37921 \\
Hancock County & 12 & 37921 \\
Hancock County & 13 & 37921 \\
Hancock County & 14 & 37921 \\
Hancock County & 19 & 37917 \\
Hancock County & 20 & 37915 \\
Hancock County & 24 & 37920 \\
Hancock County & 26 & 37919 \\
Hancock County & 28 & 37921 \\
Hancock County & 29 & 37917 \\
\hline
\end{tabular}


c. Knoxville EZ Business Growth Rate

\begin{tabular}{lccc}
\hline EZ Zip Codes & Businesses in 1998 & Businesses in 2007 & Percentage Change \\
\hline 37902 & 529 & 467 & -11.72 \\
37915 & 115 & 109 & -5.22 \\
37917 & 885 & 832 & -5.99 \\
37919 & 1748 & 1744 & -0.23 \\
37920 & 743 & 684 & -7.94 \\
37921 & 680 & 677 & 0.44 \\
\hline TOTAL & $\mathbf{4 7 0 0}$ & $\mathbf{4 5 1 3}$ & $\mathbf{- 3 . 9 8}$ \\
\hline
\end{tabular}

d. Knoxville EZ Employment Growth rate

\begin{tabular}{lccc}
\hline EZ Zip Codes & Employees in 1998 & Employees in 2007 & Percentage Change \\
\hline 37902 & 8687 & 8965 & 3.20 \\
37915 & 2679 & 2712 & 1.23 \\
37917 & 17546 & 16161 & -7.89 \\
37919 & 31700 & 26675 & -15.85 \\
37920 & 13907 & 13741 & -1.19 \\
37921 & 12007 & 18313 & 52.52 \\
\hline TOTAL & $\mathbf{8 6 5 2 6}$ & $\mathbf{8 6 5 6 7}$ & $\mathbf{0 . 0 5}$ \\
\hline
\end{tabular}

10) Miami-Dade County, Florida

a. Miami-Dade County Map of EZ Census Tracts designated by HUD

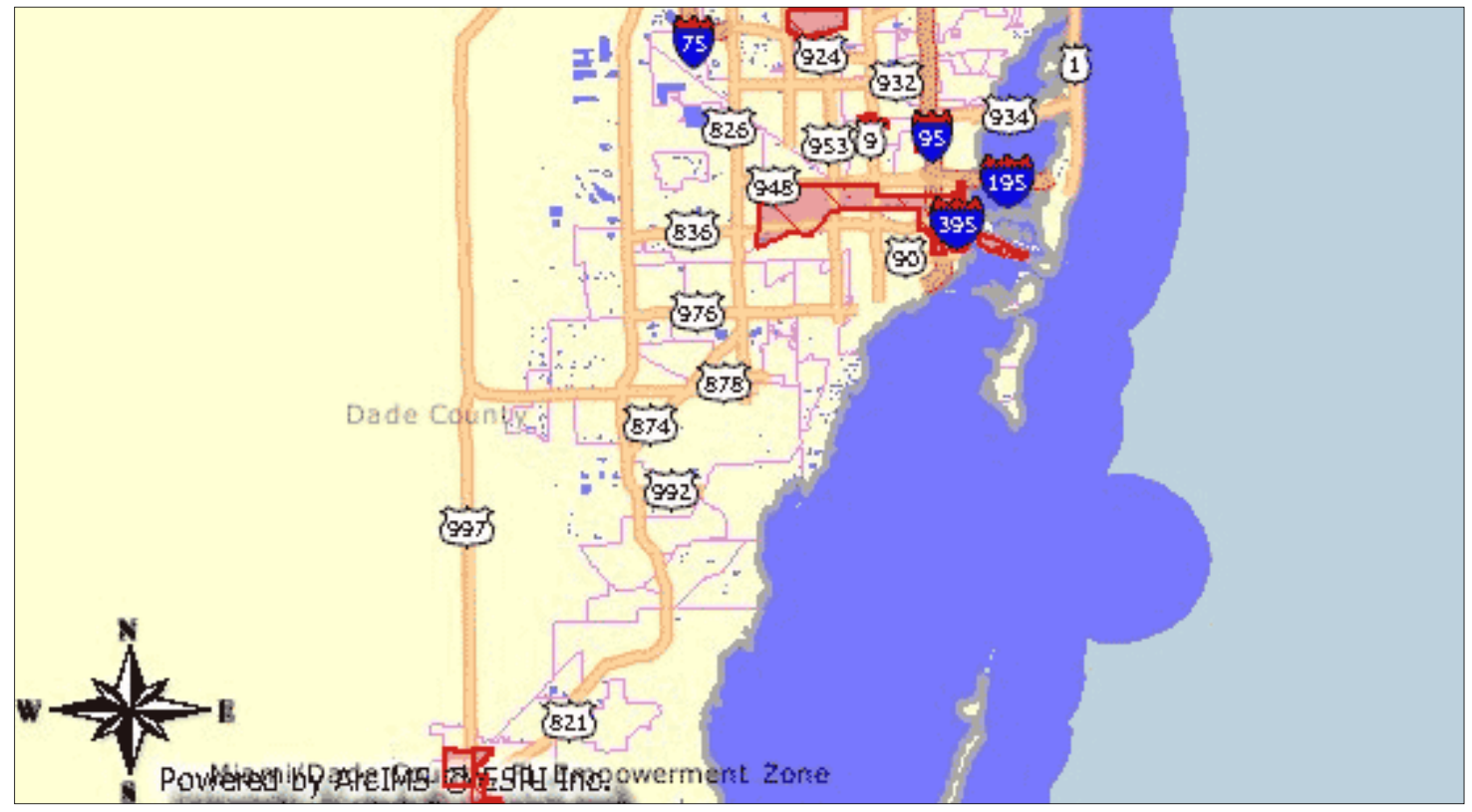


b. Miami-Dade County Census Tracts and corresponding Zip Codes

\begin{tabular}{lll}
\hline County & Census Tracts & Zip Codes \\
\hline Miami-Dade, FL & 17.03 & 33142 \\
Miami-Dade, FL & 19.01 & 33150 \\
Miami-Dade, FL & 24.02 & 33142 \\
Miami-Dade, FL & 27.02 & 33132 \\
Miami-Dade, FL & 28 & 33127 \\
Miami-Dade, FL & 29 & 33127 \\
Miami-Dade, FL & 30.01 & 33136 \\
Miami-Dade, FL & 31 & 33136 \\
Miami-Dade, FL & 34 & 33132 \\
Miami-Dade, FL & 36.02 & 33130 \\
Miami-Dade, FL & 37.01 & 33132 \\
Miami-Dade, FL & 37.02 & 33132 \\
Miami-Dade, FL & 48 & 33136 \\
Miami-Dade, FL & 113 & 33030 \\
\hline
\end{tabular}

c. Miami-Dade County Business Growth Rate

\begin{tabular}{lccc}
\hline EZ Zip Codes & Businesses in 1998 & Businesses in 2007 & Percentage Change \\
\hline 33030 & 551 & 714 & 29.58 \\
33127 & 622 & 679 & 9.16 \\
33130 & 848 & 814 & -4.01 \\
33132 & 949 & 841 & -11.38 \\
33136 & 252 & 227 & -9.92 \\
33142 & 1777 & 1605 & -9.68 \\
33150 & 331 & 333 & 0.60 \\
\hline TOTAL & $\mathbf{5 3 3 0}$ & $\mathbf{5 2 1 3}$ & $\mathbf{- 2 . 2 0}$ \\
\hline
\end{tabular}

d. Miami-Dade County Employment Growth rate

\begin{tabular}{lccc}
\hline EZ Zip Codes & Employees in 1998 & Employees in 2007 & Percentage Change \\
\hline 33030 & 5740 & 6683 & 0.16 \\
33127 & 6602 & 7462 & 0.13 \\
33130 & 7496 & 7678 & 0.02 \\
33132 & 15511 & 18258 & 0.18 \\
33136 & 18609 & 20654 & 0.11 \\
33142 & 24775 & 20398 & -0.18 \\
33150 & 3971 & 4079 & 0.03 \\
\hline TOTAL & $\mathbf{8 2 7 0 4}$ & $\mathbf{8 5 2 1 2}$ & $\mathbf{3 . 0 3}$ \\
\hline
\end{tabular}


e. Miami-Dade County Location Quotient (LQ), compared to the Miami, Ft. Lauderdale-Pompano Beach, FL Metro Statistical Area (MSA) in 1998

\begin{tabular}{lrrrrr}
\hline & EZ $\mathbf{1 9 9 8}$ & \multicolumn{1}{c}{ MSA } & & & \\
Industry Code Description & Firms & Firms & (Li/Lt) & (Ri/Rt) & LQ \\
\hline Agriculture & 2 & 104 & 0.00 & 0.00 & 0.42 \\
Mining & 0 & 0 & 0.00 & 0.00 & 0.00 \\
Utilities & 2 & 48 & 0.00 & 0.00 & 0.91 \\
Construction & 175 & 7,864 & 0.03 & 0.07 & 0.48 \\
Manufacturing & 419 & 4,959 & 0.08 & 0.04 & 1.84 \\
Wholesale trade & 937 & 13,163 & 0.18 & 0.11 & 1.55 \\
Retail trade & 1,083 & 16,641 & 0.20 & 0.14 & 1.41 \\
Transportation & 210 & 3,711 & 0.04 & 0.03 & 1.23 \\
Information & 52 & 1,853 & 0.01 & 0.02 & 0.61 \\
Finance \& insurance & 182 & 6,841 & 0.03 & 0.06 & 0.58 \\
Real estate & 209 & 5,816 & 0.04 & 0.05 & 0.78 \\
Professional, scientific \& technical & 447 & 14,649 & 0.08 & 0.13 & 0.66 \\
Management of companies & 13 & 508 & 0.00 & 0.00 & 0.56 \\
Administrative support & 203 & 7,415 & 0.04 & 0.06 & 0.60 \\
Educational services & 32 & 997 & 0.01 & 0.01 & 0.70 \\
Health care and social assistance & 362 & 11,256 & 0.07 & 0.10 & 0.70 \\
Arts, recreation, entertainment & 32 & 1,368 & 0.01 & 0.01 & 0.51 \\
Accommodation \& food services & 351 & 6,946 & 0.07 & 0.06 & 1.10 \\
Other services & 564 & 10,315 & 0.11 & 0.09 & 1.19 \\
Unclassified establishments & 56 & 1,444 & 0.01 & 0.01 & 0.84 \\
\hline TOTAL & $\mathbf{5 , 3 3 1}$ & $\mathbf{1 1 5 , 8 9 8}$ & & & \\
\hline & & & & &
\end{tabular}

f. Miami-Dade County Location Quotient (LQ), compared to the Miami, Ft. Lauderdale-Pompano Beach, FL Metro Statistical Area (MSA) in 2007

\begin{tabular}{|c|c|c|c|c|c|}
\hline Industry Code Description & $\begin{array}{c}\text { EZ } \\
2007 \\
\text { Firms }\end{array}$ & $\begin{array}{c}\text { MSA } \\
2007 \\
\text { Firms } \\
\end{array}$ & $(\mathbf{L i} / \mathbf{L t})$ & (Ri/Rt) & LQ \\
\hline Agriculture & 1 & 175 & 0.00 & 0.00 & 0.00 \\
\hline Mining & 1 & 60 & 0.00 & 0.00 & 0.00 \\
\hline Utilities & 2 & 84 & 0.00 & 0.00 & 0.00 \\
\hline Construction & 246 & 14554 & 0.05 & 0.08 & 0.63 \\
\hline Manufacturing & 270 & 5051 & 0.05 & 0.03 & 1.67 \\
\hline Wholesale trade & 771 & 15682 & 0.15 & 0.09 & 1.67 \\
\hline Retail trade & 1057 & 23188 & 0.20 & 0.13 & 1.54 \\
\hline
\end{tabular}




\begin{tabular}{lrrrrr} 
Transportation & 195 & 5141 & 0.04 & 0.03 & 1.33 \\
Information & 76 & 3188 & 0.01 & 0.02 & 0.50 \\
Finance \& insurance & 204 & 12461 & 0.04 & 0.07 & 0.57 \\
Real estate & 269 & 11119 & 0.05 & 0.06 & 0.83 \\
Professional, scientific \& technical & 543 & 28296 & 0.10 & 0.16 & 0.63 \\
Management of companies & 8 & 827 & 0.00 & 0.00 & 0.00 \\
Administrative support & 215 & 10617 & 0.04 & 0.06 & 0.67 \\
Educational services & 51 & 1933 & 0.01 & 0.01 & 1.00 \\
Health care and social assistance & 403 & 18847 & 0.08 & 0.11 & 0.73 \\
Arts, recreation, entertainment & 53 & 2734 & 0.01 & 0.02 & 0.50 \\
Accommodation \& food services & 340 & 10641 & 0.07 & 0.06 & 1.17 \\
Other services & 448 & 14361 & 0.09 & 0.08 & 1.13 \\
Unclassified establishments & 6 & 206 & 0.00 & 0.00 & 0.00 \\
\hline TOTAL & $\mathbf{5 2 1 3}$ & $\mathbf{1 7 4 1 1 4}$ & & & \\
\hline
\end{tabular}

11) Minneapolis, Minnesota

a. Map of Minneapolis EZs

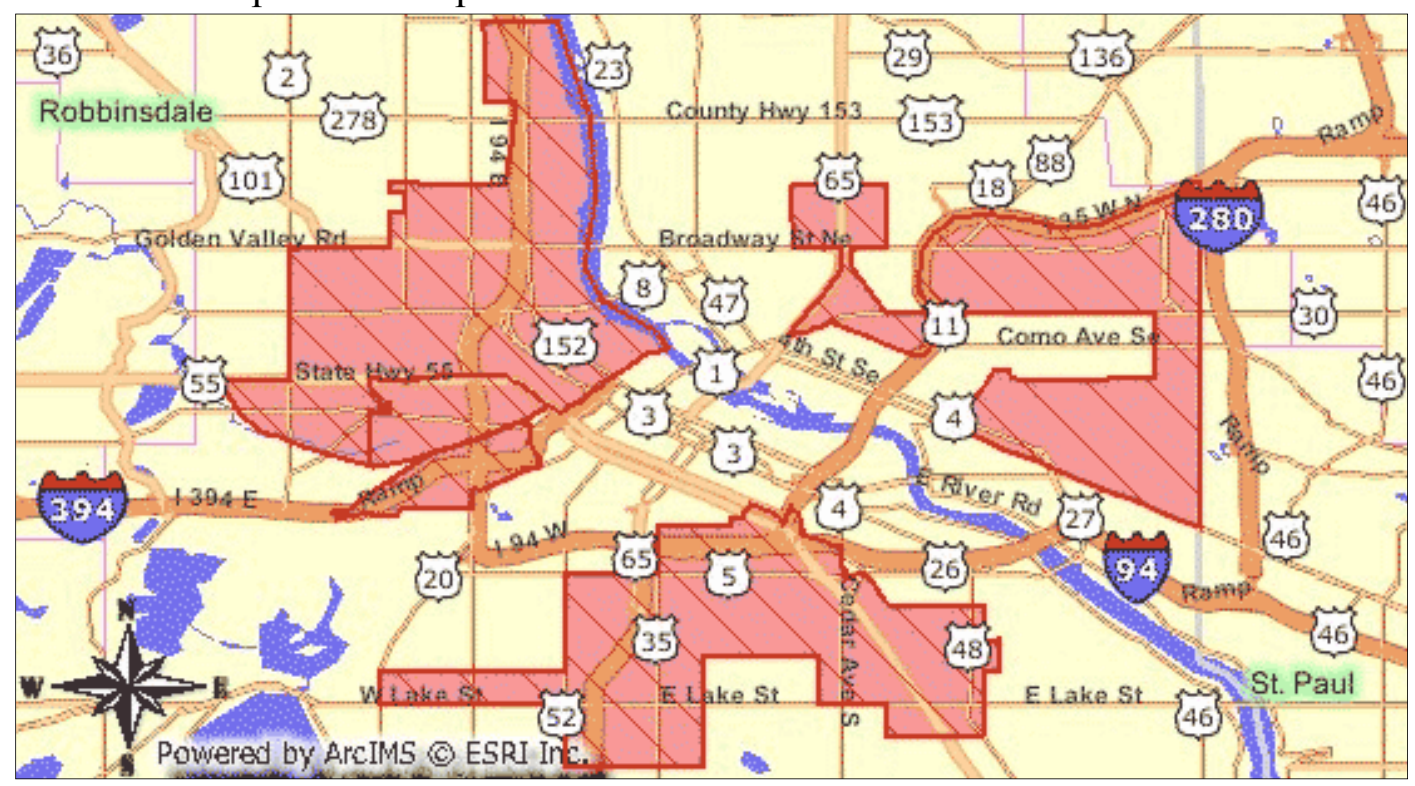

b. Minneapolis Census Tracts and corresponding Zip Codes

\begin{tabular}{lcc}
\hline County & Census Tracts & Zip Codes \\
\hline Hennepin, MN & 10 & 55388 \\
Hennepin, MN & 22 & 55389 \\
Hennepin, MN & 23 & 55390 \\
Hennepin, MN & 28 & 55391
\end{tabular}




\begin{tabular}{lll} 
Hennepin, MN & 29 & 55392 \\
Hennepin, MN & 33 & 55393 \\
Hennepin, MN & 34 & 55394 \\
Hennepin, MN & 35 & 55395 \\
Hennepin, MN & 41 & 55396 \\
Hennepin, MN & 43 & 55397 \\
Hennepin, MN & 59 & 55398 \\
Hennepin, MN & 60 & 55399 \\
Hennepin, MN & 61 & 55400 \\
Hennepin, MN & 69 & 55401 \\
Hennepin, MN & 71 & 55402 \\
Hennepin, MN & 72 & 55403 \\
Hennepin, MN & 73 & 55404 \\
Hennepin, MN & 74 & 55406 \\
Hennepin, MN & 77 & 55408 \\
Hennepin, MN & 78 & 55408 \\
Hennepin, MN & 83 & 55408 \\
Hennepin, MN & 84 & 55408 \\
\hline
\end{tabular}

c. Minneapolis Business Growth Rate

\begin{tabular}{lccc}
\hline EZ Zip Codes & Businesses in 1998 & Businesses in 2007 & Percentage Change \\
\hline 55401 & 1011 & 1009 & -0.20 \\
55404 & 591 & 628 & 6.26 \\
55405 & 492 & 513 & 4.27 \\
55406 & 661 & 713 & 7.87 \\
55407 & 514 & 588 & 14.40 \\
55408 & 834 & 889 & 6.59 \\
55411 & 455 & 446 & -1.98 \\
55412 & 212 & 185 & -12.74 \\
\hline TOTAL & $\mathbf{4 7 7 0}$ & $\mathbf{4 9 7 1}$ & $\mathbf{4 . 2 1}$ \\
\hline
\end{tabular}

d. Minneapolis Employment Growth rate

\begin{tabular}{lccc}
\hline EZ Zip Codes & Employees in 1998 & Employees in 2007 & Percentage Change \\
\hline 55401 & 18351 & 17641 & -3.87 \\
55404 & 14877 & 17188 & 15.53 \\
55405 & 6320 & 5345 & -15.43 \\
55406 & 9018 & 8658 & -3.99 \\
55407 & 10024 & 13757 & 37.24 \\
55408 & 12817 & 12433 & -3.00 \\
55411 & 8811 & 8270 & -6.14
\end{tabular}




\section{2) New Haven, Connecticut}

a. Map of New Haven EZs

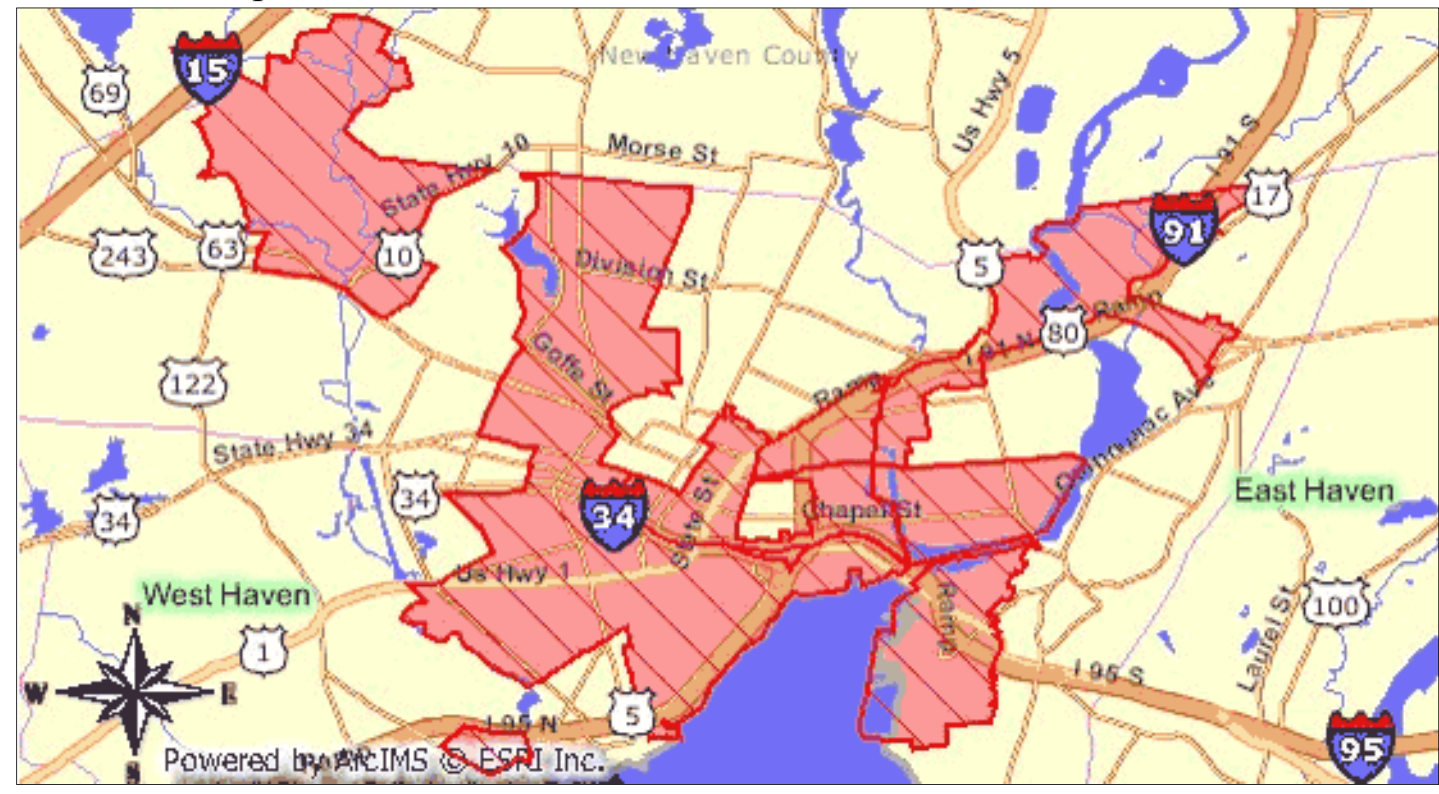

b. New Haven Census Tracts and corresponding Zip Codes

\begin{tabular}{lcc}
\hline County & Census Tracts & Zip Codes \\
\hline New Haven, CT & 1402 & 06519 \\
New Haven, CT & 1403 & 06519 \\
New Haven, CT & 1405 & 06519 \\
New Haven, CT & 1406 & 06519 \\
New Haven, CT & 1407 & 06511 \\
New Haven, CT & 1413 & 06515 \\
New Haven, CT & 1415 & 06511 \\
New Haven, CT & 1416 & 06511 \\
New Haven, CT & 1421 & 06511 \\
New Haven, CT & 1423 & 06513 \\
\hline
\end{tabular}

c. New Haven Business Growth Rate

\begin{tabular}{lccc}
\hline EZ Zip Codes & Businesses in 1998 & Businesses in 2007 & Percentage Change \\
\hline 06511 & 1250 & 1205 & -3.60 \\
06513 & 436 & 405 & -7.11
\end{tabular}




\begin{tabular}{lccc}
06515 & 238 & 238 & 0.00 \\
06519 & 232 & 223 & -3.88 \\
\hline TOTAL & $\mathbf{2 1 5 6}$ & $\mathbf{2 0 7 1}$ & $\mathbf{- 3 . 9 4}$ \\
\hline
\end{tabular}

d. New Haven Employment Growth rate

\begin{tabular}{lccc}
\hline EZ Zip Codes & Employees in 1998 & Employees in 2007 & Percentage Change \\
\hline 06511 & 34069 & 40960 & 20.23 \\
06513 & 5560 & 5863 & 5.45 \\
06515 & 5749 & 2605 & -54.69 \\
06519 & 3450 & 3092 & -10.38 \\
\hline TOTAL & $\mathbf{4 8 8 2 8}$ & $\mathbf{5 2 5 2 0}$ & $\mathbf{7 . 5 6}$ \\
\hline
\end{tabular}

\section{3) Norfolk, Virginia/ Portsmouth, Virginia}

a. Map of Norfolk EZs

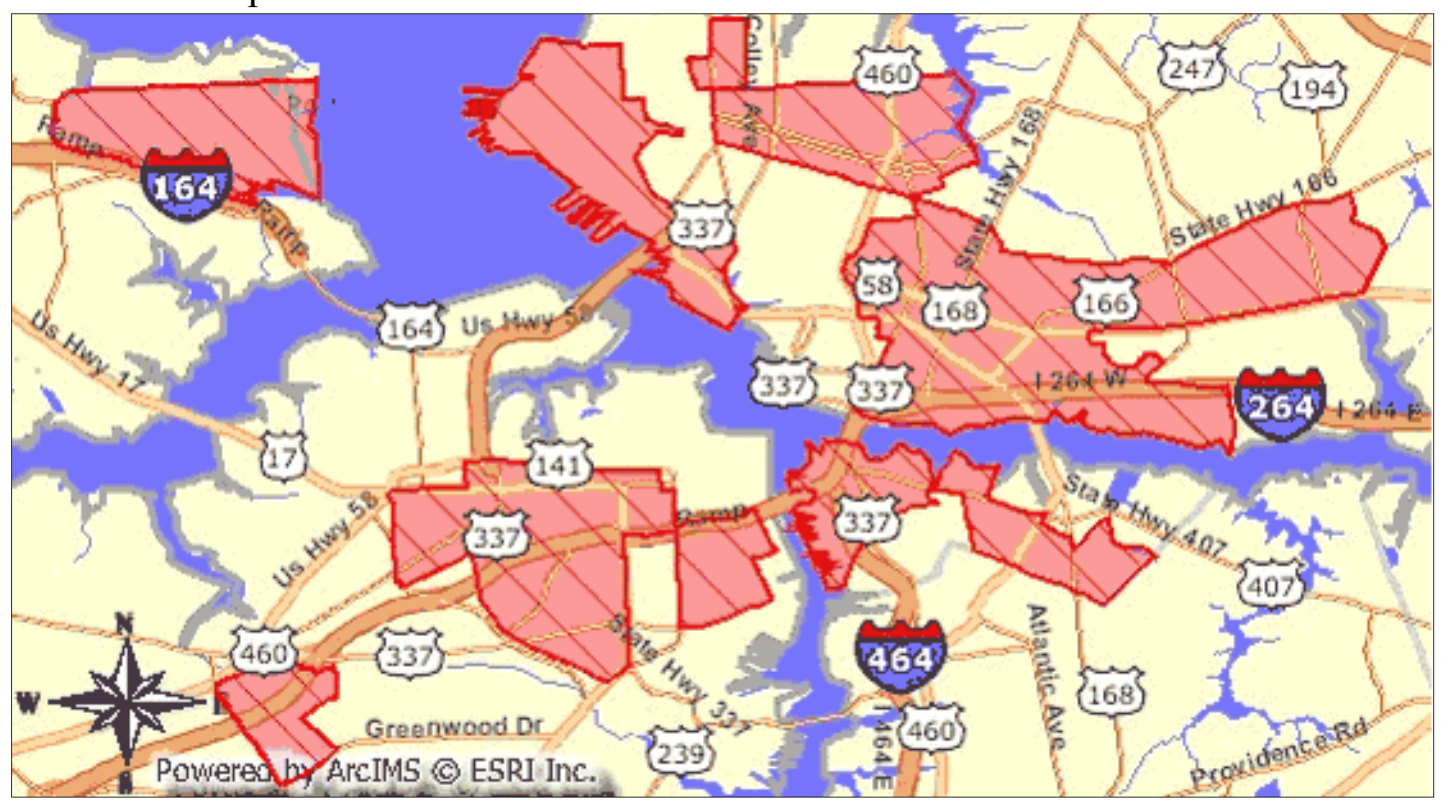

b. Norfolk Census Tracts and corresponding Zip Codes

\begin{tabular}{lcc}
\hline County & Census Tracts & Zip Codes \\
\hline Norfolk city & 27 & 23517 \\
Norfolk city & 29 & 23517 \\
Norfolk city & 35.01 & 23504 \\
Norfolk city & 35.02 & 23504 \\
Norfolk city & 39 & 23507 \\
Norfolk city & 41 & 23510
\end{tabular}


Norfolk city

Norfolk city

Norfolk city

Norfolk city

Norfolk city

Norfolk city

Norfolk city

Norfolk city

Norfolk city

Portsmouth city

Portsmouth city

Portsmouth city

Portsmouth city

Portsmouth city

Portsmouth city
42

23510

23504

23504

23504

23504

23504

23523

23523

23504

23704

23704

23707

23704

23704

23704

c. Norfolk Business Growth Rate

\begin{tabular}{lccc}
\hline EZ Zip Codes & Businesses in 1998 & Businesses in 2007 & Percentage Change \\
\hline 23504 & 298 & 310 & 4.03 \\
23507 & 180 & 169 & -6.11 \\
23510 & 891 & 1087 & 22.00 \\
23517 & 417 & 443 & 6.24 \\
23523 & 106 & 98 & -7.55 \\
23704 & 463 & 481 & 3.89 \\
23707 & 378 & 359 & -5.03 \\
\hline TOTAL & $\mathbf{2 7 3 3}$ & $\mathbf{2 9 4 7}$ & $\mathbf{7 . 8 3}$ \\
\hline
\end{tabular}

d. Norfolk Employment Growth rate

\begin{tabular}{lccc}
\hline EZ Zip Codes & Employees in 1998 & Employees in 2007 & Percentage Change \\
\hline 23504 & 5394 & 5827 & 8.03 \\
23507 & 8654 & 7601 & -12.17 \\
23510 & 18200 & 26822 & 47.37 \\
23517 & 5434 & 5223 & -3.88 \\
23523 & 6511 & 3681 & -43.46 \\
23704 & 6609 & 7762 & 17.45 \\
23707 & 6288 & 7679 & 22.12 \\
\hline TOTAL & $\mathbf{5 7 0 9 0}$ & $\mathbf{6 4 5 9 5}$ & $\mathbf{1 3 . 1 5}$ \\
\hline
\end{tabular}


e. Norfolk Location Quotient, compared to the Virginia Beach-Norfolk-Newport News, VA-NC Metropolitan Statistical Area (MSA) in 1998

\begin{tabular}{|c|c|c|c|c|c|}
\hline \multirow[b]{2}{*}{ Industry Firm Description } & \multicolumn{3}{|c|}{ MSA } & \multirow[b]{2}{*}{ (Ri/Rt) } & \multirow[b]{2}{*}{$\mathbf{L Q}$} \\
\hline & EZ 1998 & 1998 & $(\mathbf{L i} / \mathbf{L t})$ & & \\
\hline Agriculture & 0 & 47 & 0.00 & 0.00 & 0.00 \\
\hline Mining & 0 & 14 & 0.00 & 0.00 & 0.00 \\
\hline Utilities & 4 & 30 & 0.00 & 0.00 & 1.66 \\
\hline Construction & 156 & 4120 & 0.06 & 0.12 & 0.47 \\
\hline Manufacturing & 133 & 1050 & 0.05 & 0.03 & 1.57 \\
\hline Wholesale trade & 128 & 1612 & 0.05 & 0.05 & 0.99 \\
\hline Retail trade & 379 & 5999 & 0.14 & 0.18 & 0.79 \\
\hline Transportation & 107 & 928 & 0.04 & 0.03 & 1.43 \\
\hline Information & 59 & 444 & 0.02 & 0.01 & 1.65 \\
\hline Finance \& insurance & 171 & 2053 & 0.06 & 0.06 & 1.04 \\
\hline Real estate & 132 & 1596 & 0.05 & 0.05 & 1.03 \\
\hline Professional, scientific \& technical & 303 & 2845 & 0.11 & 0.08 & 1.32 \\
\hline Management of companies & 19 & 170 & 0.01 & 0.01 & 1.39 \\
\hline Administrative support & 120 & 1944 & 0.04 & 0.06 & 0.77 \\
\hline Educational services & 23 & 341 & 0.01 & 0.01 & 0.84 \\
\hline Health care and social assistance & 347 & 2987 & 0.13 & 0.09 & 1.44 \\
\hline Arts, recreation, entertainment & 33 & 466 & 0.01 & 0.01 & 0.88 \\
\hline Accommodation \& food services & 223 & 2918 & 0.08 & 0.09 & 0.95 \\
\hline Other services & 378 & 4120 & 0.14 & 0.12 & 1.14 \\
\hline Unclassified establishments & 18 & 287 & 0.01 & 0.01 & 0.78 \\
\hline TOTAL & 2733 & 33971 & & & \\
\hline
\end{tabular}

f. Norfolk Location Quotient, compared to the Virginia Beach-Norfolk-Newport News, VA-NC Metropolitan Statistical Area (MSA) in 1998

\begin{tabular}{lrrrrr}
\hline & EZ & \multicolumn{1}{c}{ MSA } & & & \\
Industry Firm Description & $\mathbf{2 0 0 7}$ & $\mathbf{2 0 0 7}$ & $(\mathbf{L i} / \mathbf{L t})$ & $(\mathbf{R i} / \mathbf{R t})$ & LQ \\
\hline Agriculture & 0 & 54 & 0.00 & 0.00 & 0.00 \\
Mining & 0 & 16 & 0.00 & 0.00 & 0.00 \\
Utilities & 0 & 33 & 0.00 & 0.00 & 0.00 \\
Construction & 176 & 5245 & 0.06 & 0.13 & 0.46 \\
Manufacturing & 105 & 988 & 0.04 & 0.02 & 2.00 \\
Wholesale trade & 96 & 1576 & 0.03 & 0.04 & 0.75 \\
Retail trade & 446 & 6204 & 0.15 & 0.16 & 0.94 \\
Transportation & 111 & 1114 & 0.04 & 0.03 & 1.33 \\
Information & 146 & 705 & 0.05 & 0.02 & 2.50 \\
Finance \& insurance & 187 & 2489 & 0.06 & 0.06 & 1.00
\end{tabular}




\begin{tabular}{lrrrrr} 
Real estate & 150 & 2222 & 0.05 & 0.06 & 0.83 \\
Professional, scientific \& technical & 351 & 4045 & 0.12 & 0.10 & 1.20 \\
Management of companies & 25 & 205 & 0.01 & 0.01 & 1.00 \\
Administrative support & 108 & 2226 & 0.04 & 0.06 & 0.67 \\
Educational services & 25 & 465 & 0.01 & 0.01 & 1.00 \\
Health care and social assistance & 343 & 3380 & 0.12 & 0.09 & 1.33 \\
Arts, recreation, entertainment & 51 & 561 & 0.02 & 0.01 & 2.00 \\
Accommodation \& food services & 270 & 3623 & 0.09 & 0.09 & 1.00 \\
Other services & 353 & 4385 & 0.12 & 0.11 & 1.09 \\
Unclassified establishments & 0 & 31 & 0.00 & 0.00 & 0.00 \\
\hline TOTAL & $\mathbf{2 9 4 7}$ & $\mathbf{3 9 5 6 7}$ & & & \\
\hline
\end{tabular}

g. Virginia Beach-Norfolk-Newport News, VA-NC Metro Statistical Area (MSA) Location Quotient, compared to the State of Virginia in 1998

\begin{tabular}{lrrrrrr}
\hline Industry Firm Description & MSA & State & & & \\
\cline { 1 - 3 } Agriculture & $\mathbf{1 9 9 8}$ & $\mathbf{1 9 9 8}$ & $(\mathbf{L i} / \mathbf{L t})$ & $\mathbf{( R i / R t )}$ & LQ \\
Mining & 47 & 797 & 0.00 & 0.00 & 0.30 \\
Utilities & 14 & 399 & 0.00 & 0.00 & 0.18 \\
Construction & 30 & 284 & 0.00 & 0.00 & 0.54 \\
Manufacturing & 4120 & 20163 & 0.12 & 0.12 & 1.04 \\
Wholesale trade & 1050 & 6027 & 0.03 & 0.04 & 0.88 \\
Retail trade & 1612 & 8035 & 0.05 & 0.05 & 1.02 \\
Transportation & 5999 & 28927 & 0.18 & 0.17 & 1.05 \\
Information & 928 & 4715 & 0.03 & 0.03 & 1.00 \\
Finance \& insurance & 444 & 3120 & 0.01 & 0.02 & 0.72 \\
Real estate & 2053 & 10309 & 0.06 & 0.06 & 1.01 \\
Professional, scientific \& technical & 1596 & 6811 & 0.05 & 0.04 & 1.19 \\
Management of companies & 2845 & 19677 & 0.08 & 0.11 & 0.73 \\
Administrative support & 170 & 1140 & 0.01 & 0.01 & 0.76 \\
Educational services & 1944 & 9282 & 0.06 & 0.05 & 1.06 \\
Health care and social assistance & 341 & 1765 & 0.01 & 0.01 & 0.98 \\
Arts, recreation, entertainment & 2987 & 14361 & 0.09 & 0.08 & 1.05 \\
Accommodation \& food services & 466 & 2275 & 0.01 & 0.01 & 1.04 \\
Other services & 2918 & 12329 & 0.09 & 0.07 & 1.20 \\
Unclassified establishments & 4120 & 20254 & 0.12 & 0.12 & 1.03 \\
\hline TOTAL & 287 & 1512 & 0.01 & 0.01 & 0.96 \\
\hline
\end{tabular}


h. Virginia Beach-Norfolk-Newport News, VA-NC Metro Statistical Area (MSA) Location Quotient, compared to the State of Virginia in 2007

\begin{tabular}{lrrrrr}
\hline Industry Firm Description & MSA & State & & & \\
\hline Agriculture & $\mathbf{2 0 0 7}$ & $\mathbf{2 0 0 7}$ & $(\mathbf{L i} / \mathbf{L t})$ & (Ri/Rt) & LQ \\
Mining & 54 & 695 & 0.00 & 0.00 & 0.39 \\
Utilities & 16 & 320 & 0.00 & 0.00 & 0.25 \\
Construction & 33 & 320 & 0.00 & 0.00 & 0.52 \\
Manufacturing & 5245 & 25227 & 0.13 & 0.13 & 1.05 \\
Wholesale trade & 988 & 5743 & 0.02 & 0.03 & 0.87 \\
Retail trade & 1576 & 7795 & 0.04 & 0.04 & 1.02 \\
Transportation & 6204 & 29382 & 0.16 & 0.15 & 1.07 \\
Information & 1114 & 5359 & 0.03 & 0.03 & 1.05 \\
Finance \& insurance & 705 & 4119 & 0.02 & 0.02 & 0.87 \\
Real estate & 2489 & 12499 & 0.06 & 0.06 & 1.01 \\
Professional, scientific \& technical & 2222 & 9328 & 0.06 & 0.05 & 1.21 \\
Management of companies & 4045 & 27882 & 0.10 & 0.14 & 0.74 \\
Administrative support & 205 & 1161 & 0.01 & 0.01 & 0.89 \\
Educational services & 2226 & 10459 & 0.06 & 0.05 & 1.08 \\
Health care and social assistance & 465 & 2427 & 0.01 & 0.01 & 0.97 \\
Arts, recreation, entertainment & 3380 & 17539 & 0.09 & 0.09 & 0.98 \\
Accommodation \& food services & 561 & 2762 & 0.01 & 0.01 & 1.03 \\
Other services & 3623 & 15701 & 0.09 & 0.08 & 1.17 \\
Unclassified establishments & 4385 & 21623 & 0.11 & 0.11 & 1.03 \\
\hline TOTAL & 31 & 162 & 0.00 & 0.00 & 0.97 \\
\hline
\end{tabular}




\section{4) Santa Ana, California}

a. Santa Ana Map of EZ Census Tracts designated by HUD

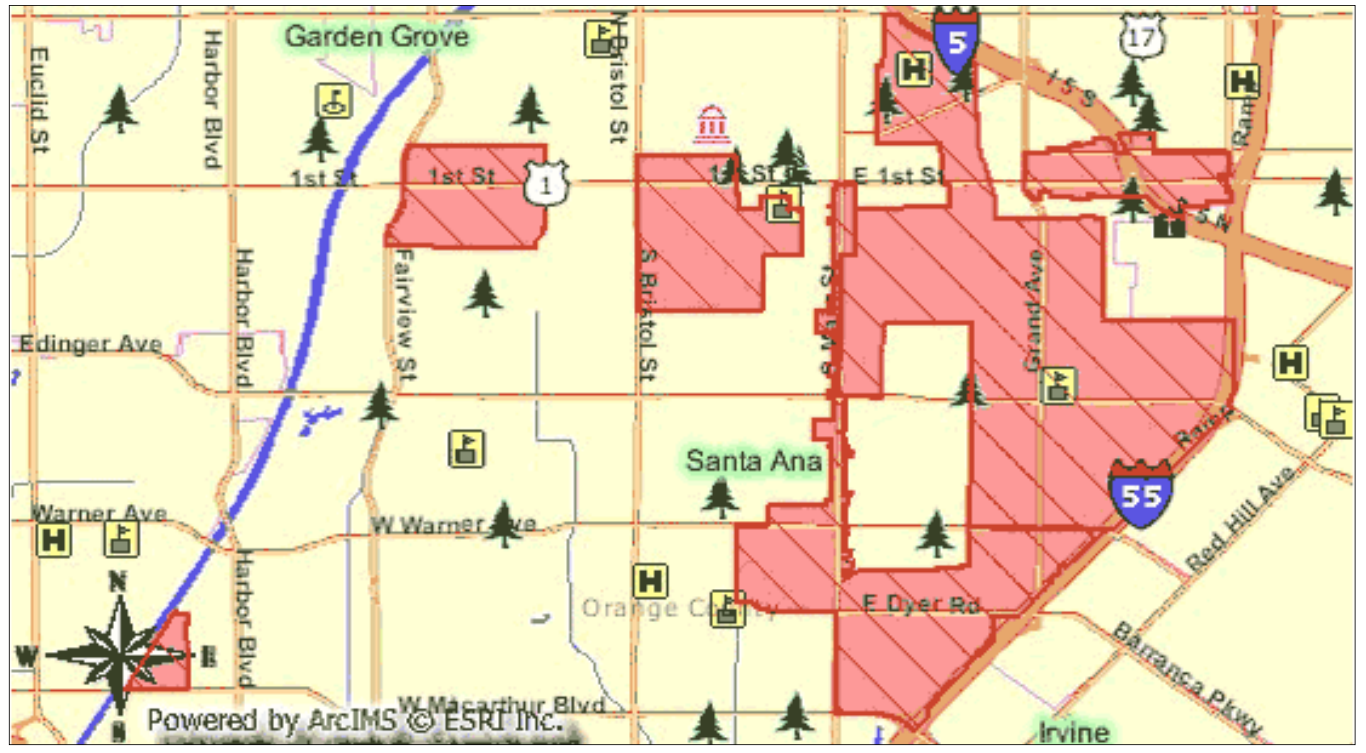

b. Santa Ana Census Tracts and corresponding Zip Codes

\begin{tabular}{lcc}
\hline County & Census Tracts & Zip Codes \\
\hline Orange, CA & 744.03 & 92707 \\
Orange, CA & 744.05 & 92701 \\
Orange, CA & 745.01 & 92701 \\
Orange, CA & 746.02 & 92707 \\
Orange, CA & 748.02 & 92703 \\
Orange, CA & 749.01 & 92703 \\
Orange, CA & 749.02 & 92703 \\
\hline
\end{tabular}

c. Santa Ana Business Growth Rate

\begin{tabular}{lccc}
\hline EZ Zip Codes & Businesses in 1998 & Businesses in 2007 & Percentage Change \\
\hline 92701 & 1211 & 1200 & -0.91 \\
92703 & 531 & 570 & 7.34 \\
92707 & 858 & 980 & 14.22 \\
\hline TOTAL & $\mathbf{2 6 0 0}$ & $\mathbf{2 7 5 0}$ & $\mathbf{5 . 7 7}$ \\
\hline
\end{tabular}

d. Santa Ana Employment Growth rate

\begin{tabular}{lccc}
\hline EZ Zip Codes & Employees in 1998 & Employees in 2007 & Percentage Change \\
\hline 92701 & 2022 & 1719 & -14.99 \\
92703 & 1263 & 908 & -28.11
\end{tabular}




\begin{tabular}{llll}
92707 & 20000 & 19102 & -4.49 \\
\hline TOTAL & $\mathbf{2 3 2 8 5}$ & $\mathbf{2 1 7 2 9}$ & $\mathbf{- 6 . 6 8}$ \\
\hline
\end{tabular}

e. Santa Ana Location Quotient (LQ), compared to the Los Angeles-Long Beach-Santa Ana, CA Metropolitan Statistical Area (MSA) in 1998

\begin{tabular}{lrrrrr}
\hline Industry Firm Description & EZ $\mathbf{1 9 9 8}$ & \multicolumn{1}{c}{ MSA } & & & \\
\cline { 5 - 6 } Agriculture & 0 & 142 & 0.00 & 0.00 & 0.00 \\
Mining & 0 & 153 & 0.00 & 0.00 & 0.00 \\
Utilities & 0 & 172 & 0.00 & 0.00 & 0.00 \\
Construction & 138 & 12,057 & 0.05 & 0.05 & 0.97 \\
Manufacturing & 247 & 18,091 & 0.10 & 0.08 & 1.15 \\
Wholesale trade & 168 & 21,676 & 0.06 & 0.10 & 0.66 \\
Retail trade & 405 & 27,547 & 0.16 & 0.13 & 1.24 \\
Transportation & 58 & 4,870 & 0.02 & 0.02 & 1.01 \\
Information & 28 & 7,787 & 0.01 & 0.04 & 0.30 \\
Finance \& insurance & 141 & 10,554 & 0.05 & 0.05 & 1.13 \\
Real estate & 98 & 10,962 & 0.04 & 0.05 & 0.76 \\
Professional, scientific \& technical & 360 & 23,850 & 0.14 & 0.11 & 1.28 \\
Management of companies & 25 & 1,254 & 0.01 & 0.01 & 1.69 \\
Administrative support & 122 & 10,732 & 0.05 & 0.05 & 0.96 \\
Educational services & 24 & 2,426 & 0.01 & 0.01 & 0.84 \\
Health care and social assistance & 249 & 22,550 & 0.10 & 0.10 & 0.93 \\
Arts, recreation, entertainment & 18 & 7,468 & 0.01 & 0.03 & 0.20 \\
Accommodation \& food services & 217 & 15,831 & 0.08 & 0.07 & 1.16 \\
Other services & 279 & 19,049 & 0.11 & 0.09 & 1.24 \\
Unclassified establishments & 3 & 2,762 & 0.00 & 0.01 & 0.09 \\
\hline TOTAL & $\mathbf{2 , 6 0 0}$ & $\mathbf{2 1 9 , 9 3 3}$ & & & \\
\hline & & & & &
\end{tabular}

f. Santa Ana Location Quotient (LQ), compared to the Los Angeles-Long Beach-Santa Ana, CA Metropolitan Statistical Area (MSA) in 2007

\begin{tabular}{lrrrrrr}
\hline & \multicolumn{1}{c}{ EZ } & MSA & & & \\
Industry Firm Description & $\mathbf{2 0 0 7}$ & $\mathbf{2 0 0 7}$ & $(\mathbf{L i} / \mathbf{L t})$ & $(\mathbf{R i} / \mathbf{R t})$ & LQ \\
\hline Agriculture & 0 & 161 & 0.00 & 0.00 & 0.00 \\
Mining & 0 & 173 & 0.00 & 0.00 & 0.00 \\
Utilities & 1 & 322 & 0.00 & 0.00 & 0.39 \\
Construction & 144 & 21808 & 0.05 & 0.06 & 0.83 \\
Manufacturing & 208 & 20583 & 0.08 & 0.06 & 1.26 \\
Wholesale trade & 151 & 31230 & 0.05 & 0.09 & 0.60
\end{tabular}




\begin{tabular}{lrrrrr} 
Retail trade & 374 & 40184 & 0.14 & 0.12 & 1.16 \\
Transportation & 79 & 7783 & 0.03 & 0.02 & 1.27 \\
Information & 35 & 11151 & 0.01 & 0.03 & 0.39 \\
Finance \& insurance & 210 & 20775 & 0.08 & 0.06 & 1.26 \\
Real estate & 141 & 19335 & 0.05 & 0.06 & 0.91 \\
Professional, scientific \& technical & 388 & 46014 & 0.14 & 0.13 & 1.05 \\
Management of companies & 21 & 1952 & 0.01 & 0.01 & 1.35 \\
Administrative support & 149 & 15333 & 0.05 & 0.04 & 1.22 \\
Educational services & 25 & 4360 & 0.01 & 0.01 & 0.72 \\
Health care and social assistance & 292 & 37657 & 0.11 & 0.11 & 0.97 \\
Arts, recreation, entertainment & 15 & 12150 & 0.01 & 0.04 & 0.15 \\
Accommodation \& food services & 250 & 26147 & 0.09 & 0.08 & 1.20 \\
Other services & 263 & 26263 & 0.10 & 0.08 & 1.25 \\
Unclassified establishments & 4 & 573 & 0.00 & 0.00 & 0.87 \\
\hline TOTAL & $\mathbf{2 7 5 0}$ & $\mathbf{3 4 3 9 5 4}$ & & & \\
\hline
\end{tabular}

g. Los Angeles-Long Beach-Santa Ana, CA Metro Statistical Area (MSA) Location Quotient, compared to the State of California in 1998

\begin{tabular}{lrrrrr}
\hline Industry Firm Description & \multicolumn{1}{c}{ MSA } & \multicolumn{1}{c}{ State } & & & \\
\hline Agriculture & 1998 & $\mathbf{1 9 9 8}$ & (Li/Lt) & (Ri/Rt) & LQ \\
Mining & 142 & 2384 & 0.00 & 0.00 & 0.15 \\
Utilities & 153 & 925 & 0.00 & 0.00 & 0.43 \\
Construction & 172 & 874 & 0.00 & 0.00 & 0.51 \\
Manufacturing & 12057 & 64108 & 0.04 & 0.07 & 0.49 \\
Wholesale trade & 18091 & 50050 & 0.05 & 0.06 & 0.94 \\
Retail trade & 21676 & 58092 & 0.06 & 0.07 & 0.97 \\
Transportation & 27547 & 106254 & 0.08 & 0.12 & 0.67 \\
Information & 4870 & 16733 & 0.01 & 0.02 & 0.75 \\
Finance \& insurance & 7787 & 18373 & 0.02 & 0.02 & 1.10 \\
Real estate & 10554 & 42102 & 0.03 & 0.05 & 0.65 \\
Professional, scientific \& technical & 10962 & 37627 & 0.03 & 0.04 & 0.76 \\
Management of companies & 23850 & 87214 & 0.07 & 0.10 & 0.71 \\
Administrative support & 1254 & 4477 & 0.00 & 0.01 & 0.73 \\
Educational services & 10732 & 41188 & 0.03 & 0.05 & 0.68 \\
Health care and social assistance & 2426 & 8488 & 0.01 & 0.01 & 0.74 \\
Arts, recreation, entertainment & 22550 & 80562 & 0.07 & 0.09 & 0.73 \\
Accommodation \& food services & 7468 & 14328 & 0.02 & 0.02 & 1.35 \\
Other services & 15831 & 62682 & 0.05 & 0.07 & 0.65 \\
Unclassified establishments & 19049 & 69315 & 0.06 & 0.08 & 0.71 \\
\hline TOTAL & 2762 & 8149 & 0.01 & 0.01 & 0.88 \\
\hline
\end{tabular}


h. Los Angeles-Long Beach-Santa Ana, CA Metro Statistical Area (MSA) Location Quotient, compared to the State of California in 2007

\begin{tabular}{lrrrrr}
\hline Industry Firm Description & \multicolumn{1}{c}{ MSA } & \multicolumn{1}{c}{ State } & & & \\
\hline Agriculture & 161 & 2045 & 0.00 & 0.00 & 0.20 \\
Mining & 173 & 839 & 0.00 & 0.00 & 0.53 \\
Utilities & 322 & 1137 & 0.00 & 0.00 & 0.73 \\
Construction & 21,808 & 80244 & 0.06 & 0.09 & 0.70 \\
Manufacturing & 20583 & 44262 & 0.06 & 0.05 & 1.21 \\
Wholesale trade & 31230 & 60805 & 0.09 & 0.07 & 1.33 \\
Retail trade & 40184 & 114025 & 0.12 & 0.13 & 0.91 \\
Transportation & 7783 & 21553 & 0.02 & 0.02 & 0.94 \\
Information & 11151 & 21610 & 0.03 & 0.02 & 1.34 \\
Finance \& insurance & 20775 & 54781 & 0.06 & 0.06 & 0.98 \\
Real estate & 19335 & 50630 & 0.06 & 0.06 & 0.99 \\
Professional, scientific \& technical & 46014 & 115605 & 0.13 & 0.13 & 1.03 \\
Management of companies & 1952 & 4876 & 0.01 & 0.01 & 1.04 \\
Administrative support & 15333 & 42708 & 0.04 & 0.05 & 0.93 \\
Educational services & 4360 & 11360 & 0.01 & 0.01 & 1.00 \\
Health care and social assistance & 37657 & 97289 & 0.11 & 0.11 & 1.00 \\
Arts, recreation, entertainment & 12150 & 19898 & 0.04 & 0.02 & 1.58 \\
Accommodation \& food services & 26147 & 75497 & 0.08 & 0.08 & 0.90 \\
Other services & 26263 & 71473 & 0.08 & 0.08 & 0.95 \\
Unclassified establishments & 573 & 1360 & 0.00 & 0.00 & 1.09 \\
\hline TOTAL & $\mathbf{3 4 3 9 5 4}$ & $\mathbf{8 9 1 9 9 7}$ & & & \\
\hline
\end{tabular}




\section{5) St. Louis, Missouri}

a. Map of St. Louis EZs

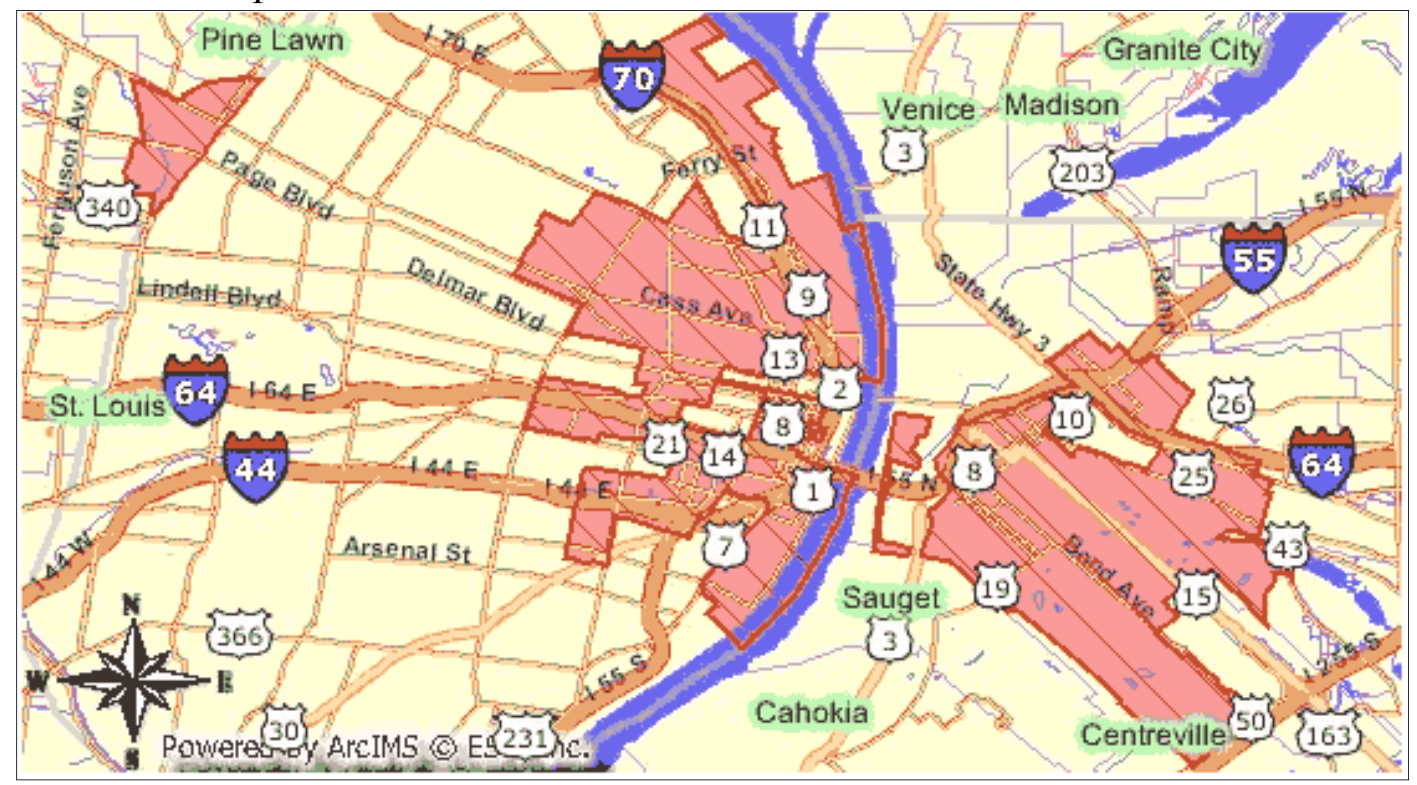

b. St. Louis Census Tracts and corresponding Zip Codes

\begin{tabular}{lcc}
\hline County & Census Tracts & Zip Codes \\
\hline St. Louis city & 1114 & 63107 \\
St. Louis city & 1115 & 63107 \\
St. Louis city & 1184 & 63103 \\
St. Louis city & 1201 & 63106 \\
St. Louis city & 1202 & 63107 \\
St. Louis city & 1203 & 63106 \\
St. Louis city & 1212 & 63106 \\
St. Louis city & 1212 & 63106 \\
St. Louis city & 1214 & 63106 \\
St. Louis city & 1222 & 63103 \\
St. Louis city & 1224 & 63103 \\
St. Louis city & 1232 & 63104 \\
St. Louis city & 1235 & 63102 \\
St. Louis city & 1257 & 63103 \\
St. Louis city & 1266 & 63102 \\
St. Louis County & 2139 & 63133 \\
St. Louis County & 2140 & 63133 \\
St. Clair County & 5010 & 62207 \\
St. Clair County & 5011 & 62205 \\
St. Clair County & 5012 & 62205 \\
St. Clair County & 5042.01 & 62201
\end{tabular}




\begin{tabular}{lll} 
St. Clair County & 5044 & 62201 \\
St. Louis city & 1104 & 63107 \\
St. Louis city & 1231 & 63104 \\
St. Clair County & 5009 & 62207 \\
St. Clair County & 5027 & 62207 \\
\hline
\end{tabular}

c. St. Louis Business Growth Rate

\begin{tabular}{lccc}
\hline EZ Zip Codes & Businesses in 1998 & Businesses in 2007 & Percentage Change \\
\hline 62201 & 226 & 202 & -10.62 \\
62205 & 144 & 124 & -13.89 \\
62207 & 77 & 73 & -5.19 \\
63102 & 572 & 544 & -4.90 \\
63103 & 848 & 744 & -12.26 \\
63104 & 536 & 567 & 5.78 \\
63106 & 228 & 202 & -11.40 \\
63107 & 162 & 167 & 3.09 \\
63133 & 209 & 182 & -12.92 \\
\hline TOTAL & $\mathbf{3 0 0 2}$ & $\mathbf{2 8 0 5}$ & $\mathbf{- 6 . 5 6}$ \\
\hline
\end{tabular}

d. St. Louis Employment Growth rate

\begin{tabular}{lccc}
\hline EZ Zip Codes & Employees in 1998 & Employees in 2007 & Percentage Change \\
\hline 62201 & 6014 & 4614 & -23.28 \\
62205 & 2022 & 1719 & -14.99 \\
62207 & 1263 & 908 & -28.11 \\
63102 & 20000 & 19102 & -4.49 \\
63103 & 35641 & 32671 & -8.33 \\
63104 & 16819 & 14993 & -10.86 \\
63106 & 4863 & 5434 & 11.74 \\
63107 & 1888 & 1481 & -21.56 \\
63133 & 3870 & 3152 & -18.55 \\
\hline TOTAL & $\mathbf{9 2 3 8 0}$ & $\mathbf{8 4 0 7 4}$ & $\mathbf{- 8 . 9 9}$ \\
\hline
\end{tabular}




\section{Appendix B}

I. Statistical Models Tables and Charts

1) Model A: Change in Business

a. Regression Results

\begin{tabular}{|c|c|c|c|c|c|c|}
\hline Source & SS & $d f$ & MS & & \multirow{3}{*}{$\begin{array}{l}\text { Number of obs }= \\
\text { F( } 17, \quad 158)= \\
\text { Prob }>\text { F } \\
\text { R-squared } \\
\text { Adj R-squared } \\
\text { Root MSE }\end{array}$} & \multirow{3}{*}{$\begin{array}{r}=176 \\
=\quad 4.85 \\
=0.0000 \\
=0.3429 \\
=0.2722 \\
=14.409\end{array}$} \\
\hline $\begin{array}{r}\text { Mode1 } \\
\text { Residual }\end{array}$ & $\begin{array}{l}17115.7771 \\
32805.0559\end{array}$ & $\begin{array}{r}17 \\
158\end{array}$ & $\begin{array}{l}81042 \\
26936\end{array}$ & & & \\
\hline Total & 49920.833 & 175 & 61903 & & & \\
\hline chgbiz & Coef. & std. Err. & $\mathrm{t}$ & $P>|t|$ & [95\% Conf. & Interval] \\
\hline $\begin{array}{c}\text { empzone } \\
\text { perwhite } \\
\text { avgage } \\
\text { perrent } \\
\text { pervcnt } \\
\text { retaildn } \\
\text { popdens } \\
\text { tenure } \\
\text { highgrad } \\
\text { perbach } \\
\text { othlang } \\
\text { unemp1 } \\
\text { peremp } \\
\text { trvltme } \\
\text { avginc } \\
\text { fampov } \\
\text { indpov } \\
\text { _cons }\end{array}$ & $\begin{array}{r}.0444576 \\
-.0682241 \\
.5908927 \\
-.1015676 \\
-.4276651 \\
.2403012 \\
-.3487147 \\
-.5322048 \\
.0002445 \\
-.1786664 \\
.0603729 \\
.0590522 \\
.1497409 \\
.3134412 \\
.622536 \\
.5712495 \\
-.4857082 \\
-12.79916\end{array}$ & $\begin{array}{l}2.689703 \\
.0735067 \\
.2918732 \\
.1288446 \\
.2562009 \\
.2065183 \\
.2318224 \\
.1897017 \\
.2087113 \\
.1526658 \\
.0733973 \\
.2746161 \\
.1927698 \\
.3556101 \\
.1838441 \\
.2447611 \\
.2639767 \\
28.76294\end{array}$ & $\begin{array}{r}0.02 \\
-0.93 \\
2.02 \\
-0.79 \\
-1.67 \\
1.16 \\
-1.50 \\
-2.81 \\
0.00 \\
-1.17 \\
0.82 \\
0.22 \\
0.78 \\
0.88 \\
3.39 \\
2.33 \\
-1.84 \\
-0.44\end{array}$ & $\begin{array}{l}0.987 \\
0.355 \\
0.045 \\
0.432 \\
0.097 \\
0.246 \\
0.135 \\
0.006 \\
0.999 \\
0.244 \\
0.412 \\
0.830 \\
0.438 \\
0.379 \\
0.001 \\
0.021 \\
0.068 \\
0.657\end{array}$ & $\begin{array}{r}-5.267953 \\
-.2134065 \\
.0144162 \\
-.3560476 \\
-.9336855 \\
-.1675915 \\
-.8065853 \\
-.9068831 \\
-.4119795 \\
-.4801954 \\
-.0845935 \\
-.4833399 \\
-.2309972 \\
-.3889215 \\
.2594271 \\
-0878237 \\
-1.007086 \\
-69.60862\end{array}$ & $\begin{array}{r}5.356868 \\
.0769584 \\
1.167369 \\
.1529123 \\
.0783553 \\
.648194 \\
.1091558 \\
-.1575264 \\
.4124684 \\
.1228626 \\
.2053393 \\
.6014443 \\
.530479 \\
1.015804 \\
.985645 \\
1.054675 \\
.03567 \\
44.01031\end{array}$ \\
\hline
\end{tabular}




\section{b. Multicollinearity}

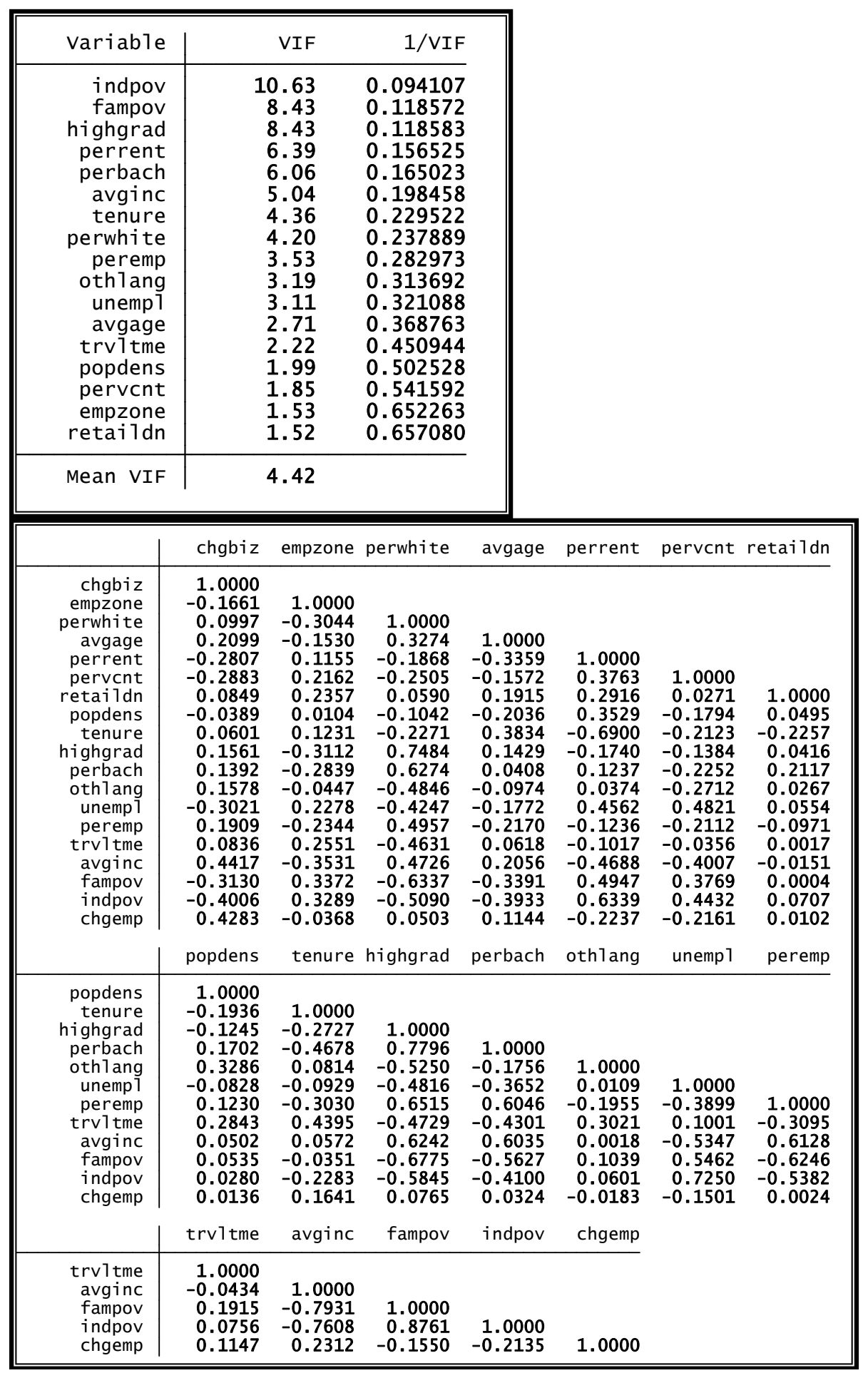




\section{c. Heteroskedasticity}

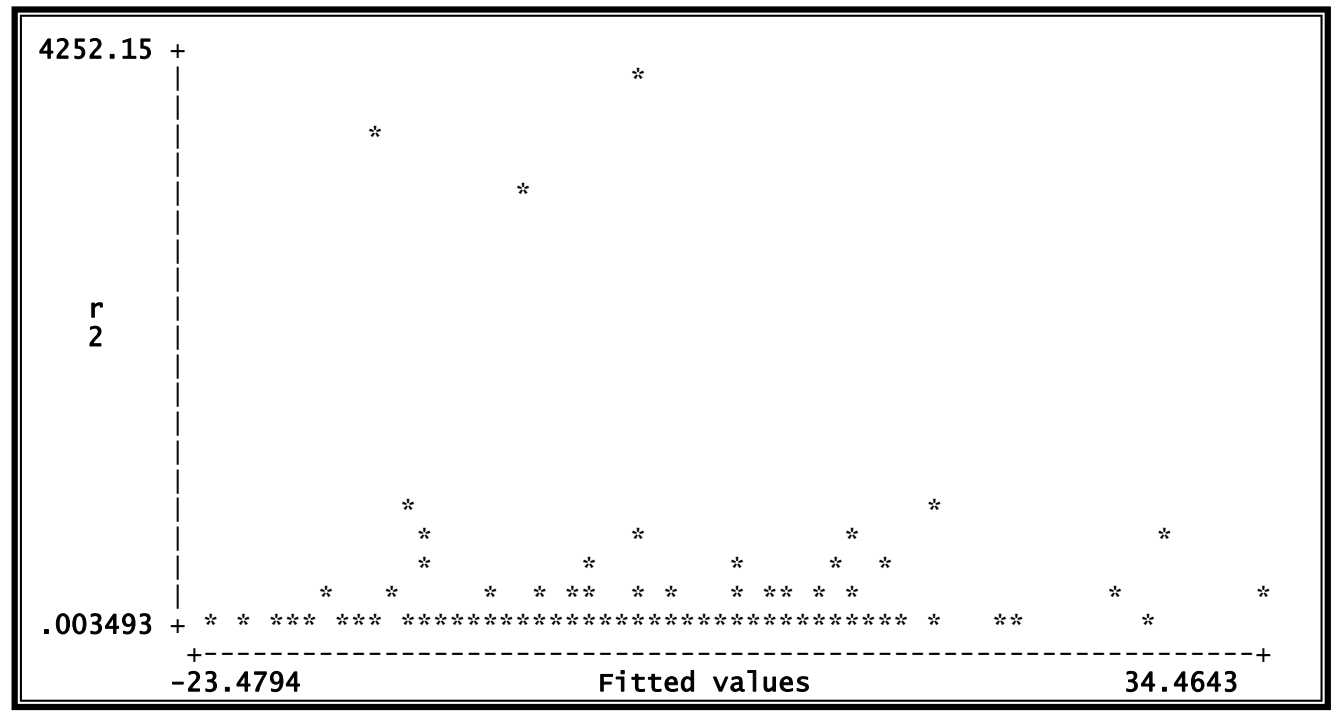

Breusch-Pagan / Cook-Weisberg test for heteroskedasticity Ho: Constant variance

variables: fitted values of chgbiz

$\begin{array}{llr}\operatorname{chi} 2(1) & 0.58 \\ \text { Prob }>\text { chi2 } & = & 0.4448\end{array}$

\begin{tabular}{|c|c|c|c|c|c|c|}
\hline \multicolumn{5}{|c|}{ Linear regression } & \multirow{2}{*}{$\begin{array}{l}\text { Number of obs } \\
\text { F( } 17, \quad 158) \\
\text { Prob > F } \\
\text { R-squared } \\
\text { Root MSE } \\
\qquad \text { [95\% Conf. }\end{array}$} & \multirow{2}{*}{$\begin{array}{lr}= & 176 \\
= & 5.72 \\
= & 0.0000 \\
= & 0.3429 \\
= & 14.409 \\
& \\
& \end{array}$} \\
\hline chgbiz & Coef. & $\begin{array}{l}\text { Robust } \\
\text { std. Err. }\end{array}$ & $\mathrm{t}$ & $P>|t|$ & & \\
\hline $\begin{array}{r}\text { empzone } \\
\text { perwhite } \\
\text { avgage } \\
\text { perrent } \\
\text { pervcnt } \\
\text { retaildn } \\
\text { popdens } \\
\text { tenure } \\
\text { highgrad } \\
\text { perbach } \\
\text { othlang } \\
\text { unemp } \\
\text { peremp } \\
\text { trvltme } \\
\text { avginc } \\
\text { fampov } \\
\text { indpov }\end{array}$ & $\begin{array}{r}.0444576 \\
-.0682241 \\
.5908927 \\
-.1015676 \\
-.4276651 \\
.2403012 \\
-.3487147 \\
-.5322048 \\
.0002445 \\
-.1786664 \\
.0603729 \\
.0590522 \\
.1497409 \\
.3134412 \\
.622536 \\
.5712495 \\
-.4857082\end{array}$ & $\begin{array}{l}2.243428 \\
.0776352 \\
.2430088 \\
.1487404 \\
.3677388 \\
.251517 \\
.2241655 \\
.1947738 \\
.2465534 \\
.1427193 \\
.0749296 \\
.2249662 \\
.1836573 \\
.3792671 \\
.1738871 \\
.2679325 \\
.2260435\end{array}$ & $\begin{array}{r}0.02 \\
-0.88 \\
2.43 \\
-0.68 \\
-1.16 \\
0.96 \\
-1.56 \\
-2.73 \\
0.00 \\
-1.25 \\
0.81 \\
0.26 \\
0.82 \\
0.83 \\
3.58 \\
2.13 \\
-2.15\end{array}$ & $\begin{array}{l}0.984 \\
0.381 \\
0.016 \\
0.496 \\
0.247 \\
0.341 \\
0.122 \\
0.007 \\
0.999 \\
0.212 \\
0.422 \\
0.793 \\
0.416 \\
0.410 \\
0.000 \\
0.035 \\
0.033 \\
\end{array}$ & $\begin{array}{r}-4.386519 \\
-.2215608 \\
.110928 \\
-.3953436 \\
-1.153983 \\
-.2564679 \\
-.7914623 \\
-.9169009 \\
-.4867212 \\
-.4605502 \\
-.08762 \\
-.3852768 \\
-.2129992 \\
-.4356462 \\
.2790929 \\
.0420581 \\
-.9321649\end{array}$ & $\begin{array}{r}4.475434 \\
.0851127 \\
1.070857 \\
.1922083 \\
.2986529 \\
.7370704 \\
.0940328 \\
-.1475087 \\
.4872101 \\
.1032174 \\
.2083658 \\
.5033812 \\
.512481 \\
1.062529 \\
.9659791 \\
1.100441 \\
-.0392516\end{array}$ \\
\hline
\end{tabular}




\section{d. Skewness/ Kurtosis}

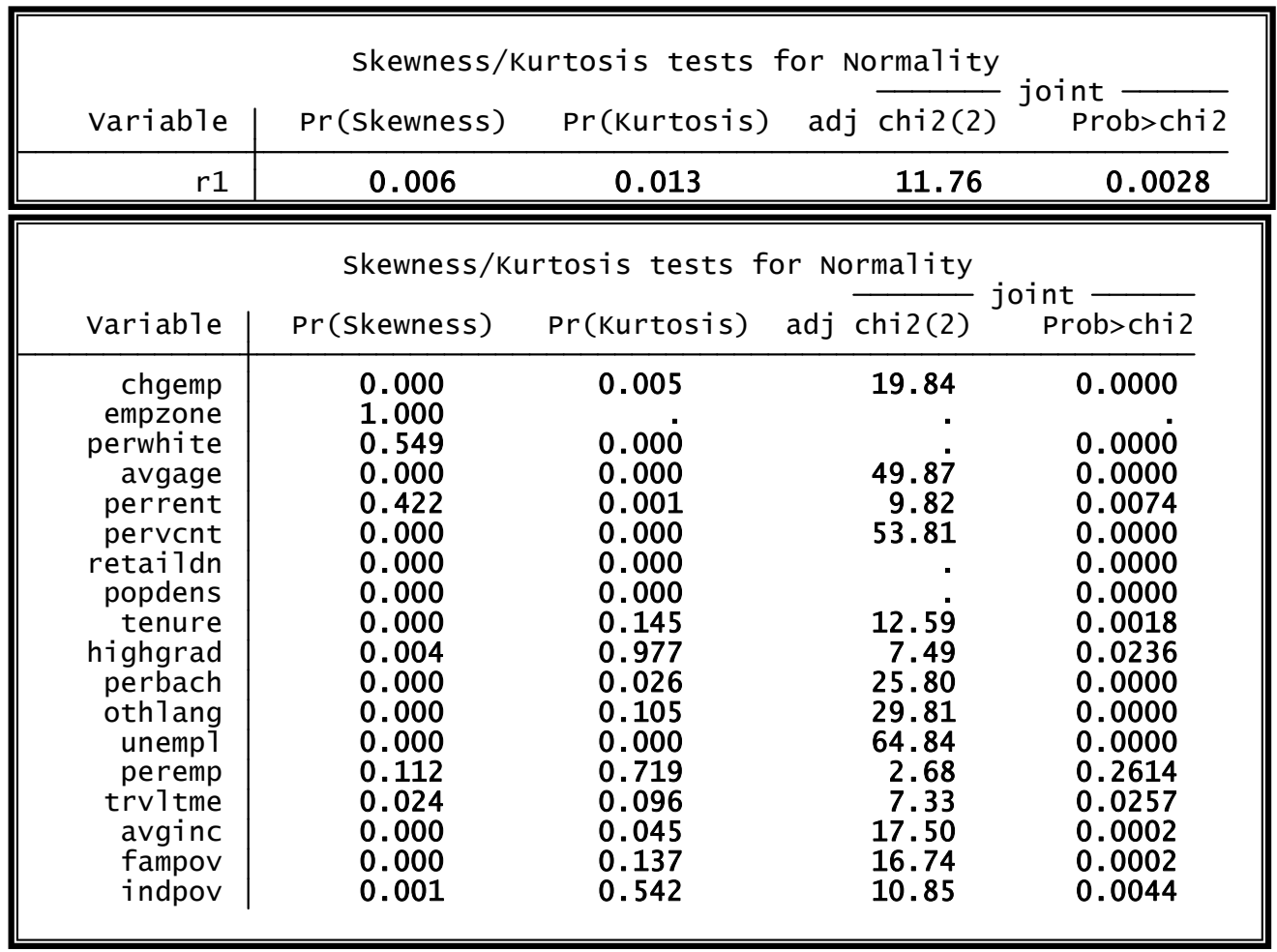

2) Model B: Change in Employees

a. Regression Results

\begin{tabular}{|c|c|c|c|c|c|c|}
\hline Source & SS & $d f$ & MS & & \multirow{3}{*}{$\begin{array}{l}\text { Number of obs } \\
\text { F( } 17, \quad 158) \\
\text { Prob > F } \\
\text { R-squared } \\
\text { Adj R-squared } \\
\text { Root MSE }\end{array}$} & \multirow{3}{*}{$\begin{array}{rr}= & 176 \\
= & 1.49 \\
= & 0.1054 \\
= & 0.1380 \\
= & 0.0452 \\
= & 27.132\end{array}$} \\
\hline $\begin{array}{r}\text { Mode1 } \\
\text { Residua } 1\end{array}$ & $\begin{array}{l}18614.8313 \\
116312.438\end{array}$ & $\begin{array}{r}17 \\
158\end{array}$ & $\begin{array}{l}99007 \\
154672\end{array}$ & & & \\
\hline Total & 134927.269 & 175 & 012968 & & & \\
\hline chgemp & coef. & std. Err. & $\mathrm{t}$ & $P>|t|$ & [95\% Conf. & Interva1] \\
\hline $\begin{array}{c}\text { empzone } \\
\text { perwhite } \\
\text { avgage } \\
\text { perrent } \\
\text { pervcnt } \\
\text { retaildn } \\
\text { popdens } \\
\text { tenure } \\
\text { highgrad } \\
\text { perbach } \\
\text { oth1ang } \\
\text { unemp1 } \\
\text { peremp } \\
\text { trvitme } \\
\text { avginc } \\
\text { fampov } \\
\text { indpov }\end{array}$ & $\begin{array}{r}1.164628 \\
-.0753665 \\
-.2977559 \\
-.0863601 \\
-.9474508 \\
.1667873 \\
.2291258 \\
-.1606157 \\
-.0133887 \\
-.0941802 \\
-.2106061 \\
-.341571 \\
-.6881302 \\
.1846251 \\
.6935929 \\
.2264528 \\
-.4987085 \\
\end{array}$ & $\begin{array}{r}5.064621 \\
.1384106 \\
.5495876 \\
.2426101 \\
.4824179 \\
.3888672 \\
.4365139 \\
.357202 \\
.3929964 \\
.2874646 \\
.1382046 \\
.5170931 \\
.3629791 \\
.669602 \\
.3461723 \\
.4608771 \\
.4970593\end{array}$ & $\begin{array}{r}0.23 \\
-0.54 \\
-0.54 \\
-0.36 \\
-1.96 \\
0.43 \\
0.52 \\
-0.45 \\
-0.03 \\
-0.33 \\
-1.52 \\
0.66 \\
-1.90 \\
0.28 \\
2.00 \\
0.49 \\
-1.00\end{array}$ & $\begin{array}{l}0.818 \\
0.587 \\
0.589 \\
0.722 \\
0.051 \\
0.669 \\
0.600 \\
0.654 \\
0.973 \\
0.744 \\
0.130 \\
0.510 \\
0.060 \\
0.783 \\
0.047 \\
0.624 \\
0.317\end{array}$ & $\begin{array}{r}-8.838465 \\
-.3487403 \\
-1.383242 \\
-.5655375 \\
-1.900271 \\
-.6012612 \\
-.6330293 \\
-.8661226 \\
-.7895928 \\
-.6619493 \\
-.483573 \\
-.6797354 \\
-1.405047 \\
-1.137901 \\
.0098708 \\
-.6838219 \\
-1.480446\end{array}$ & $\begin{array}{l}11.16772 \\
.1980072 \\
.7877302 \\
.3928173 \\
.0053689 \\
.9348357 \\
1.091281 \\
.5448912 \\
.7628153 \\
.4735888 \\
.0623608 \\
1.362877 \\
.028787 \\
1.507151 \\
1.377315 \\
1.136728 \\
.4830294\end{array}$ \\
\hline
\end{tabular}




\section{b. Multicollinearity}

\begin{tabular}{|c|c|c|c|c|c|c|c|c|c|}
\hline Variable & \multicolumn{2}{|c|}{ VIF } & \multicolumn{2}{|r|}{$1 /$ VIF } & & & & & \\
\hline $\begin{array}{r}\text { indpov } \\
\text { fampov } \\
\text { highgrad } \\
\text { perrent } \\
\text { perbach } \\
\text { avginc } \\
\text { tenure } \\
\text { perwhite } \\
\text { peremp } \\
\text { oth1ang } \\
\text { unemp1 } \\
\text { avgage } \\
\text { trvitme } \\
\text { popdens } \\
\text { pervcnt } \\
\text { empzone } \\
\text { retai1dn }\end{array}$ & \multicolumn{2}{|c|}{$\begin{array}{r}10.63 \\
8.43 \\
8.43 \\
6.39 \\
6.06 \\
5.04 \\
4.36 \\
4.20 \\
3.53 \\
3.19 \\
3.11 \\
2.71 \\
2.22 \\
1.99 \\
1.85 \\
1.53 \\
1.52\end{array}$} & \multicolumn{2}{|c|}{$\begin{array}{l}0.094107 \\
0.118572 \\
0.118583 \\
0.156525 \\
0.165023 \\
0.198458 \\
0.229522 \\
0.237889 \\
0.282973 \\
0.313692 \\
0.321088 \\
0.368763 \\
0.450944 \\
0.502528 \\
0.541592 \\
0.652263 \\
0.657080\end{array}$} & & & & & \\
\hline \multirow[t]{2}{*}{ Mean VIF } & \multicolumn{4}{|c|}{4.42} & & & & & \\
\hline & chgbiz & emr & one & perwhite & avgage & perrent & pervent & retaildn & popdens \\
\hline $\begin{array}{r}\text { chgbiz } \\
\text { empzone } \\
\text { perwhite } \\
\text { avgage } \\
\text { perrent } \\
\text { pervcnt } \\
\text { retaildn } \\
\text { popdens } \\
\text { tenure } \\
\text { highgrad } \\
\text { perbach } \\
\text { oth1ang } \\
\text { unemp1 } \\
\text { peremp } \\
\text { trv1tme } \\
\text { avginc } \\
\text { fampov } \\
\text { indpov } \\
\text { chgemp }\end{array}$ & $\begin{array}{r}1.0000 \\
-0.1661 \\
0.0997 \\
0.2099 \\
-0.2807 \\
-0.2883 \\
0.0849 \\
-0.0389 \\
0.0601 \\
0.1561 \\
0.1392 \\
0.1578 \\
-0.3021 \\
0.1909 \\
0.0836 \\
0.4417 \\
-0.3130 \\
-0.4006 \\
0.4283 \\
\text { tenure }\end{array}$ & $\begin{array}{r}1 \\
-0 \\
-0 \\
0 \\
0 \\
0 \\
0 \\
0 \\
-0 \\
-0 \\
-0 \\
0 \\
-0 \\
0 \\
-0 \\
0 \\
0 \\
-0\end{array}$ & $\begin{array}{l}000 \\
044 \\
530 \\
155 \\
162 \\
357 \\
104 \\
231 \\
112 \\
839 \\
447 \\
278 \\
344 \\
551 \\
531 \\
372 \\
289 \\
368 \\
\\
\mathrm{rad}\end{array}$ & $\begin{array}{r}1.0000 \\
0.3274 \\
-0.1868 \\
-0.2505 \\
0.0590 \\
-0.1042 \\
-0.2271 \\
0.7484 \\
0.6274 \\
-0.4846 \\
-0.4247 \\
0.4957 \\
-0.4631 \\
0.4726 \\
-0.6337 \\
-0.5090 \\
0.0503 \\
\text { perbach }\end{array}$ & $\begin{array}{r}1.0000 \\
-0.3359 \\
-0.1572 \\
0.1915 \\
-0.2036 \\
0.3834 \\
0.1429 \\
0.0408 \\
-0.0974 \\
-0.1772 \\
-0.2170 \\
0.0618 \\
0.2056 \\
-0.3391 \\
-0.3933 \\
0.1144 \\
\text { othlang }\end{array}$ & $\begin{array}{r}1.0000 \\
0.3763 \\
0.2916 \\
0.3529 \\
-0.6900 \\
-0.1740 \\
0.1237 \\
0.0374 \\
0.4562 \\
-0.1236 \\
-0.1017 \\
-0.4688 \\
0.4947 \\
0.6339 \\
-0.2237 \\
\\
\text { unemp }\end{array}$ & $\begin{array}{r}1.0000 \\
0.0271 \\
-0.1794 \\
-0.2123 \\
-0.1384 \\
-0.2252 \\
-0.2712 \\
0.4821 \\
-0.2112 \\
-0.0356 \\
-0.4007 \\
0.3769 \\
0.4432 \\
-0.2161 \\
\text { peremp }\end{array}$ & $\begin{array}{r}1.0000 \\
0.0495 \\
-0.2257 \\
0.0416 \\
0.2117 \\
0.0267 \\
0.0554 \\
-0.0971 \\
0.0017 \\
-0.0151 \\
0.0004 \\
0.0707 \\
0.0102 \\
\text { trv } 1 \text { tme }\end{array}$ & $\begin{array}{r}1.0000 \\
-0.1936 \\
-0.1245 \\
0.1702 \\
0.3286 \\
-0.0828 \\
0.1230 \\
0.2843 \\
0.0502 \\
0.0535 \\
0.0280 \\
0.0136 \\
\text { avginc }\end{array}$ \\
\hline $\begin{array}{r}\text { tenure } \\
\text { highgrad } \\
\text { perbach }\end{array}$ & $\begin{array}{r}1.0000 \\
-0.2727 \\
-0.4678 \\
\end{array}$ & & & 1.0000 & & & & & \\
\hline
\end{tabular}

\section{c. Heteroskedasticity}

\begin{tabular}{|l||}
\hline hettest \\
Breusch-Pagan / Cook-Weisberg test for heteroskedasticity \\
Ho: Constant variance \\
Variables: fitted values of chgemp \\
chi2(1) $\quad 11.96$ \\
Prob $>$ chi2 $=0.0005$
\end{tabular}




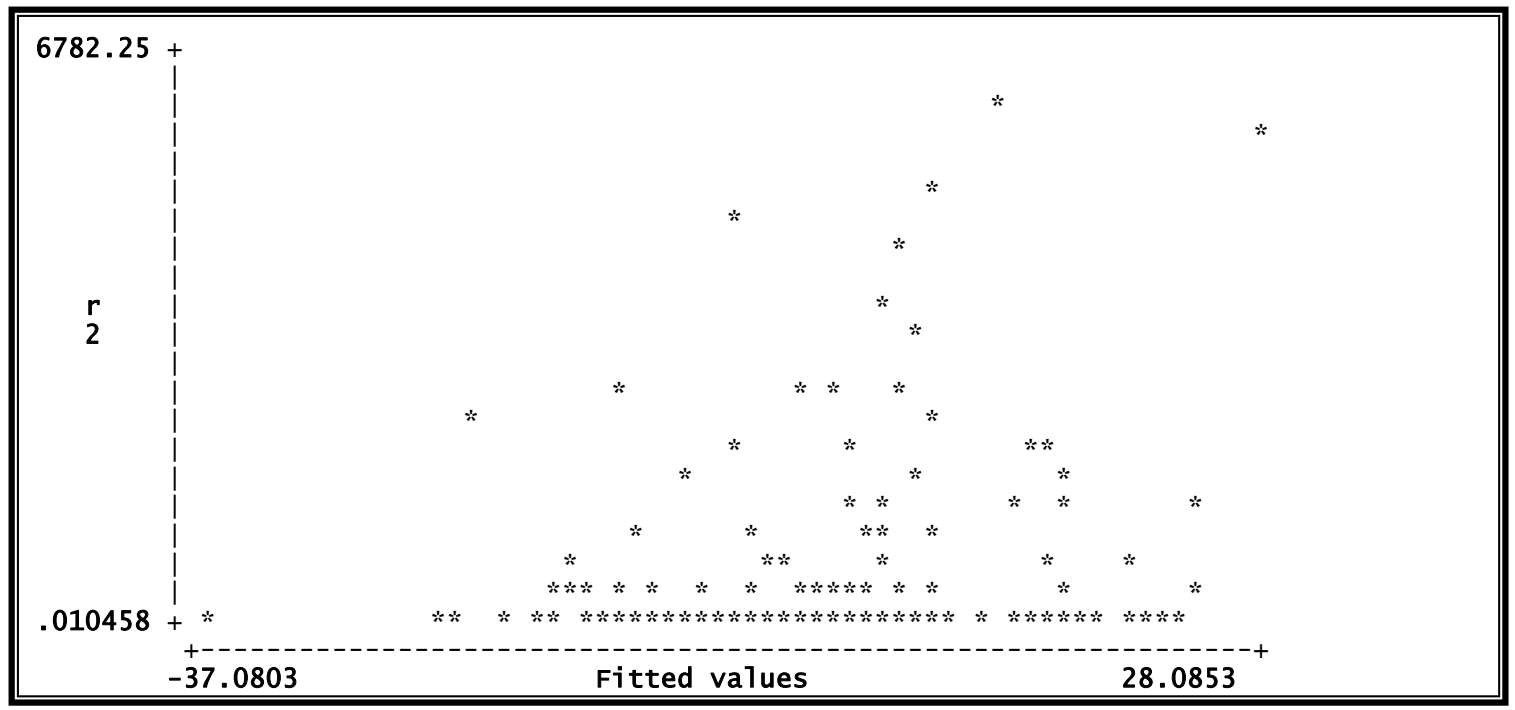

d. Skewness/ Kurtosis

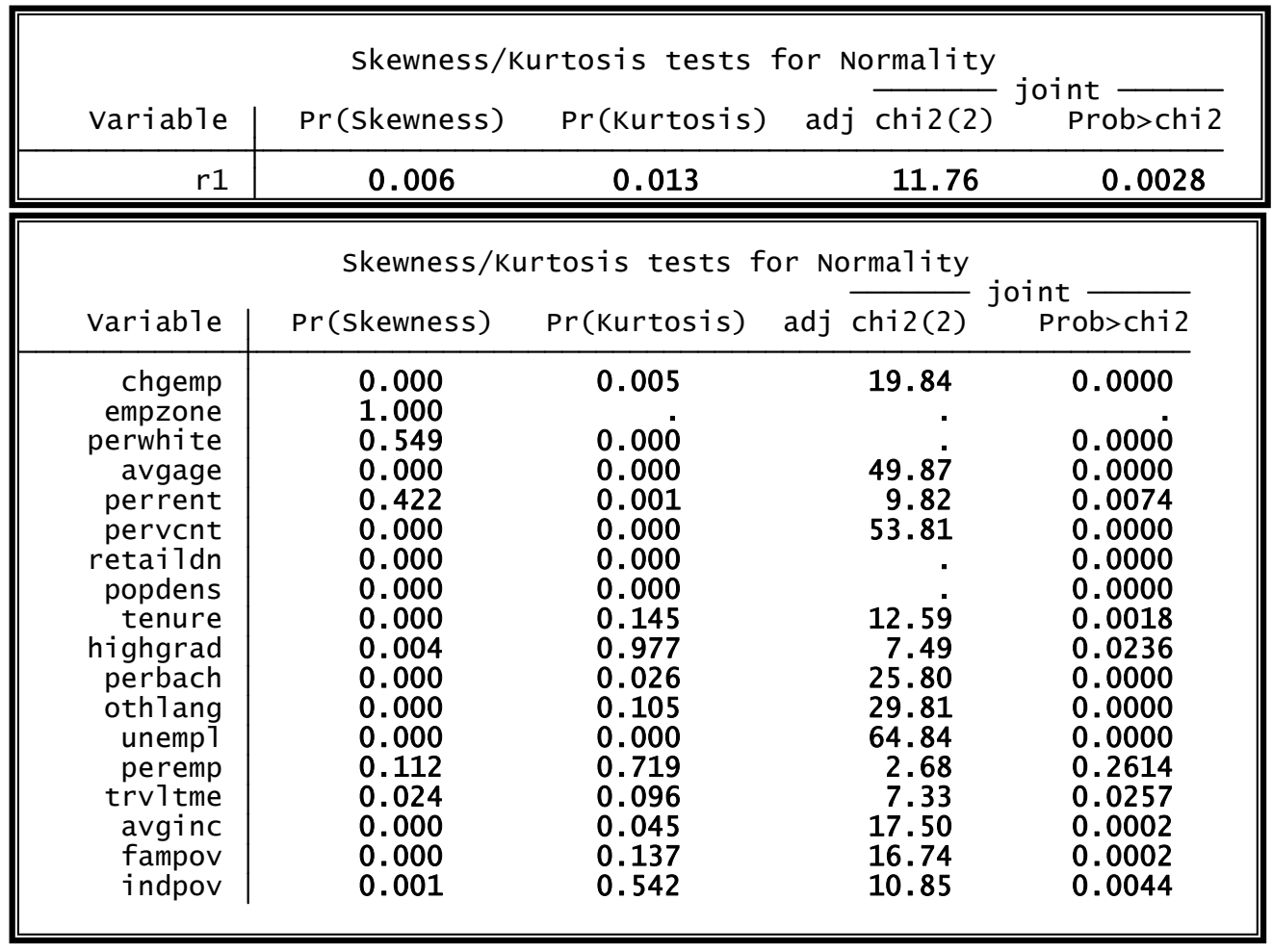




\section{Appendix $C$}

I. Interview Recruitment Letter

Dear $<$ FIRST NAME $><$ LAST NAME $>$ :

My name is Agatha Caraballo and I am a PhD candidate in the Department of Public Administration at Florida International University. I am contacting you because of your involvement with the Miami-Dade County Empowerment Zones. The Office of Community Renewal at the United States Department of Housing and Urban Development (HUD) referred me.

The reason that I am contacting you is that I am conducting a dissertation study that investigates the impact of Round II Urban Empowerment Zones on local communities. I am currently seeking stakeholders of the Round II Empowerment Zones (Board of Directors, program officials, residents, business owners, community leaders, etc.) as participants in this study.

Participation in this study involves a one-on-one interview that will be video and/or audio-recorded. The open-ended interview questions will ask for your opinion on possible factors that may influence the effectiveness of the Empowerment Zone program, in terms of creating and retaining local businesses and jobs for residents. Participation in this study would take approximately 1-2 hours of your time.

There are no known personal risks or benefits to your participation. The anticipated benefit to society is the development of recommendations for policy makers on successful location-based economic development strategies, through the identification of common institutional factors found in EZ communities that experienced business and job growth. You will not receive compensation for your participation and you will not be 
responsible for any costs to participate in this study. However, the final decision about participation is yours.

The interviews will be conducted during the week of November 14-18, 2011. The following time slots are available to participate in this study.

Monday, November 14, $2011 \quad 9 \mathrm{am}-11 \mathrm{am}, \quad 1 \mathrm{pm}-3 \mathrm{pm}, \quad 5 \mathrm{pm}-7 \mathrm{pm}$

Tuesday, November 15, $2011 \quad 9 \mathrm{am}-11 \mathrm{am}, \quad 1 \mathrm{pm}-3 \mathrm{pm}, \quad 5 \mathrm{pm}-7 \mathrm{pm}$

Wednesday, November 16, $2011 \quad 9 \mathrm{am}-11 \mathrm{am}, \quad 1 \mathrm{pm}-3 \mathrm{pm}, \quad 5 \mathrm{pm}-7 \mathrm{pm}$

Thursday, November 17, $2011 \quad 9 \mathrm{am}-11 \mathrm{am}, \quad 1 \mathrm{pm}-3 \mathrm{pm}, \quad 5 \mathrm{pm}-7 \mathrm{pm}$

Friday, November 18, $2011 \quad 9 \mathrm{am}-11 \mathrm{am}, \quad 1 \mathrm{pm}-3 \mathrm{pm}, \quad 5 \mathrm{pm}-7 \mathrm{pm}$

If you are interested in participating, please contact me at acarabal@fiu.edu and list your top three choices for when you would like to participate from the list above. I will then send a confirmation email indicating that you have been signed up for one of those times, and provide you with further information concerning the location of the study. If you have any questions, please contact me at acarabal@fiu.edu or call 786-222-1512. Thank you.

Sincerely, Agatha S. Caraballo

Doctoral Candidate $-\mathrm{PhD}$ in Public Affairs

Florida International University, Dept. of Public Administration

11200 SW 8 Street, PCA 250 B, Miami, Florida 33199

Acarabal@fiu.edu, 786-222-1512 Phone 


\title{
II. Interview Consent Form
}

\author{
ADULT CONSENT TO PARTICIPATE IN A RESEARCH STUDY \\ Impact of Round II Urban Empowerment Zones of Local Communities
}

\section{PURPOSE OF THE STUDY}

You are being asked to be in a research study. The purpose of this study is to investigate the impact of Round II Urban EZs on local communities, in terms of both business and job development, and identify the common institutional factors found in communities that experienced positive growth.

\section{NUMBER OF STUDY PARTICIPANTS}

If you decide to be in this study, you will be one of approximately 12 people in this research study.

\section{DURATION OF THE STUDY}

Your participation will require 2 to 3 hours.

\section{PROCEDURES}

If you agree to be in the study, we will ask you to do the following things:

1. Participate in a video and/or audio-recorded interview, to be scheduled during a site visit to the community, and answer open-ended questions with your perception on possible factors that may have influenced the local empowerment zone's performance, in terms of business and job growth.

\section{RISKS AND/OR DISCOMFORTS}

There are minimal personal risks associated with your participation in this study, meaning that your responses, if linked to identifying information, would not reasonably place you at risk of criminal or civil liability, or be damaging to your financial standing, employability, insurability or reputation.

\section{BENEFITS}

There are no known personal benefits associated with your participation in this study. The anticipated benefits to society are the development of recommendations for policy makers on successful location-based economic development strategies through the identification of common characteristics found in EZ communities that experienced business and job growth.

\section{ALTERNATIVES}

There are no known alternatives available to you other than not taking part in this study. However, any significant new findings developed during the course of the research, which may relate to your willingness to continue participation will be provided to you. 


\section{CONFIDENTIALITY}

The records of this study will be kept private and will be protected to the fullest extent provided by law. Research records will be stored securely and only the researcher team will have access to the records. Authorized University or other agents who will be bound by the same provisions of confidentiality may also review your records for audit purposes.

\section{COMPENSATION \& COSTS}

You will not receive compensation for your participation. You will not be responsible for any costs to participate in this study.

\section{RIGHT TO DECLINE OR WITHDRAW}

Your participation in this study is voluntary. You are free to participate in the study or withdraw your consent at any time during the study. Your withdrawal or lack of participation will not affect any benefits to which you are otherwise entitled. The investigator reserves the right to remove you without your consent at such time that they feel it is in the best interest.

\section{RESEARCHER CONTACT INFORMATION}

If you have any questions about the purpose, procedures, or any other issues relating to this research study you may contact Agatha S. Caraballo at Florida International University, $11200 \mathrm{SW} 8^{\text {th }}$ Street, PCA 250B, Miami, FL 33199, 786-222-1512 phone, or acarabal@fiu.edu.

\section{IRB CONTACT INFORMATION}

If you would like to talk with someone about your rights of being a subject in this research study or about ethical issues with this research study, you may contact the FIU Office of Research Integrity by phone at 305-348-2494 or by email at ori@fiu.edu.

\section{PARTICIPANT AGREEMENT}

I have read the information in this consent form and agree to participate in this study. I have had a chance to ask any questions I have about this study, and they have been answered for me. I understand that I am entitled to a copy of this form after it has been read and signed.

Signature of Participant

Printed Name of Participant

Signature of Person Obtaining Consent
Date

Date 


\section{Interview Questions}

1) What is your name?

2) What is your organizational affiliation and job title?

3) Describe your involvement with the local empowerment zone?

4) What do you feel are the community's greatest needs? Examples: Jobs, Housing, Childcare, Retail and Food Service, etc.

5) Which initiatives do you feel were most effective at creating new businesses and jobs?

Examples: Affordable Housing, Business Incentives, Job Training, etc.

6) Which initiatives do you feel were least effective at creating new businesses or jobs?

Examples: Tax credits, bond financing, business loans, incubators, etc.

7) What are some of the major factors that may have contributed to the program's effectiveness?

Examples: Leadership, private-public partnerships, community participation, governance structure, funding, etc.

8) Which industries are the major employers in the area?

a. If known, was business and job growth encouraged in those specific industries?

9) What type of education and human resource training programs were available to zone residents?

10) What aspects of the EZ program do you think could have been done differently? 
IV. Interview Participants

1) Pamela Glekas-Spring: Director of the Office of Community Renewal at the United States Department of Housing and Urban Development (Washington DC - August 9, 2011)

2) John Haines: Deputy Director of the Office of Community Renewal at the United States Department of Housing and Urban Development (Washington DC - August 9, 2011)

3) Valerie Piper: Deputy Assistant Secretary for Economic Development, Office of Community Planning and Development at the United States Department of Housing and Urban Development (Washington DC - August 8, 2011)

4) Nancy Gilbert: Program Manager, Office of Small Business Development Centers at the United States Small Business Administration/ Former Presidential Management Fellow in the Office of Community Renewal at the United States Department of Housing and Urban Development (Washington DC - August 8, 2011)

5) Dr. Erlinda Martinez: President of Santa Ana Community College and on the Board of Directors for the Santa Ana Empowerment Zones (via conference call - February 2, 2012)

6) Bryan Finnie: Former President and CEO of the Miami-Dade Empowerment Trust and Former Director of the Miami-Dade County Office of Community and Economic Development (Miami Shores, FL - December 7, 2011)

7) Irby McKnight: Chairman of the Miami-Dade County Empowerment Zones and Chairman of the Overtown Neighborhood Assembly Board (Miami, FL December 1, 2011)

8) Ario Lundy: Owner of Palmetto Homes (Miami Gardens, FL - December 15, 2011)

9) Gary Ferguson: Owner of Ferguson Jewelers and Chairman of the Homestead Neighborhood Assembly Board (Homestead, FL 12/15/11)

10) Dean Goldsby: President and CEO of Work America and Vice Chair of the MiamiDade Empowerment Trust Board (Miami, FL - December 16, 2011)

11) Paul Velez: Chief Administrative Officer of the Borinquen Medical Centers of Miami-Dade (Miami, FL - December 12, 2012) 
VITA

\section{AGATHA SWIFT CARABALLO}

June 4, 1979

1999

2002

2001-2003

2005-2006

2006-2008

2008-2011

2012
Born, Asuncion, Paraguay

A.A., Communication

Santa Rosa Junior College

Santa Rosa, California

B.S., Communications

Florida International University

Miami, Florida

Executive Assistant

Martin Z. Margulies

Key Biscayne, Florida

Financial Aid Officer

Miami International University of Art \& Design

Miami, Florida

Career Services Advisor

Miami International University of Art \& Design

Miami, Florida

Graduate Research and Teaching Assistant

Florida International University

Miami, Florida

Career Development Coordinator

Florida International University

Miami, Florida

\section{PRESENTATIONS}

Caraballo, A.S. (2010). Skills Mismatch in the Miami-Dade County Urban Empowerment Zones. Paper presented at the annual conference of the American Society for Public Administration, San Jose, California.

Caraballo, A.S. (2012). Promoting Sustainable Economic Development in Inner Cities. Paper presented at the annual conference of the American Society for Public Administration, Las Vegas, Nevada. 